ANL-7 7-93

ANL-77-93

\title{
TRANSIENT-OVERPOWER TEST E8 ON FFTF-TYPE LOW-POWER-IRRADIATED FUEL
}

by

R. Simms, R. K. Lo, W. F. Murphy,

G. S. Stanford, and A. B. Rothman

BASE TECHNOLOGY

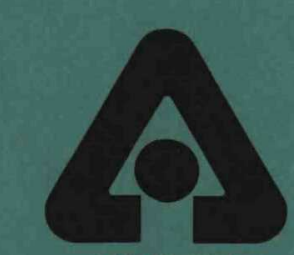

U of C-AUA-USDOE

ARGONNE NATIONAL LABORATORY, ARGONNE, ILLINOIS

Prepared for the U. S. DEPARTMENT OF ENERGY under Contract W-31-109-Eng-38 


\section{DISCLAIMER}

Portions of this document may be illegible in electronic image products. Images are produced from the best available original document. 
The facilities of Argonne National Laboratory are owned by the United States Government. Under the terms of a contract (W-31-109-Eng-38) between the U. S. Department of Energy, Argonne Universities Association and The University of Chicago, the University employs the staff and operates the Laboratory in accordance with policies and programs formulated, approved and reviewed by the Association.

\section{MEMBERS OF ARGONNE UNIVERSITIES ASSOCIATION}

The University of Arizona

Carnegie-Mellon University

Case Western Reserve University

The University of Chicago

University of Cincinnati

Illinois Institute of Technology

University of Illinois

Indiana University

Iowa State University

The University of Iowa
Kansas State University

The University of Kansas

Loyola University

Marquette University

Michigan State University

The University of Michigan

University of Minnesota

University of Missouri

Northwestern University

University of Notre Dame
The Ohio State University

Ohio University

The Pennsylvania State University

Purdue University

Saint Louis University

Southern Illinois University

The University of Texas at Austin

Washington University

Wayne State University

The University of Wisconsin

\section{NOTICE}

This report was prepared as an account of work sponsored by the United States Government. Neither the United States nor the United States Department of Energy, nor any of their employees, nor any of their contractors, subcontractors, or their employees, makes any warranty, express or implied, or assumes any legal liability or responsibility for the accuracy, completeness or usefulness of any information, apparatus, product or process disclosed, or represents that its use would not infringe privately-owned rights. Mention of commercial products, their manufacturers, or their suppliers in this publication does not imply or connote approval or disapproval of the product by Argonne National Laboratory or the U. S. Department of Energy.

Printed in the United States of America

$$
\text { Available from }
$$

National Technical Information Service

U. S. Department of Commerce 5285 Port Royal Road

Springfield, Virginia 22161

Price: Printed Copy \$क्षicrofiche $\$ 3.00$

$$
6.50
$$


ANL-77-93

\section{ARGONNE NATIONAL LABORATORY \\ 9700 South Cass Avenue \\ Argonne, Illinois 60439}

\section{TRANSIENT-OVERPOWER TEST E8 ON FFTF-TYPE LOW - POWER-IRRADIATED FUEL}

by

R. Simms, R. K. Lo, W. F. Murphy,*

G. S. Stanford, and A. B. Rothman

Edited by

C. E. Dickerman

Reactor Analysis and Safety Division

December 1977

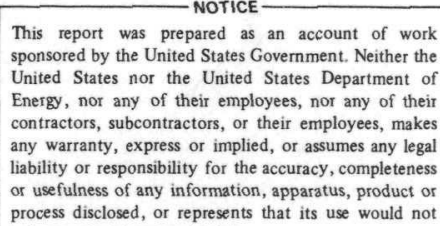

*Materials Science Division 
• 
TABLE OF CONTENTS

$\underline{\text { Page }}$

ABSTRACT

I. INTRODUCTION AND SUMMARY . . . . . . . . . . . . . . 14

II. TEST OBJECTIVES AND DEFINITIONS ............... 18
A. Requirements and Constraints
B. Selection of Fuel Elements.
C. Description of Test Hardware .
D. Transient Planning 26

III. INSTRUMENT AND TEST-ELEMENT CALIBRATIONS . . . . . .

A. Calibrations of Loop Instrumentation ............. 29

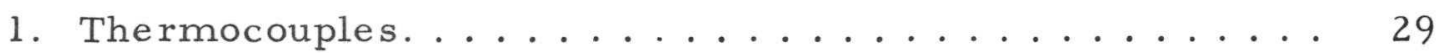

2. Pressure Transducers. .................. 29

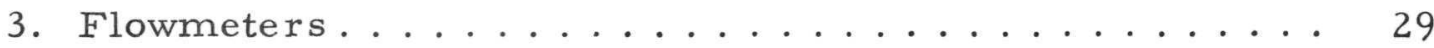

B. Power-calibration Experiments ............. 30

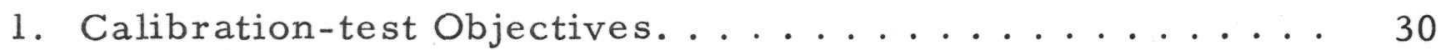

2. Description of Experimental Hardware.......... 32

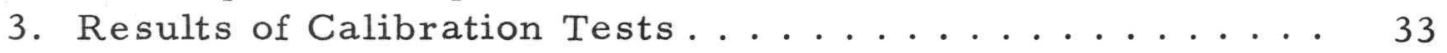

IV. HEAT-BALANCE TEST RESULTS. . . . . . . . . . . . . 37

A. Comparison of Results with Thermal Analysis . . . . . . 37

B. Instrument Responses ...................... 37

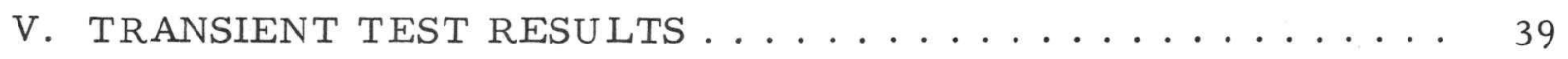

A. Test Transient Characteristics .................... 39

B. Test-instrumentation Results ............... 40

C. Results from fast-neutron Hodoscope . . . . . . . . . . 43

1. Brief Description of Hodoscope Techniques......... 43

2. Fuel-motion Results .................. 44

3. Net Axial Profiles of Fuel Motion ............ 58

D. Summary of Test Results Based on Instrumentation. . . . . . 58 
TABLE OF CONTENTS

$\underline{\text { Page }}$

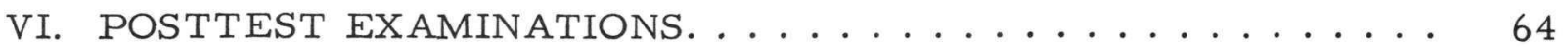

A. Neutron Radiography . . . . . . . . . . . . . . . . 64

B. Disassembly of Test Train ............... 66

C. Examination Results .................... 74

1. Extent of Melting .................. 74

2. Distribution and Character of Fuel. . . . . . . . 77

3. Distribution of Melted Steel ............. 84

4. $\mathrm{UO}_{2}$ Insulator Pellets. . . . . . . . . . . . . 85

5. Element Plenum Region................ 87

D. Summary of Results of Posttest Examination ......... 88

VII. THERMAL-HYDRAULIC ANALYSIS OF TEST E8. . . . . . . 89

A. Introduction .......................... 89

B. Description of COBRA Computer Code ............ 89

C. Calculated Thermal History . . . . . . . . . . . . . 90

D. Summary and Conclusions. . . . . . . . . . . . . . 93

VIII. SUMMARY AND CONCLUSIONS . . . . . . . . . . . . . 94

A. Discussion of Test Results . . . . . . . . . . . . . 94

B. Applicability to FTR ................ 95

\section{APPENDIXES}

A. Drawing of Test-train Assembly . . . . . . . . . . 98

B. Results of Power-calibration Tests ............. 100

1. Introduction . . . . . . . . . . . . . . . . 100

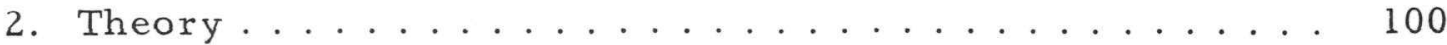

3. Transient Cor rection Factor. .............. 101

4. Power-calibration Results for Unirradiated Fuel at Lowlevel TREAT Power . . . . . . . . . . . . . 103

5. Conversion to Test Elements . . . . . . . . . . . 104

6. Internal Radial Power Distributions . . . . . . . . . . . 105 


\section{TABLE OF CONTENTS}

Page

C. Additional Data from E8 Heat-balance Test.......... 109

D. Additional Data from E8 Failure Transient Test. . . . . . 112

E. Treatment of Flowmeter Signals at Time of Failure Events in Test Region ..................... 115

F. Thermal-analysis Input .................. 118

ACKNOW LEDGMENTS . . . . . . . . . . . . . . . . . . . . 121

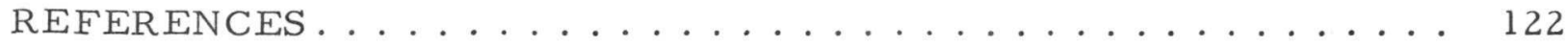




\section{LIST OF FIGURES}

No. Title

1. TREAT Reactor Power and Integrated Power for Transient

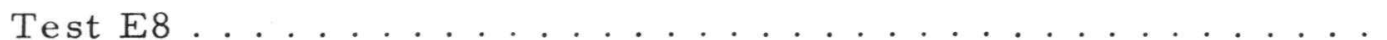

2. Posttest Neutron Radiograph of Fuel-column Region of E8 Test Section. . . . . . . . . . . . . . . . 16

3. Schematic Diagram of PNL-10 Fuel Element .......... 21

4. Cross-sectional View of Fuel-element Arrangement in

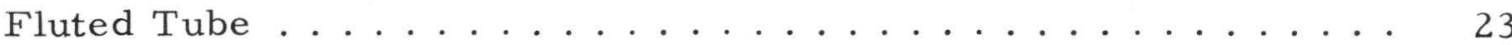

5. Schematic Diagram of Filter and Collar Configuration for

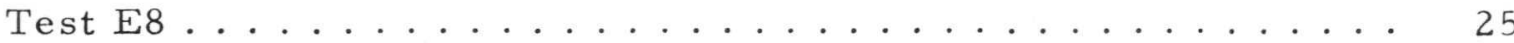

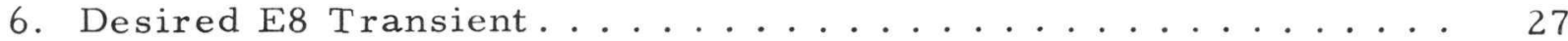

7. Radial Temperature Profile Calculated for E8 Cluster Relative to FTR at Start of TREAT Ramp. . . . . . . . . . . . 27

8. Conduct of Typical Fuel Dynamics Test Using Mark-II Integral Sodium Loop in TREAT. . . . . . . . . . . . . . . . . . 3

9. Fuel-element Arrangement for E8 Calibration Test Showing Cross-sectional View at Elevation of Identification Flat . . . . .

10. Identification of Equipment Penetrating Upper Plate of E8 Mockup Loop and Test Train. . . . . . . . . . . . . . .

11. Location of Filters, Shields, and Shaping Collars on E8 Calibration Loop . . . . . . . . . . . . . . . . . . . . . . . . . 34

12. Axial Power Profiles for Elements in E8 Calibration Test . . . . 36

13. Reactor Power, Test-region Flow, and Pressure Signals for

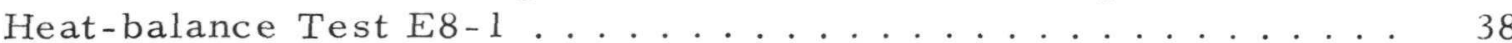

14. TREAT Power and Integrated Power for Test E8-2 . . . . . . 39

15. TREAT Energy Release as a Function of Time into Burst..... 41

16. Signal from Inlet Pressure Transducer for E8-2. . . . . . . . 4 41

17. Flowmeter Signals for E8-2..................44 41

18. Relationship between Hodoscope View Area and Test Assembly

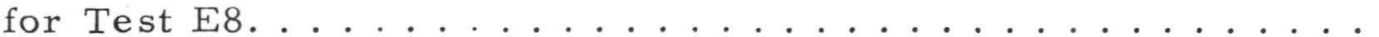

19. Ratio of Array Average to Power Monitor for Test E8 Hodoscope Data..................... 45

20. Differential Hodographs for E8 in Time Interval 7.176-7.236 s. . 46

21. Differential Hodographs for E8 in Time Interval 7.212-7.248 s. . 


\section{LIST OF FIGURES}

No.

Title

Page

22. Differential Hodographs for E8 in Time Interval 7.236-7.273 s. . 50

23. Differential Hodographs for E8 in Time Interval 7.236-7.285 s. . . 51

24. Differential Hodographs for E8 in Time Interval 7.273-7.321 s, Referenced to Preheat Plateau................ 53

25. Differential Hodographs for E8 in Time Interval 7.273-7.321 s, Referenced to Interval $7.261-7.273 \mathrm{~s} \ldots \ldots \ldots 54$

26. Differential Hodographs for E8 in Time Interval 7.321-7.406 s, Referenced to Preheat Plateau................ 55

27. Differential Hodographs for E8 in Time Interval 7.321-7.406 s, Referenced to Interval 7.297-7.309 s . . . . . . . . . . . 56

28. Selected Axial Profiles of Fuel Distribution in Transient E8 . . . 59

29. Axial Fuel-quantity Profiles in Transient E8 . . . . . . . . . . 60

30. Axial Profiles of Fuel-quantity Changes in Transient E8. . . . . . 61

31. Changes in Axial Distribution of Test Fuel in Transient E8 . . . . 62

32. Posttest Neutron Radiograph of E8 Test Section . . . . . . . . 65

33. Sectioning Schematic of Test-train Leg of the E8 Loop. . . . . . 67

34. Sectioning Schematic of Piece 147Al0 ............ 67

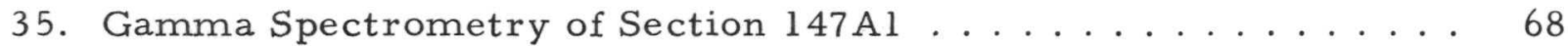

36. Gamma Spectrometry of Section 147A2a . . . . . . . . . . 69

37. Gamma Spectrometry of Section 147 A6 . . . . . . . . . . . 70

38. Gamma Spectrometry of Section 147A3 . . . . . . . . . . 71

39. Section 147Al2 with Melted Cladding and Melted Fuel. . . . . . . 72

40. Section 147A6a, Showing Melted Steel Binding Elements Together ......................... 73

41. Sections through Adiabatic-tube Wall, Showing Penetrations and Fuel on the Interior . . . . . . . . . . . . . . . 75

42. Melting of Cladding toward Interior of Cluster . . . . . . . . 76

43. Melting of Claddirig toward Outside of Cluster. . . . . . . . 76

44. Center Melting in Fuel Pellets at Top of Section 147Al4 . . . . 76

45. Debris from Sections 147Al3, 147Al7, and 147Al8. . . . . 78

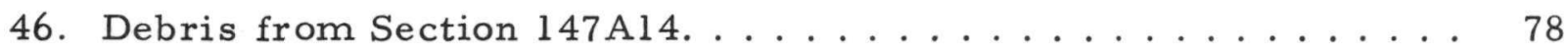


LIST OF FIGURES

No.

Title

Page

47. Longitudinal Sections from Segment $147 \mathrm{Al} 0$ after Cleaning. . . .

79

48. Transverse Sections and Some Debris from Segment 147Al0 . . . 80

49. Transverse Section through Fuel Region about $1.6 \mathrm{~cm}$ below Original Top of Fuel Columns...............

50. Melted Steel in Melted Fuel . . . . . . . . . . . . . . 82

51. Typical Melted Fuel Region with Globules of Stainless Stee1. . . 83

52. Transverse Section through Insulator-pellet Region . . . . . . . 83

53. Steel Globules in Melted Fuel from Upper Reflector-rod Region .

54. Gamma Spectrometry of Bottom Sections of Elements

PNL-10-53 and -44, Showing Gaps in Stack of Insulator

Pellets in Latter. . . . . . . . . . . . . . . . . . . . . . .

55. Comparison of Measured and Calculated Sodium Temperatures at Exit . . . . . . . . . . . . . . . . . . .

56. Radial Temperature Distribution of Central Fuel Element at TREAT Clock Time $6.712 \mathrm{~s} \ldots \ldots \ldots$

57. Radial Temperature Distribution of Peripheral Fuel Element

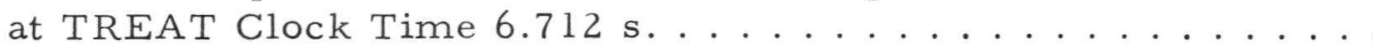

58. Radial Temperature Distribution of Central Fuel Element at TREAT Clock Time $7.212 \mathrm{~s} \ldots \ldots \ldots \ldots$

59. Radial Temperature Distribution of Peripheral Fuel Column

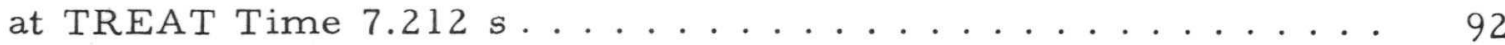

60. Areal Percentage above Solidus during Transient. . . . . . . . 92

61. Change of Fuel Enthalpy at Midplane during Transient. . . . . . . 92

A.1. E8 Test-train Assembly.................... 99

C.1. Flow and Pressure Signals in Heat-balance Test E8-1...... 109

C.2. ALIP Current and Power in Test E8-1............ 109

C.3. Temperatures of Coolant Thermocouples at Inlet and Outlet of

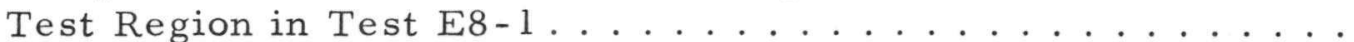

C.4. Temperatures of Coolant and Structure Thermocouples in

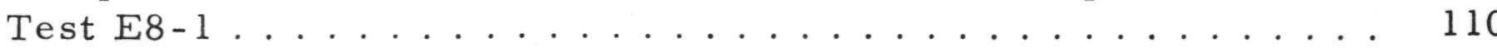

C.5. Temperatures of Structure Thermocouples in Test E8-1.... 110

C.6. Temperatures of Test-train Thermocouples above Active

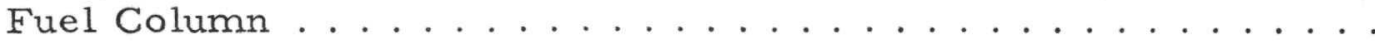




\section{LIST OF FIGURES}

No.

Title

$\underline{\text { Page }}$

D.1. Power and Energy Release in Test E8-2 . . . . . . . . 112

D.2. Power and Energy Release in Test E8-2 in Time Interval

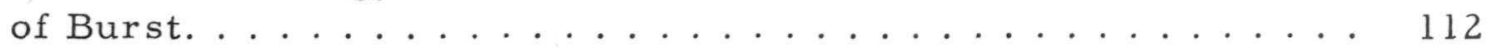

D.3. Responses of Inlet and Outlet Pressure Transducers in

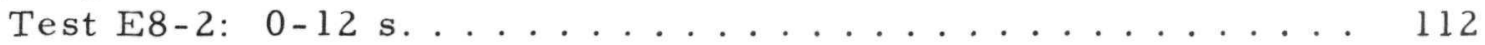

D.4. Responses of Inlet and Outlet Pressure Transducers in

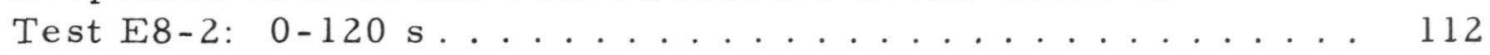

D.5. Inlet and Outlet Temperatures in Test E8-2: 0-12 s .....113

D.6. Inlet and Outlet Temperatures in Test E8-2: 0-120 s ..... 113

D.7. Temperatures from Structure Thermocouples at Elevations below Bottom of Active Fuel-column Region in Test E8-2. . . . 113

D.8. Temperatures from Structure Thermocouples at Fuel-column

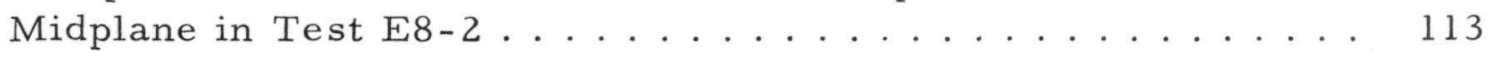

D.9. Temperatures from Structure Thermocouples $64 \mathrm{~mm}$ below Top of Active Fuel Column in Test E8-2 . . . . . . . . . 114

D.10. Temperatures from Structure Thermocouples at Top of Active Fuel Column in Test E8-2 . . . . . . . . . . 114

D.11. Temperatures from Structure Thermocouples above Top of Active Fuel Column in Test E8-2............... 114

D.12. Temperatures from Thermocouples in Upper Loop Region in

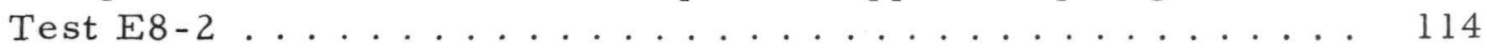

E.1. Signal Outputs from Inlet and Outlet Flowmeters from

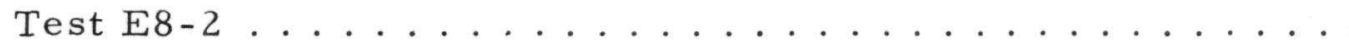

E.2. Signal Output from Flowmeter after Removal of $60-\mathrm{Hz}$

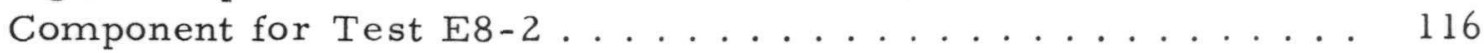

E.3. Inlet and Outlet Flow Rates for Test E8-2 . . . . . . . . 117

F.1. One-twelfth of Idealized Seven-element Test Section for

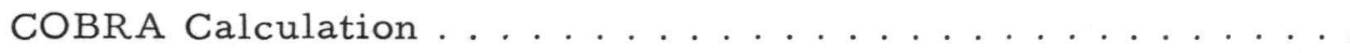


LIST OF TABLES

No.

Title

Page

I. Summary of Principal E8 Test Parameters. . . . . . . . . . 14

II. Failure Criteria for Fuel-element Classifications . . . . . . 18

III. Matrix of Transient-overpower Tests ............. 19

IV. Parameters of Irradiated, Mixed-oxide Fuel Elements Considered for Test E8. . . . . . . . . . . . . . 20

V. Comparison of Characteristics of Fuel Elements to E8 Experimental Requirements. . . . . . . . . . . . . 21

VI. Fabrication and Design Parameters for Unirradiated PNL-10 Fuel Elements . . . . . . . . . . . . . . . 22

VII. Microstructural Features for PNL-10-23 Fuel Elements. . . . 22

VIII. Thermocouple Locations for Test E8. . . . . . . . . . . 24

IX. Filters, Collars, and Shields for E8 Loop. . . . . . . . . . 24

X. As-fabricated Hexaboron Silicide Neutron Shields for E8 Loop . 25

XI. As-fabricated Dysprosium Filters and Collars for Test E8 . . 26

XII. Possible Alternative Ways to Determine Calibration Factors.. 31

XIII. Peak Values of Sample Power-calibration Factors for E8 Test Elements in TREAT Based on Calibration Tests . . . . . . 35

XIV. Properties of Fuel-element Power Distributions from

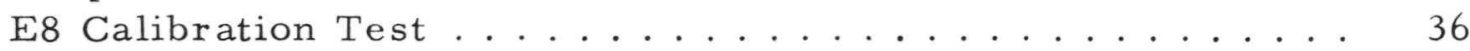

XV. E8 Transient Data for Thermal Analyses . . . . . . . . . . . 40

XVI. Thermocouple Failure Times.................. 43

XVII. Scenario of Events in Test E8. . . . . . . . . . . 63

XVIII. Summary of Test Results. . . . . . . . . . . . . . 94 94

XIX. Comparison of Test E8 Cluster Parameters with FTR . . . . 96

B.1. Summary of E8 Calibration Tests in TREAT. . . . . . . 100

B.2. Transient Correction Factor for E8, Based on Monitor-wire Results from Test Section ................. 102

B.3. Transient Correction Factor for E8, Based on Monitor-wire Results from Secondary-containment-can Guide Tube. . . . . . 103

B.4. Experimental Radiochemical Values for Low-level Calibration Factors for E8. 


\section{LIST OF TAB LES}

No.

Title

Page

B.5. Correspondence between Test and Calibration Elements. . . . 104

B.6. Data Used to Compute Burnup Corrections. . . . . . . . . 105

B.7. Dimensions of Core-drilled Specimens from Mixed-oxide Fresh-fuel Pellets in Calibration Test ............ 106

B.8. Azimuthally Averaged Radial Distribution of Fission Rate for PNL-10-79 in E8 Calibration Test ............. 106

B.9. Azimuthally Averaged Radial Distribution of Fission Rate for PNL-10-80 in E8 Calibration Test............. 107

B.10. Azimuthally Averaged Radial Distribution of Fission Rate for PNL-10-81 in E8 Calibration Test.............. 108

F.1. Dimensions of Idealized Cluster Geometry in Test E8 . . . . 118

F.2. Element-power Distributions into Adjacent Coolant Channels at Steady State . . . . . . . . . . . . . . . 119

F.3. Miscellaneous COBRA Input Values .............. 119

F.4. Input Values for Fuel Properties . . . . . . . . . . . . 120

F.5. Input Values for Gap-conductance Model . . . . . . . . . . . 120

F.6. Input Function for Exit Coolant Enthalpy . . . . . . . . . . 120 
TRANSIENT-OVERPOWER TEST E8 ON FFTF-TYPE LOW - POWER -IRRADIATED FUEL

by

R. Simms, R. K. Lo, W. F. Murphy, G. S. Stanford, and A. B. Rothman

Edited by

C. E. Dickerman

\section{ABSTRACT}

Test E8 simulated a hypothetical $\$ 3 / \mathrm{s}$ transient overpower accident in an LMFBR using seven $(\mathrm{Pu}, \mathrm{U}) \mathrm{O}_{2}$ fuel elements of the FTR type. The test elements were preirradiated in the PNL-10 assembly in EBR-II to 5 at. $\%$ burnup at $30 \mathrm{~kW} / \mathrm{m}$. The preirradiation in EBR-II caused a fuel-restructuring range characteristic of a low-to-moderate power microstructure for FTR. Failure predictions indicated that fuel with this microstructural characteristic would fail at a lower energy deposition than fuel irradiated at higher power.

Data from test-vehicle sensors, hodoscope, and postmortem examinations were used to construct the sequence of events occurring within the test zone. The sequence occurred incoherently across the test cluster, the initial event occurring abruptly at about 29 times nominal power level at an estimated stored energy of about $925 \mathrm{~kJ} / \mathrm{kg}$ with $50 \%$ of the fuel above the solidus at the suspected failure site.

After the initial failure, about $2 \%$ of the total mass of test fuel was ejected above the original top of the active fuel column. Sodium voiding occurred rapidly. A fuel-debris blockage also apparently prevented further fuel dispersal. Inherent test-vehicle limitations, loss of flow-tube geometry, and nontypical power generation after failure may have caused a departure from the fuel motion predicted for FTR conditions. No violent fuel-coolant interaction or associated work-energy conversion to the coolant was observed. 


\section{INTRODUCTION AND SUMMARY}

In TREAT Test E8, seven mixed-oxide PNL-10 elements ${ }^{1}$ from EBR-II subassembly X093 were subjected to a simulation of one type of LMFBR hypothetical core-disruptive accident (HCDA), an unprotected $\$ 3 / \mathrm{s}$ reactivity insertion. The test was the first using the $\mathrm{C}$ modification of the Mark-II TREAT Integral Sodium Loop. The fuel elements for the test had been irradiated in EBR-II at a peak linear power rate of $30 \mathrm{~kW} / \mathrm{m}$ to a burnup of about 5 at. \%. These fuel elements therefore provide a representation of fuel with the microstructure of "low-power-structure" FTR-type fuel with the possible exception that a small central void is present. Because of the low linear heating rate in the EBR-II irradiation, the fuel in E8 contained a higher content of fission gas trapped within the fuel than would be present in the high-power-structure fuel. Analytical models had indicated that this higher content of fission gas should result in a lower failure threshold and greater fuel dispersal than for the high-power-structure fuel or for fresh (unirradiated) fuel.

The seven fuel elements were arranged on a triangular spacing in the test region of the Mark-IIC loop. The principal test parameters for E8 are listed in Table I. The active 340-mm-long fuel region of these PNL-10 elements was filtered by $0.5-\mathrm{mm}$-thick dysprosium metal wrapped around the outside of the 50-mm-dia test section. Dysprosium was also used to achieve the acceptable axial power distributions. The initial sodium flow rate of about $575 \mathrm{~cm}^{3} / \mathrm{s}$ was provided by an annular linear-induction pump (ALIP) of a design used in previous Mark-II tests. The test region was instrumented with two pressure transducers, two flowmeters, and 18 thermocouples; fast-neutron hodoscope data were also recorded during the transient. The TREAT transient, shown in Fig. 1, used about a $2-\mathrm{s}$ preheat at $46 \mathrm{~kW} / \mathrm{m}$ to simulate the peak stored energy per unit length for the elements in the test cluster with the highest power generation relative to that energy stored in a low-power FTR element undergoing a $\$ 3 /$ s reactivity excursion.

TABLE I. Summary of Principal E8 Test Parameters

\begin{tabular}{ll}
\hline HCDA simulation & $\$ 3 / \mathrm{s} \mathrm{FTR} \mathrm{ramp}$ \\
Test reactor & TREAT \\
Loop & Mark-IIC \\
Filter & $0.5-\mathrm{mm}$-thick dysprosium \\
Fuel elements & $7 \mathrm{PNL}-10$ (Mixed oxide) \\
Fuel-column length & $340 \mathrm{~mm}$ \\
Preirradiation & In EBR - II at $30 \mathrm{~kW} / \mathrm{m}$ \\
Fuel microstructure & Low power \\
Burnup & $\sim 5 \mathrm{at} \%$ \\
Sodium flow per element & $\sim 82 \mathrm{~cm}^{3} / \mathrm{s}$ \\
Test-section flow area & $1.72 \mathrm{~cm}^{2}$ \\
\hline
\end{tabular}




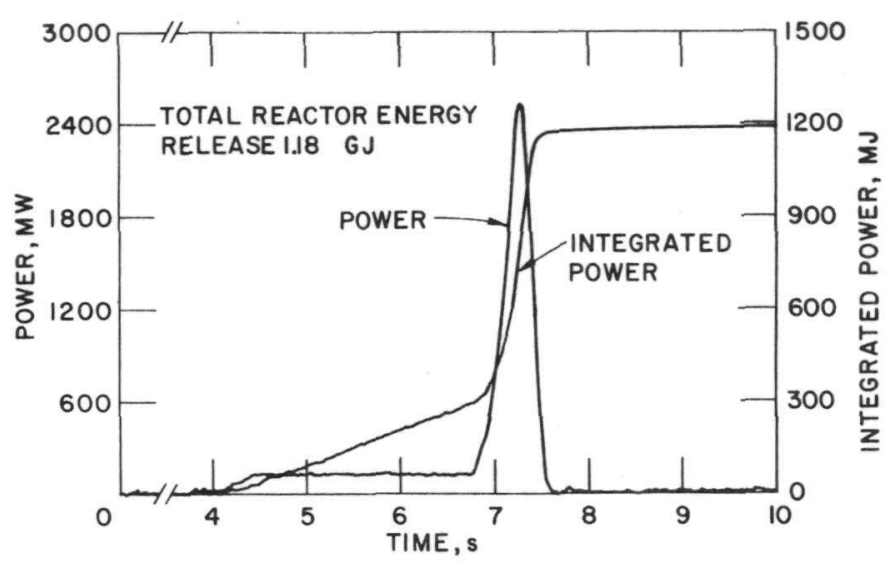

Fig. 1

TREAT Reactor Power and Integrated Power for Transient Test E8. ANL Neg. No. 900-5036 Rev. 2.

Flowmeter and pressure-transducer data indicated that the first failure event occurred at an integrated TREAT power of $676 \mathrm{MJ}$ about $500 \mathrm{~ms}$ after the preheat. At this point in the transient, COBRA computer calculations ${ }^{2}$ indicated that about $50 \%$ of the fuel at the midplane of peripheral elements had reached temperatures at, or above, the solidus. Note, however, that this $50 \%$ estimate is sensitive to the calculational model since the energy-generation rate was changing rapidly on a $160-\mathrm{ms}$ period. With this $50 \%$ factor as a criterion for the failure threshold, the E8 fuel failed about when expected based on previous TREAT tests with high-power-structure fuel. ${ }^{3}$ Immediately after the first indication of failure, the inlet pressure transducer recorded several pressure pulses in an interval of $20 \mathrm{~ms}$, but no pulse was larger than about 1. $5 \mathrm{MPa}(15 \mathrm{~atm})$. The pressure-transducer output at the outlet did not show any of these pressure events. At about this time, data from thermocouples in the plenum-gas region of the loop indicated that a sodium slug was ejected upward. After the test, attempts to reestablish flow through the test region failed, implying that a flow blockage existed.

Subsequent test evaluation depended on results from neutron radiography, fast-neutron hodoscope data, and postmortem examination of the test remains. Neutron radiographs of the entire loop were taken in the shielded radiography facility at TREAT. To improve the neutron penetration, the loop was stripped of its neutron filters and electric heaters before radiography. Figure 2 is a radiographic record of the test section containing the active fuel column and upper fuel-element structure. The radiograph shows the failed fuel elements and indicates material movement at least $30 \mathrm{~mm}$ above the top of the original unfailed fuel-column position. From the radiograph alone, it is not possible to distinguish unambiguously between steel and fuel. By use of the radiograph as a guide, the loop was disassembled so that detailed examinations of the test section could be made.

After loop disassembly, the test section was systematically dissected in an inert-gas, alpha-gamma hot-cell facility for the postmortem analysis. The dissection procedures attempted to minimize disturbance of the materials within the test region. Note that the solidified sodium coolant tends to freeze test materials in place. Where possible, segments of the test region were 
removed from the loop wall by heating to melt the sodium. Where not possible, the loop wall was removed by longitudinal cutting. Sodium remains were removed by reaction with alcohol to allow for further visual observation and photography.

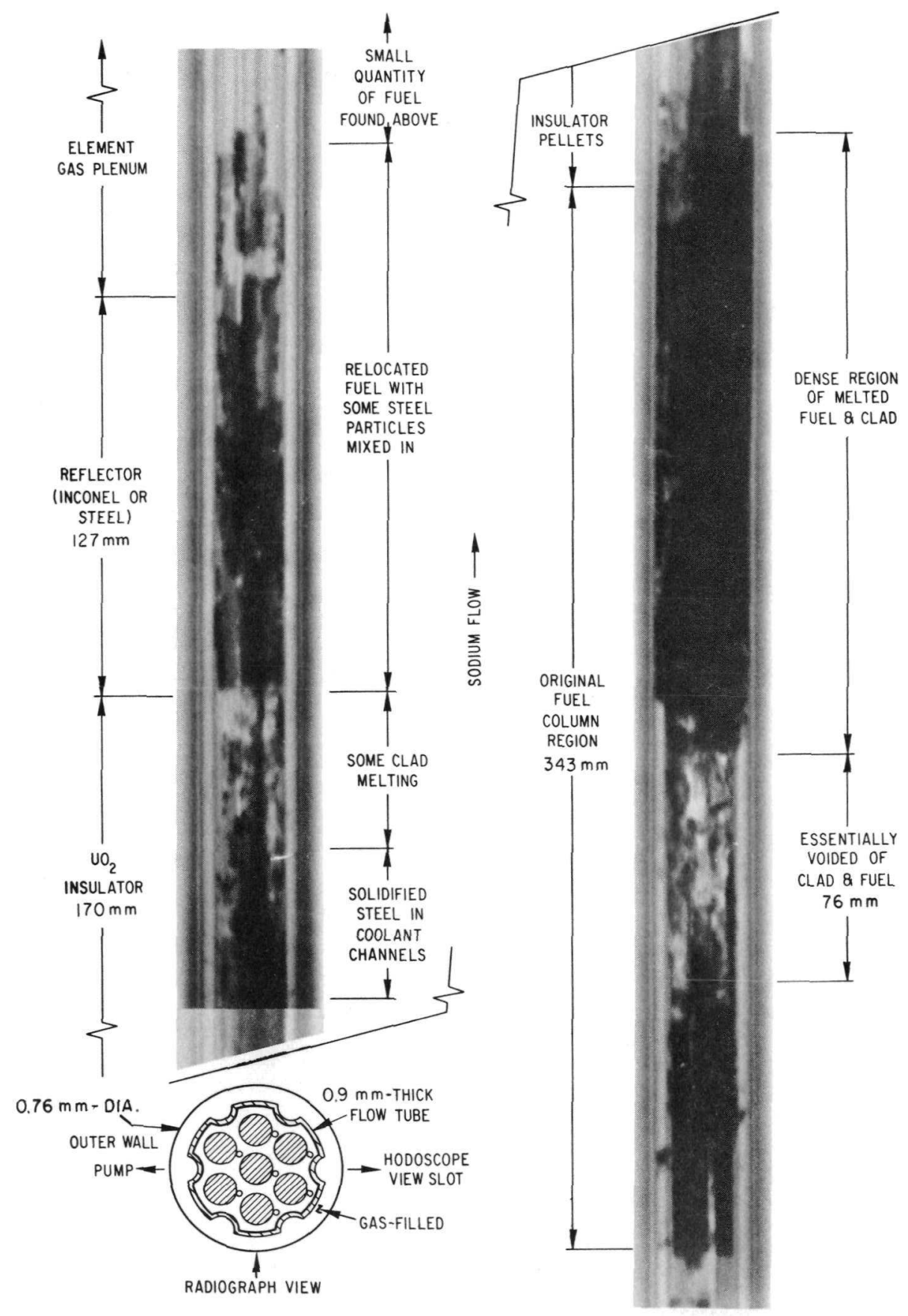

Fig. 2. Posttest Neutron Radiograph of Fuel-column Region of E8 Test Section. ANL Neg. No. 900-77-114. 
From these examinations, the following observations can be drawn by reference to Fig. 2. The region from the midplane to $76 \mathrm{~mm}$ below was essentially free of either fuel or steel. The region from the midplane to the top of the original fuel column contained a mixture of failed fuel and steel. A steel barrier formed in some of the cooling channels just above the top of the fuel column. Fuel, with a little steel entrained, also solidified above this blockage in the region containing the fuel-element reflector pieces. The latter showed that the fuel did move above the top of the original fuel column, but that the reflector pieces and flow tube acted as a heat sink. Molten fuel had apparently entered the coolant channel before very much cladding had melted, consistent with the pressure-transducer signals indicating that the element failures had been abrupt. The results substantiate that a small degree of fuel sweepout is possible for an LMFBR, even at the reduced test flow velocities. The fuel-sweepout mechanism and resultant decrease in reactivity has been postulated ${ }^{4}$ as the means to terminate hypothetical overpower LMFBR accidents. Tests with higher coolant flow rates are currently being planned.

Results obtained by an analysis of data from the fast-neutron hodoscope tend to confirm the scenario outlined above. At about the time of failure as based on flow and pressure data, a small quantity of fuel was ejected from one side of the cluster and moved upward and out of the field of view above the top of the original fuel column. Upward fuel motion beyond the top of the original fuel column ceased about $80 \mathrm{~ms}$ after the initial fuel motion, probably as a result of the formation of a blockage in the flow channels. Subsequent fuel motion occurred largely within the region originally occupied by the active fuel column. 


\section{TEST OBJECTIVES AND DEFINITIONS}

\section{A. Requirements and Constraints}

Current E-series tests simulate unterminated transient overpower accidents in LMFBRs having reactivity additions at the rate of $\$ 3 / \mathrm{s}$. Test E8 simulated this accident for fuel elements having an irradiation history at linear heating rates of about $30 \mathrm{~kW} / \mathrm{m}(9 \mathrm{~kW} / \mathrm{ft})$. For the analysis of transient overpower accidents of FFTF, it has been postulated ${ }^{5}$ that fuel-element failures can be characterized by grouping fuel into three broad categories of irradiation history defining its microstructure:

1. Fresh fuel.

2. Fuel irradiated at low linear heating rates (below about $30 \mathrm{~kW} / \mathrm{m}$ ), designated "low-power-structure" fuel.

3. Fuel irradiated at higher linear heating rates, designated "highpower-structure" fuel.

Fuel-cladding failure will occur, according to the HEDL failure criteria, when a given percentage of the fuel melts. These HEDL failure criteria are listed in Table II. Low-power-structure fuel elements contain the largest inventory of entrained fission-product gases. Based on the failure criteria, low-power-structure fuel should therefore fail more rapidly in an overpower transient than either fresh or high-power fuel, perhaps reducing the consequences of the accident. More refined failure criteria have been developed after Test E8 was conducted as more results from element-failure testing became available.

TABLE II. Failure Criteria for Fuel-element Classifications ${ }^{5}$

\begin{tabular}{lccc}
\hline \multicolumn{1}{c}{$\begin{array}{c}\text { Fuel-element } \\
\text { Classification }\end{array}$} & Fresh & $\begin{array}{c}\text { High Power } \\
\text { Irradiated }\end{array}$ & $\begin{array}{c}\text { Low Power } \\
\text { Irradiated }\end{array}$ \\
\hline $\begin{array}{l}\text { Fission-gas pressure in central } \\
\text { void, } \mathrm{MPa} \text { (atm) }\end{array}$ & $0.1(1)$ & $3.45(34)$ & $\begin{array}{c}3.45(34) \text { (small central } \\
\text { void in ring } 4)\end{array}$ \\
$\begin{array}{l}\text { Concentration of fission gas in } \\
\text { unrestructured fuel, cm } 3 \text { /g oxide }\end{array}$ & 0 & 1.0 & 1.0 \\
$\begin{array}{l}\text { Concentration of fission gas in } \\
\text { equiaxed fuel, } \text { cm }^{3} / \mathrm{g} \text { oxide }\end{array}$ & 0 & 0.5 & 0.5 \\
$\begin{array}{l}\text { Concentration of fission gas in } \\
\text { columnar-grain fuel }\end{array}$ & 0 & 0 & 0 \\
$\begin{array}{l}\text { Percent areal melting at axial } \\
\text { midplane when element failure is } \\
\text { assumed to occur }\end{array}$ & 80 & 30 & Incipient \\
\hline
\end{tabular}

alsotherm defining equiaxed region is $1623 \mathrm{~K}$.

bIsotherm defining columnar-grain region is $1973 \mathrm{~K}$. 
Test E8, which completes the matrix of overpower tests noted in Table III, was considered important for substantiation of analytical models used to predict behavior of fuel motion of transient-overpower accidents in FFTF. Other safety considerations may have also been addressed by this test, but not necessarily within the objectives as originally defined.

TABLE III. Matrix of Transient-overpower Tests

\begin{tabular}{lcc}
\hline \multicolumn{1}{c}{$\begin{array}{c}\text { Fuel-element } \\
\text { Microstructure }\end{array}$} & \multicolumn{2}{c}{ Ramp-rate Equivalent } \\
\cline { 2 - 3 } Fresh & $50 \phi / \mathrm{s}$ & $3 \mathrm{\$} / \mathrm{s}$ \\
Low power, nominal burnup & $\mathrm{H} 2, \mathrm{R} 9$ & $\mathrm{E} 5^{\mathrm{a}}$ \\
High power, nominal burnup & $\mathrm{H} 5$ & $\mathrm{E} 8$ \\
\hline
\end{tabular}

a Not performed.

The general requirements specified for Test E8 were:

1. The TREAT transient was to simulate a $\$ 3 / \mathrm{s}$ ramp reactivity addition for the FTR.

2. Low-power-structure irradiated fuel elements were to be used.

3. The data acquisition should maximize information on:

a. Time of failure of fuel-element cladding and nature of failure.

b. Nature and magnitude of fuel-coolant interaction following fuel-element failure.

c. Nature of fuel-coolant motion in coolant channels following fuel expulsion, especially as it relates to the extent and rate of fuel sweepout.

4. The following additional data were desired:

a. Location of cladding failure.

b. History of fuel motion inside the fuel element before and after cladding failure, with emphasis on rate-of-motion data.

5. The postmortem examinations were to identify:

a. Physical nature of any expelled fuel fragments.

b. Spatial and particle-size distributions of expelled fuel fragments within the test section and in the balance of the loop. 
6. The axial power distributions were to match EBR-II steady-state irradiation conditions. Temperatures at the axial midplane of the test elements were to match FTR axial midplane conditions. The fuel temperature response was to match predictions of the MELT-III code for an FTR response to a $\$ 3 / \mathrm{s}$ reactivity ramp addition.

In addition to the above requirements, Test E8 had the following limitations :

1. The existing Mark-II loop-hardware technology was to be used.

2. The TREAT transient could not exceed previous test energetics so that extensive reviews for experiment safety were not needed.

3. The first elements to fail in the cluster were required to fail while the power was increasing.

4. The test was to be as similar as possible to Tests E6 and E7, which were previously conducted in TREAT as a part of the safety-testing program.

\section{B. Selection of Fuel Elements}

Table IV lists the parameters characterizing available fuel elements irradiated at low linear power ratings in EBR-II. The selection of elements for Test E8 was based on the degree that element characteristics met typical FFTF fuel-element materials and dimensional parameters as well as the E8 test requirements. A comparison among the available elements, listed in Table V, indicates that the PNL-10 element was the desired choice.

TABLE IV. Parameters of Irradiated, Mixed-oxide Fuel Elements Considered for Test E8

\begin{tabular}{cccccc}
\hline $\begin{array}{c}\text { Fuel } \\
\text { Type }^{\mathrm{a}}\end{array}$ & $\begin{array}{c}\text { Peak Power, } \\
\mathrm{kW} / \mathrm{m}\end{array}$ & $\begin{array}{c}\text { Burnup, } \\
\text { at. } \%\end{array}$ & $\begin{array}{c}\text { Fuel-pellet } \\
\text { Diameter, mm }\end{array}$ & $\begin{array}{c}\text { Cladding } \\
\text { Material }\end{array}$ & $\begin{array}{c}\text { Cladding } \\
\text { OD, mm }\end{array}$ \\
\hline PNL-3 & 18 & 4.8 & 5.38 & $304 \mathrm{SS}$ & 6.60 \\
PNL-4 & 29 & 6.9 & 5.38 & $304 \mathrm{SS}$ & 6.60 \\
PNL-6 & 19 & 4.8 & 5.38 & $316 \mathrm{SS}$ & 6.35 \\
PNL-7 & 30 & 6.9 & 5.38 & $316 \mathrm{SS}$ & 6.35 \\
PNL-9 & 19 & 5.0 & 4.93 & $316 \mathrm{SS}$ & 5.84 \\
PNL-10 & 30 & 5.4 & & $(20 \% \mathrm{CW})$ & \\
& & & 4.93 & $316 \mathrm{SS}$ & 5.84 \\
\hline
\end{tabular}

a Each element has an active fuel-column length of $340 \mathrm{~mm}$. 
TABLE V. Comparison of Characteristics of Fuel Elements to E8 Experimental Requirements

\begin{tabular}{ccccc}
\hline $\begin{array}{c}\text { Fuel-element } \\
\text { Designation }\end{array}$ & $\begin{array}{c}\text { Loop } \\
\text { Required }\end{array}$ & $\begin{array}{c}\text { Prototype Clad } \\
\text { Material }\end{array}$ & $\begin{array}{c}\text { Prototype Fuel } \\
\text { Diameter }\end{array}$ & $\begin{array}{c}\text { Desired Linear } \\
\text { Power Density }\end{array}$ \\
\hline PNL-3 & Mark-IIA & No & No & Lower \\
PNL-4 & Mark-IIA & No & No & Yes \\
PNL-6 & Mark-IIC & Yes $^{\mathrm{a}}$ & No & Lower \\
PNL-7 & Mark-IIC & Yes $^{\mathrm{a}}$ & No & Slightly higher \\
PNL-9 & Mark-IIC & Yes & Yes & Lower \\
PNL-10 & Mark-IIC & Yes & Yes & Yes \\
\hline
\end{tabular}

a Degree of cold work may be different.

Figure 3 is a schematic drawing of the PNL-10 fuel element. The fabrication and design characteristics of these elements before EBR-II irradiations are listed in Table VI. Neutron radiographs of the PNL-10 elements indicated the presence of a small-diameter central void. The central void appeared to exist along about one-third of the fueled length of the element centered at the fuel-column midplane. After the fuel elements were selected for the test, two sibling elements from the set were chosen for destructive examination. Results of this examination were reported by Scott et al. ${ }^{6}$ For example, examination of the PNL-10-23 element yielded the microstructural features listed in Table VII, which confirm the suitability of the selection of the PNL-10 elements for the test.

\section{Description of Test Hardware}

The Mark-IIC loop Cl with ALIP 1.001lA was used for Test E8. The test train for E8 was of the same general design used in previous transientoverpower tests in the Mark-IIA loop. The seven test elements were contained within a fuel holder containing six flutes, as shown in Fig. 4. The idealized

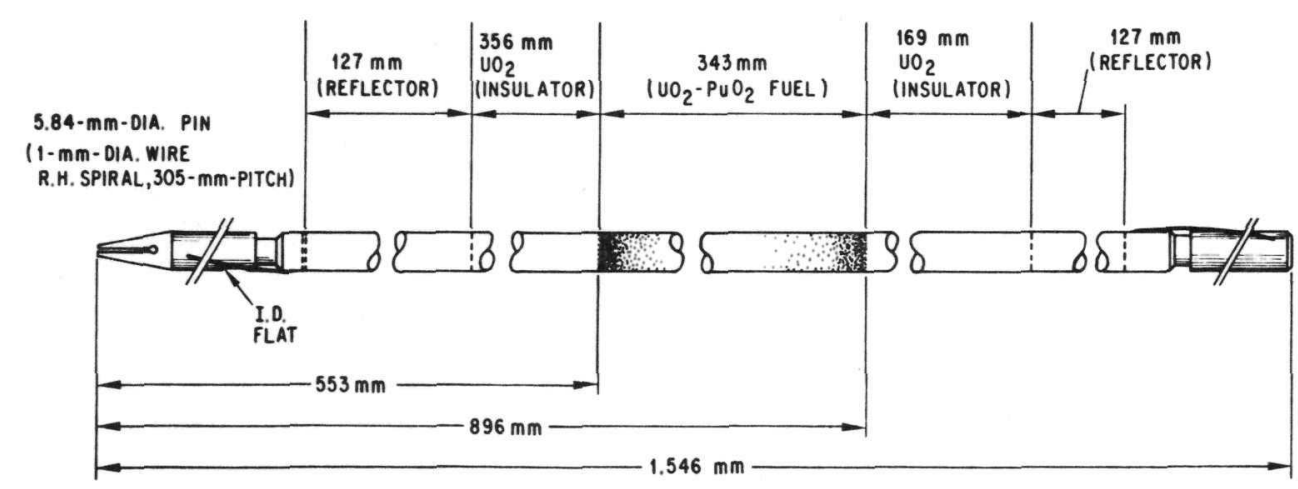

Fig. 3. Schematic Diagram of PNL-10 Fuel Element. ANL Neg. No. 900-77-35. 
TABLE VI. Fabrication and Design Parameters for Unirradiated PNL-10 Fuel Elements ${ }^{6}$

Fuel

Fuel composition, $\mathrm{Pu} /(\mathrm{U}+\mathrm{Pu})$

Uranium enrichment

Plutonium enrichment

Fuel-pellet diameter

Fuel-pellet geometry

Dish depth

Fuel-column length

Fuel-pellet density

Fuel smeared density

Fuel-Cladding diametral gap

Fuel weight

Diameter of natural- $\mathrm{UO}_{2}$ pellet

Total length of natural- $\mathrm{UO}_{2}$ column

Reflector material

Reflector diameter

Total reflector length

Total reflector volume

Total reflector weight

Reflector density

Cladding material

Cladding outer diameter

Cladding wall thickness

Wire-wrap material

Wire-wrap diameter

End-cap material

Gas-plenum volume

Plenum gas

Gas pressure

Drawing number
$\mathrm{UO}_{2}-\mathrm{PuO}_{2}$

$0.25 \pm 0.013$

$65 \pm 1$ wt $\%{ }^{235} \mathrm{U}$ in uranium

$88 \pm 1.0$ wt $\%{ }^{239} \mathrm{Pu}+{ }^{241} \mathrm{Pu}$ in plutonium

(0.5 wt \% wt $\max { }^{238} \mathrm{Pu}+$ other plutonium isotopes, balance ${ }^{240} \mathrm{Pu}$ )

$4.93 \mathrm{~mm}$

Dished ends

$0.07 \mathrm{~mm}$

$343 \mathrm{~mm}$

$90.9 \pm 2.0 \% \mathrm{TD}$

$85.5 \pm 2.5 \% \mathrm{TD}$

$0.15 \mathrm{~mm}$

$65.2 \pm 3.1 \mathrm{~g}$

$4.93 \mathrm{~mm}$

$526 \mathrm{~mm}$

Inconel-600 (odd-numbered elements) $20 \% \mathrm{CW}$ 316 stainless steel (even numbered elements)

$4.94 \mathrm{~mm}$

$254 \mathrm{~mm}$

$4.85 \mathrm{~cm}^{3}$

$4.31 \pm 1.0 \mathrm{~g}$

$8.90 \mathrm{~g} / \mathrm{cm}^{3}$

$20 \%$ CW 316 stainless steel

$5.84 \mathrm{~mm}$

$0.38 \mathrm{~mm}$

$20 \%$ CW 316 stainless steel (ASTM A-478-63)

$1 \mathrm{~mm}$

Annealed 316 stainless steel (ASTM A-276-55T)

$6.1 \mathrm{~cm}^{3}$

Helium $+1 \mathrm{~cm}^{3}$ xenon tag

$100 \mathrm{kPa}$ at room temperature

PNL-H-3-29176 (Rev. 2)

TABLE VII. Microstructural Features for PNL-10-23 Fuel Elements ${ }^{6}$

Location along Active Fuel Length, mm

Fuel-region Structure

Near Lower End At Midplane

Radius of central void

None

0.16

Outer radius of columnar-grain region

None

1.35

Outer radius of equiaxed-grain region

1.42

1.75

Unrestructured region

Remainder

Remainder

Diametral fuel-cladding gap

0.053

0.033 


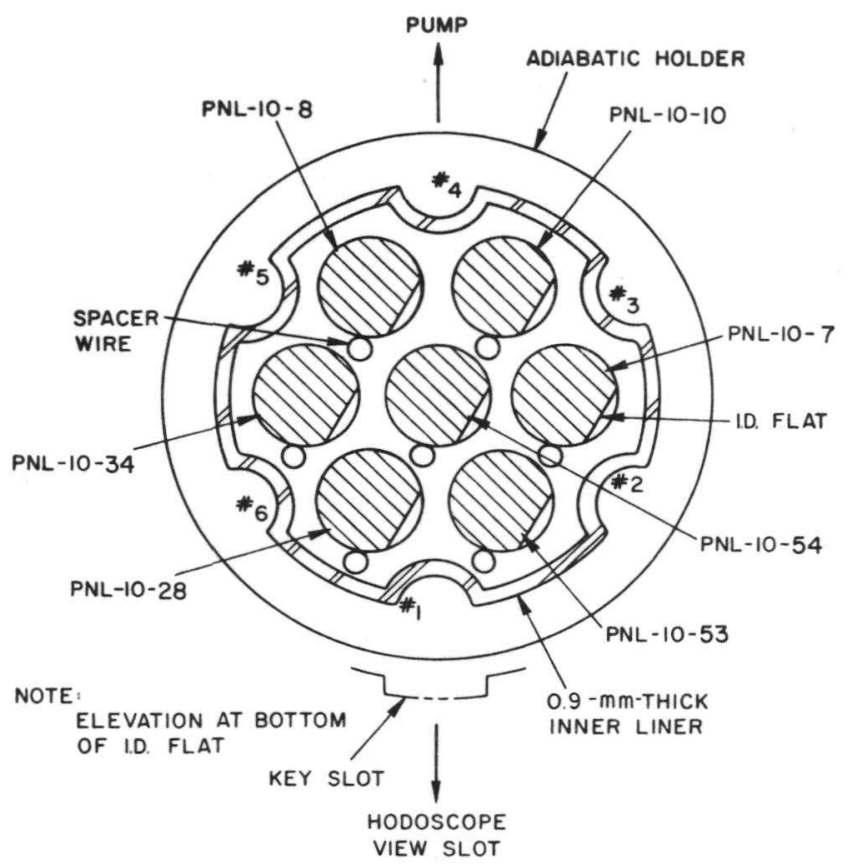

Fig. 4

Cross-sectional View (Looking down) of Fuel-element Arrangement in Fluted Tube. ANL Neg. No. 900-3425 Rev. 2. net area for sodium flow within the fuel holder was $1.329 \mathrm{~cm}^{2}$. In practice, the actual area is larger than the idealized flow area, because sufficient clearances must be provided to permit the insertion of the seven irradiated elements in a hot cell. Variations within fabrication tolerances also cause differences among experiments using the identical fluted-tube design. For the E8 fuel holder, an alcohol-displacement measurement indicated an average cross-sectional area within the fuel holder of $3.649 \mathrm{~cm}^{2}$. Since the seven fuel elements occupy $1.933 \mathrm{~cm}^{2}$, about $1.72 \mathrm{~cm}^{2}$ remain for sodium flow. This $30 \%$ increase in flow area above the idealized value reduces the bulk coolant velocity within the test region and the pressure drop across the test section for a given mass flow rate.

An adiabatic section containing helium (at $\sim 0.1 \mathrm{MPa}$ ) reduced heat loss between the test region and the loop wall. The tops of the elements and the fuel holder terminated below an outlet pressure transducer. As in some previous tests, thermocouple instrumentation leads, tack-welded to the flutes inside the adiabatic section and elsewhere along the test train, passed through the exit gland at the top of the test train. Sodium temperature at the inlet was monitored by two thermocouples which passed through the loop pressure boundary in a special high-pressure fitting in the lower-loop instrument section.

The test section was instrumented with 18 thermocouples (including the two inlet thermocouples), an inlet flowmeter, an inlet pressure transducer, an outlet flowmeter, and an outlet pressure transducer. Table VIII shows the location at room temperature of each thermocouple relative to the lower end of the fuel element.

The hodoscope was also operated for the test. The test section and pump orientation were changed from previous Mark-II loop tests so that the test region and pump leg were in line with the hodoscope slot. The test section was located between the slot and the pump leg as indicated in Fig. 4.

The Mark-IIC loop was outfitted with a dysprosium filter, dysprosium shaping collars, and boron shields consistent with the E8 calibration experiment. The filter types and configuration identified in Table IX are shown schematically in Fig. 5. 
TABLE VIII. Thermocouple Locations for Test E8

\begin{tabular}{|c|c|c|c|}
\hline $\begin{array}{l}\text { Thermocouple } \\
\text { Number }\end{array}$ & Flute Positiona & $\begin{array}{l}\text { Vertical Position from } \\
\text { Bottom of Pin, b } \mathrm{mm}\end{array}$ & Remarks \\
\hline 1,2 & Centered in flow path & $\begin{array}{l}\text { Set by Mark-IIC design } \sim 64 \mathrm{~mm} \\
\text { below test sections }\end{array}$ & $\begin{array}{l}\text { Thermocouples at test- } \\
\text { section inlet }\end{array}$ \\
\hline 3 & 1 & 476 & $\begin{array}{l}75 \mathrm{~mm} \text { below fuel column } \\
\text { in insulator region }\end{array}$ \\
\hline 4 & 1 & 552 & $\begin{array}{l}\text { At lower fuel-insulator } \\
\text { interface }\end{array}$ \\
\hline 5 & 1 & 578 & $\begin{array}{l}25 \mathrm{~mm} \text { above bottom of } \\
\text { fuel-pellet region }\end{array}$ \\
\hline 6 & 1 & 724 & At axial center of column \\
\hline 7 & 4 & 724 & $\begin{array}{l}\text { On opposite side of fluted } \\
\text { tube from TC- } 6\end{array}$ \\
\hline 8 & 1 & 832 & $\begin{array}{l}64 \mathrm{~mm} \text { below top of fuel } \\
\text { column }\end{array}$ \\
\hline 9 & 4 & 832 & $\begin{array}{l}\text { On opposite side of fluted } \\
\text { tube from TC- } 8\end{array}$ \\
\hline 10 & 6 & 895 & At top of fuel column \\
\hline 11 & 3 & 895 & $\begin{array}{l}\text { On opposite side of fluted } \\
\text { tube from TC-10 }\end{array}$ \\
\hline 12 & 1 & 920 & $\begin{array}{l}25 \mathrm{~mm} \text { above top of fuel } \\
\text { column }\end{array}$ \\
\hline 13 & 1 & 1022 & $\begin{array}{l}127 \mathrm{~mm} \text { above top of fuel } \\
\text { column }\end{array}$ \\
\hline 14 & Extends in from 2 & 1554 & $\begin{array}{l}\text { Outlet thermocouple (in re- } \\
\text { gion above top of elements) }\end{array}$ \\
\hline 15 & Extends in from 5 & 1554 & $\begin{array}{l}\text { Outlet thermocouple (in re- } \\
\text { gion above top of elements) }\end{array}$ \\
\hline 16 & Above center of cluster & 1708 & At sodium return \\
\hline 17 & $\begin{array}{l}\text { Above Flute } 3 \text { on upper- } \\
\text { test-train weldment }\end{array}$ & 1870 & $\begin{array}{l}\sim 50 \mathrm{~mm} \text { above sodium level } \\
\left(\text { at } 260^{\circ} \mathrm{C} \text { ) in gas space and }\right. \\
6 \mathrm{~mm} \text { below end baffle }\end{array}$ \\
\hline 18 & $\begin{array}{l}\text { Above Flute } 3 \text { on upper- } \\
\text { test-train weldment }\end{array}$ & 2003 & $\begin{array}{l}190 \mathrm{~mm} \text { above sodium level } \\
\left(\text { at } 260^{\circ} \mathrm{C}\right) \text { in gas space and } \\
6 \mathrm{~mm} \text { below midbaffle }\end{array}$ \\
\hline
\end{tabular}

a Flute positions are shown on Fig. 4.

$\mathrm{b}_{\mathrm{A}}$ tolerance of $\pm 1.5 \mathrm{~mm}$ for thermocouple placement.

TABLE IX. Filters, Collars, and Shields for E8 Loop

\begin{tabular}{|c|c|c|}
\hline Loop Location & Function & Material \\
\hline $\begin{array}{l}\text { Test section, test ele- } \\
\text { ment active fuel region }\end{array}$ & Filter & $0.51-\mathrm{mm}$ dysprosium \\
\hline $\begin{array}{l}\text { Test section, ends of } \\
\text { active fuel region }\end{array}$ & $\begin{array}{l}\text { Collars for } \\
\text { axial shaping }\end{array}$ & $\begin{array}{l}0.38-\text { and } 0.635-\mathrm{mm} \\
\text { dysprosium, stacked }\end{array}$ \\
\hline Test section, balance & Shields & $\begin{array}{l}\mathrm{B}_{6} \mathrm{Si}-\text { Pyromark paint on } \\
16 \times 16 \text { wire mesh screen }\end{array}$ \\
\hline $\begin{array}{l}\text { Dump tanks, pump, } \\
\text { and spool piece }\end{array}$ & Shields & $\begin{array}{l}\mathrm{B}_{6} \mathrm{Si}-\text { Pyromark paint on } \\
16 \times 16 \text { wire mesh screen }\end{array}$ \\
\hline Bends & Shields & $\begin{array}{l}\mathrm{B}_{6} \mathrm{Si}-\text { Pyromark paint on } \\
\text { knitted wire mesh }\end{array}$ \\
\hline
\end{tabular}

a The screens were tack-welded to 0.38 -mm-thick stainless steel shim stock, and the weight of $\mathrm{B}_{6} \mathrm{Si}$ per unit area was controlled during fabrication to at least $\pm 7 \%$ of the average value for the loop of $60 \mathrm{mg}$ of boron $/ \mathrm{cm}^{2}$. 


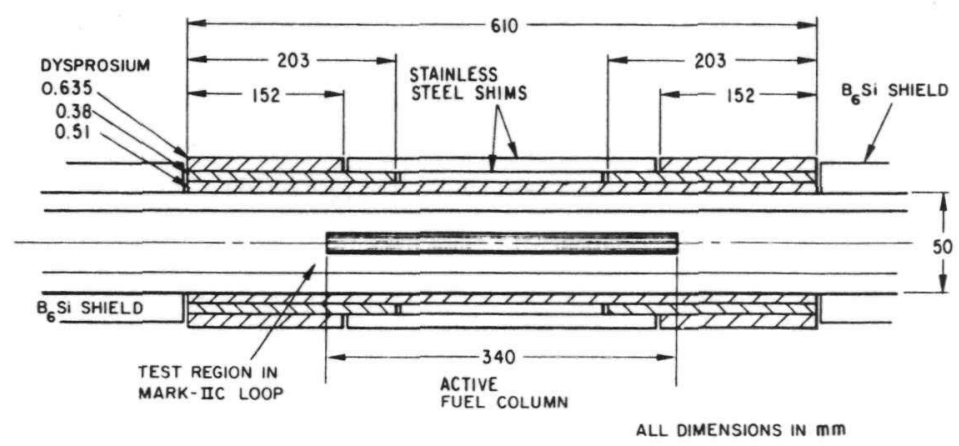

Fig. 5

Schematic Diagram of Filter and Collar Configuration for Test E8. ANL Neg. No. 900-77-21.

Table X lists the as-fabricated data for the $\mathrm{B}_{6}$ Si filters (each halfcylinder) placed on the loop and dump tanks. Note that the average value for the loop of $59.3 \mathrm{mg}$ natural boron $/ \mathrm{cm}^{2}$ was nearly identical with the value of $60 \mathrm{mg}$ natural boron $/ \mathrm{cm}^{2}$ obtained for the E8 mockup loop used for the calibration tests. Measurements of neutron-beam transmission with samples prepared from the boron-paint mixtures for the mockup loop and the test loop verified the adequacy of the measurements based on weight.

TABLE X. As-fabricated Hexaboron Silicide (B6Si) Neutron Shields for E8 Loop

\begin{tabular}{|c|c|c|c|c|}
\hline $\begin{array}{l}\text { Part } \\
\text { Number }\end{array}$ & $\begin{array}{l}\text { Mixture } \\
\text { Weight, }{ }^{a} \mathrm{~g}\end{array}$ & $\begin{array}{l}\text { Area of } \\
\text { Part, } \mathrm{cm}^{2}\end{array}$ & $\begin{array}{l}\text { Boron Weight per } \\
\text { Unit Area, } \mathrm{mg} / \mathrm{cm}^{2}\end{array}$ & Location on Loop \\
\hline $\begin{array}{l}29-01 \\
29-02\end{array}$ & $\begin{array}{l}18.6 \\
18.6\end{array}$ & $\begin{array}{l}136.7 \\
136.7\end{array}$ & $\begin{array}{l}63.4 \\
63.4\end{array}$ & $\begin{array}{l}\text { Spool piece (upper part) } \\
\text { Spool piece (upper part) }\end{array}$ \\
\hline $\begin{array}{l}30-01 \\
30-02\end{array}$ & $\begin{array}{l}42.8 \\
43.1\end{array}$ & $\begin{array}{l}327.2 \\
327.2\end{array}$ & $\begin{array}{l}61.0 \\
61.4\end{array}$ & $\begin{array}{l}\text { Spool piece (lower part) } \\
\text { Spool piece (lower part) }\end{array}$ \\
\hline $\begin{array}{l}31-01 \\
31-02\end{array}$ & $\begin{array}{l}17.8 \\
18.2\end{array}$ & $\begin{array}{l}140.3 \\
104.3\end{array}$ & $\begin{array}{l}59.1 \\
60.5\end{array}$ & $\begin{array}{l}\text { Small dump tube (upper part) } \\
\text { Small dump tube (upper part) }\end{array}$ \\
\hline $\begin{array}{l}32-01 \\
32-02\end{array}$ & $\begin{array}{l}43.3 \\
41.0\end{array}$ & $\begin{array}{l}324.9 \\
324.9\end{array}$ & $\begin{array}{l}62.1 \\
58.8\end{array}$ & $\begin{array}{l}\text { Small dump tube (lower part) } \\
\text { Small dump tube (lower part) }\end{array}$ \\
\hline $\begin{array}{l}33-01 \\
33-02 \\
33-03 \\
33-04\end{array}$ & $\begin{array}{l}21.1 \\
20.9 \\
20.9 \\
21.4\end{array}$ & $\begin{array}{l}164.8 \\
164.8 \\
164.8 \\
164.8\end{array}$ & $\begin{array}{l}59.7 \\
59.1 \\
59.1 \\
60.5\end{array}$ & $\begin{array}{l}\text { Large dump tubes (upper part) } \\
\text { Large dump tubes (upper part) } \\
\text { Large dump tubes (upper part) } \\
\text { Large dump tubes (upper part) }\end{array}$ \\
\hline $\begin{array}{l}34-01 \\
34-02 \\
34-03 \\
34-04\end{array}$ & $\begin{array}{l}48.5 \\
47.8 \\
47.7 \\
48.1\end{array}$ & $\begin{array}{l}382.3 \\
382.3 \\
382.3 \\
382.3\end{array}$ & $\begin{array}{l}59.1 \\
58.3 \\
58.2 \\
58.6\end{array}$ & $\begin{array}{l}\text { Large dump tubes (lower part) } \\
\text { Large dump tubes (lower part) } \\
\text { Large dump tubes (lower part) } \\
\text { Large dump tubes (lower part) }\end{array}$ \\
\hline $\begin{array}{l}35-01 \\
35-02\end{array}$ & $\begin{array}{l}43.5 \\
45.2\end{array}$ & $\begin{array}{l}352.0 \\
352.0\end{array}$ & $\begin{array}{l}57.6 \\
59.9\end{array}$ & $\begin{array}{l}\text { Lower test section } \\
\text { Lower test section }\end{array}$ \\
\hline $\begin{array}{l}36-01 \\
36-02\end{array}$ & $\begin{array}{l}50.3 \\
51.0\end{array}$ & $\begin{array}{l}393.4 \\
393.4\end{array}$ & $\begin{array}{l}59.6 \\
60.4\end{array}$ & $\begin{array}{l}\text { Upper test section } \\
\text { Upper test section }\end{array}$ \\
\hline $\begin{array}{l}37-01 \\
37-02\end{array}$ & $\begin{array}{l}97.8 \\
97.2\end{array}$ & $\begin{array}{l}784.4 \\
788.9\end{array}$ & $\begin{array}{l}58.1 \\
57.4\end{array}$ & $\begin{array}{l}\text { ALIP pump } \\
\text { ALIP pump }\end{array}$ \\
\hline Sum & 904.8 & 7110.1 & 1315.3 & - \\
\hline Parts average & - & - & 59.8 & Average of parts weight per unit area \\
\hline Loop average & - & - & 59.3 & Total boron weight $\div$ total area \\
\hline Archive 3 & 13.3 & 103.2 & 60.1 & Samples prepared from same paint mixture \\
\hline Archive 4 & 13.3 & 103.2 & 60.1 & Samples prepared from same paint mixture \\
\hline
\end{tabular}

$\mathrm{a}_{6} \mathrm{Si}$ was $97.99 \%$ pure; $31.8 \%$ of the mixture was paint pigment after solvent evaporated.

Table XI lists the as-fabricated data for the dysprosium filters and shaping collars. The dysprosium was cut and rolled in the form of halfcylinders and placed on the loop according to Fig. 5. Careful control of the filter and shield material between the actual loop and the mockup (calibration) loop was required to ensure repeatability of the test-fuel calibration constants measured in the calibration experiments for E8. 
TABLE XI. As-fabricated Dysprosium Filters and Collars for Test E8

\begin{tabular}{ccccccc}
\hline $\begin{array}{c}\text { Part } \\
\text { Number }\end{array}$ & $\begin{array}{c}\text { Nominal } \\
\text { Dimensions, } \\
\mathrm{mm}\end{array}$ & $\begin{array}{c}\text { Weight, } \\
\mathrm{g}\end{array}$ & $\begin{array}{c}\text { Area, } \\
\mathrm{cm}^{2}\end{array}$ & $\begin{array}{c}\text { Dysprosium } \\
\text { Weight/Area, } \\
\mathrm{mg} / \mathrm{cm}^{2}\end{array}$ & $\begin{array}{c}\text { Micrometer } \\
\text { Measurement, } \\
\mathrm{mm}\end{array}$ & $\begin{array}{c}\text { Function } \\
\text { of Part }\end{array}$ \\
\hline $\begin{array}{l}25-01 \\
25-02\end{array}$ & $203 \times 0.381 \times 52.4$ ID & 56.3 & 167.2 & 337 & $0.383 \pm 0.005$ & Shaping collar \\
$25-03$ & & 57.9 & 167.2 & 346 & $0.394 \pm 0.005$ & \\
$25-04$ & & 57.6 & 167.2 & 344 & $0.396 \pm 0.005$ & \\
$26-01$ & $152 \times 0.635 \times 53.2$ ID & 70.6 & 127.3 & 555 & $0.642 \pm 0.005$ & Shaping collar \\
$26-02$ & & 70.9 & 127.3 & 557 & $0.640 \pm 0.005$ & \\
$26-03$ & & 70.7 & 127.3 & 555 & $0.638 \pm 0.005$ & \\
$26-04$ & & 70.6 & 127.3 & 555 & $0.635 \pm 0.005$ & \\
$27-01$ & $610 \times 0.381 \times 51.2$ ID & 162.9 & 490.2 & 332 & $0.383 \pm 0.005$ & Filter \\
$27-02$ & & 163.3 & 490.2 & 333 & $0.383 \pm 0.005$ & \\
$28-01$ & $610 \times 0.13 \times 51.6$ ID & 57.3 & 494.0 & 116 & $0.130 \pm 0.005$ & Filter \\
$28-02$ & & 57.6 & 494.0 & 117 & $0.130 \pm 0.005$ & \\
\hline
\end{tabular}

D. Transient Planning

The following test parameters must be defined for an overpower simulation in TREAT:

1. Flow rate in the test section.

2. Initial sodium temperature.

3. Duration and level of TREAT reactor preheat phase.

4. TREAT power ramps and scram setting.

The flow rate in the test section was limited to about $575 \mathrm{~cm}^{3} / \mathrm{s}$ to prevent "overcooling" the cladding (with respect to FTR-like conditions) of the short elements. The actual test pump required about $30 \mathrm{~A}$ to obtain this flow rate. The inlet sodium temperature was selected at $400^{\circ} \mathrm{C}$ to match the sodium temperature in previous Mark-II loop tests.

In previous overpower tests, an initial radial temperature profile was attained by "preheating" the fuel. The preheat offsets the likelihood that the fuel would melt in a nonprototypical way. For a fast-reactor element in an operating fast reactor, the radial temperature profile is parabolic downward, perturbed somewhat by the density variation caused by restructuring. Consequently, melting in an overpower accident occurs from the center of an element outward. In TREAT, however, the highly thermalized neutrons from the reactor cause radial power distributions within each element that deviate from the desired constant value. As a result, it is possible to have melt fronts that originate elsewhere radially in the pellet in an overpower simulation. The use of a neutron filter reduces the peak-to-average power density within the pellet. A preheat is also desired to minimize the undesirable melting pattern. The preheat period also is used to calibrate the hodoscope detectors since, during this time interval, the power generation is constant and the element geometry is relatively fixed. 
It is not possible to specify a preheat in TREAT to produce fueltemperature profiles that exactly match the FTR thermal profiles everywhere. The requirement to meet only the radial temperature distribution at the midplane was interpreted as that the stored energy should be matched. In this way, a quantitative basis of comparison could be used for cases in which the temperature distributions differ. Establishing the radial temperature distribution by preheating the fuel at a level of $30 \mathrm{~kW} / \mathrm{m}$ would be desirable, since this linear heating rate corresponds to the preirradiation level for the test elements. However, the preheat duration and subsequent power excursion would require all available TREAT reactivity before the fuel elements would fail. The higher the preheat level, the less will be the duration required to meet the thermal criteria. A parametric study indicated that a preheat at $46 \mathrm{~kW} / \mathrm{m}$ for the cluster elements in the test with the highest calibration factor would be a reasonable compromise so that sufficient reactivity would be available for the rapid-power-increase portion of the failure transient. The corresponding TREAT power level is $115 \mathrm{MW}$.

The TREAT reactor scram setting at a l-GJ energy release was based on the desire to guarantee that the first element in the seven-element cluster to fail would do so before peak power was reached. Failure criteria, data from previous capsule tests, and uncertainties in test constants were balanced to achieve this objective. As a result of the compromises made based on hardware and reactor limitations, the TREAT transient identified in Fig. 6 was specified. Figure 7 shows the calculated radial temperature distribution at the axial fuel-column midplane at the start of the power ramp. At this

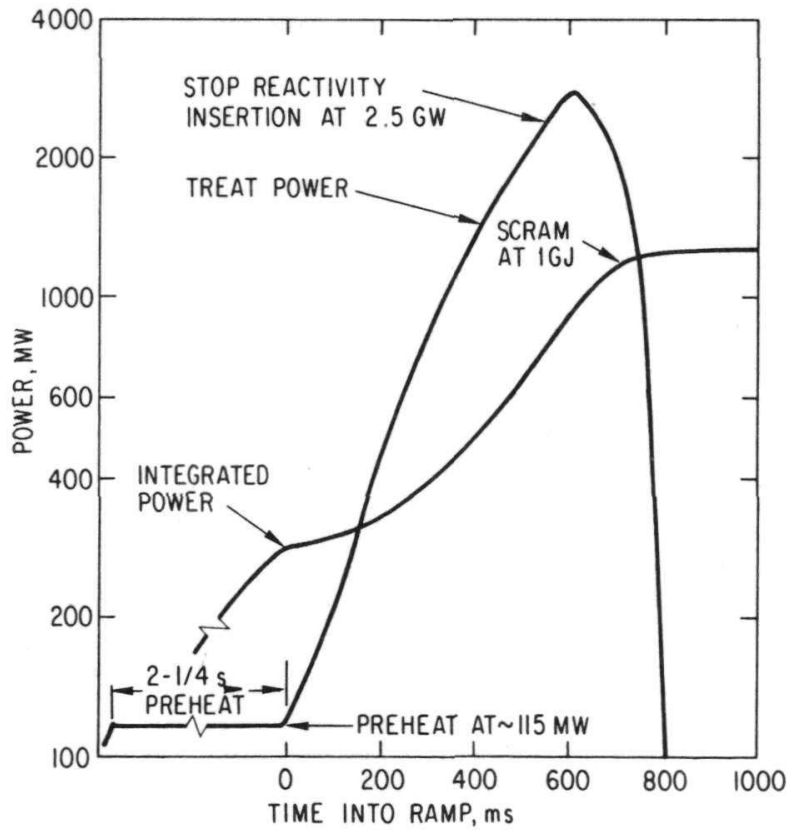

Fig. 6. Desired E8 Transient. ANL Neg. No. 900-77-17.

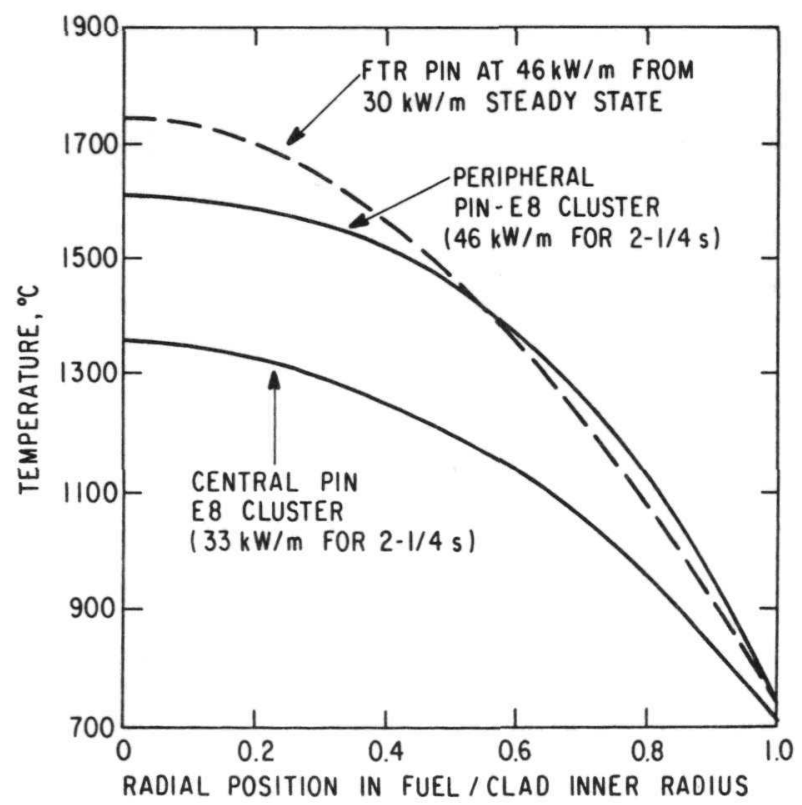

Fig. 7. Radial Temperature Profile Calculated for E8 Cluster Relative to FTR at Start of TREAT Ramp. ANL Neg. No. 900-77-46 Rev. 1. 
point, COBRA calculations indicated that the stored enthalpy for the FTR at $46 \mathrm{~kW} / \mathrm{m}$ (on a ramp from steady-state operation at $30 \mathrm{~kW} / \mathrm{m} *$ ) will equal the energy stored in the E8 element with the highest calibration factor. In other words, the TREAT transient catches up to the FTR ramp at $46 \mathrm{~kW} / \mathrm{m}$, the level of loading for the test element during the TREAT preheat. A further refinement in the modeling for simulating the accident conditions at the end of a preheat within the test region is probably not warranted when all the experimental uncertainties are considered.

For the transient specified in Fig. 6, a failure point at $655 \mathrm{MJ}$ was estimated before the test. This estimate was based on the attainment of temperatures above the solidus for about $50 \%$ of the fuel-pellet area at about the midplane. At this point, the solidus isotherm in the hottest elements in the cluster would have reached the unrestructured zone. About $40 \%$ of the total energy would therefore be generated after the nominal first failure point, a consequence of the desire to guarantee failure during a period of rising power with the uncertainties involved. After failure and fuel motion in an analogous fast-reactor accident, the resulting reactivity feedback would alter the power-time profile, and this profile may not be duplicated by the features of the TREAT transient. Since fuel motion in the test region of the loop will not result in any significant reactivity feedback in TREAT, the transient will therefore proceed as if fuel motion in the test cluster had not occurred.

During the test planning, it was recognized that posttest calculations for the test might differ from the pretest analysis. Since the pretest analyses were conducted, the COBRA code has been improved and the cluster parameters better defined. One might also find some differences in numerical results when different computer codes are compared with the results obtained here with the COBRA code. These differences have occurred in the past primarily because each individual code attempts to treat a specific part of the thermal analysis somewhat more explicitly, leading to difficulty in providing identical input parameters.

*The preirradiation level in EBR-II was $30 \mathrm{~kW} / \mathrm{m}$. 


\section{INSTRUMENT AND TEST-ELEMENT CALIBRATIONS}

A. Calibrations of Loop Instrumentation

1. Thermocouples

Test-section thermocouples were of the Chromel-Alumel type. Standard reduction of millivolt output to temperature was based on tabulated values related to a $65.5^{\circ} \mathrm{C}$ reference junction.

\section{Pressure Transducers}

Statham unbonded, strain, bridge pressure transducers, Model PG 732 TC-2.5M-350, were used at the test-section inlet and outlet. This transducer model meets the loop pressure requirement of $34 \mathrm{MPa}$ without bursting, although its pressure-sensitive diaphragm would be damaged. At $5-\mathrm{V}$ excitation, the calibration constant for the transducer model is about $840 \mathrm{pV} / \mathrm{Pa}$ in the range of $0-17 \mathrm{MPa}$. Because of space and temperature limitations, the transducers are mounted on NaK standoffs.

Manufacturer-supplied calibration information was verified with the transducers mounted on the loop, at operating temperatures, using a known pressure source in the range of 0-1.5 MPa with a 5-V dc excitation. For the tests in the reactor, the excitation source was switched to a $5-\mathrm{V}, 5-\mathrm{kHz}$ source to eliminate potential ionization-current effects in the resistance-bridge circuit. At the time of the test, the transducer bridge was balanced to null its output with the loop in the reactor at the initial equilibrium thermal conditions of about $400^{\circ} \mathrm{C}$ specified for the experiment. At this point the loop could not be pressurized to recheck the pressure-transducer calibrations since the expansion bellows on the test train would collapse. The transducer calibrations were therefore based on the earlier in situ calibration verification, and on the specification above the range for which the calibration had been verified. (Pressure pulses above the verified range were not necessarily expected.)

\section{Flowmeters}

The lower (inlet) electromagnetic flowmeter was calibrated by measuring its output ( $1-\mathrm{A}$ coil current) as a function of the pressure drop across a $7.98-\mathrm{mm}$-dia orifice before the fuel-bearing test section was loaded into the loop. The orifice was calibrated separately in a water loop to relate flow rate to pressure drop. When the no-flow, zero-shift signal output of the inlet electromagnetic flowmeter was subtracted from its total output, a calibration constant of about $620 \mathrm{~cm}^{3} / \mathrm{s} \cdot \mathrm{mV}( \pm 10 \%)$ was obtained at sodium temperatures of $260-540^{\circ} \mathrm{C}$. The upper (outlet) flowmeter was calibrated after the loaded test train was inserted into the loop, using the inlet flowmeter as the reference at a sodium temperature of $400^{\circ} \mathrm{C}$. The sensitivity of the outlet flowmeter is usually poorer than the inlet by a factor of 2-3. 
Just before the experiment was conducted, a malfunction of the inlet flowmeter occurred that resulted in a marked reduction in its sensitivity, although its output was stable. Unfortunately, the sensitivity of the inlet flowmeter was reduced even below that for the outlet flowmeter, leading to some difficulty in establishing the initial flow rate and in interpreting test results. Because of its location on the loop, the lower flowmeter could not be conveniently replaced, and the associated schedule delay was judged unacceptable. After the test, the inlet electromagnet was removed for examination. From the examination it was concluded that the malfunction had occurred because several turns of the electromagnet had been shorted out to ground. Mark-II tests subsequent to E8 have used a permanent-magnet flowmeter at the inlet as a backup to the inlet electromagnetic flowmeter.

\section{B. Power-calibration Experiments}

\section{Calibration-test Objectives}

The execution of a TREAT fuel-motion test using the Mark-II loop involves the necessary step of "calibrating" the power generated in the test fuel. These calibrations relate the power being generated in each fuel element in the test cluster to a detection apparatus external to the test region. The detection devices must be continuously recording during the test for the purposes of reactor control and posttest evaluation. The relationship between the detection device and the reactor power level also needs to be known so that the acceptability of the transient can be established on reactor operational grounds. Although various possibilities exist, the practice at TREAT has been to use either a reactor-power or a reactor-power-integrator channel for this detector. For Test E8, calibrations were based on "Integrator 1," an ion chamber (uncompensated). Calibration factors were determined for four of the seven elements in the cluster; symmetry was assumed for the rest because of the core symmetry. The value of a calibration factor is expressed as the specific power generated in the sample per megawatt of TREAT power; its peak axial value is generally quoted. The precise power level of the reactor need not be known as long as the instrument calibration, the core loading, and control-rod configuration are the same for the calibration test and the actual test.

The calibration factor must be known sufficiently in advance of the test to plan the transient and to evaluate the experiment safety. For example, a test fuel element with $200 \mathrm{~g} / \mathrm{m}$ of fuel and a calibration factor of $4 \mathrm{~kW} / \mathrm{kg}$ per megawatt will generate heat at $40 \mathrm{~kW} / \mathrm{m}$ when TREAT operates at $50 \mathrm{MW}$. The knowledge of these calibration factors and the associated internal radial and axial power distributions is essential to the planning, execution, and analysis of TREAT fuel-motion tests. Calculations show a limit, for the filtered loop, of about $20 \%$ on the change caused by fuel relocation within the test region. These factors will change once fuel motion occurs, and no experimental or analytical method has, as yet, been devised to treat the detailed changes once the original fuel geometry is lost. 
The schematic diagram shown in Fig. 8 illustrates the sequence of events that represent a TREAT test program such as for Test E8. These calibration experiments may not be required in all fuel-motion tests, since previous calibrations may apply with minor calculational corrections. Since Test E8 was the first to use the new Mark-IIC loop, calibration tests were required.

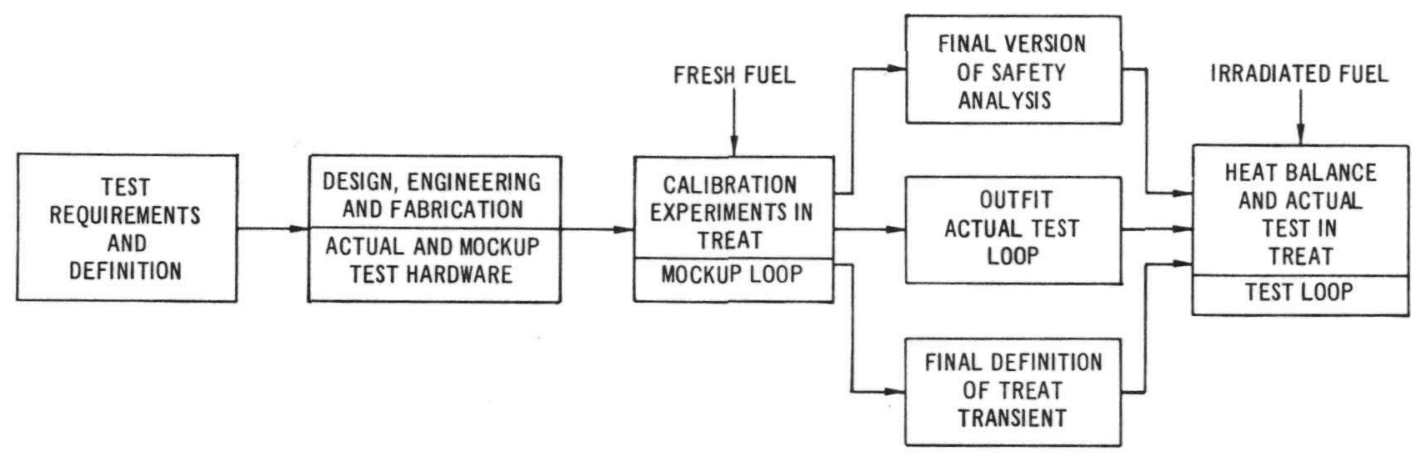

Fig. 8. Conduct of Typical Fuel Dynamics Test Using Mark-II Integral Sodium Loop in TREA T. ANL Neg. No. 900-5735.

Several possible alternatives, identified in Table XII, might have been used to obtain an acceptable calibration result. Each alternative depends either on a radiochemical determination of the sample fission rate or on calorimetry (temperature and flow measurements). Option 3 in the table was selected for Test E8 primarily because of schedule considerations.

TABLE XII. Possible Alternative Ways to Determine Calibration Factors

\begin{tabular}{lll}
\hline \multicolumn{1}{c}{ Option } & \multicolumn{1}{c}{ Pro } & Con \\
\hline $\begin{array}{l}\text { 1. Fresh fuel in mockup with } \\
\text { planned transient. No sodium } \\
\text { present (dry). }\end{array}$ & $\begin{array}{l}\text { All factors nearly identical to } \\
\text { test conditions. }\end{array}$ & $\begin{array}{l}\text { Fuel would fail and could not be } \\
\text { analyzed easily. Safety in } \\
\text { question. }\end{array}$ \\
$\begin{array}{l}\text { 2. Fresh fuel in mockup with } \\
\text { clipped transient (dry). }\end{array}$ & $\begin{array}{l}\text { Conditions similar to an } \\
\text { actual test transient. }\end{array}$ & $\begin{array}{l}\text { High risk of failing fuel unless } \\
\text { factors known well enough. }\end{array}$ \\
$\begin{array}{l}\text { 3. Fresh fuel in mockup at low } \\
\text { power level. Correct to } \\
\text { transient using monitor-wire } \\
\text { ratios. (Dry.) }\end{array}$ & $\begin{array}{l}\text { Low risk of fuel failure. } \\
\text { Readily accomplished after } \\
\text { shaping-collar configuration }\end{array}$ & $\begin{array}{l}\text { Approach may not be adequate } \\
\text { to predict transient correction." }\end{array}$ \\
$\begin{array}{l}\text { fresh fuel in loop at constant } \\
\text { flow (heat balance). }\end{array}$ & $\begin{array}{l}\text { Test approaches actual test } \\
\text { conditions. }\end{array}$ & $\begin{array}{l}\text { No time available to commit } \\
\text { loop. Sodium handling re- } \\
\text { quired. Safety analysis } \\
\text { required. }\end{array}$ \\
$\begin{array}{ll}\text { Irradiated fuel in loop at con- } \\
\text { stant flow. (Heat balance.) }\end{array}$ & $\begin{array}{l}\text { Highly desirable and usually } \\
\text { performed. (Done for E8.) }\end{array}$ & $\begin{array}{l}\text { Usually performed } 1 \text { day before } \\
\text { test, and data not available for } \\
\text { pretest analysis. }\end{array}$ \\
\hline
\end{tabular}

Option 3 is based on the assumption that the ratio of the calibration factor for fuel in the test region to a monitor-wire factor for similar reactor transients is invariant. In addition, this ratio is assumed to remain constant 
even though the reactor is operated at very low, steady power levels which do not involve significant control-rod motions or sample power generation. If this were indeed true, then the calibration factor for fuel during a transient could be inferred by measuring its value for fuel irradiated at a low power level without coolant present and then predicting its value for the failure transient by using the ratio of monitor-wire activations, or fission rate, per megajoule. The actual conduct of previous tests with both this procedure (Option 3) and the heat-balance (calorimetry) transients performed before the transient (Option 5) indicate surprisingly good agreement within experimental uncertainties $( \pm 10 \%)$.

The use of Option 3 also greatly simplified TREAT operations for the E8 calibrations, since only fresh (unirradiated) fuel and monitor wires were required. The absence of sodium and its associated handling procedures are also desirable. In summary, the calibration procedure for fresh-fuel calibrations involved:

a. Analysis of selected pellets from fuel elements for fissions per gram (four elements of seven) using barium-lanthanum pair.

b. Analysis of monitor wires for fission rate to determine transient correction.

c. Computation for estimated sample-to-reactor coupling.

Sample power calibration factor $=\left(\frac{\mathrm{W}}{\mathrm{g} \cdot \mathrm{MW}}\right)_{\text {Low level }}^{\text {Fuel }} \times \frac{\left(\frac{\text { fissions }}{\mathrm{g} \cdot \mathrm{MJ}}\right)_{\text {Transient }}^{\text {Wire }}}{\left(\frac{\text { fissions }}{\mathrm{g} \cdot \mathrm{MJ}}\right)_{\text {Low level }}^{\text {Wire }}}$.

d. Partial verification by heat balance with actual test fuel in sodium loop before TOP simulation (Option 5, Table XII).

\section{Description of Experimental Hardware}

The execution of the calibration tests used a special mockup loop and test train with unirradiated fuel. The general experiment requirements met by this calibration hardware were:

Fuel for Calibrations

- Similar to E8 test fuel (mixed-oxide; $340 \mathrm{~mm}$ fuel column).

- Unirradiated.

- Met Q/A for plutonium-bearing capsules. 
Mockup Loop and Test Train

Neutronic equivalent of the E8 hardware without sodium.

- Leaktight (in case of fuel-element failure).

- Provisions for monitor-wire guides.

- Qualified for transient irradiations without fuel.

- Provisions required for adjusting axial power-shaping collars.

The fuel requirements were met by using PNL-10 fuel elements supplied by HEDL that had originally been designated as spares for the EBR-II irradiation, but were not used in EBR-II irradiations. The seven cali-

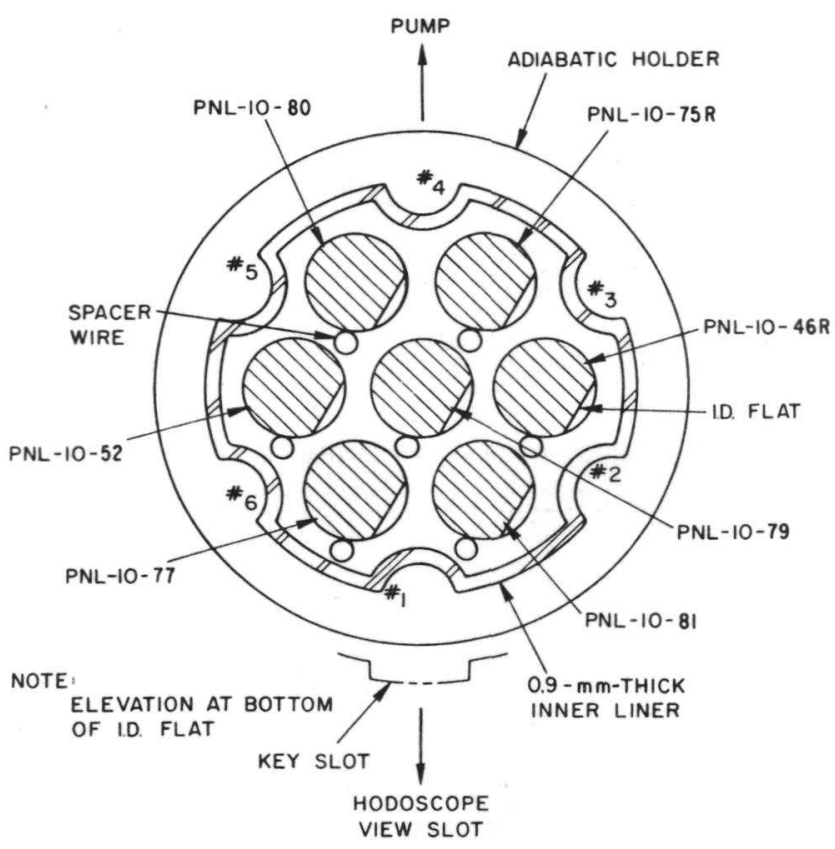

Fig. 9. Fuel-element Arrangement for E8 Calibration Test Showing Cross-sectional View at Elevation of Identification Flat (Looking down). ANL Neg. No. 900-3425 Rev. 3. bration fuel elements were designated PNL-10-X, where $X$ was 46R, 52, $75 \mathrm{R}, 77,79,80$, and 81 . The design parameters of these elements met the criteria established for the PNL-10 irradiations given in Ref. 1; Table VI also applies to the calibration elements. The fuel elements were arranged in a seven-element cluster on a triangular spacing as shown in Fig. 9. Calibration test results are based primarily on destructive analysis of elements PNL$10-79,-80,-81$, and $-46 R$.

Figure 10 is a photograph of the upper plate region of the mockup loop and shows some of the features of the hardware used. Figure 11 shows the various loop components in the region of the active fuel column and, in particular, identifies the neutron-filter arrangement. Neutron filters were fabricated from $\mathrm{B}_{6} \mathrm{Si}$

or dysprosium in the form of half-cylinders to permit easy assembly, quality control, and disassembly, as needed. When the low-level fueled test was completed, the test-train mockup was removed and an aluminum monitor-wire guide-tube assembly installed for the monitor-wire irradiations for transients and at low level.

\section{Results of Calibration Tests}

The calibration factors for the E8 test elements are based on the results of calibration experiments performed in February and March 1974. A more complete discussion of the calibration results appears in Appendix $B$. 


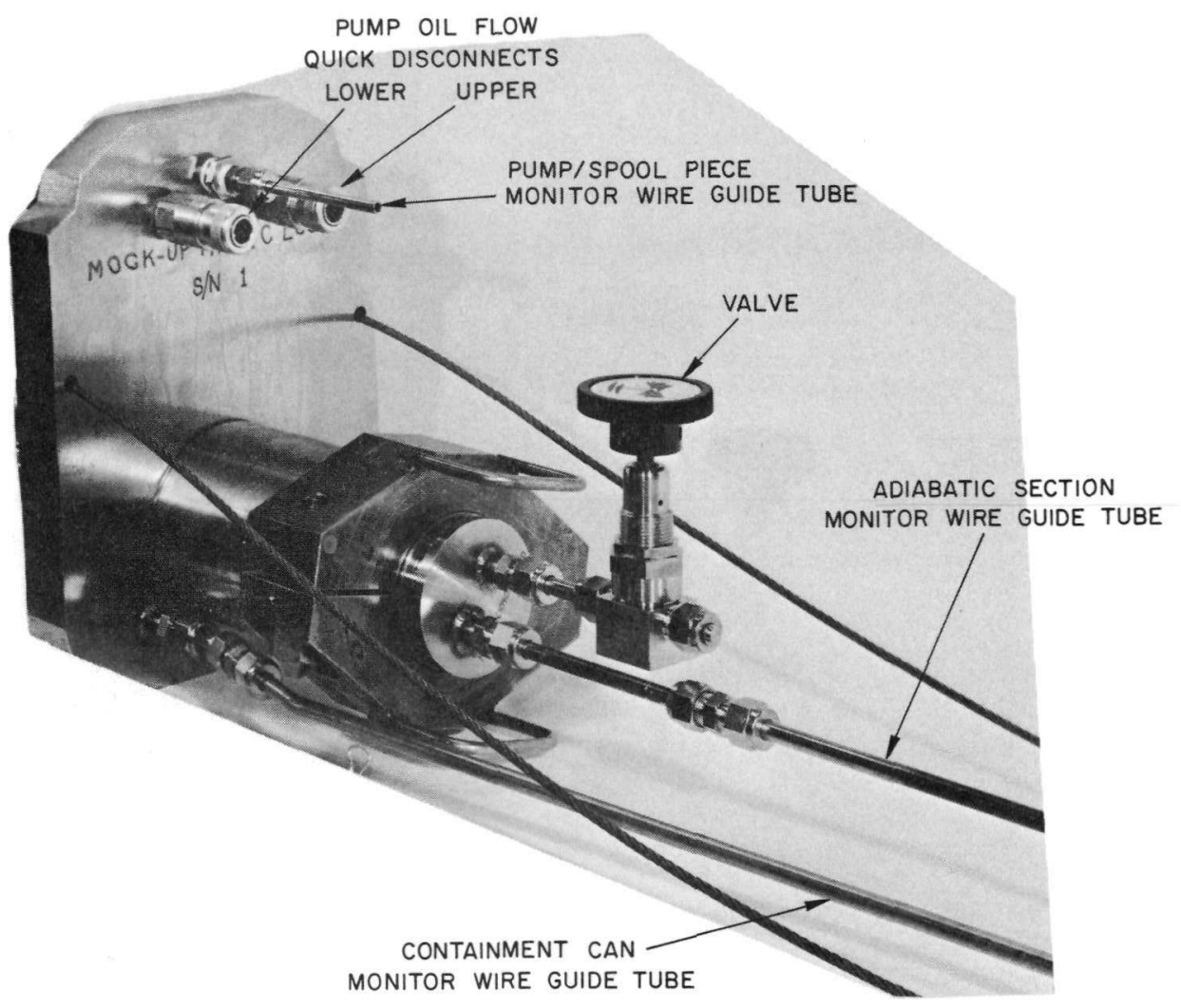

Fig. 10. Identification of Equipment Penetrating Upper Plate of E8 Mockup Loop and Test Train. ANL Neg. No. 900-3374.

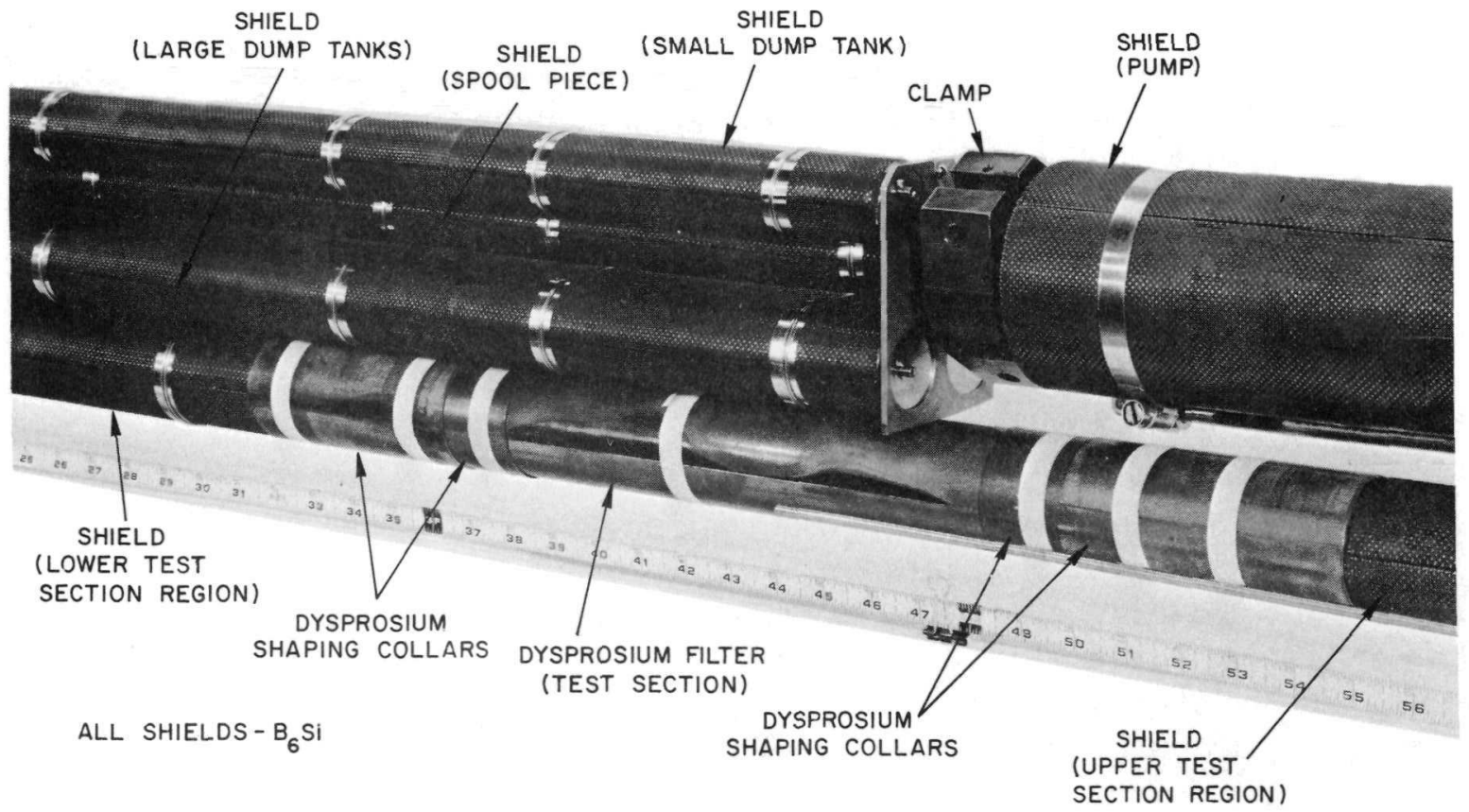

Fig. 11. Location of Filters, Shields, and Shaping Collars on E8 Calibration Loop. ANL Neg. No. 900-3375A. 
Additional monitor-wire irradiations were performed both at low-level steady state and with an E8-type transient, both without fuel in the loop. These monitor-wire measurements were used to compute the ratio approximating the change for the irradiations with fuel elements at low level to the transient conditions. This ratio was measured to be 1.35. Additional corrections were made to consider the burnup from the EBR-II irradiations and deviations of the filter from its nominally specified thickness.

The dysprosium filter for the Test E8 was measured to be $449 \mathrm{mg} / \mathrm{cm}^{2}$ of dysprosium (about $1 \%$ greater than the filter used in the calibration runs). This $1 \%$ variation between the Test E8 filter and the calibration filter has essentially no effect on the calibration factors.

The burnup correction for each element in the cluster was based on:
a. Isotopic changes from fresh to irradiated fuel for ${ }^{235} \mathrm{U}$ and ${ }^{239} \mathrm{Pu}$ calculated from Vigilante-code estimates in EBR-II.
b. A value of 1.5 for the relative fissions per atom of ${ }^{239} \mathrm{Pu}$ per atom of ${ }^{235} \mathrm{U}$ in the TREAT reactor.
c. The assumption that self-shielding changes and fission- product poisoning can be ignored.

The burnup correction was estimated from the above, assuming that the factors are proportional to the reduction in equivalent ${ }^{235} \mathrm{U}$ atoms per element. The corrections are listed in Table XIII.

\begin{tabular}{|c|c|c|c|c|c|c|c|}
\hline $\begin{array}{c}\text { Test } \\
\text { Element }\end{array}$ & $\begin{array}{c}\text { Burnup, b } \\
\text { at. \% }\end{array}$ & $\begin{array}{l}\text { Fuel-batch } \\
\text { Designation }\end{array}$ & $\begin{array}{c}\text { Calibration Factor } \\
\text { Based on Element } \\
\text { Number }\end{array}$ & $\begin{array}{c}\text { Fresh-element Low-level } \\
\text { Calibration Factor. } \\
\text { W/g.MW }\end{array}$ & $\begin{array}{c}\text { Transient Correction } \\
\text { from Monitor-wire } \\
\text { Data }\end{array}$ & $\begin{array}{c}\text { Burnup Correction } \\
\text { Factor }\end{array}$ & $\begin{array}{c}\text { Estimated Calibration } \\
\text { Factor, W/g.MW }\end{array}$ \\
\hline PNL-10-7 & 5.58 & $\mathrm{FE}-79.0$ & PNL-10-46R & 1.462 & 1.35 & 0.923 & 1.82 \\
\hline PNL-10-8 & 5.52 & $\mathrm{FE}-79.0$ & PNL-10-80 & 1.224 & 1.35 & 0.923 & 1.52 \\
\hline PNL-10-10 & 5.41 & $\mathrm{FE}-79.0$ & PNL-10-80C & 1.224 & 1.35 & 0.925 & 1.53 \\
\hline PNL-10-28 & 5.36 & $\mathrm{FE}-79.0$ & PNL-10-81C & 1.649 & 1.35 & 0.926 & 2.06 \\
\hline PNL-10-34 & 5.04 & $\mathrm{FE}-92.0$ & PNL-10-46RC & 1.462 & 1.35 & 0.930 & 1.83 \\
\hline PNL-10-53 & 4.94 & $\mathrm{FE}-79.0$ & PNL-10-81 & 1.649 & 1.35 & 0.932 & 2.07 \\
\hline PNL-10-54 & 4.85 & FE- 92.0 & PNL-10-79 & 1.154 & 1.35 & 0.933 & 1.45 \\
\hline
\end{tabular}

The calibration factor for each element in the cluster, given in Table XIII, corresponds to the axial midplane of the fuel column. The calibration factor at this location was also the peak value for each element. The average of the peak values for the E8 cluster was about $1.75 \mathrm{~W} / \mathrm{g} \cdot \mathrm{MW}$.

Axial power profiles for Test E8 are also based on the measurements made from the calibration tests. The fresh (unirradiated) elements used in the calibrations were disassembled, and selected individual pellets 
were counted for gamma-ray activity in the energy interval $0.45-0.80 \mathrm{MeV}$ with an NaI gamma-ray spectrometer. The fresh elements examined were located (1) in the center, (2) nearest the pump leg, and (3) nearest the hodoscope slot. A fourth element, located in the intermediate peripheral location, was also examined. The results from this fourth element should be treated cautiously, since it had been irradiated in a previous calibration test. Because the burnup of fuel in EBR-II does vary appreciably along the element length, the data from the fresh elements provide an adequate basis for establishing axial power distribution for the test elements by assuming that the power distributions are the same. The results obtained from the calibration tests are shown in Fig. 12. Some properties of the axial power distributions are given in Table XIV.
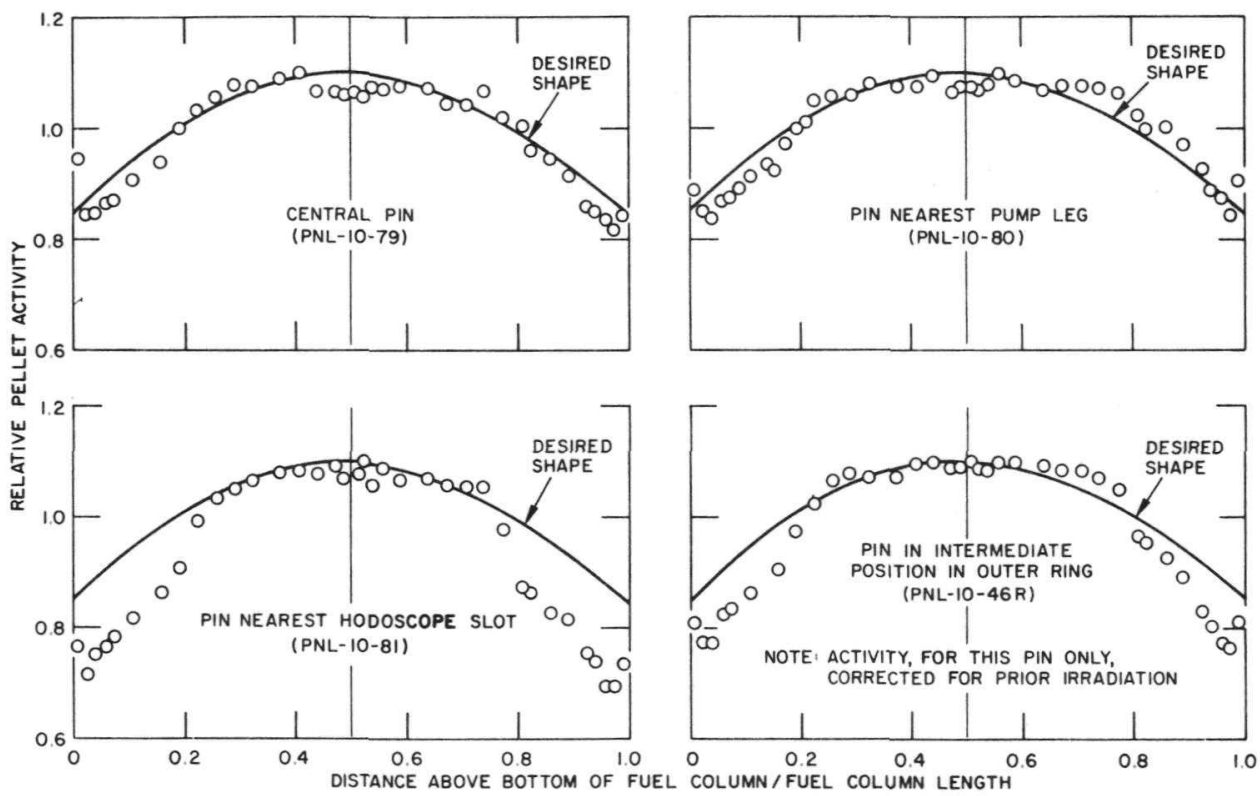

Fig. 12. Axial Power Profiles for Elements in E8 Calibration Test. ANL Neg. No. 900-3942 Rev. 1.

TABLE XIV. Properties of Fuel-element Power Distributions from E8 Calibration Test

\begin{tabular}{|c|c|c|c|c|}
\hline $\begin{array}{l}\text { Fuel-element } \\
\text { Designation }\end{array}$ & Location in Cluster & $\begin{array}{l}\text { Peak-to-Average }^{\mathrm{a}} \\
\text { Power Ratio }\end{array}$ & $\begin{array}{l}\text { Power Generated above } \\
\text { Midplane } \div \text { Power } \\
\text { Generated below Midplane }\end{array}$ & $\begin{array}{l}\text { Low-level } \\
\text { Power-calibration } \\
\text { Factor, W/g-MW }\end{array}$ \\
\hline PNL-10-79 & Central & 1.09 & 1.01 & 1.15 \\
\hline PNL-10-80 & Nearest pump & 1.08 & 0.977 & 1.22 \\
\hline PNL-10-81 & Nearest hodoscope slot & 1.15 & 1.01 & 1.65 \\
\hline PNL-10-46R & $\begin{array}{l}\text { Peripheral element be- } \\
\text { tween slot and pump }\end{array}$ & 1.11 & 1.01 & 1.46 \\
\hline Desired ${ }^{b}$ & - & $\sim 1.1$ & $\sim 1.0$ & - \\
\hline
\end{tabular}

a Based on pellet activity.

bBased on power distribution in EBR-II Subassembly X093.

Internal radial power distributions within selected pellets at the midplane locations of the calibration elements were obtained by counting cylindrical sections. The sections were obtained by an ultrasonic trepanning technique described in Ref. 7. The internal peak-to-average values did not exceed about 1.3. 


\section{HEAT -BALANCE TEST RESULTS}

Test E8 consisted of a heat-balance (nonfailure) transient (1587) and the overpower simulation transient (1588). These tests were conducted on consecutive days in July 1974 at the TREAT Reactor at the ANL site of the Idaho National Engineering Laboratory. This section deals with the results of the heat-balance test designated E8-1. The heat-balance test was conducted primarily as a check on the consistency of the power-calibration factors of the fuel elements and as an operational test of the loop.

\section{A. Comparison of Results with Thermal Analysis}

The heat-balance test was conducted so that the fuel element with the highest calibration factor would be run at a peak linear heating rate of about $30 \mathrm{~kW} / \mathrm{m}$. This element, PNL-10-53, had a calibration factor of $2.07 \mathrm{~W} / \mathrm{g} \cdot \mathrm{MW}$ and a fuel loading of $190 \mathrm{~g} / \mathrm{m}$. The TREAT power needed to run this element at $30 \mathrm{~kW} / \mathrm{m}$ was

$$
\mathrm{P}=30 \frac{\mathrm{kW}}{\mathrm{m}} \frac{1}{190 \mathrm{~g} / \mathrm{m}} \frac{1}{2.07 \mathrm{~W} / \mathrm{g} \cdot \mathrm{MW}} \frac{1000 \mathrm{~W}}{\mathrm{~kW}}=76 \mathrm{MW} .
$$

The flow rate was set to correspond to $575 \mathrm{~cm}^{3} / \mathrm{s}$ at an initial sodium temperature of $400^{\circ} \mathrm{C}$. The calculated average temperature rise of the coolant across the test section was estimated at $103^{\circ} \mathrm{C}$ without heat los from the test section. A more refined thermal analysis of the heat-balance test with the COBRA code indicated that a near-steady-state temperature rise of $94^{\circ} \mathrm{C}$ would be attained in the average sodium subflow channel* about $10 \mathrm{~s}$ after the reactor reached $76 \mathrm{MW}$. The actual, observed temperature rise was slightly higher, about 100 to $106^{\circ} \mathrm{C}$, based primarily on TC 12 (in the flute between the elements with the highest calibration factors) and the inlet thermocouple. This result indicated that an acceptably consistent set of test parameters was used in the planning, so that no change in the failure transient was needed.

The TREAT transient for the heat-balance test (E8-1) is shown in Fig. 13. Note from Fig. 13 that the reactor power increased abruptly at about $14 \mathrm{~s}$ into the transient, an unexpected departure from the desired constant power, caused by an apparent malfunction of the computer-controlled rod sequence. Up to this time, the average reactor power was about $76 \mathrm{MW}$, based on the power integrator meter used for the determination of the sample-toreactor power-calibration factors.

\section{B. Instrument Responses}

The heat-balance test also offered the opportunity to examine the instrument response to a relatively simple reactor transient. The pressuretransducer signals, shown in Fig. 13, indicated that the lower transducer

\footnotetext{
*The subchannel description is a calculational model of the multielement cluster.
} 
(that at the inlet) responded significantly to the radiation and thermal environment at its location, since no pressure changes in the loop should have occurred. Similar observations were made in other Mark-II loop tests.

Subsequent study of this phenomenon has identified the problem as the radiation response of the cables with the electronic circuitry used. The output signal from the lower transducer failed to return to its initial value of zero during the data-recording period of $2 \mathrm{~min}(120 \mathrm{~s})$. The outlet (upper) trans ducer was nearly unaffected by the transient.

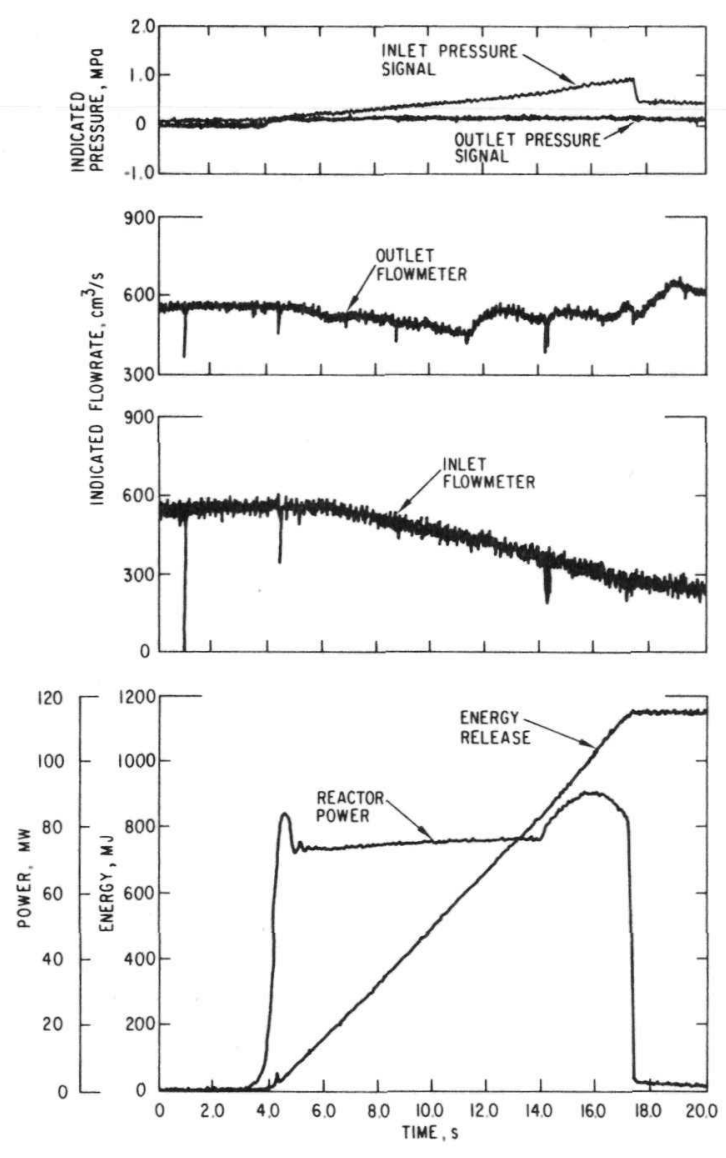

Fig. 13. Reactor Power, Test-region Flow, and Pressure Signals for Heat-balance Test E8-1. ANL Neg. No. 900-77-36.
Figure 13 also shows the flowmeter data for the first $20 \mathrm{~s}$ into the transient. The lower (inlet) flowmeter results indicated a decline in flow when the reactor was at $76 \mathrm{MW}$ and for $4 \mathrm{~s}$ thereafter. During this time, the pump voltage was held constant and should ordinarily have resulted in a constant flow rate. The outlet flowmeter behaved more erratically. These anomalous behavior characteristics have been observed in other Mark-II loop experiments in TREAT. However, no phenomenon has, as yet, been identified to unambiguously explain the observed flowmeter signal behavior. Both output signals returned to the pretest settings within the dataacquisition period of $2 \mathrm{~min}(120 \mathrm{~s})$.

Additional graphical displays of the data obtained from the heat-balance test appear in Appendix C. These data were largely unavailable for review when the transient test was conducted, and no opportunity was therefore available to examine the anomalous behavior of instrumentation more closely before destroying the fuel in the final transient.

The hodoscope was also operated during the heat-balance test so that, in the event of a malfunction leading to fuel-element failure, the fuel-motion data would not be lost. Since the transient for the heat balance was executed as planned, hodoscope data were not analyzed. 


\section{TRANSIENT TEST RESULTS}

A. Test Transient Characteristics

Test E8 was executed on July 9, 1974, at 1816 hours. The TREAT transient (1588), designated E8-2, is shown in Fig. 14. Although the scram point was set at $1 \mathrm{GJ}$, the actual transient released $1.18 \mathrm{GJ}$, since normal circuit delays and the effect of delayed neutrons resulted in additional energy release after the signal. (See Fig. 6 for the expected transient.) The characteristics of the burst were:

$\begin{array}{ll}\text { Energy release } & 886 \mathrm{MJ} \\ \text { Peak power (at } 7.278 \mathrm{~s}) & 2.53 \mathrm{GW} \\ \text { Initial Period } & 160 \mathrm{~ms} \\ \text { Width at half peak power } & 325 \mathrm{~ms}\end{array}$

The time indicated in Fig. 14 represents the TREAT clock time for the start of the control-program initiation recorded on the analog tapes. The TREAT clock time was a recording of the output pulses from a $1-\mathrm{kHz}$ oscillator.

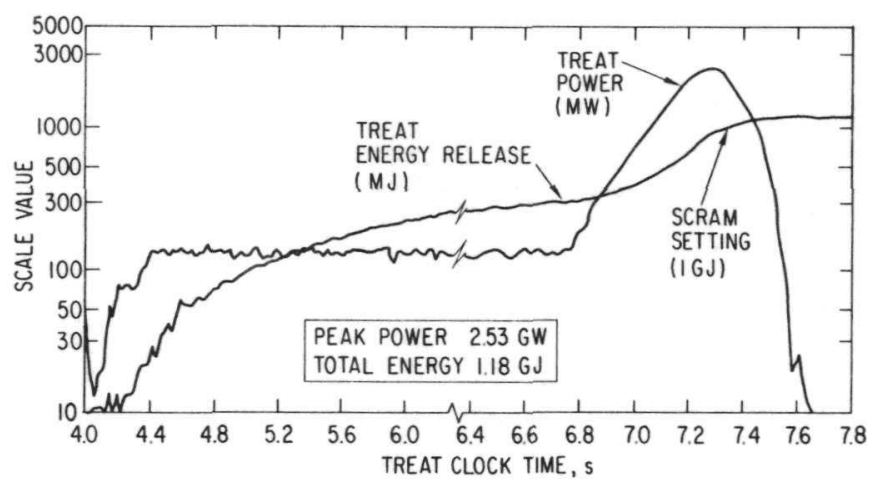

Fig. 14

TREAT Power and Integrated Power for Test E8-2 (TREAT Transient 1588). ANL Neg. No. 900-77-18.

The peak reactor power of $2.53 \mathrm{GW}$ occurred at about $7.278 \mathrm{~s}$ at an integrated power of $834 \mathrm{MJ}$. At $2.53 \mathrm{GW}$, the two fuel elements in the E8 cluster with the highest calibration factor would generate power at about $1 \mathrm{MW} / \mathrm{m}$ if the fuel geometry had remained intact.

When data from the TREAT power meter are integrated numerically, the resulting energy release does not necessarily agree with the output data from the TREAT integrator channel at every point along the transient. Since the power-calibration factors are based on the integrator channel, a potentially small error can be introduced in any thermal analysis of the cluster, unless a slight adjustment of the power curve is made. For purposes of analysis, the power-time history given in $\mathrm{Table} \mathrm{XV}$ is recommended for times up to about peak power. The power-time history in the table was normalized to the integrator at the ends of the intervals noted in the table and includes the time corresponding to the first element failure. The expected uncertainty in the 
meter readings at TREAT is given as $\pm 1 \%$ full scale, or about $\pm 15 \mathrm{MJ}$ for Test E8. Adjustments to the power curve to match the integrator output did not exceed about $5 \%$.

TABLE XV. E8 Transient Data for Thermal Analyses

\begin{tabular}{clll}
\hline $\begin{array}{c}\text { Time Interval, } \\
\mathrm{s}\end{array}$ & $\begin{array}{c}\text { Period, } \\
\mathrm{ms}\end{array}$ & $\begin{array}{c}\text { Power Range, } \\
\mathrm{MW}\end{array}$ & $\begin{array}{c}\text { Interpolation } \\
\text { for Power }\end{array}$ \\
\hline $3.411-4.360$ & 200 & $1.0-115.2$ & Logarithmic \\
$4.360-6.712$ & $\infty$ & 115.2 & Constant \\
$6.712-7.100$ & 160 & $115.2-1304$ & Logarithmic \\
$7.100-7.200$ & 210 & $1304-2100$ & Logarithmic \\
$7.200-7.250$ & Varies & $2100-2456$ & Linear \\
\hline
\end{tabular}

a The accuracy of the power curve is less than the number of digits shown. The number of digits was retained so that the analytic integration of the power-time history would agree with the integrator output at the ends of the time intervals to about $\pm 1 \mathrm{MJ}$.

With the time and power curve defined in Table XV, the TREAT energy release can be recalculated uniquely. Figure 15 shows the energy release, using the tabulated values of power versus time. Note that the period defined over the time interval has been rounded to three digits. Therefore a minor error might be introduced in a thermal analysis if the listed period is used instead of the power-time curve.

B. Test-instrumentation Results

The sensor data from flowmeters, pressure transducers, thermocouples, and transient power meters were recorded during the test on two analog tape recorders and a CRT Visicorder. Hodoscope data were recorded independently using the special photographic system normally employed; hodoscope results are reported in Sec. C below. Subsequent data handling and processing for the sensor data involved reduction of the analog-data record to digital form. The analog-to-digital conversion of the analog record was accomplished over time intervals appropriate for the observations being made. The data-reduction steps included processing to eliminate any $60-\mathrm{Hz}$ signals present on the analog record. The CRT Visicorder record served as the basic qualitative guide to ensure that the analog-to-digital conversion from the analog tape recordings did not introduce erroneous results inadvertently.

From the Visicorder data, a small perturbation in the inlet-pressuretransducer signal occurred at $7.204 \mathrm{~s}$. The perturbation appeared to be distinct 


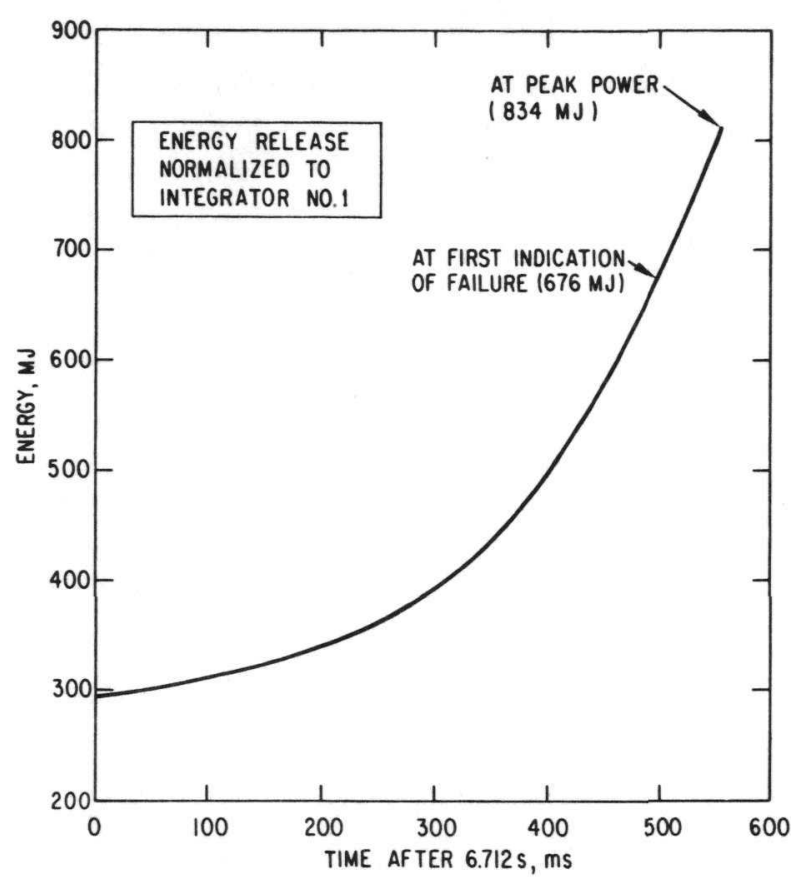

Fig. 15. TREAT Energy Release as a Function of Time into Burst. ANL Neg. No. 900-77-19 Rev. 1. from the radiation-induced drift normally encountered with the Mark-II inlet pressure transducer in energetic transients. Although not distinctly correlated with anomalies registered by other instrumentation, the inlet pressure transducer output at $7.204 \mathrm{~s}$ may have corresponded to the first indication of a dis ruption in the test zone. The power level was $2.13 \mathrm{GW}$, with a TREAT energy release of $659 \mathrm{MJ}$ at $7.204 \mathrm{~s}$.

The first definite indication of a major dis ruption in the test zone occurred about $8 \mathrm{~ms}$ later, at $7.212 \mathrm{~s}$, or about $500 \mathrm{~ms}$ from the start of the power burst at the end of the preheat. At this point, the inlet pressure trans ducer recorded a series of pressure pulses of about 1 -ms duration, as shown in Fig. 16. None of the initial pressure pulses exceeded $700 \mathrm{kPa}(\sim 7 \mathrm{~atm})$ when

the radiation-induced drift signal was subtracted from the total. Almost simultaneously, the flowmeter signals, shown in Fig. 17, indicated initiation of a rapid voiding of the test zone. The TREAT power level at this time was about $2.18 \mathrm{GW}$, with an energy release of $676 \mathrm{MJ}$. The two elements with the highest calibration factor generated power at $857 \mathrm{~kW} / \mathrm{m}$, or 29 times the $30-\mathrm{kW} / \mathrm{m}$ rate in the EBR-II preirradiation, at the 2.18-GW TREAT power level at the first indication of failure. The corresponding energy generated in this fuel was $1.4 \mathrm{MJ} / \mathrm{kg}$.

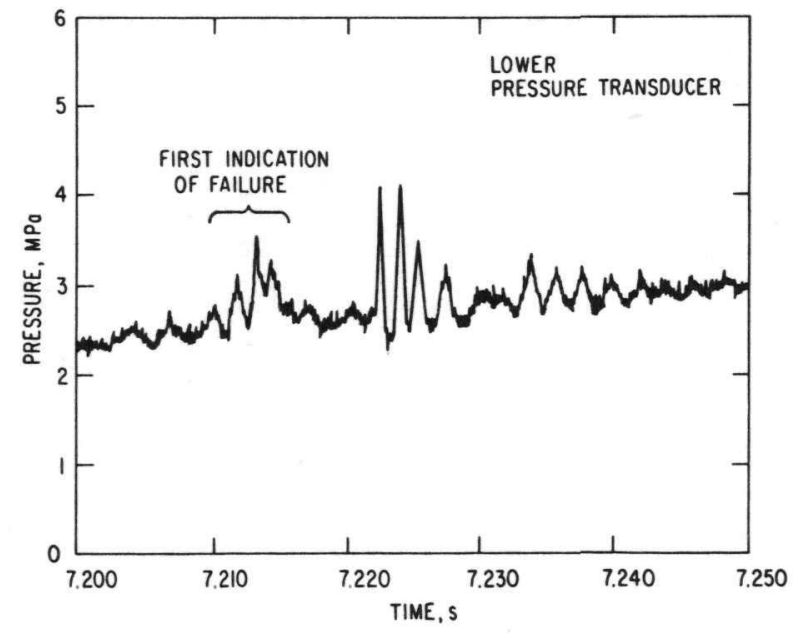

Fig. 16. Signal from Inlet Pressure Transducer for E8-2. ANL Neg. No. 900-77-30.

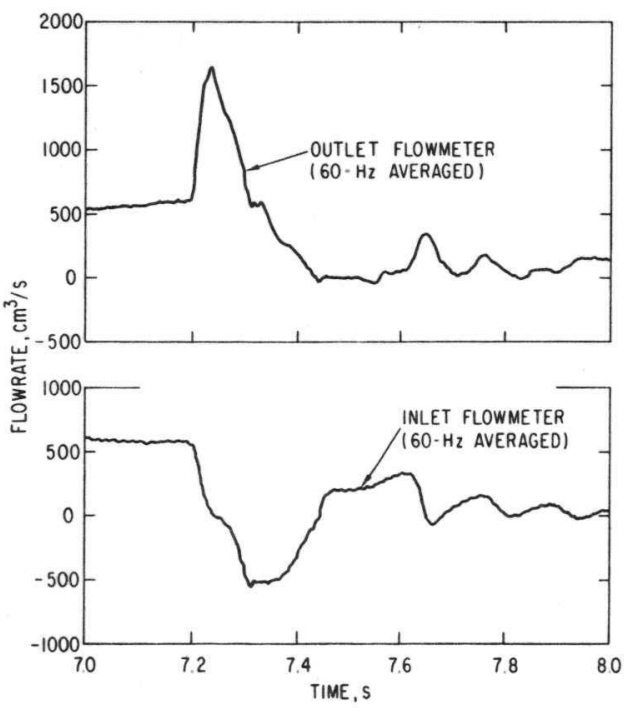

Fig. 17. Flow meter Signals for E8-2. ANL Neg. No. 900-77-28. 
The observed sensor indications correspond to what might be expected by the sudden release of fission gas and/or fuel into the coolant channel and a rapid vaporization of sodium coolant at the time of a fuel-element failure. Additional pressure pulses, none having a magnitude exceeding $1.7 \mathrm{MPa}$ (17 atm), were recorded about $10 \mathrm{~ms}$ later, a probable result of the failure of other elements in the cluster. The first thermocouple failure occurred $144 \mathrm{~ms}$ later $74 \mathrm{~mm}$ below the top of the active fuel column, probably as a result of an overheating of its junction. The failure of this thermocouple probably signals the as sociated melthrough of the flow tube and the loss of test geometry.

The outlet pressure transducer recorded no significant pressure events. The inlet pressure transducer showed a radiation-induced drift with the reactor power similar to the behavior exhibited in heat-balance Test E8-1. However, the pressure events recorded by the inlet pressure transducer discussed above were clearly distinct from this drift.

Since the flowmeters were not calibrated for the presence of vapor and/or noncondensable gas in the flow stream, the calibration constants used to convert flowmeter output to flow rate after the first failure indication at $7.212 \mathrm{~s}$ were probably somewhat in error. Dips in the flowmeter output signals (not shown in the time interval covered by Fig. 16) occurring at about $6.7 \mathrm{~s}$ are considered spurious since (1) no other test sensors indicated any events, and (2) the time corresponds to the point at the end of the preheat phase when the burst was begun, and the flowmeters may have picked up an associated signal. The flowmeter data after the test indicated that the flow path was blocked. A flow blockage could result from debris either in the test region or elsewhere along the flow path of the loop. A potential flow bypass around the test region through the penetrated gas-filled adiabatic section apparently did not occur. Subsequent postmortem examinations indicated that a blockage caused by packed fuel and cladding in the test region had indeed occurred. Caution in the use of the flowmeter output for other than qualitative evaluation is advised because of the flowmeter-coil malfunction and its attendant reduction in sensitivity. The flowmeter signal data are interpreted more fully in Appendix E.

The thermocouples in the region of the active fuel column were located on the outside of the $0.9-\mathrm{mm}$-thick flow tube. These thermocouples therefore lagged behind the actual temperatures of the fuel cladding. Once the test region voids of coolant after the first fuel-element failure, the lag becomes considerable, thereby negating the further usefulness of the thermocouples for monitoring temperatures in the test region. Most of the thermocouples did not survive the melthrough of the flow tube. The failure time may be useful for timing such an event, with due caution, since a thermocouple failure can occur either by an overheating of its junction or by a meltthrough of its sheath elsewhere along its length. The times of failure of the test thermocouples are listed in Table XVI. 
TABLE XVI. Thermocouple Failure Times

\begin{tabular}{ccc}
\hline Thermocouple & Time, s & Energy Release, GJ \\
\hline TC -8 & 7.356 & 1.03 \\
TC -9 & 7.380 & 1.06 \\
TC - 10 & 7.428 & 1.13 \\
TC -6 & 7.452 & 1.15 \\
TC -3, 4, & 7.476 & 1.16 \\
TC - 11 & 7.524 & 1.17 \\
TC -12 & 7.548 & 1.18 \\
\hline
\end{tabular}

Further interpretations of the events occurring in the E8 test zone depend on results from the hodoscope and postmortem examinations of the test-section remains.

C. Results from Fast-neutron Hodoscope

1. Brief Description of Hodoscope Techniques

The neutron hodoscope consists of an array of 334 fast-neutron detectors and collimators, arranged so that each detector is exposed to neutrons from a small portion of the test region in the TREAT reactor. Details of the construction and operation are given by De Volpi. ${ }^{8}$ Figure 18 shows the approximate position of the E8 test cluster in the hodoscope field of view. The original position of fuel cluster in the hodoscope field was determined from the hodoscope data by the EFFI code, which accounts for slight alignment shifts. The test fuel was positioned low in the field, leaving some hodoscope detectors to view fuel motion for $130 \mathrm{~mm}$ above the top of the original fuel column. Each channel of the hodoscope array covered a spatial element nominally 3.6 by $22.2 \mathrm{~mm}$. Each channel is therefore more elongated in the vertical direction than it appears in Fig. 18. Not all the detectors were functioning for the test. Nonfunctioning channels are marked by $\mathrm{X}$ in Fig. 18.

In operation, the counts accumulated by the detectors are periodi cally displayed in binary form on a bank of 720 neon lights, and the display is photographed on high-speed film. Six frames of film are required to read out all 36 scalers. Such a set of six readouts, or cycle, can be preset to values that range upward from 1-5 ms, depending on the duration of the transient and the anticipated rapidity of fuel motion. In E8, a $3-\mathrm{ms}$ cycle time was used.

The grid coordinates of the ignited lamps for each frame are determined from the recording film by the ALICE flying-spot scanner, which operates in conjunction with a PDP-10 computer. The coordinates are recorded 


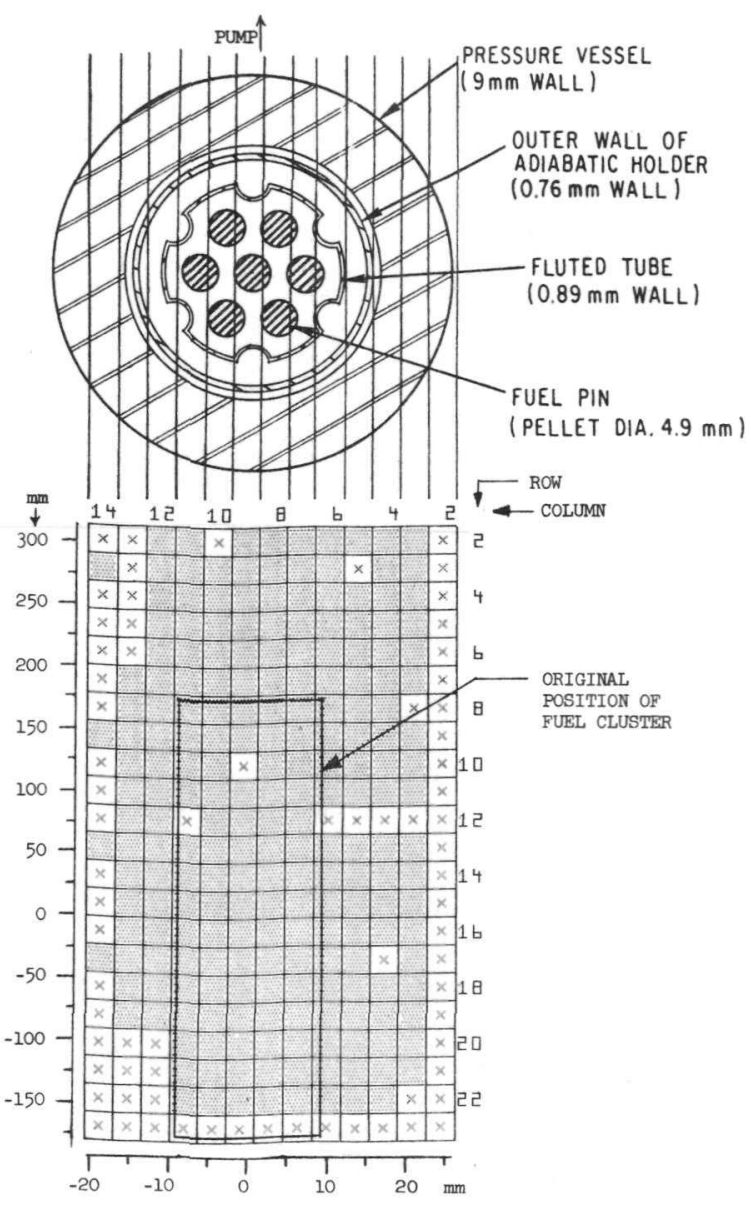

Fig. 18

Relationship between Hodoscope View Area and Test Assembly for Test E8 on magnetic tape, to be reduced to the desired counting-rate data by the DIGILITES code on a PDP-10 computer. The reduction of the hodoscope data required several manipulations and cor rections for supralinearity, efficiency, and dead time.

The hodoscope detects fast neutrons, primarily associated only with the fissions taking place within the test zone. Background from the reactor will also contribute to the signal. In addition, the interpretations from the hodoscope data assume that the changes in power calibrations will not vary significantly during the transient, even after fuel motion occurs. Although internal consistency checks are made on the hodoscope data, note that changes in the count rate may not always arise from fuel motion. The detailed data must be examined closely to distinguish between fuel failure and fuel motion that might be associated with other effects, such as bowing. This painstaking task requires some feedback from some of the other sensor data recorded for a test.

\section{Fuel-motion Results}

To verify that the hodoscope curve is not affected by loss of fuel from the viewing area, the array-averaged rate was compared with the average counting rate of the hodoscope power-monitor scalers. The power monitors are 43 detectors that did not view any of the test fuel during the test. Figure 19 shows the ratio of the array average to the power-monitor average. From Fig. 19, there is no indication that any appreciable amount of fuel (upper limit $3 \%$, or $15 \mathrm{~g}$ ) left the field of view of the hodoscope during the transient. At $7.55 \mathrm{~s}$, after $\mathrm{scram}$, the ratio of array average to power monitor increased abruptly. Counting statistics, particularly in the power monitors, became poor after this time due to the low reactor power (see Fig. 14) and may have contributed to the abrupt change. Loss of fuel, however, would appear as a decrease rather than an increase. The array average is therefore equivalent to the power-monitor average, at least until $7.55 \mathrm{~s}$. Consequently, the array average was used as the reference counting rate in analyzing the hodoscope data. 


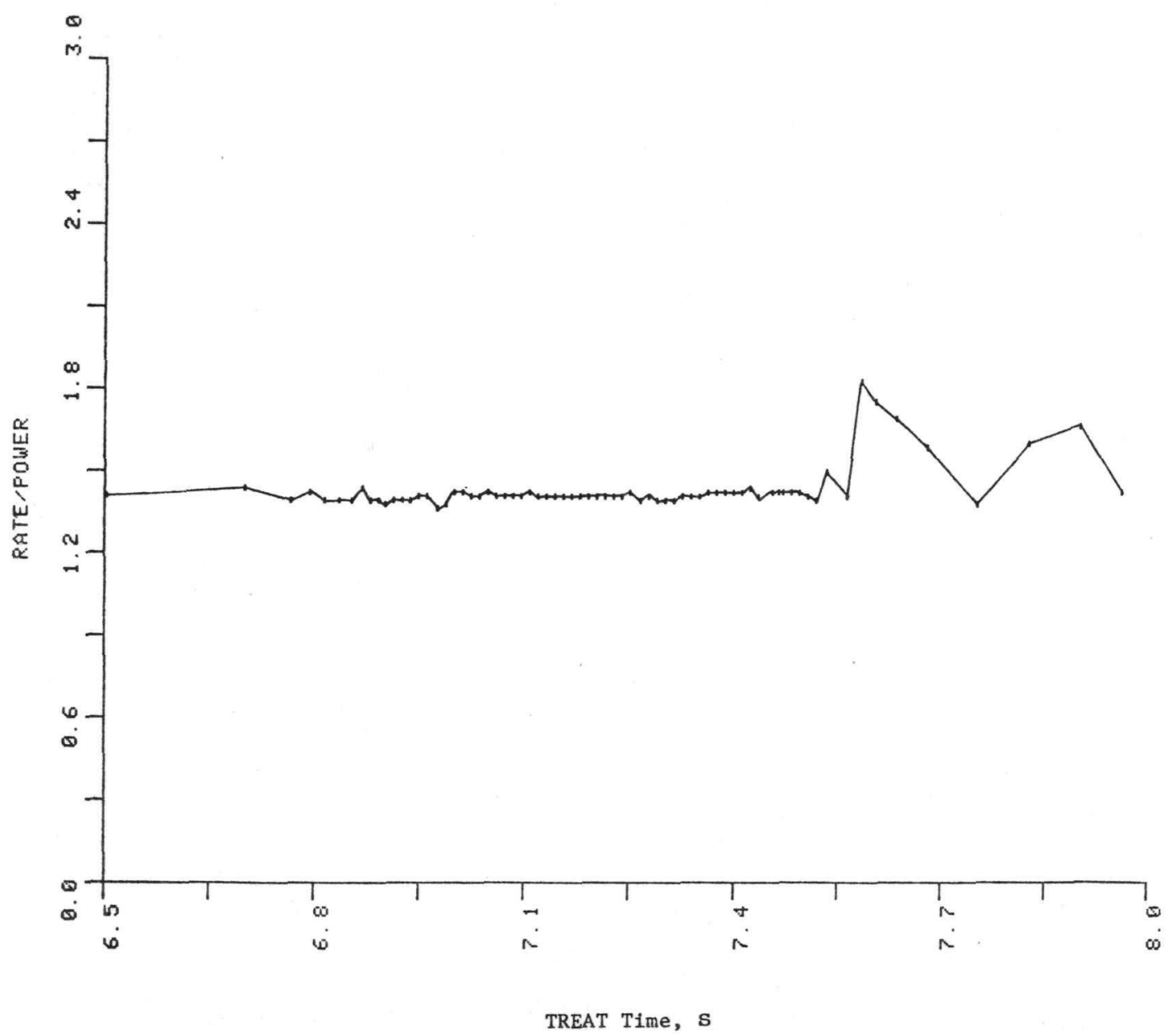

Fig. 19. Ratio of Array Average to Power Monitor for Test E8 Hodoscope Data

The primary tool for interpreting the hodoscope data is the "differential hodograph." A differential hodograph depicts the change that occurs in fuel configuration between two time intervals. The differential hodographs used in this report were produced by the PDP-11 program HODO. In a hodograph, a uniform grey shading in a channel indicates very little net change in (power-normalized) signal between the initial and final intervals, with greater increases and decreases shown by the symbols given in the key at the left, as in Fig. 20.

A differential hodograph shows only the changes in count rate. In the top hodograph in Fig. 20, for example, the entire array has been rendered uniformly grey, even though the counting rates in the fueled region outlined by the large rectangle were considerably larger than the background rates over the test of the array. The channels marked $\mathrm{X}$ around the borders were not functioning. Additional nonfunctioning or malfunctioning channels within the array were "smoothed" in the analysis by using count rates computed as the average of neighboring scalers. To put the key in Fig. 20 into perspective, note that the amount of fuel viewed by one of the channels at the center of the fueled region was about $8.5 \mathrm{~g}$. 

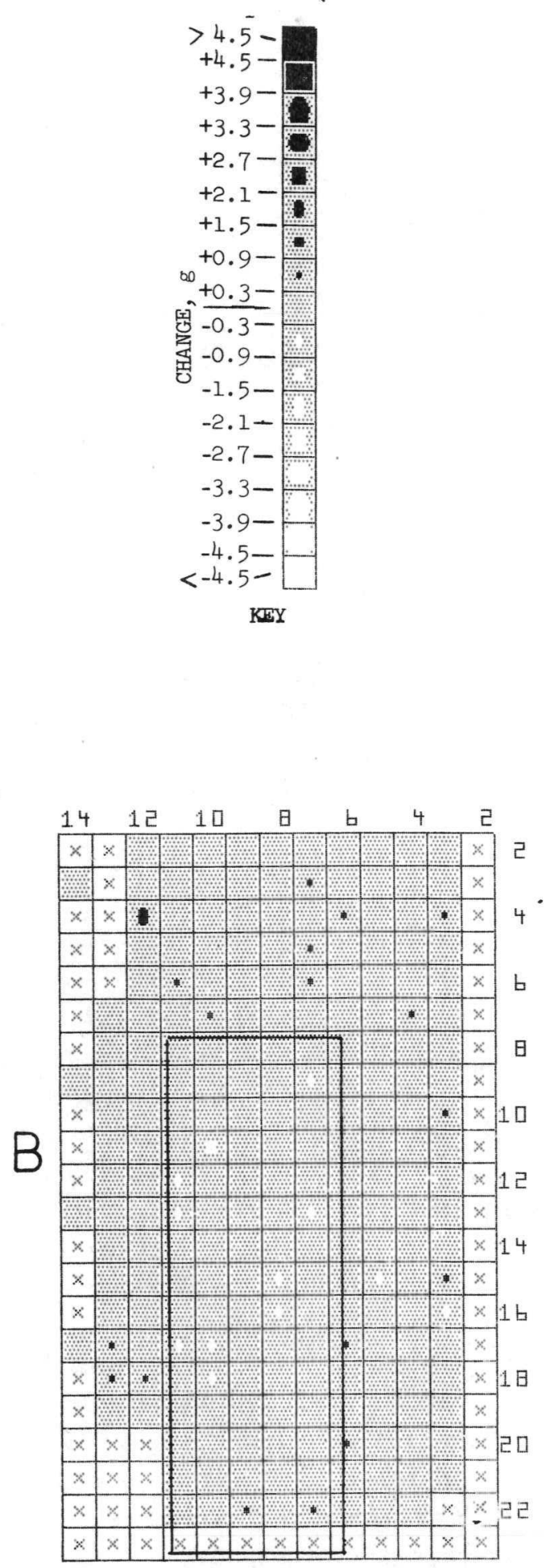

$$
\begin{gathered}
7.212-7.224 \mathrm{~s} \\
(12 \mathrm{~ms})
\end{gathered}
$$

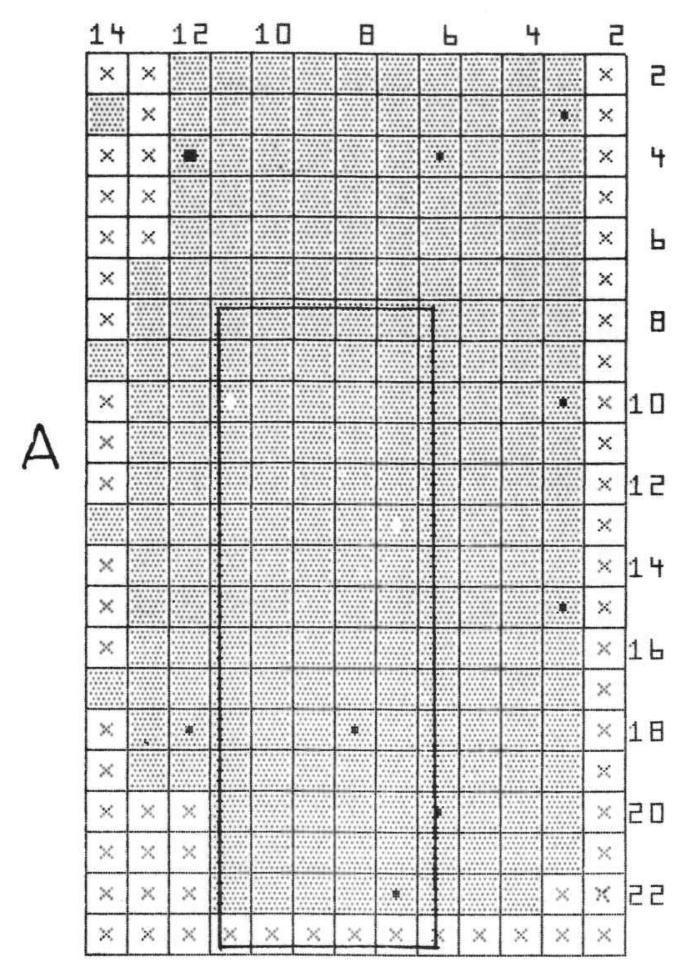

$$
\begin{gathered}
7.176-7.212 \mathrm{~s} \\
(36 \mathrm{~ms})
\end{gathered}
$$

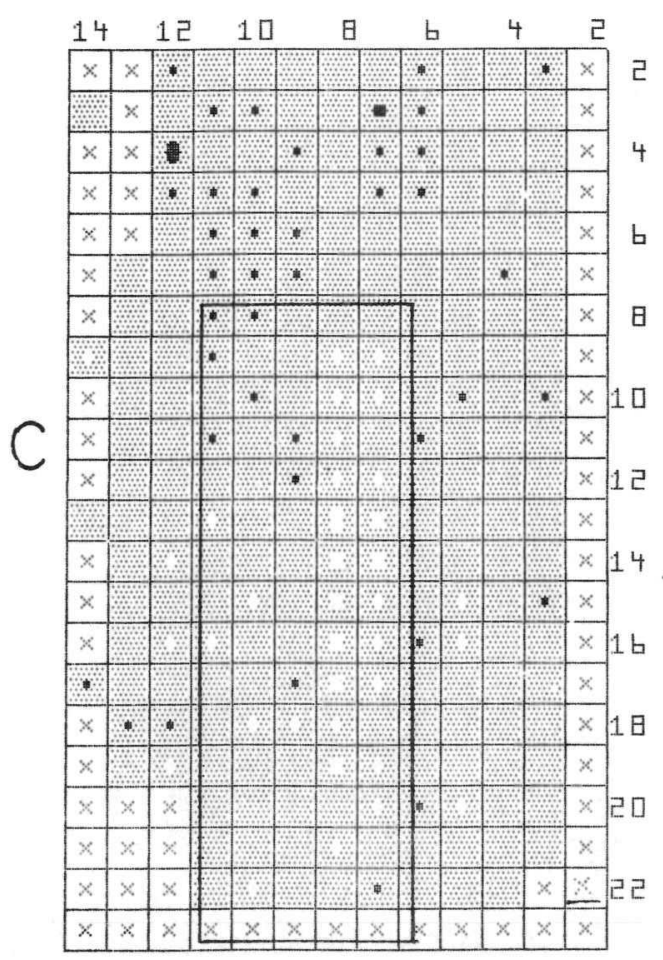

$$
\begin{gathered}
7.224-7.236 \mathrm{~ms} \\
(12 \mathrm{~ms})
\end{gathered}
$$

Fig. 20. Differential Hodographs for E8 in Time Interval 7.176-7.236 s. Referenced to preheat plateau $(4.53-6.65 \mathrm{~s})$. Scale maximum, $4.5 \mathrm{~g}$ fuel. The data-averaging interval is given below each hodograph. 
For each differential hodograph, the associated data-collection interval is identified on the figure. The initial configuration is based on data collected over the interval from 4.53 to $6.65 \mathrm{~s}$, a span covered by the preheat plateau, during which no noticeable fuel motion was expected. As Fig. 20 shows, no observable fuel motion occurred earlier than $7.21 \mathrm{~s}$.

In interpreting hodoscope data, note that the hodoscope gives only a two-dimensional picture, since only the components of fuel motion normal to the hodoscope axis are observed. Motion toward or away from the collimator cannot be detected.

a. Time Interval of 7.21-7.23 s. Observable fuel motion began at $7.219 \pm 0.002 \mathrm{~s}$. This time also corresponds, within $7 \mathrm{~ms}$, to the first definite indication by the loop sensors of a major disruption in the test zone. Differential hodographs for the time intervals of interest are shown in Figs. 20 and 21. The hodograph displays show the fuel motion schematically: the voided dotted arrays are largely within the original fuel zone, and the darkened area largely above. The observation is particularly evident in hodograph B in Fig. 21. Although Figs. $21 \mathrm{~B}$ and $21 \mathrm{C}$ have the same cutoff intervals as Figs. $20 \mathrm{~B}$ and $20 \mathrm{C}$, respectively, their reference intervals differ. For Fig. 21, the reference interval is the same as the final interval for the hodograph of Fig. 20A. The reason Figs. $20 \mathrm{~B}$ and $21 \mathrm{~B}$ are not more alike is that the data in Fig. $20 \mathrm{~A}$ contain some counting-rate changes that were too small to show up in that figure, but nevertheless had an effect on the base for Fig. $21 \mathrm{~B}$.

Figure 20B indicates that perceptible fuel motion began be tween 7.21 and $7.22 \mathrm{~s}$. The changes in the individual channels in Figs. 20B and $21 \mathrm{~B}$ are small enough that one could interpret the changes as being caused by counting statistics. Since these changes occur in clusters, it is evident that real changes were occurring. Although the details remain uncertain, an interpretation consistent with the data is that the changes are associated with the rapid expulsion of $6 \pm 2 \mathrm{~g}$ of fuel from the left-hand side (east*) of the cluster. The time of the event was at about $7.219 \pm 0.002 \mathrm{~s}$. Based on a higher-resolution examination within the time interval under consideration, additional details can be identified.

In both Figs. 20B and 21B, a string of count-rate deficits is observed in columns 10 and 11 . From this observation, we can postulate that some of the fuel had moved axially to a breach before being expelled. From the data, the location of this breach cannot be precisely identified. The breach probably occurred somewhere between the elevations defined by rows 10 and 18, or between $130 \mathrm{~mm}$ above to $65 \mathrm{~mm}$ below the original fuel-column midplane. Further analysis on a less certain basis places the breach at $30 \pm$ $20 \mathrm{~mm}$ above the midplane. The expelled fuel moved upward in a thin dispersal

*For orientation, the hodoscope slot faces north; the pump leg of the loop is to the south of the test section. 

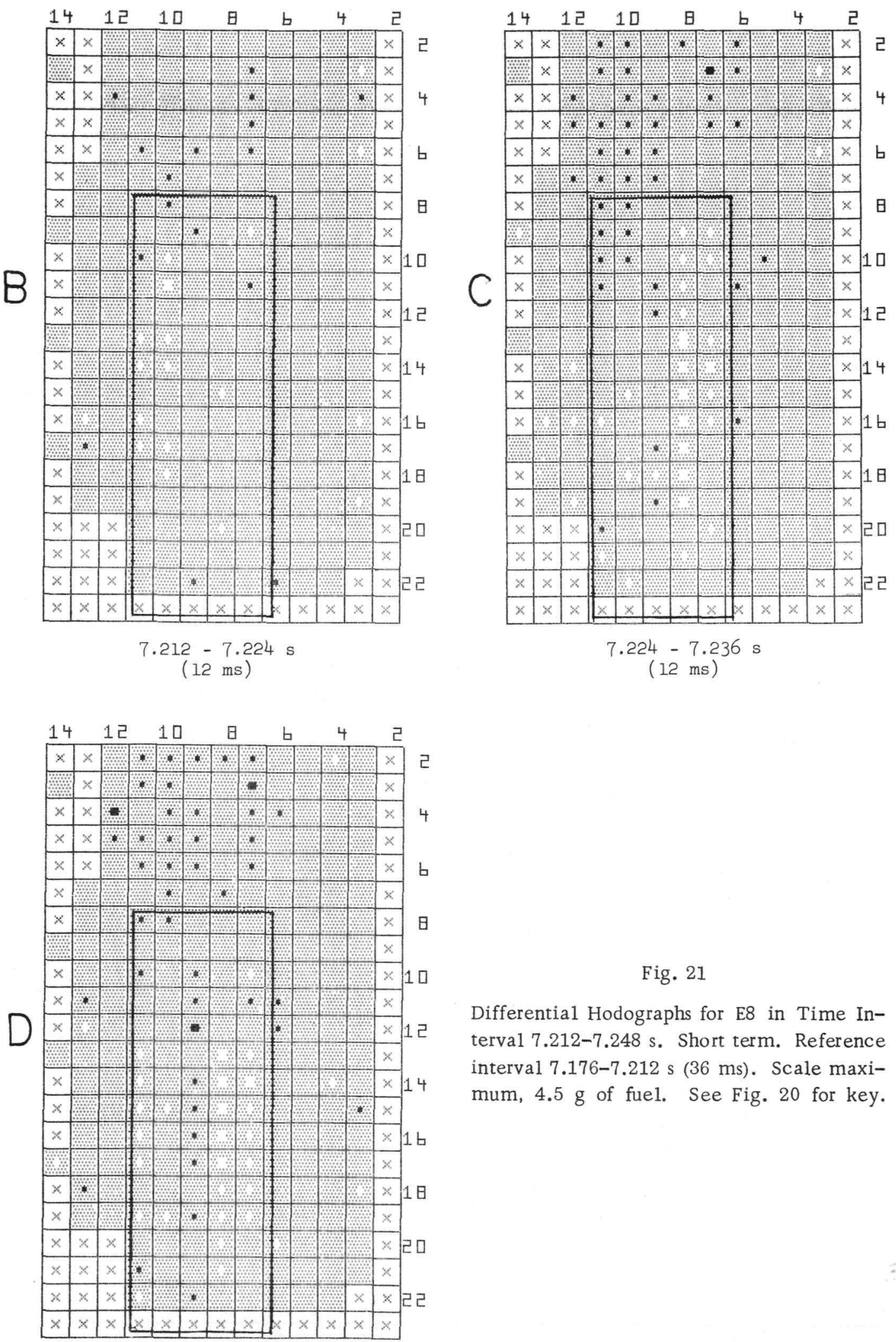

Fig. 21

Differential Hodographs for E8 in Time Interval 7.212-7.248 s. Short term. Reference interval 7.176-7.212 s (36 ms). Scale maximum, $4.5 \mathrm{~g}$ of fuel. See Fig. 20 for key.

$$
\begin{gathered}
7.236-7.248 \mathrm{~s} \\
(12 \mathrm{~ms})
\end{gathered}
$$


to collect in the cooler upper structural regions of the test section. The region in the upper structure was covered in the hodographs along rows 3-6, equivalent to $220-285 \mathrm{~mm}$ above the midplane. Little or none of this fuel accumulated within the original fuel zone, as indicated by the voided areas in both Figs. $20 \mathrm{~B}$ and $21 \mathrm{~B}$.

Evidence from the hodoscope data indicates that the upward velocity of the expelled fuel was about $18 \mathrm{~m} / \mathrm{s}$. This velocity corresponds to about five times the initial average sodium coolant velocity and about twice the peak average sodium coolant velocity after voiding occurred at $7.238 \mathrm{~s}$. The higher upward velocity of the fuel might be a result of a nonuniformity in the sodium-voiding radial profile.

The hodographs in Figs. $20 \mathrm{C}$ and $21 \mathrm{C}$ cover the time interval 7.224-7.236 ms after the first observed fuel motion. These hodographs suggest a more extensive fuel failure on the west side of the cluster than the one occurring in the preceding $12 \mathrm{~ms}$. The event involves the relocation of about $20 \mathrm{~g}$ of fuel. Again, loss of fuel from a large axial region was observed, with the displaced fuel appearing on the opposite side of the cluster in the upper structure. The deficit on the left side of Fig. $21 \mathrm{~B}$ has been largely canceled in Fig. 2lC, possibly by a slight leftward displacement of some of the fuel elements.

b. Time Interval of 7.23-7.27 $\mathrm{s}$. Changes in the time period between 7.23 and $7.27 \mathrm{~s}$ are shown in Figs. 22 and 23. The hodographs in Fig. 22 depict changes from the initial, unperturbed configuration; those in Fig. 23 are referenced to the closing interval of Fig. 21C. Figure 2lD is for the same interval as Figs. $22 \mathrm{~A}$ and $23 \mathrm{~A}$, the difference being the reference interval. In contrast with Fig. 21C, Figs. $21 \mathrm{D}$ and $23 \mathrm{~A}$ depict a relatively quiescent 12 -ms period. A resumption of fuel loss on the left-hand side (east) can be seen, with the dispersed fuel (about $6 \mathrm{~g}$ ) appearing in the upper right of the fuel zone, rather than directly above. Figure 23B shows the fuel loss extending upward in column 11 , because the fuel elements were shifting to the right, and/or because molten fuel was being emitted from one or two elements. The upward velocities in Fig. 23 are considerably less than the one from Fig. 21. Figures $22 \mathrm{~B}$ and $23 \mathrm{~B}$ show a thin stream of fuel in column 9, rows 12 16, presumably in a coolant channel, and presumably moving upward, since Fig. 23C shows rows 13-15 of column 9 returned to normal, with fuel increases higher up in the original fuel region and above.

Figure 23C also shows fuel being lost from the right-hand side of the fuel bundle below the midplane at $7.27 \mathrm{~s}$. The relocated fuel again appears as a thin dispersal in the upper half of the viewing area of the hodoscope. The extra fuel still within the original fuel zone is presumably moving upward; the fuel higher up is congealing on the colder reflector portions of the elements. Most of the fuel that reached the reflector region remained there. 

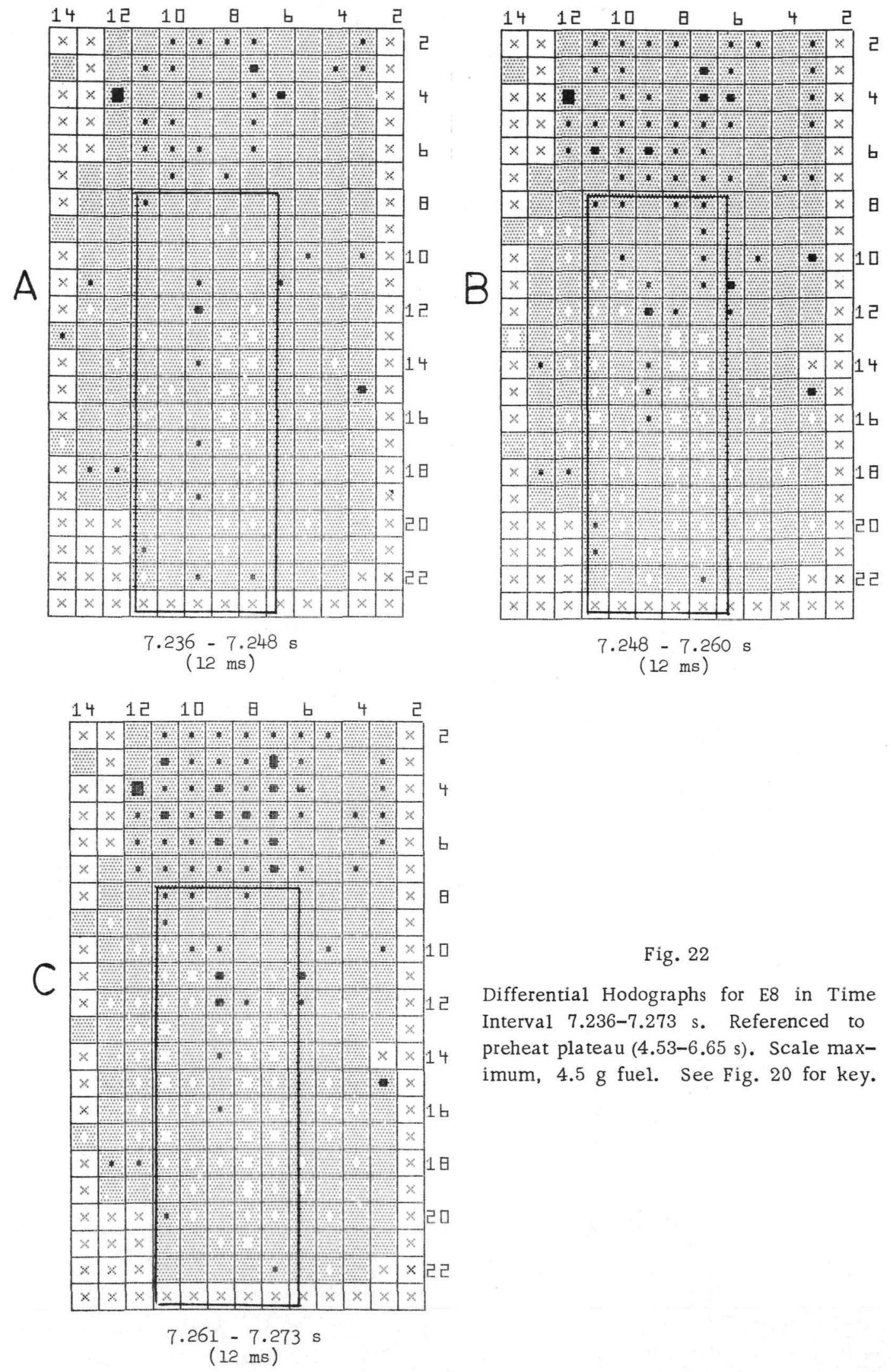

Fig. 22

Differential Hodographs for E8 in Time Interval 7.236-7.273 s. Referenced to preheat plateau $(4.53-6.65 \mathrm{~s})$. Scale maximum, $4.5 \mathrm{~g}$ fuel. See Fig. 20 for key. 


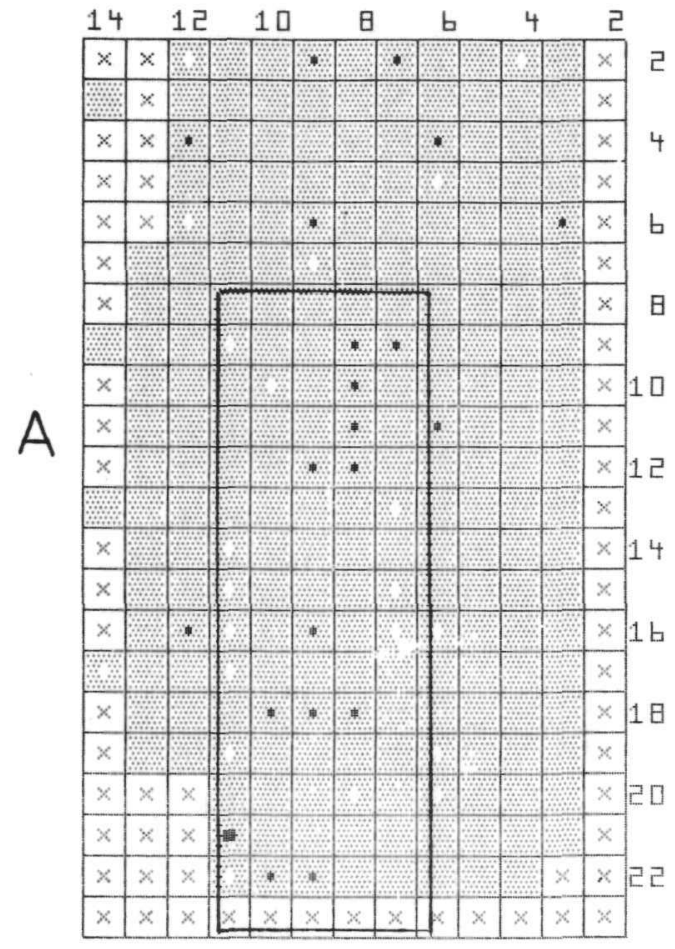

$7.236-7.248 \mathrm{~s}$

(12 ms)

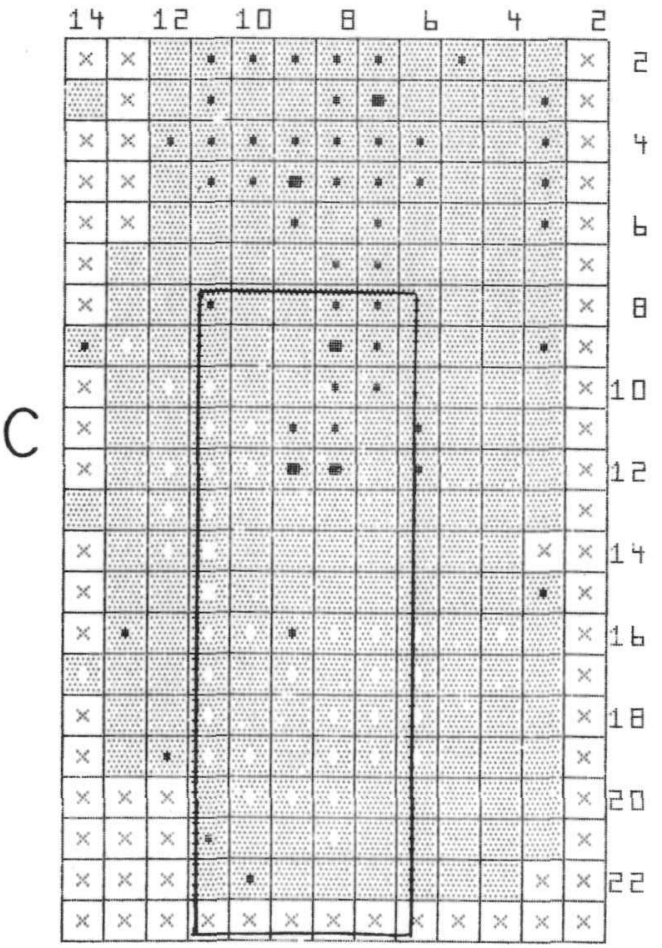

$7.261-7.273 \mathrm{~s}$

(12 ms)

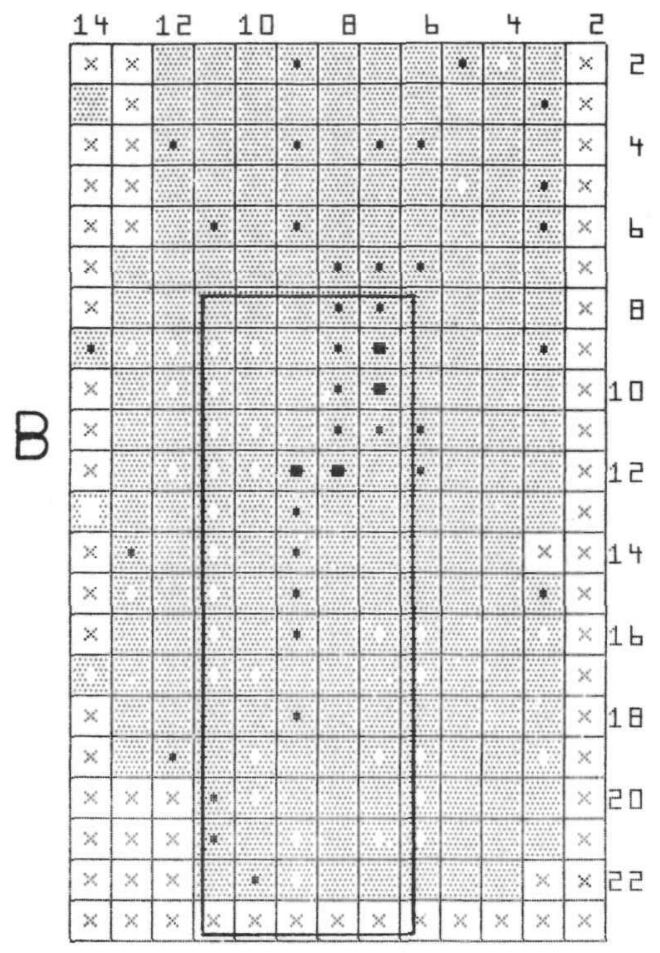

$7.248-7.260 \mathrm{~s}$

(12 ms)

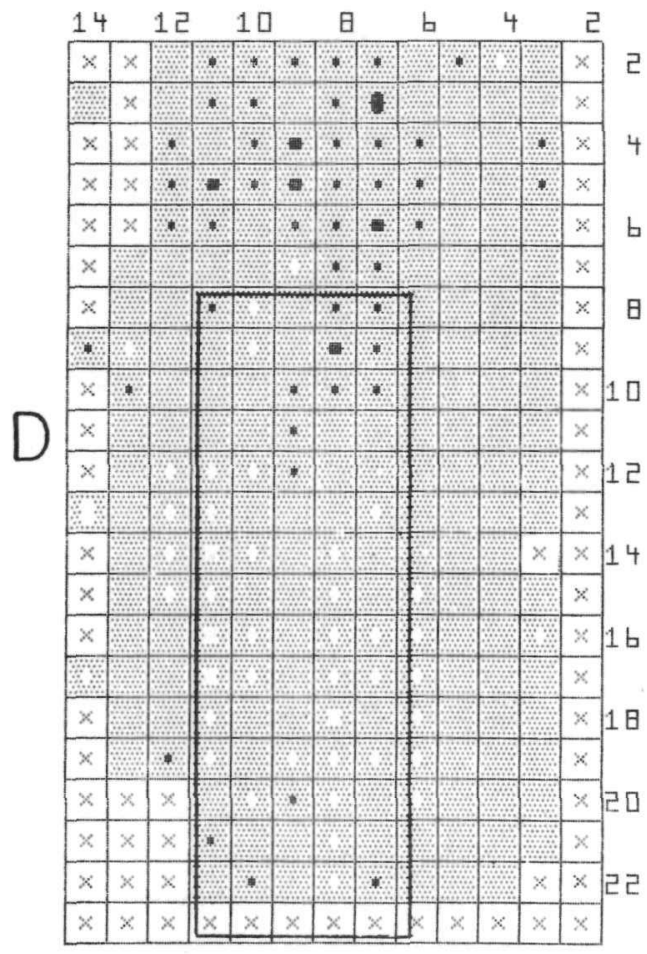

$7.273-7.285 \mathrm{~s}$

(12 ms)

Fig. 23. Differential Hodographs for E8 in Time Interval 7.236-7.285 s. Short term. Reference interval 7.224-7.236 s (12 ms). Scale maximum $4.5 \mathrm{~g}$ fuel. See Fig. 20 for key. 
c. Time Interval of 7.27-7.32 s. The hodographs for this time interval (see Figs. 24 and 25) show that the upward dispersal continued. Fuel has begun to be lost from the central column of the fuel zone. A general loss below the midplane is observed by $7.31 \mathrm{~s}$ in Figs. 25C and 25D, with virtually all the dispersed fuel above the top of the original fuel zone. By this time, gram quantities of fuel have probably proceeded above the hodoscope field of view, which only extended about $135 \mathrm{~mm}$ above the top of original fuel region. However, not more than $15 \mathrm{~g}$ of fuel left the field of view before $7.55 \mathrm{~s}$.

In Fig. 24C, a cluster of small deficits appears at the lower right of the array. Most of those channels were not focused on any of the test fuel initially. The channels therefore could not have lost fuel in the course of the transient. The deficits in columns 6 and 12 are reasonable, however, because the spatial resolution of the detectors is such that the detectors in column 12 respond to fuel that does not extend beyond the nominal limits of column 11. Similarly, the gains appearing at the top end of column 3 are unreasonable; column 3 sees nothing but the wall of the test-loop pressure vessel. A possible explanation for this observation might be that the flux distribution is a function of control-rod position. If this is indeed the cause, then the presence of spurious losses at the lower right and spurious gains at the upper right implies that both the gains at the top of the test assembly and the losses at the bottom have been spuriously augmented.

d. Time Interval of $7.32-7.40 \mathrm{~s}$. At about $7.30 \mathrm{~s}$, with the power still close to its maximum, the character of the fuel motion changed. Dis persal to regions more than $40 \mathrm{~mm}$ above the original fuel zone ceased, while churning continued below that level. Figures 26 and 27 cover the $100-\mathrm{ms}$ period between 7.3 and $7.4 \mathrm{~s}$. The reference interval for Fig. 27 is the closing interval for Fig. 25C. For the first half of this period, as shown by Figs. 26A and $26 \mathrm{~B}$, there is a loss of fuel from the top and bottom of the fuel region, with accumulation at the center of that region (canceling some of the deficit previously created), and at the upper edge and upper left corner of the fuel zone.

Note again that the hodoscope cannot observe motion toward or away from the pump. Thus, the fuel. gains seen at the midregion of the fuel zone could represent either (a) fuel moving from above and below, within the fuel bundle, or (b) accumulation outside the fuel bundle, fuel perhaps having penetrated the fluted tube, either on the pump side of the test region or on the side away from the pump.

Figure $27 \mathrm{C}$ shows further los from the regions above and below the midplane, with gains appearing at the right in the lower two-thirds of the fuel zone, and at the left in the upper half. Gains in columns 6 and 12 do not necessarily indicate penetration of the fluted tube, unless accompanied by gains in columns 5 and 13. Thus, there is no indication in Fig. $27 \mathrm{C}$ that the fluted tube has been appreciably penetrated on the left or the right, although it may well have been at the front or back. Figure 27D, however, gives strong 


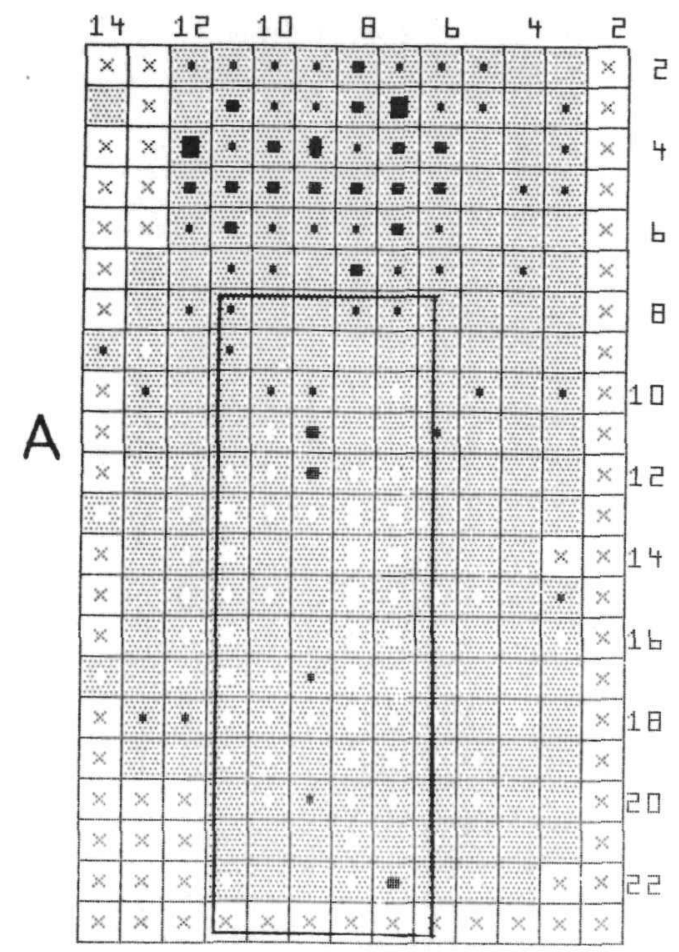

$7.273-7.285 \mathrm{~s}$

(12 ms)

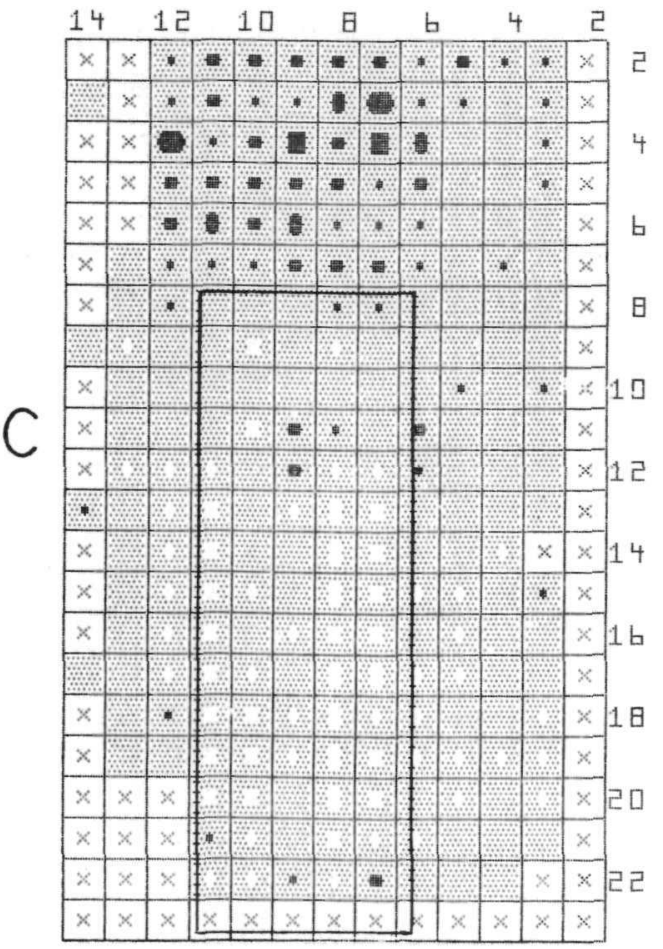

$$
7.297-7.309 \mathrm{~s}
$$

(12 ms)

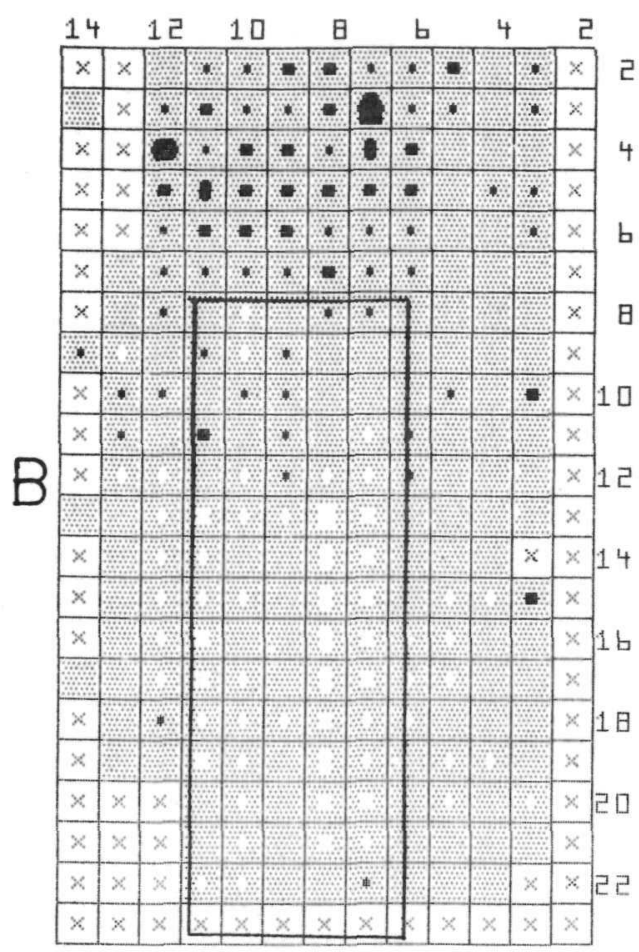

$7.285-7.297 \mathrm{~s}$

(12 ms)

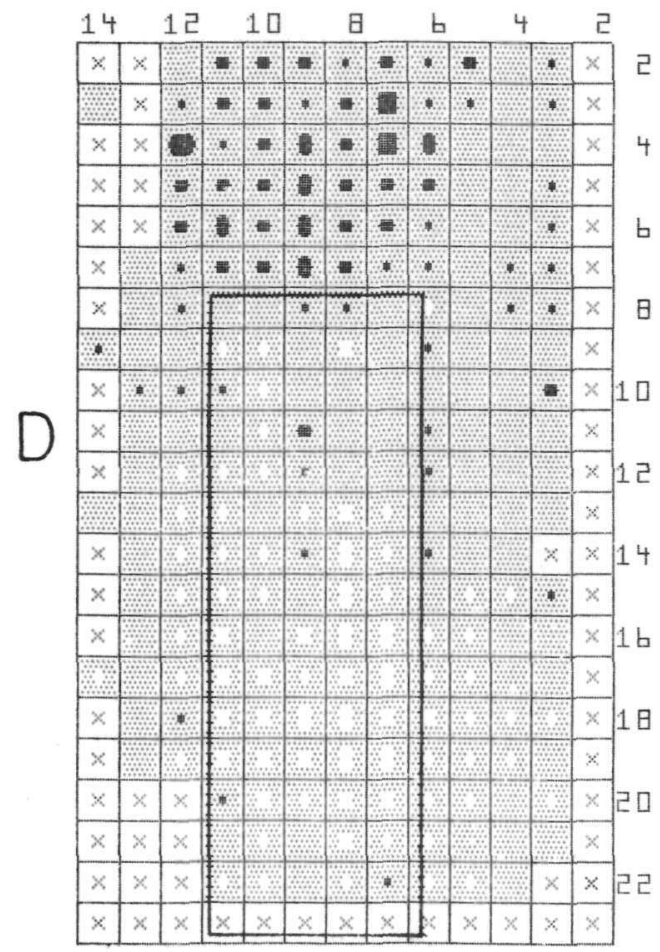

$7.309-7.321 \mathrm{~s}$

(12 ms)

Fig. 24. Differential Hodographs for E8 in Time Interval 7.273-7.321 s, Referenced to Preheat Plateau (4.53-6.65 s). Scale maximum, 4.5 g fuel. See Fig. 20 for key. 


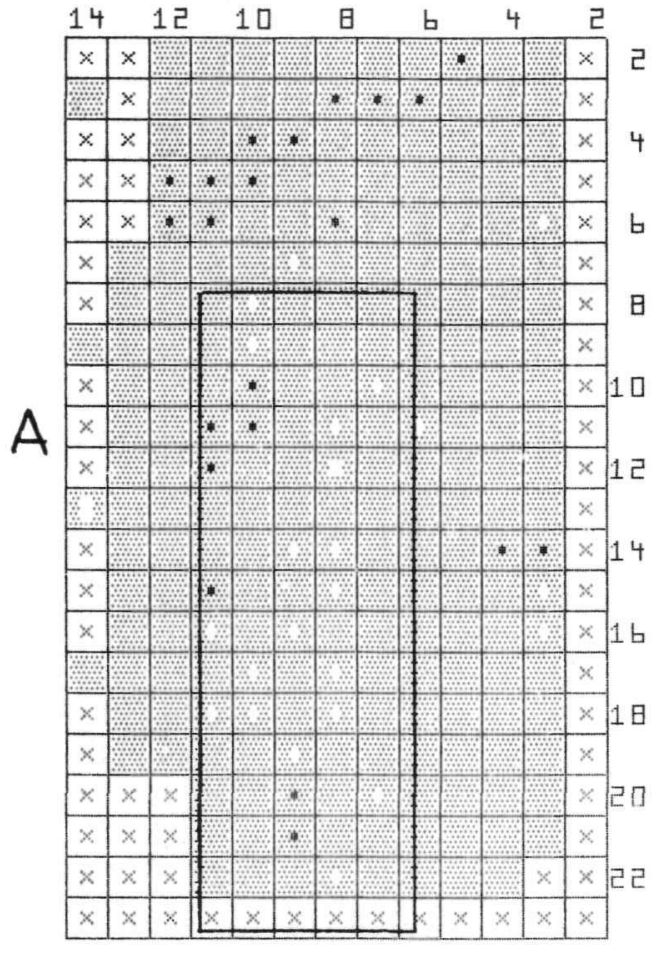

$7.273-7.285 \mathrm{~s}$

(12 ms)

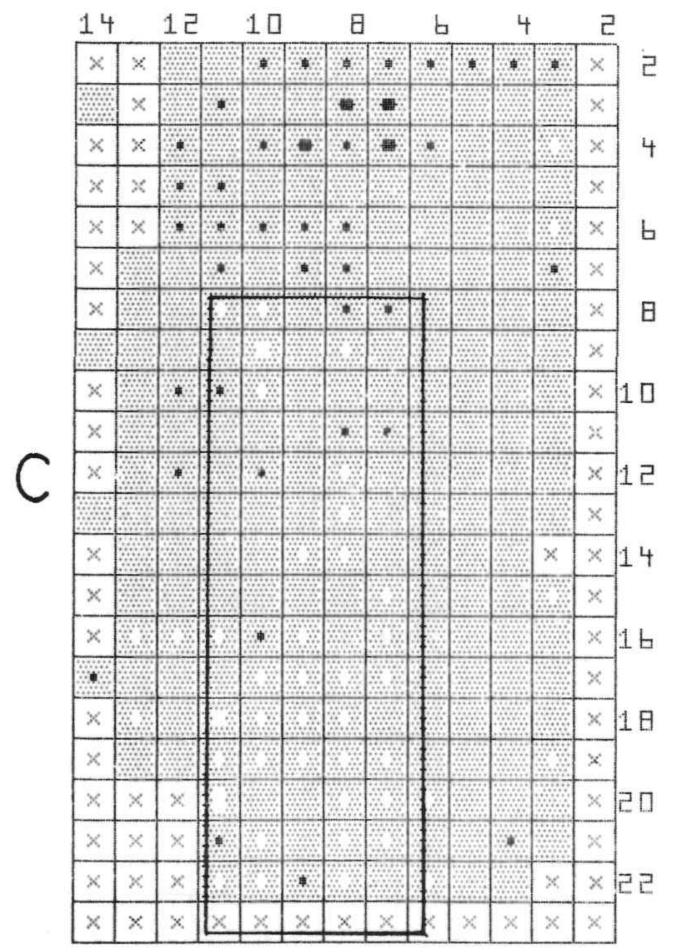

$7.297-7.309 \mathrm{~s}$

(12 ms)

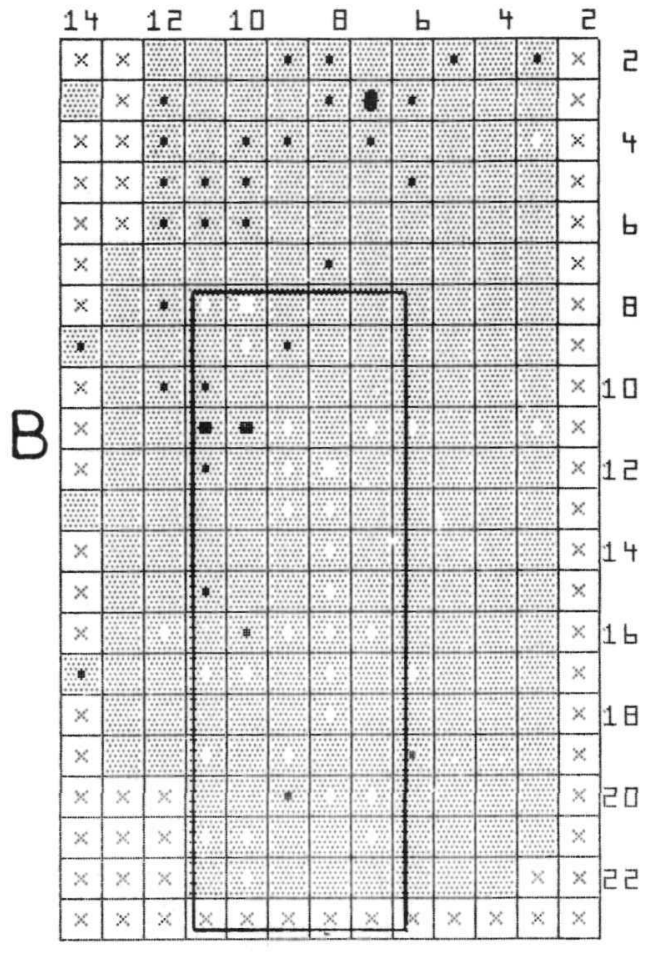

$7.285-7.297 \mathrm{~s}$

(12 ms)

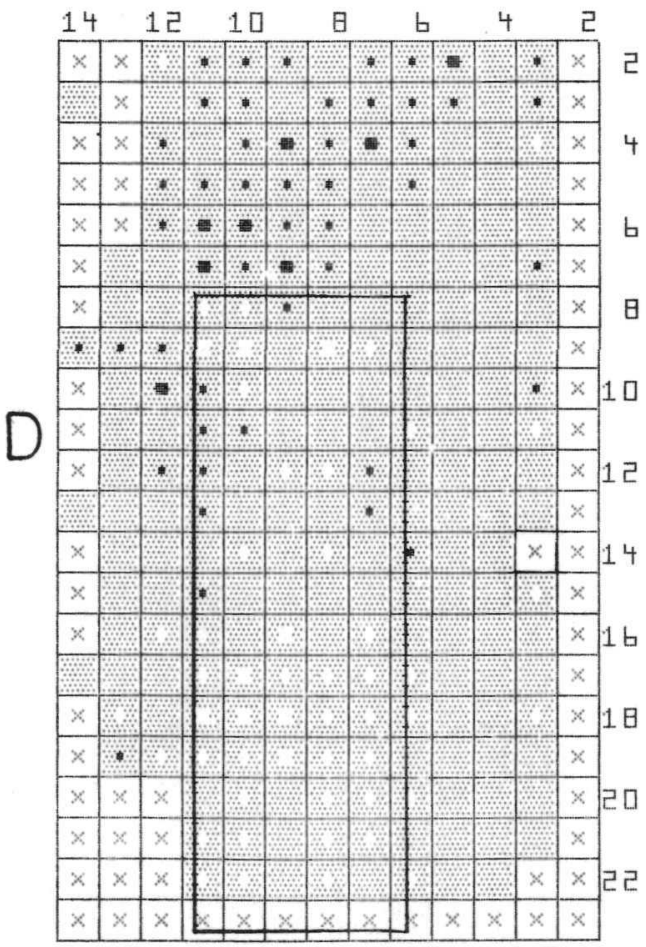

$7.309-7.321 \mathrm{~s}$
$(12 \mathrm{~ms})$

Fig. 25. Differential Hodographs for E8 in Time Interval 7.273-7.321 s, Referenced to Interval 7.261-7.273 s (12 ms). Scale maximum, $4.5 \mathrm{~g}$ fuel. See Fig. 20 for key. 


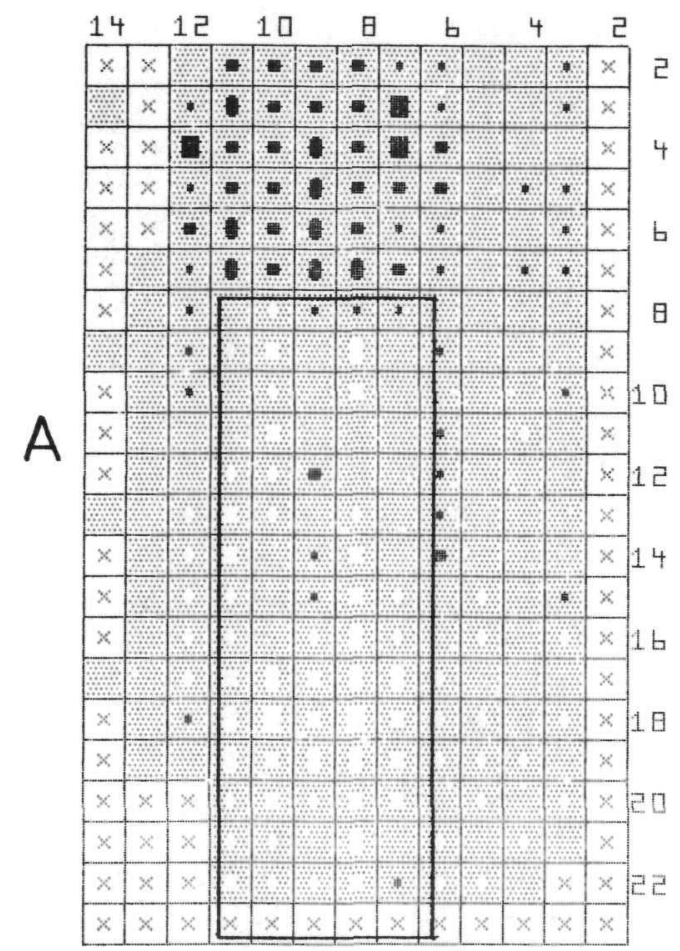

$7.321-7.333 \mathrm{~s}$

(12 ms)

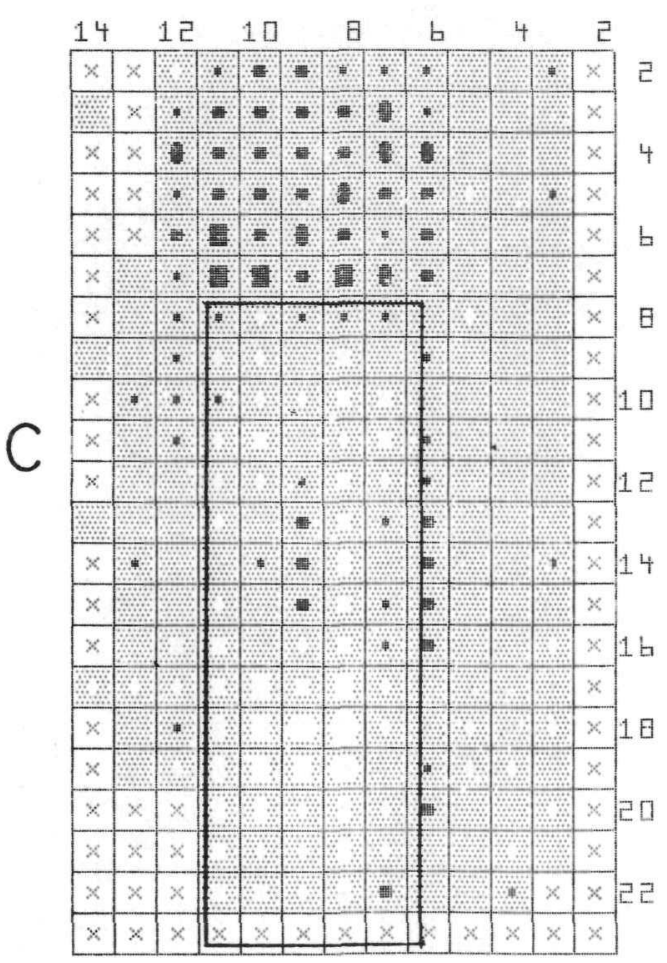

$7.358-7.370 \mathrm{~s}$
$(12 \mathrm{~ms})$

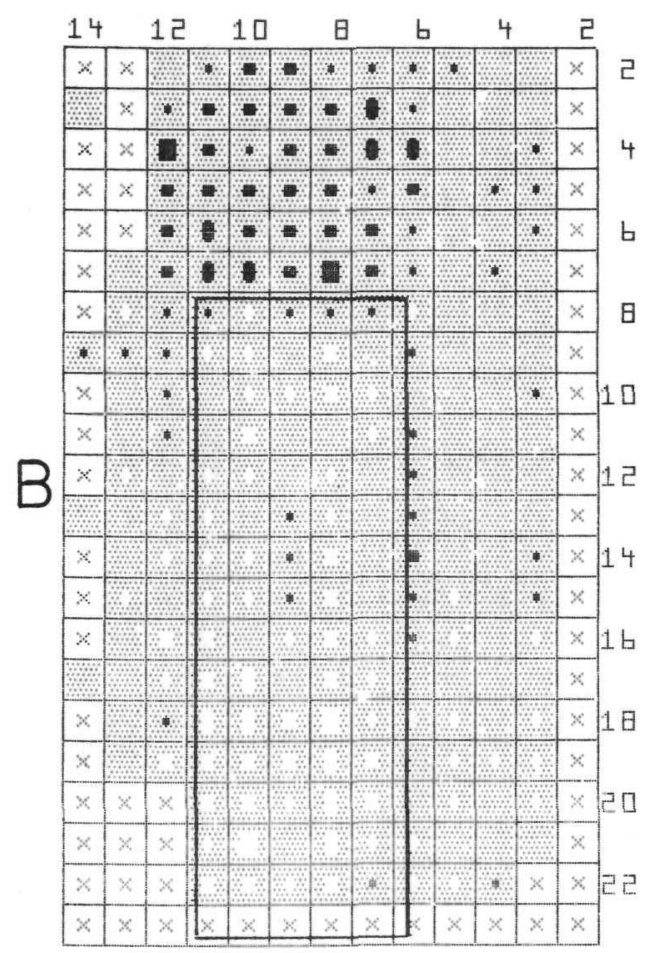

$7.333-7.345 \mathrm{~s}$

(12 ms)

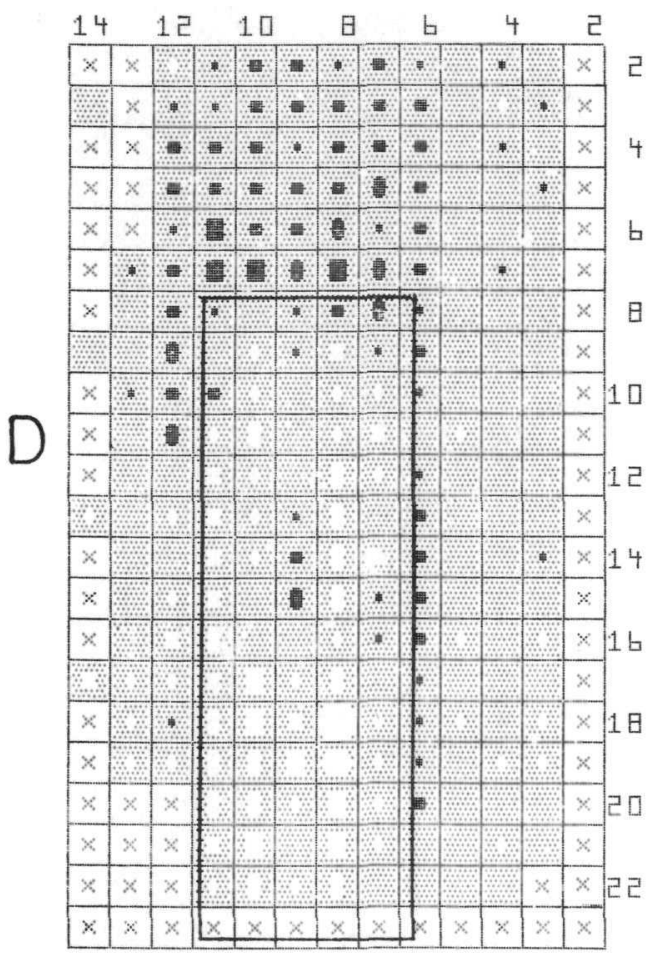

$7.382-7.406 \mathrm{~s}$ (24 ms)

Fig. 20. Differential Hodographs for E8 in Time Interval 7.321-7.406 s, Referenced to Preheat Plateau (4.53-6.65 s). Scale maximum, 4.5 g fuel. See Fig. 20 for key. 


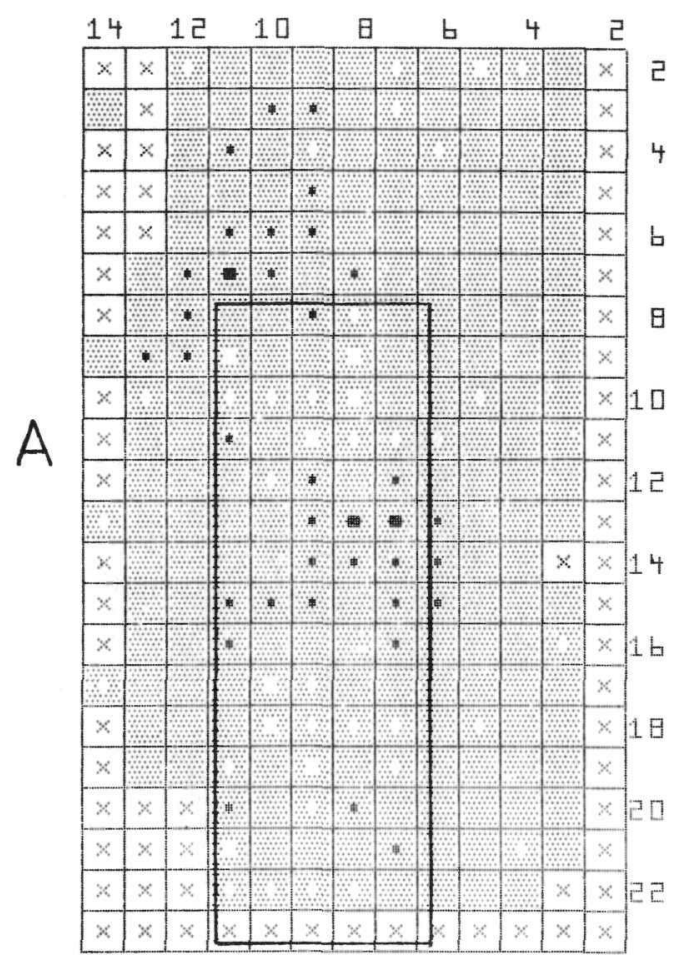

$7.321-7.333 \mathrm{~s}$

(12 ms)

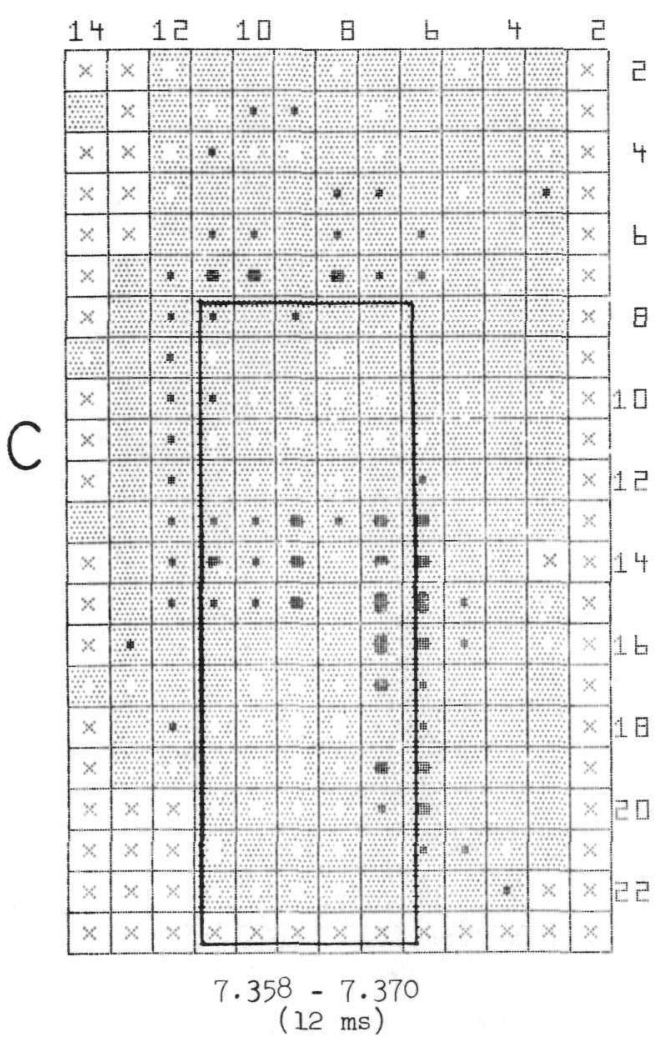

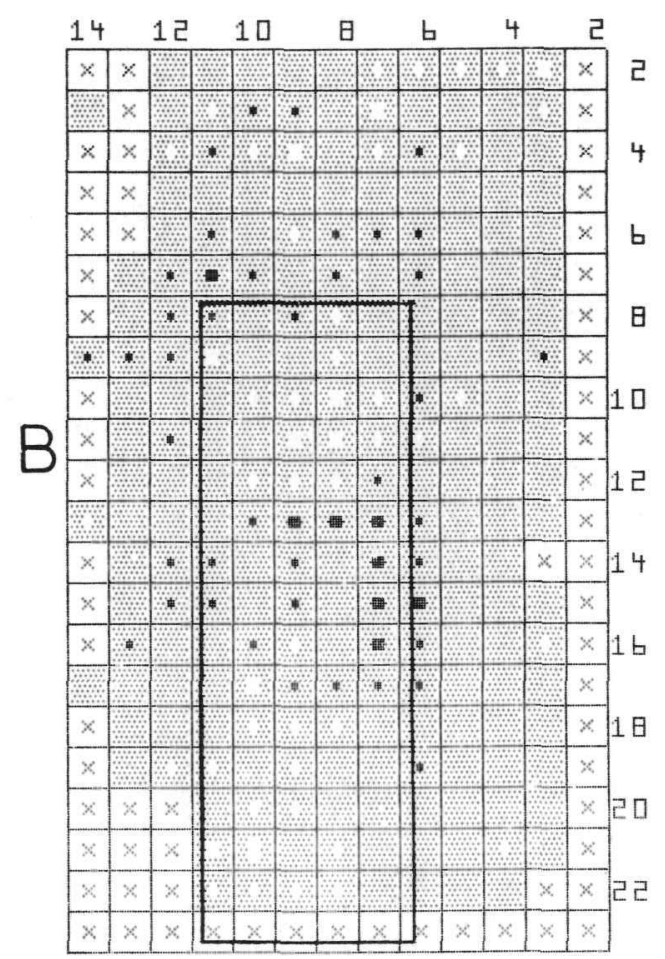

$7.333-7.345 \mathrm{~s}$

(12 ms)

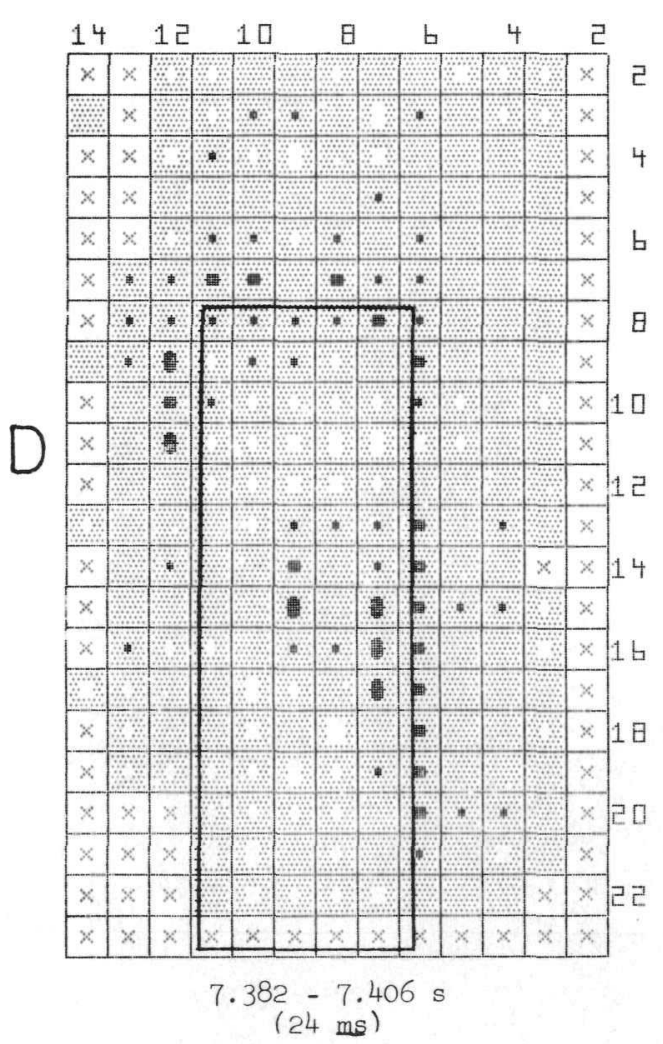

Fig. 27. Differential Hodographs for E8 in Time Interval 7.321-7.406 s, Referenced to Interval 7.297-7.309 s (12 ms). Scale maximum, $4.5 \mathrm{~g}$ fuel. See Fig. 20 for key. 
indication that there is fuel outside the fluted tube at the upper left. Figure 27B shows fuel continuing to accumulate at the top of the original fuel zone (rows 7 and 8), but no higher, confirming the presence of a rather complete blockage. The hodographs in Fig. 26 show how the fuel was distributed above the fuel zone. Although this distribution was fairly uniform, the average fuel density of $1-2 \mathrm{~g} /$ channel is considerably less than the original fuel-zone density of about $8.5 \mathrm{~g} /$ channel.

e. Time Interval of 7.4-8.0 s. Continued fuel voiding of the original fuel region occurred in this time interval. Short-term differential hodographs show the process of loss of fuel from the original fuel zone, with accumulation at the top of the original fuel zone and on the left against the outer wall of the adiabatic holder if not against the wall of the test chamber. Most of the upper half of the original fuel zone was largely voided at $7.5 \mathrm{~s}$, with fuel located around the periphery in an apparent annular configuration. The bottom half of the fuel zone was less than half voided, the missing fuel apparently having gone upward rather than outward.

Because of the low position of the fuel zone in the hodoscope field, no definitive estimate could be made of how much fuel moved downward to regions below the fuel zone. The total amount of fuel lost to the hodoscope, either above or below its field of view, could not have exceeded $15 \mathrm{~g}$. There are strong indications that at least several grams of fuel did pass upward out of the field of view before $7.3 \mathrm{~s}$. Thus, the amount of fuel passing downward was probably less than $10 \mathrm{~g}$.

By $7.5 \mathrm{~s}$, the hodoscope counting statistics were becoming poor, leading to greater scatter from channel to channel. Some additional loss of fuel from the original fuel zone took place in the 7.503-7.527-s interval, with gains around the edges. Also, the beginning of fuel return from the upper region can be seen.

The return of about $10 \mathrm{~g}$ of fuel from above the original fuel zone was observed, the main accumulation occurring at the right-hand side of the cluster. The lateral motion seems to have been stopped by the fluted tube rather than by the test-cavity wall or the outer wall of the adiabatic holder.

By $8.0 \mathrm{~s}$, there had been considerable additional fuel voiding on the bottom half of the original fuel zone. About $5 \mathrm{~g}$ more fuel had left the region above the original fuel zone, and the fuel deficit that existed in the top half of the original fuel zone at $7.5 \mathrm{~s}$ had been more than compensated for, with fuel at this elevation occupying a larger radial region than initially. The poor statistics in the time period following $7.55 \mathrm{~s}$ make it difficult to set limits on how much fuel might have moved below the bottom of the original fuel zone during this time interval. 


\section{Net Axial Profiles of Fuel Motion}

The axial motion of the test fuel is of particular significance in accident analysis. This component of the motion can be determined from the hodoscope data by integrating, for each row of detectors, over the columns (in this case, columns 5-13) that view the test region. Such axial countingrate profiles are shown in Fig. 28. The reason the change at the top of the fuel column is not more abrupt is that each hodoscope channel is somewhat sensitive to fuel that is in the viewing areas of its neighbors.

The "initial" curve is the profile for the preheat plateau phase. The "final" curve is the axial profile corresponding to the last differential hodograph. The scales in these and the following axial profiles are calibrated in $\mathrm{g} / \mathrm{mm}$ of axial distance.

Figure 29 presents a series of profiles covering the course of the E8 transient. Many of the axial-motion features mentioned in discussing the differential hodographs can be seen here--for example, the increase in fuel quantity at the top of the viewing area until $\sim 7.3 \mathrm{~s}$, followed by a gradual re versal. The curves of Figs. 28 and 29 have had the background counting rate subtracted.

To emphasize the changes in fuel quantity, the counting rates corresponding to the initial configuration (the "initial" curve of Fig. 28) can be subtracted. When this is done to the data that Fig. 29 is based on, the R/P change curves presented in Figs. 30 and 31 result.

The mechanism by which fuel was transferred from below to above the midplane after $7.45 \mathrm{~s}$ is not completely clear. One possibility is that sodium, under pump pressure, reentered from the bottom as the power fell off, pushing some fuel up ahead of it. Figure 17 does indicate the possibility of some coolant flow up into the test section between 7.45 and $7.65 \mathrm{~s}$, and sporadically thereafter.

D. Summary of Test Results Based on Instrumentation

Based on the loop instrumentation and hodoscope analysis, the scenario of events taking place in the E8 test zone is summarized in Table XVII. 


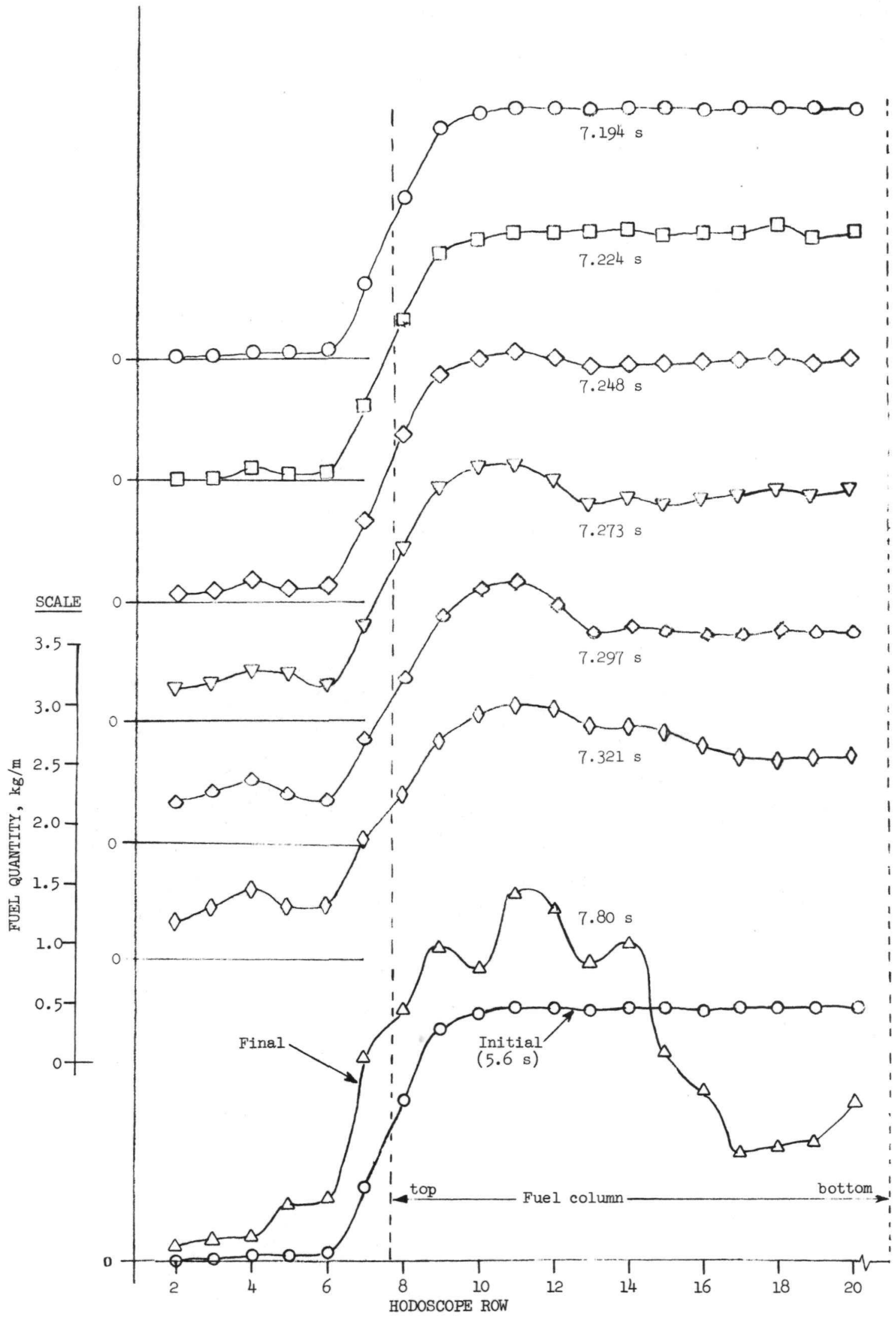

Fig. 28. Selected Axial Profiles of Fuel Distribution in Transient E8 


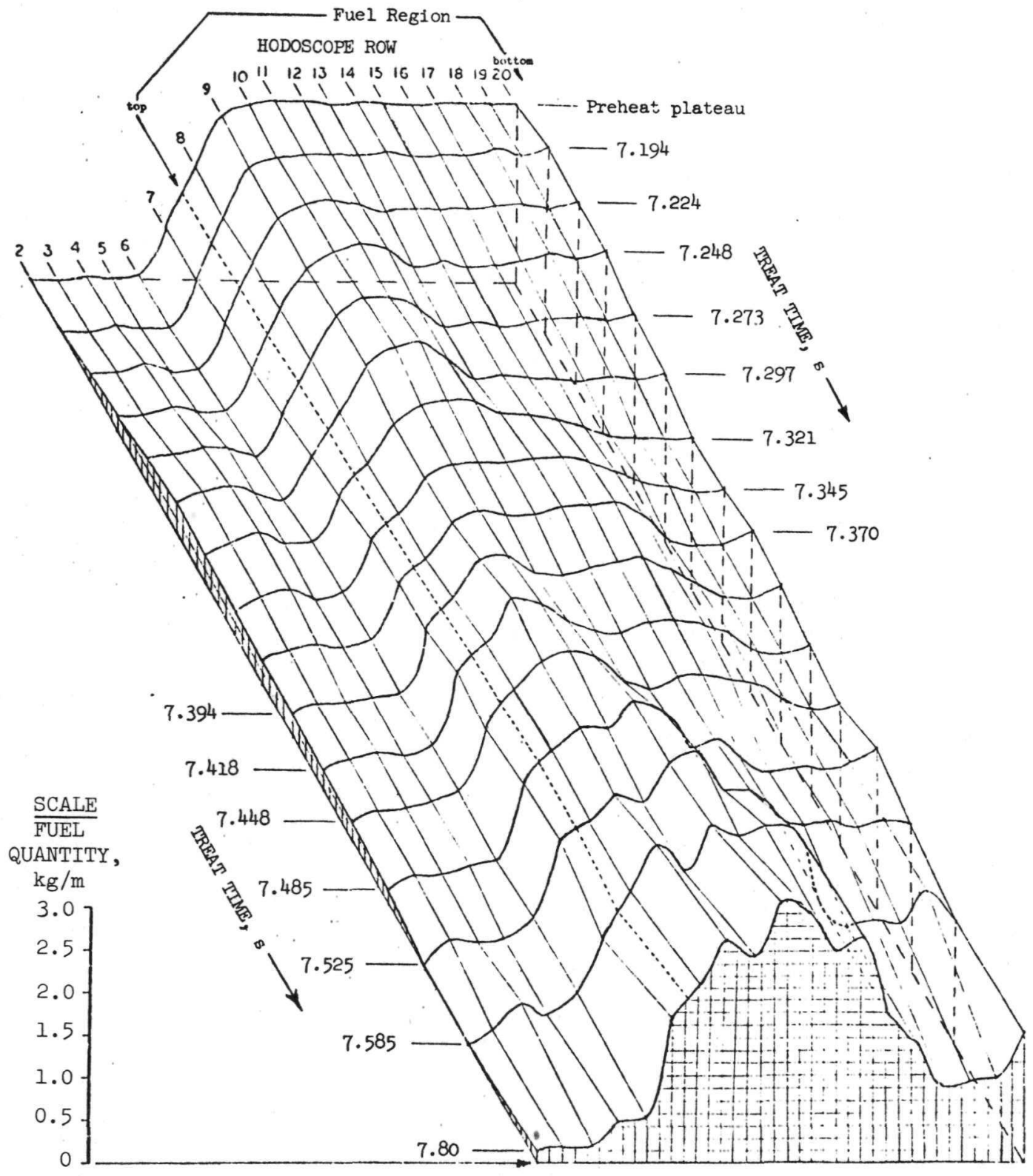

Fig. 29. Axial Fuel-quantity Profiles in Transient E8 


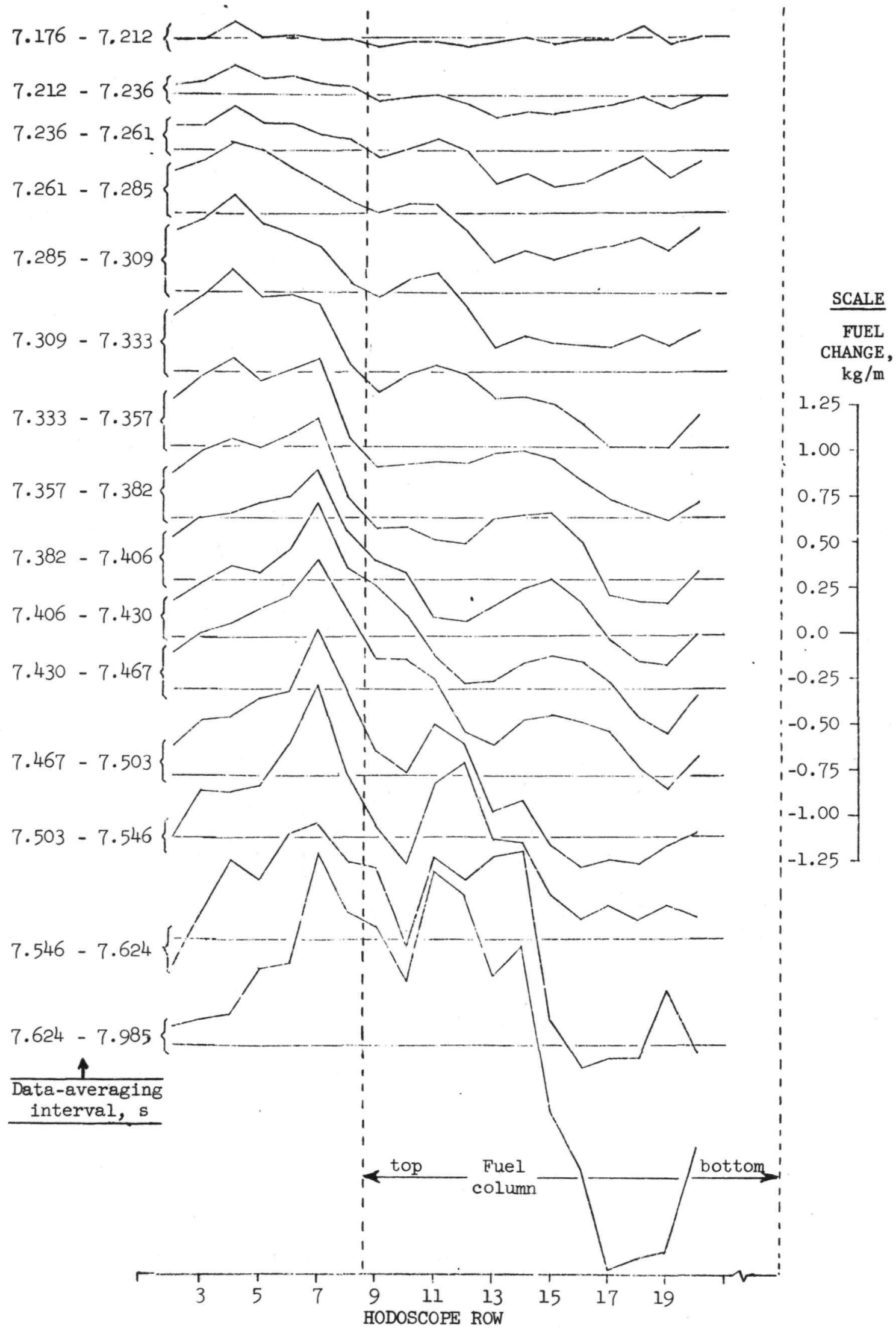

Fig. 30. Axial Profiles of Fuel-quantity Changes in Transient E8 


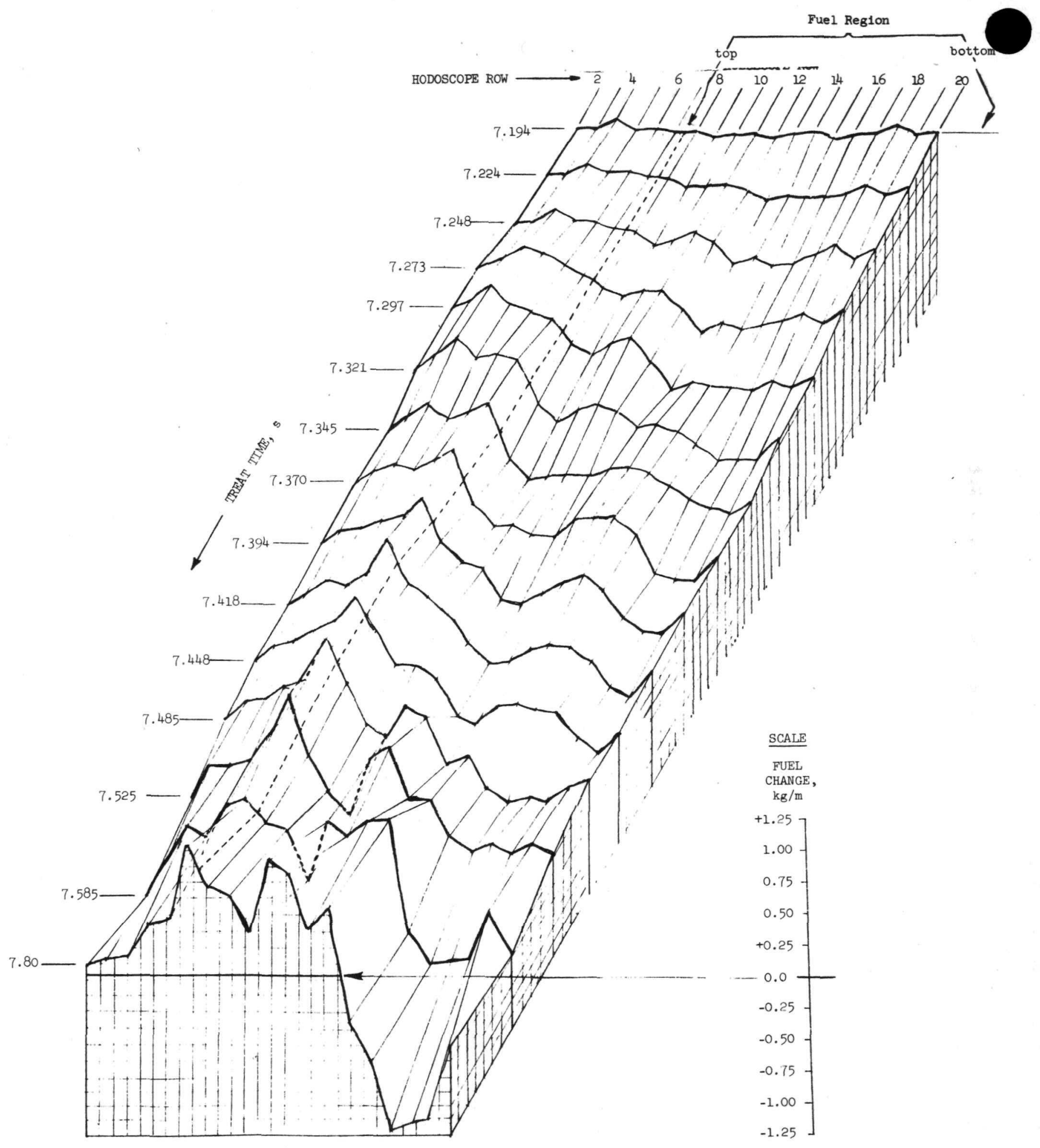

Fig. 31. Changes in Axial Distribution of Test Fuel in Transient E8 
TABLE XVII. Scenario of Events in Test E8

\begin{tabular}{|c|c|c|c|}
\hline Time, s & Power Level, MW & Sensor ${ }^{a}$ & Observation \\
\hline $4.0-7.219$ & & $\mathrm{H}$ & No observable fuel motion. \\
\hline 4.4 & 115 & $\mathrm{R}$ & Start of preheat plateau. \\
\hline 6.7 & 115 & $\mathrm{R}$ & Power ramp begins. \\
\hline 7.204 & 2130 & $\mathrm{P}$ & $\begin{array}{l}\text { Beginning of observable pres - } \\
\text { sure changes. }\end{array}$ \\
\hline 7.212 & 2185 & $P, F$ & $\begin{array}{l}\text { Pressure pulses recorded as } \\
\text { first element ruptures. }\end{array}$ \\
\hline $7.219-7.30$ & & $\mathrm{H}$ & $\begin{array}{l}\text { Loss of fuel from elements, } \\
\text { over extended axial region; lost } \\
\text { fuel swept upward to lodge above } \\
\text { original fuel zone. }\end{array}$ \\
\hline 7.219 & 2235 & $\mathrm{H}$ & $\begin{array}{l}\text { About } 6 \mathrm{~g} \text { of fuel leaves periph- } \\
\text { eral element on east }{ }^{b} \text { side of } \\
\text { bundle. Expelled fuel travels } \\
\text { upward to region above fuel zone. }\end{array}$ \\
\hline 7.223 & 2250 & $\mathrm{P}$ & $\begin{array}{l}\text { Second set of pressure events } \\
\text { recorded. }\end{array}$ \\
\hline 7.228 & 2300 & $\mathrm{H}$ & $\begin{array}{l}\text { About } 18 \mathrm{~g} \text { of fuel leaves west } \\
\text { side of bundle, again moving } \\
\text { rapidly to superstructure over } \\
\text { fuel zone. }\end{array}$ \\
\hline 7.234 & 2340 & $\mathrm{P}$ & $\begin{array}{l}\text { Third set of pressure pulses } \\
\text { recorded. }\end{array}$ \\
\hline 7.238 & 2370 & $F$ & $\begin{array}{l}\text { Maximum exit flow rate } \\
\left(1650 \mathrm{~cm}^{3} / \mathrm{s}\right) \text {; inlet flow } \\
\text { crosses zero. }\end{array}$ \\
\hline 7.278 & 2535 & $\mathrm{R}$ & Peak power reached. \\
\hline $7.30-7.40$ & & $\mathrm{H}$ & $\begin{array}{l}\text { Fuel moving about within origi- } \\
\text { nal fuel zone. }\end{array}$ \\
\hline 7.30 & 2500 & $\mathrm{H}$ & $\begin{array}{l}\text { Upward sweepout greatly dimin- } \\
\text { ishes as upper blockage is } \\
\text { largely completed. }\end{array}$ \\
\hline 7.32 & 2470 & $\mathrm{H}$ & $\begin{array}{l}\text { Inner wall of flow tube pene- } \\
\text { trated on east side. (Penetra- } \\
\text { tions of flow tube in line with } \\
\text { hodoscope would not be } \\
\text { observable.) }\end{array}$ \\
\hline 7.34 & 2150 & $F$ & $\begin{array}{l}\text { Inlet flow at maximum negative } \\
\text { value }\left(500 \mathrm{~cm}^{3} / \mathrm{s}\right) \text {. }\end{array}$ \\
\hline
\end{tabular}

${ }^{a_{H}}$ : Hodoscope; P: Inlet pressure sensor; F: Flowmeters; R: Reactor Power Meter.

borientation: Pump on south side of test zone; hodoscope to north. 


\section{POSTTEST EXAMINATIONS}

The final disposition of material for the test was determined by a sequence of examinations that began with neutron radiography at TREAT. The loop was cut into lengths in the Hot Fuel Examination Facility (HFEF). Further disassembly and detailed examinations were carried out in the AlphaGamma Hot Cell Facility (AGHCF). The results of these examinations are discussed in this section.

A. Neutron Radiography

Neutron radiographs of the test section, upper bend, pump, downcomer, and lower bend were taken in $430-\mathrm{mm}$ frames with about a $50-\mathrm{mm}$ overlap in the neutron-radiography facility at TREAT. A composite of neutron radiographs for the test region is shown in Fig. 32. The neutron radiograph shows dark regions due to the presence of both strong neutron absorbers and neutron scatterers; it is therefore not possible to identify fuel from steel unambiguously from the radiograph alone.

The neutron radiographs of the E8 test section were taken in a direction perpendicular to the plane of the pump and the test section after stripping the loop. As a result, fuel elements PNL-10-8 and -10 and PNL-10-28 and -54, where still intact, appear as single elements on the side toward and away from the pump, respectively. Similarly elements PNL-10-34, -54, and-7 were aligned and appear as a single element in the neutron radiograph.

Only the bottom fourth of the fuel columns showed any evidence of the original pellet stacks. The region above the remains of the pellet stacks appeared to have lost much of its fuel up to about the midlength of the original fuel columns. The remainder of the fuel-column region (the upper half) was occupied by a dense mass of material. Additional material, presumably mostly fuel, was abundant for about $330 \mathrm{~mm}$ above the original tops of the fuel columns. A deposit of material was observed on the header joining the adiabatic tube to the fluted tube above the fuel column.

A small amount of material was observed on the bottom of the loop on the side under the test section. Some material was deposited among the bottom end plugs and among the elements just above the header joining the adiabatic tube to the fluted tube at the bottom of the test section.

The adiabatic tube appeared to be intact on the neutron radiograph, although two tube penetrations were subsequently found during disassembly. The fluted (flow) tube appeared to have melted completely over the top half (165 mm) of the fuel column, with evidence for partial or local melting for some distance above and below. 


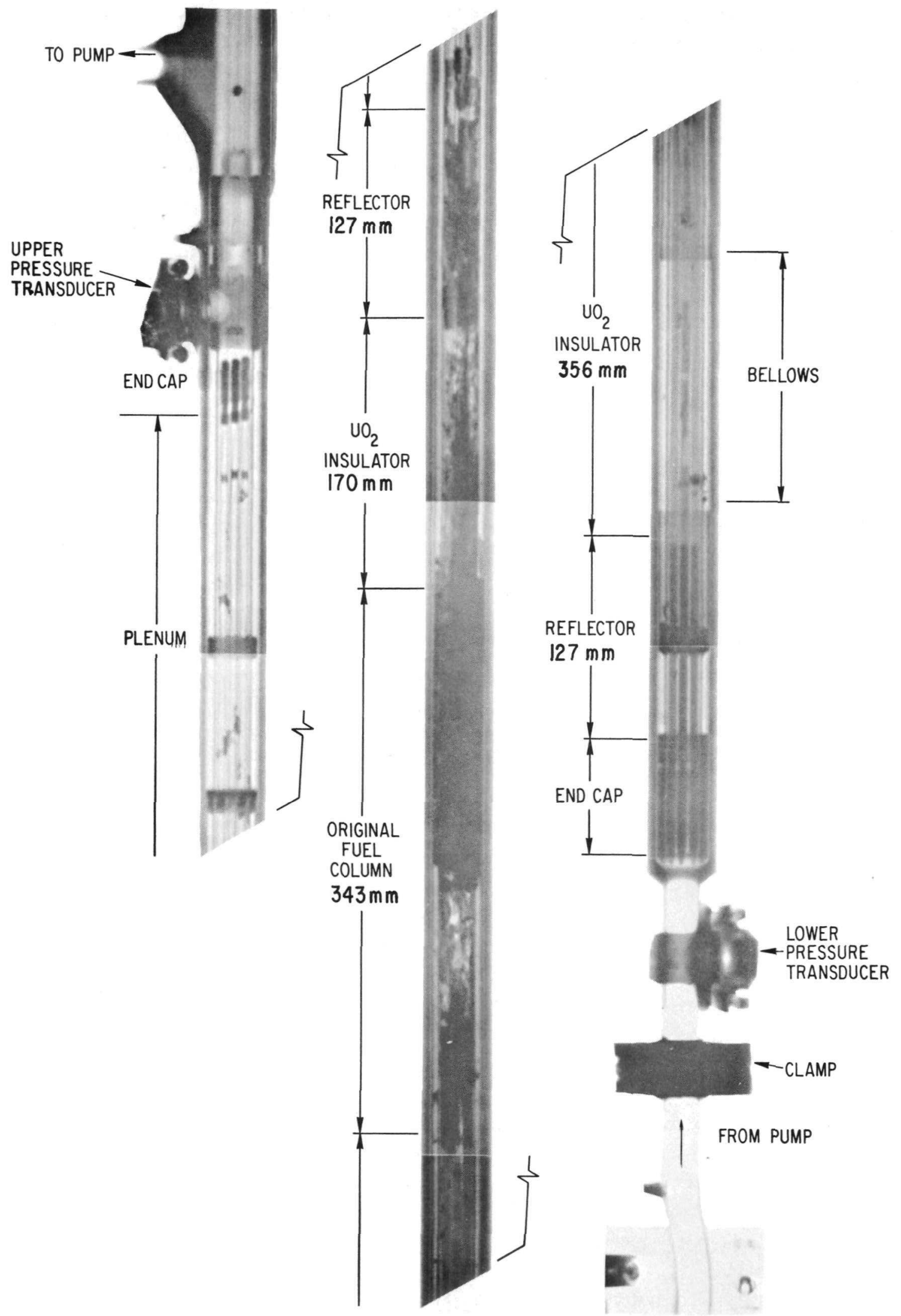

Fig. 32. Posttest Neutron Radiograph of E8 Test Section. ANL Neg. No. 900-77-1444. 
In the lower insulator-pellet region, gaps were evident in the $\mathrm{UO}_{2}$ pellet stacks of one or more of the three fuel elements in the center (PNL-10-34, -54 , and -7 ). Summing of the gaps gave a length of about $100 \mathrm{~mm}$.

A pretest neutron radiograph had showed that the tops of the elements were all at the same elevation. The posttest neutron radiograph showed an approximately 3- $\mathrm{mm}$ elevation of the tops of the elements on the side away from the pump. The tops of the elements on the side toward the pump seemed to be at their initial elevations. The plugs indicating the tops of the spacer tubes showed only a small relative displacement. However, the length of tubing available to the springs was about $3 \mathrm{~mm}$ greater than indicated before the test. A relative displacement of about $6 \mathrm{~mm}$ appeared to exist among the upper reflector rods.

B. Disassembly of Test Train

The part of the loop containing the test train was separated from the rest of the loop at HFEF. The pressure transducers were also removed. The section of the loop containing the test train was shipped to the AGHCF at ANL/ East for detailed examination. The section received at the AGHCF extended from the flange below the test train to a cut made just above the side arm for the return of sodium to the pump. The overall length was about $1.87 \mathrm{~m}$.

In the loop section as received, sodium was observed at the openings for the upper and lower pressure transducers, at the flange at the bottom, and at the pressure-relief opening. Sodium was not observed at the side arm to the pump or at the transverse cut through the loop above the side arm. Subsequent cutting revealed a large shrinkage cavity in the sodium in the heavy loop section where the bottom pressure transducer and the pressure-relief tube were connected.

For the purpose of orientation, a $0.8-\mathrm{mm}$ groove was inscribed with an abrasive cutoff wheel on the surface of the loop tube along the side toward the pump. The overall sectioning scheme is shown in Figs. 33 and 34 . The neutron radiographs taken at TREAT served as a guide for the cutting scheme. The sodium was still in place for the initial cuts.

Section 147Al in Fig. 33 contained the bottoms of the fuel elements, including reflector rods, and almost all the stacks of insulator pellets. This piece was $553 \mathrm{~mm}$ long. Section 147A2, $729 \mathrm{~mm}$ long, contained the full length of fuel columns, the upper insulator pellets and reflector rods, and part of the spacer tubes. Section 147A3, $287 \mathrm{~mm}$ long, contained the tops of the elements, including the spring and more than half of the spacer tube. Section 147A4 was set aside, since it appeared to be a little interest. 


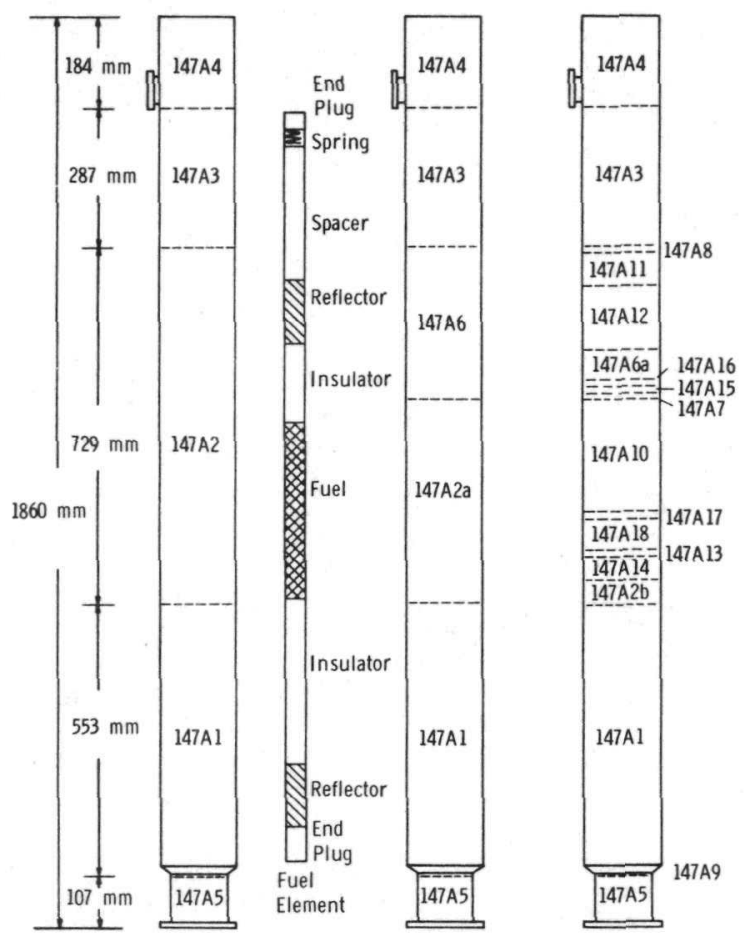

Fig. 33. Sectioning Schematic of Test-train Leg of E8 Loop

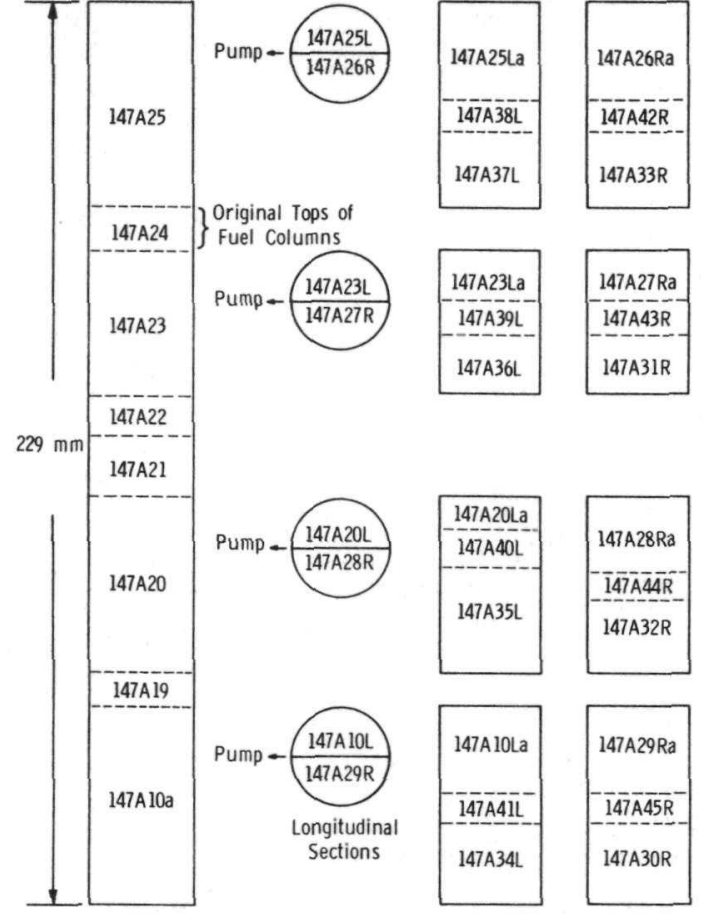

Fig. 34. Sectioning Schematic of Piece 147A10

Continuous axial gamma scans were made of section 147A3, as cut, with the sodium and the loop tube still in place. Sections $147 \mathrm{Al}$ and $147 \mathrm{~A} 2$ were too large to make continuous gamma scans with the equipment available. Section $147 \mathrm{~A} 2$ was cut into two parts, $147 \mathrm{~A} 2 \mathrm{a}$ and $147 \mathrm{~A} 6$, which could be gammascanned. Section 147Al was heated to melt the sodium partially, and the loop wall was easily removed from around the test-train segment. The test-train segment 147Al was then gamma-scanned. The gamma scans for the energy range 0.1-2.0 MeV (gross), cesium, and rhodium are shown in Figs. 35-38 for the four sections.

After gamma scanning, section $147 \mathrm{~A} 3$ was heated to melt the sodium. The loop wall was easily removed, and the top sections of the elements were taken out of the flow tube for examination. Element PNL-10-7 appeared to have a very small spot on the cladding that had melted.

Section $147 \mathrm{~A} 6$ was similarly heated and the loop tube removed. The adiabatic tube and the flow tube were held together by a header. The part of the spacer tube in element PNL-10-28 was loose and came out of the cladding at this point. The header at the top of section $147 \mathrm{~A} 6$ was cut off (section 147A8). The adiabatic tube could then be separated from the flow tube. The fuel-element segments were still not free in this section. Sections 147All and 147Al2 were therefore cut from the upper part of 147A6. The fuel-element parts in both of these new sections were free. The disassembled section $147 \mathrm{~A} 12$ is shown in Fig. 39. The lower part of section 147A6, now 147A6a, was held together by melted steel as shown in Fig. 40 with a section of the flow tube removed from the PNL-10-7 side. 

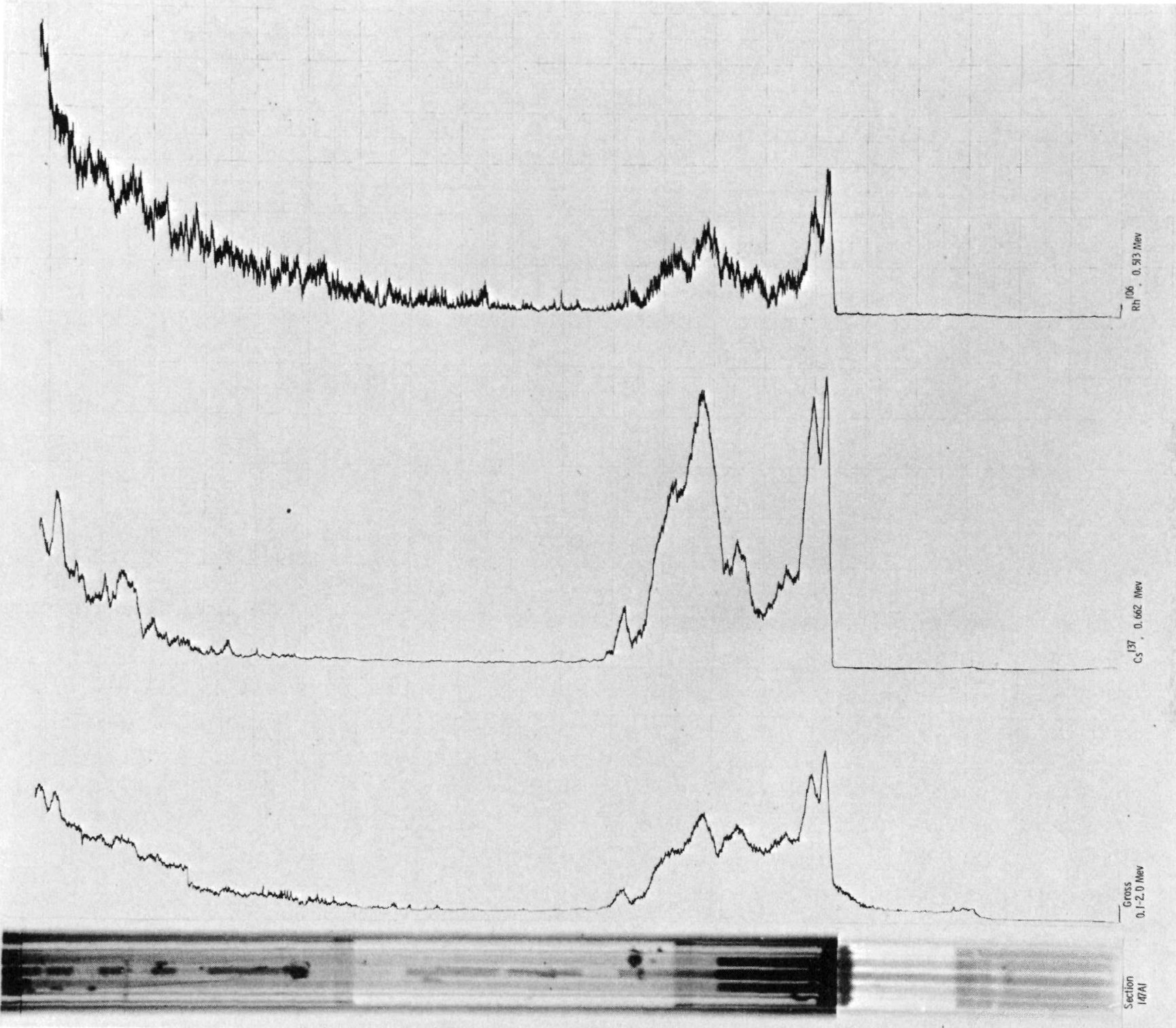

Fig. 35. Gamma Spectrometry of Section 147A1. Neg. No. MSD-188532. 

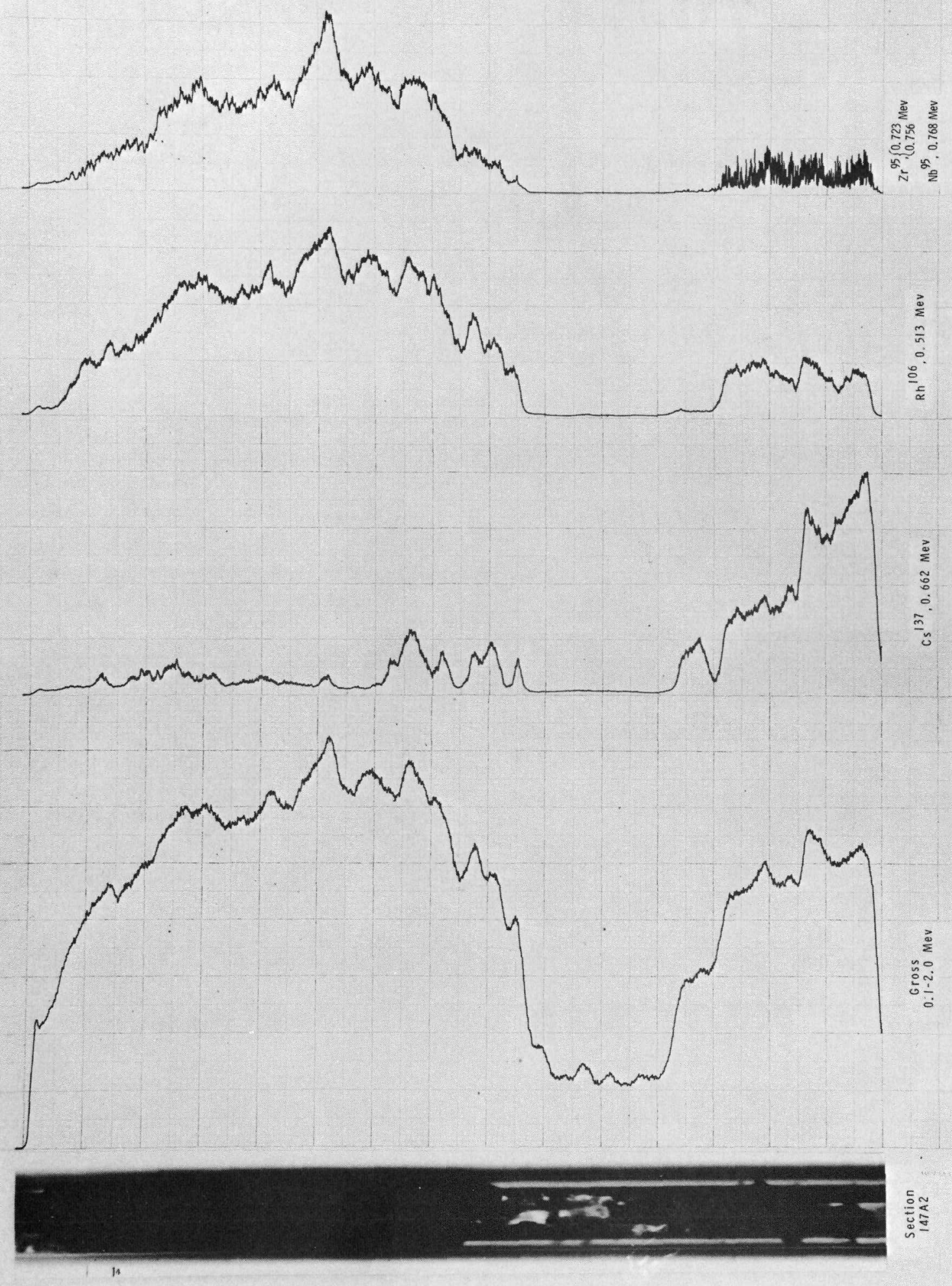

Fig. 36. Gamma Spectrometry of Section 147A2a. Neg. No. MSD-188534. 


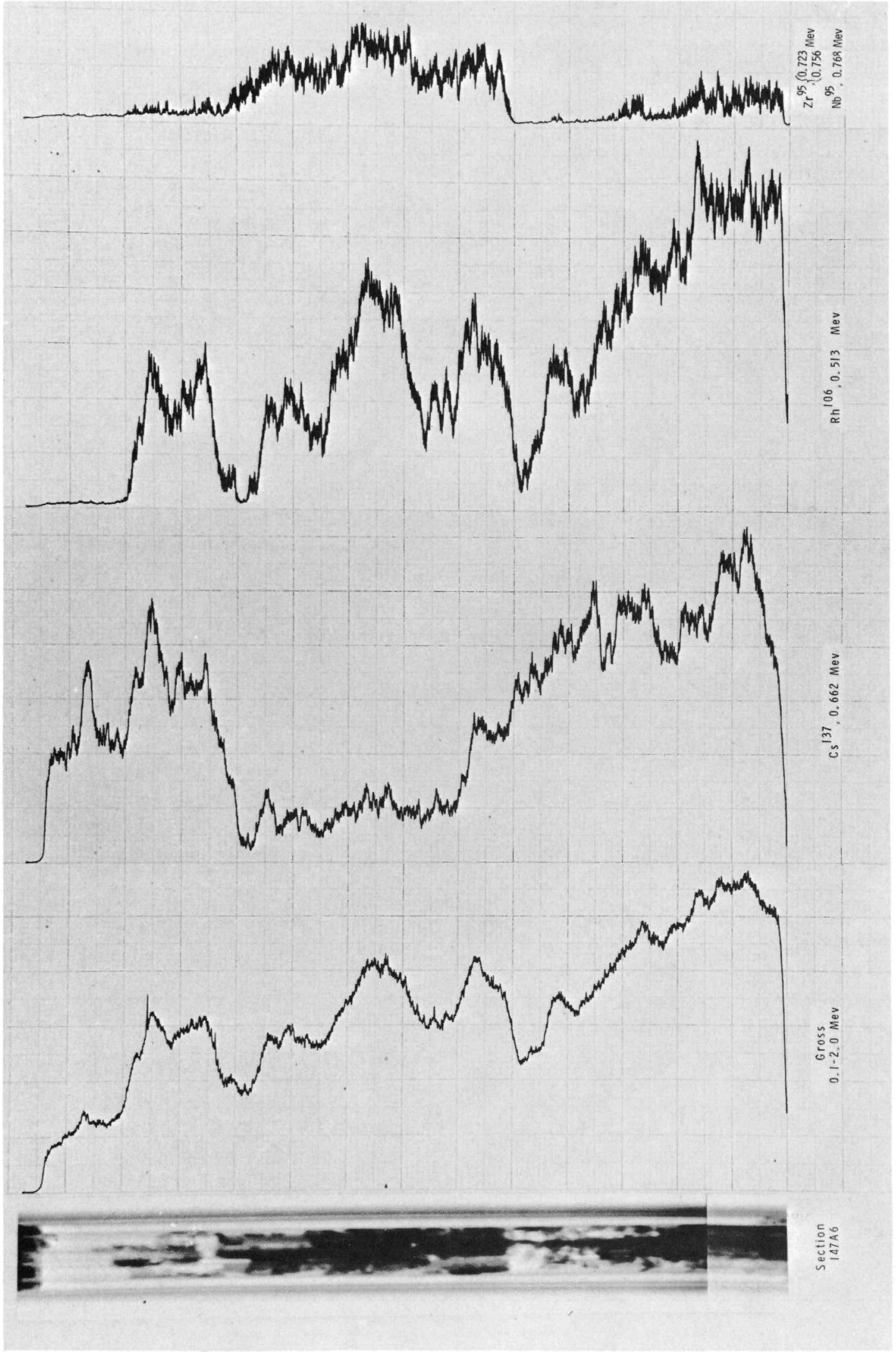

Fig. 37. Gamma Spectrometry of Section 147A6. Neg. No. MSD-188535. 
O

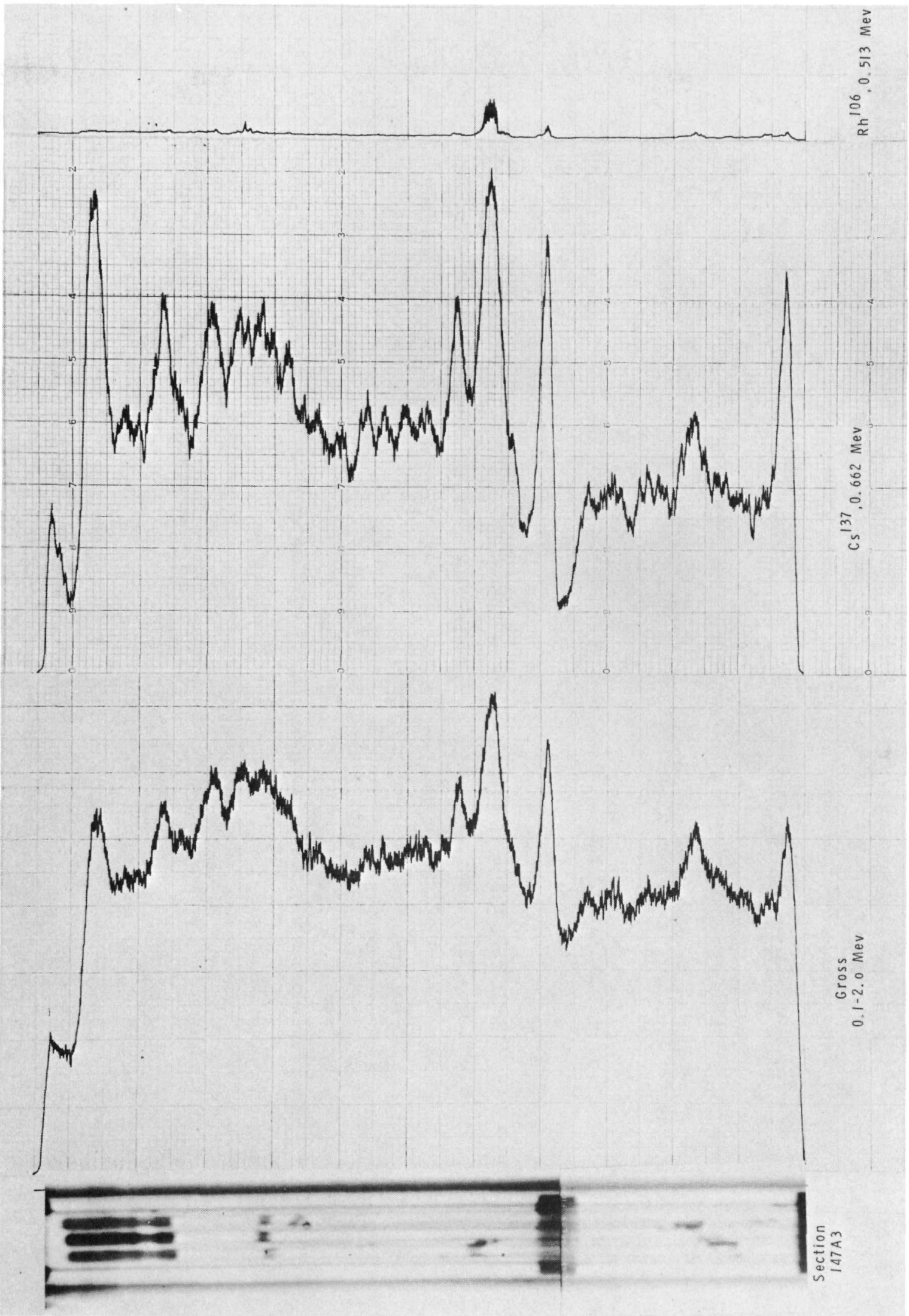

Fig. 38. Gamma Spectrometry of Section 147A3. Neg. No. MSD-188430. 

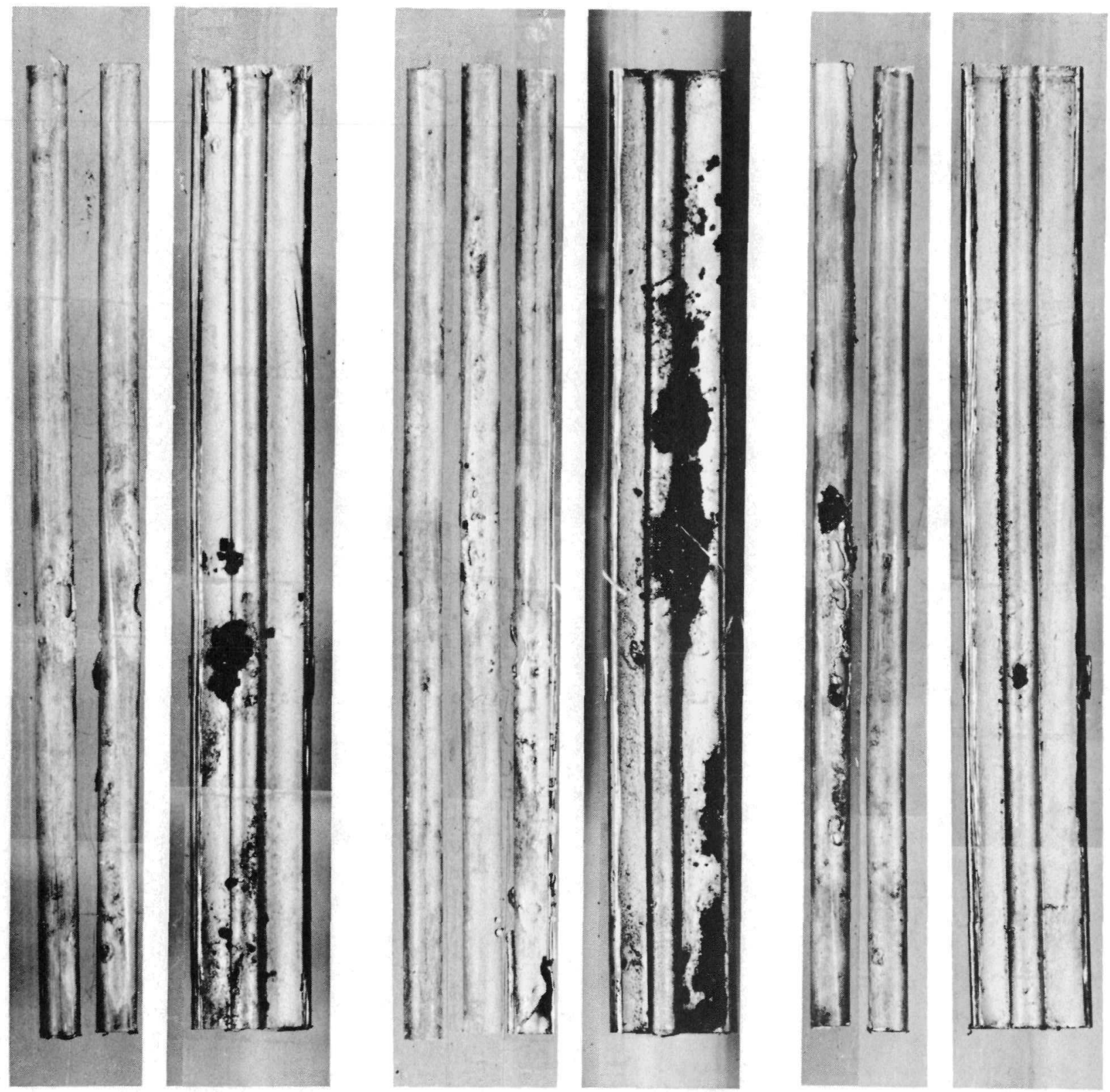

Fig. 39. Section 147A12 with Melted Cladding and Melted Fuel. Mag. 1X. Neg. No. MSD-188435. 


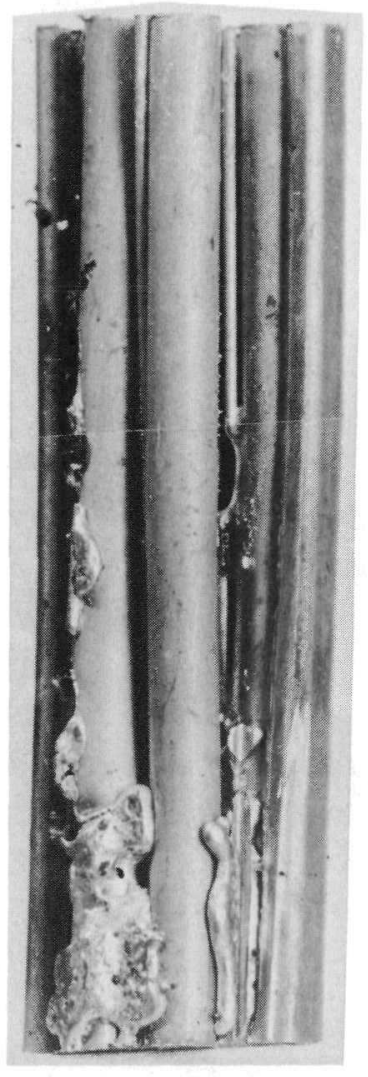

Fig. 40

Section 147A6a, Showing Melted Steel Binding Elements Together. Mag. 1X. Neg. No. MSD-184384.
The loop wall could not be removed from section $147 \mathrm{~A} 2 \mathrm{a}$. Therefore this $390-\mathrm{mm}$ section was cut $230 \mathrm{~mm}$ from the top and through the upper part of the fuel region partly emptied of fuel on the neutron radiograph. The upper piece was designated $147 \mathrm{Al} 0$, and the remainder (in Fig. 33, including 147A 13, 147A14, $147 \mathrm{Al} 7$ and 147A18) became 147A2b. The fluted tube and its contents were easily separated from the loop tube and the adiabatic tube of section 147A2b.

The loop wall could not be slipped from section 147A10. The loop wall was therefore cut through on opposite sides in the axial direction in the plane of the pump. Half the loop wall came off fairly easily, revealing a hole in the adiabatic tube and some melted steel on the loop wall opposite the hole. A similar hole was also observed when the other half of the loop wall was pried off.

After the loop tube was removed from 147Al0, the section, which appeared to contain most of the fuel, was cut into small pieces for examination, as shown in Fig. 34. These pieces were

cleaned with an alcohol-water mixture to remove sodium, and mounted in epoxy for further examination. As noted on the sectioning schematic (Fig. 33), other small pieces were cut from other parts and similarly prepared. During the preparation of the small pieces, particles of fuel and steel frequently become detached. These remains were identified by section and saved.

After section 147Al was gamma-scanned, the pins holding the elements in place were removed, and the element sections were separated and identified. During this operation, the bellows portion of the adiabatic tube of this section was observed to have collapsed locally at the bottom.

Subsequently, the top sections of the elements from section 147A3 were taken apart to check on the springs. Sodium was found on the springs from elements PNL-10-7, $-8,-28$, and -34 . 
C. Examination Results

Metallographic examination and various measurements were made of the disassembled test train in some detail. The results are presented in this section.

\section{Extent of Melting}

Melthrough of the adiabatic tube occurred only at two local spots. One location was $38 \mathrm{~mm}$ below the top of the original fuel columns near elements PNL-10-28 and -34, about $120^{\circ}$ counterclockwise from the pump as viewed from above. The second location was $20 \mathrm{~mm}$ below the first, near element PNL-10-7, about 90 clockwise from the pump. These melthroughs were irregular in shape and about $5 \mathrm{~mm}$ across. Melted steel from both meltthroughs impinged on the loop wall and fused to it. Figure 41 shows a section through the hole in the adiabatic tube at each location. Fuel is present on the inside of each penetration. Complete melting of the flow tube had occurred. Small amounts of fuel were associated with the steel fused to the loop wall. Some fuel may have been removed during disassembly and removal of the sodium.

Complete melting of the flow tube had occurred from about $13 \mathrm{~mm}$ below the original tops of the fuel columns to $105 \mathrm{~mm}$ farther down the fuel columns. Partial melting of the flow tube occurred for another $105 \mathrm{~mm}$ downward to somewhat below the midpoint of the fuel columns and upward for $85 \mathrm{~mm}$ to the midlength of the original stacks of insulator pellets. The rest of the flow tube above and below these locations was intact.

The examination revealed that the cladding and spacer wires of the fuel elements completely melted from about $25 \mathrm{~mm}$ above the original top of the fuel columns down to about $50 \mathrm{~mm}$ below the middle of the fuel columns. In addition, partial melting occurred for about $230 \mathrm{~mm}$ upward to the middle of the length of the reflector rods (see Fig. 39) and downward to within $13 \mathrm{~mm}$ of the bottom of the fuel columns. At the bottom of the fuel columns, the partial melting of the claddings of the peripheral elements tended to occur on the side toward the center of the cluster (see Fig. 42). Where cladding melting occurred in the region of the insulator pellets and reflector rods, melting was often on the outside of the cluster (see Fig. 43).

All the fuel in the upper two-thirds of the fuel columns appears to have melted. Even in the bottom third of the fuel columns, pellets had melted in the center, practically down to the bottom of the fuel column. Large central voids were evident in some of the pellets (see Figs. 42 and 44). 


\section{○}

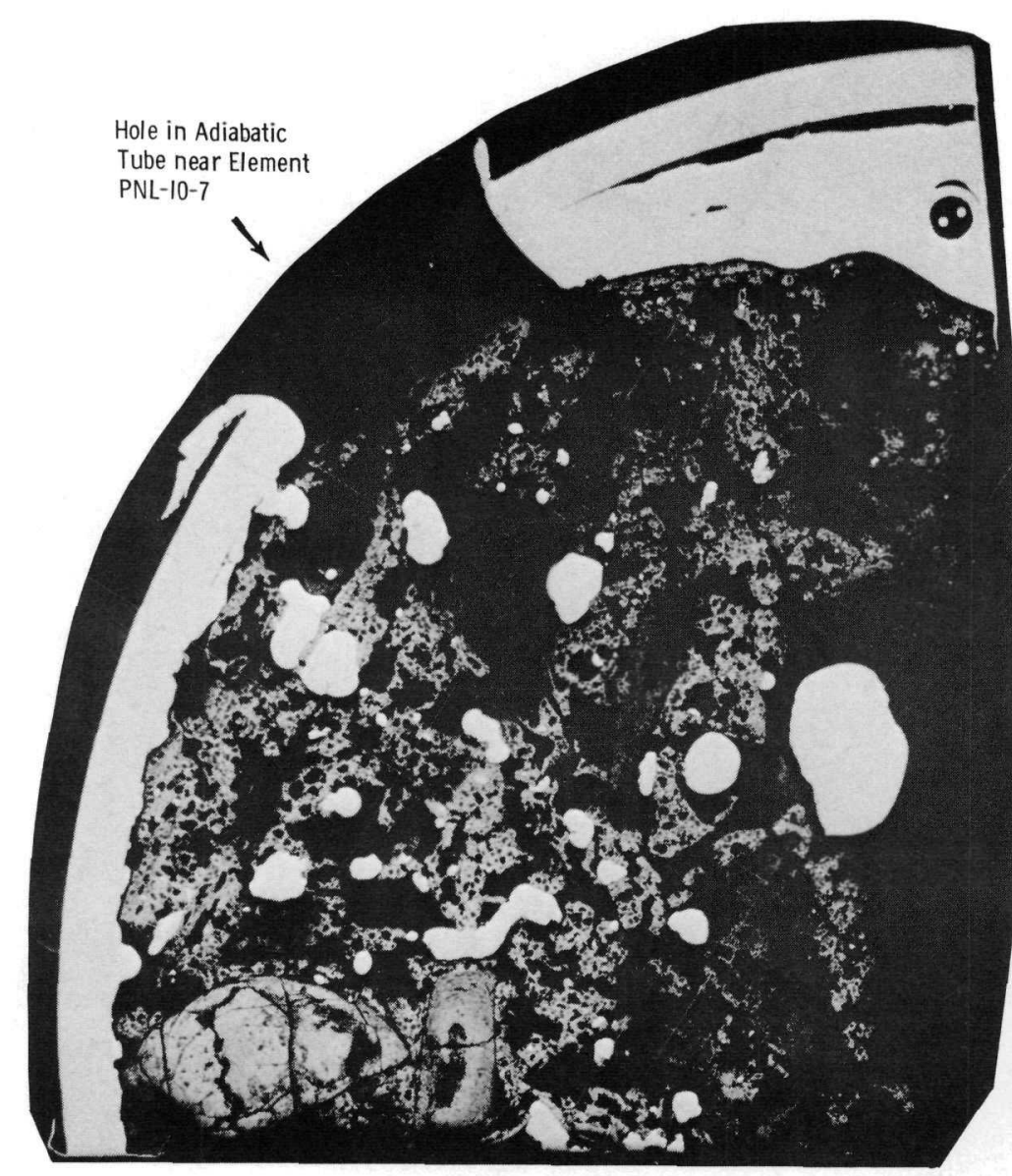

Section I47A2I

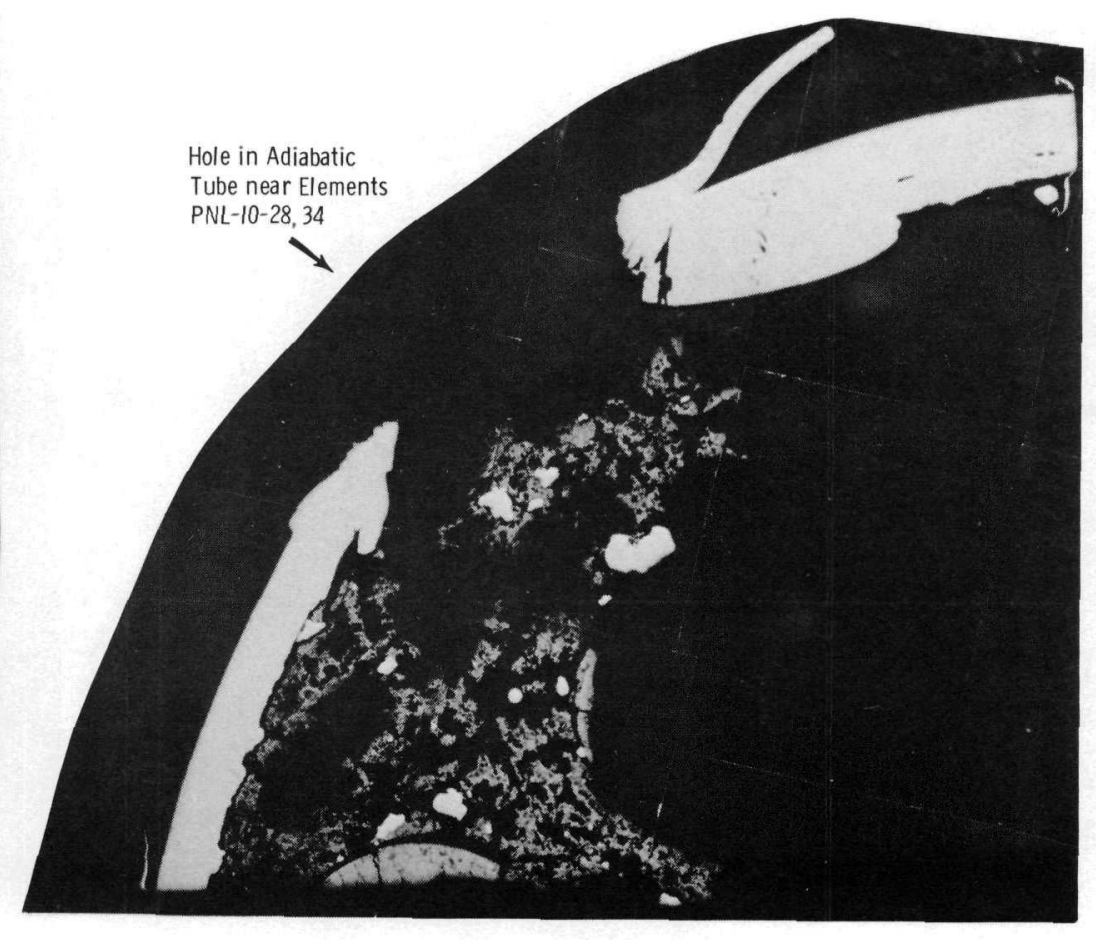

Section $147 \mathrm{~A} 22$

Fig. 41. Sections through Adiabatic-tube Wall, Showing Penetrations and Fuel on the Interior. Mag. 7-1/2X. Neg. No. MSD-188536. 


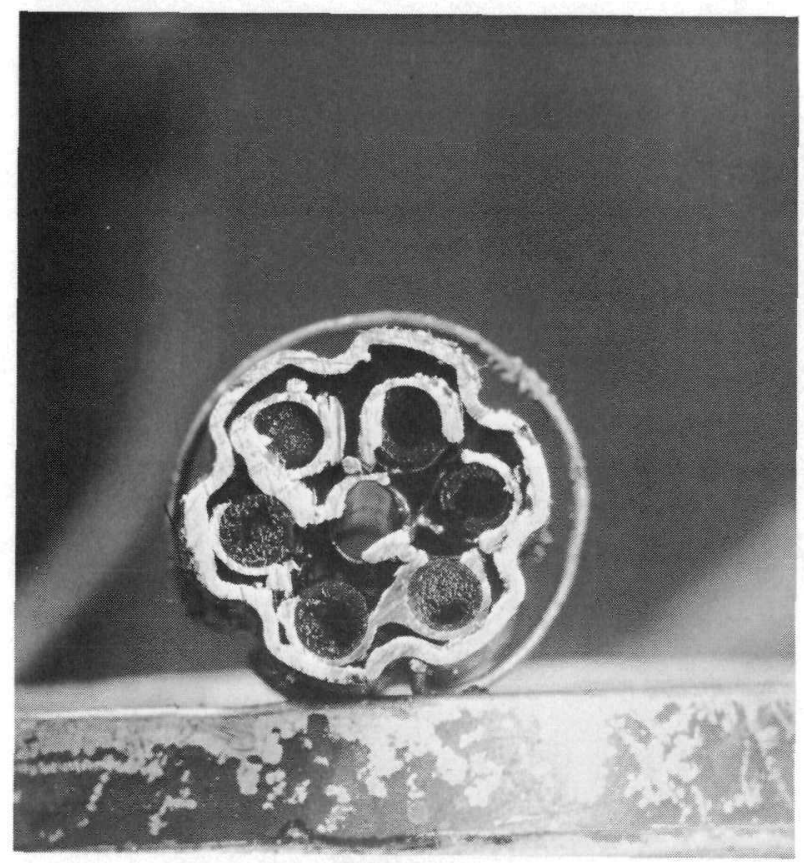

Fig.42. Melting of Cladding toward Interior of Cluster. Top view of section 147A2b. Mag. 1-3/4X. Neg. No. MSD-184455.

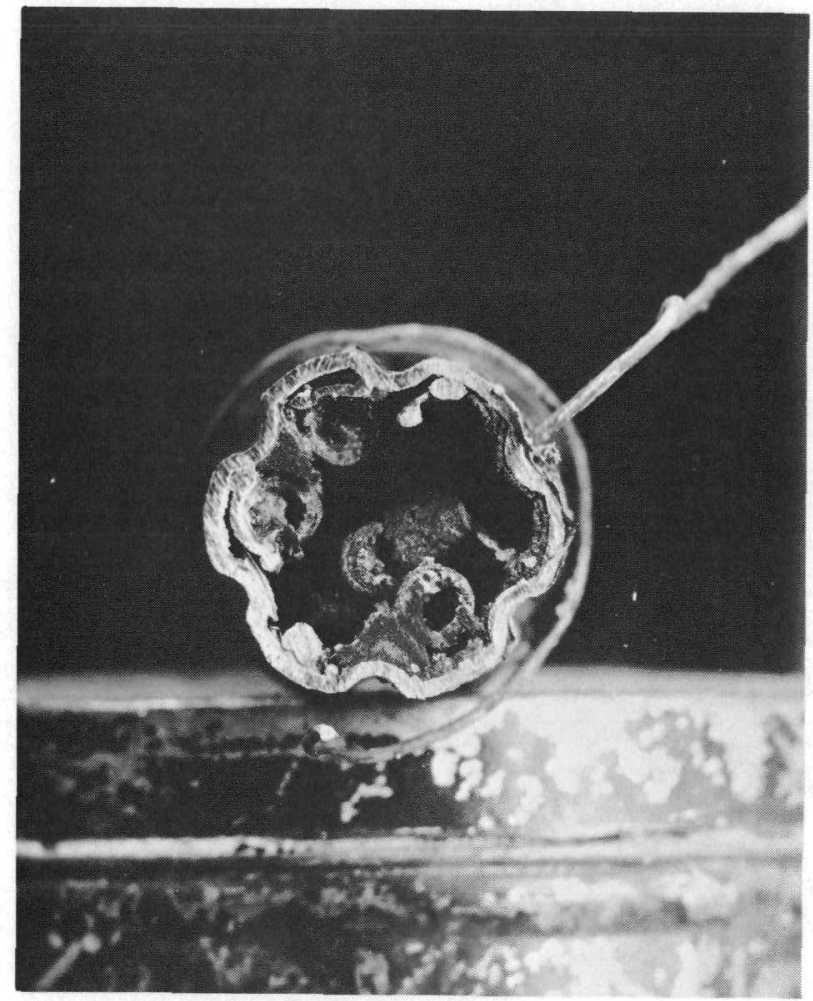

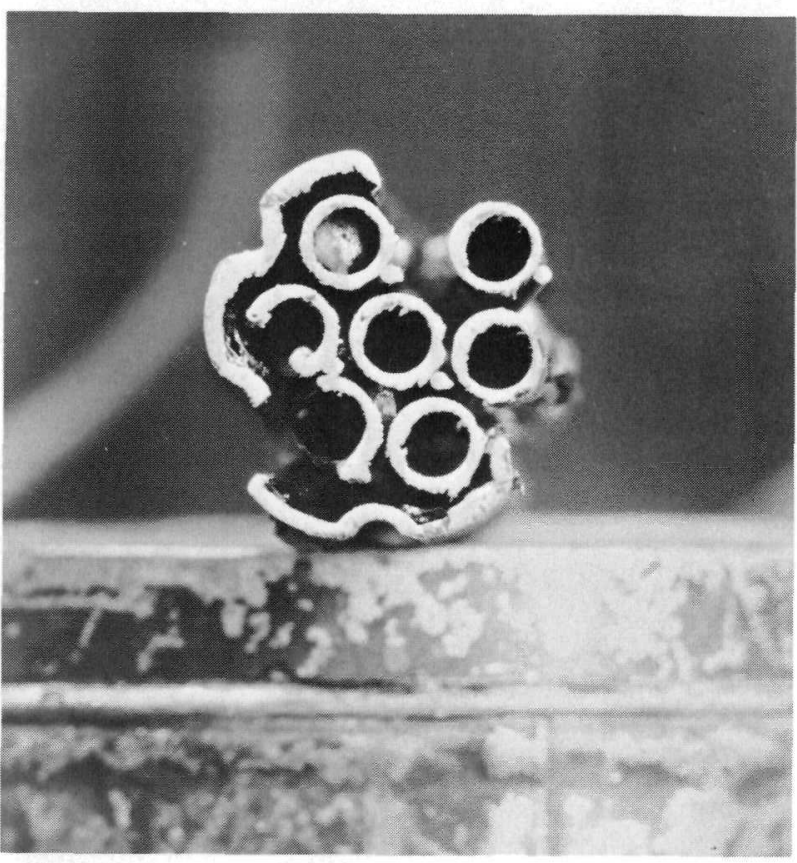

Fig. 43. Melting of Cladding toward Outside of Cluster. Top view of section $147 \mathrm{~A} 6 \mathrm{a}$ with part of flow tube removed. Mag. 1-3/4X. Neg. No. MSD-184462.

Fig. 44

Center Melting in Fuel Pellets at Top of Section 147A14. Mag. 1-3/4X.

Neg. No. MSD-184123. 
2. Distribution and Character of Fuel

Very little fuel was found below the bottoms of the original fuel columns. As noted in the discussion of the neutron radiograph (Sec. VI.A), a small amount of neutron-absorbing material appeared to be present in the bottom bend of the loop on the side of the test section. This section of the loop was not available for examination, but, based on experience with other E-, $\mathrm{H}-$, and L-series tests, the material probably consisted of small particles of melted steel and fuel. The neutron radiograph of the section $147 \mathrm{Al}$ containing the bottom parts of the fuel elements indicated a few dark areas that were shown to contain fission products by gamma scanning (see Fig. 35) and were presumably fuel. Some of the small dark areas that did not register in the gamma scans were presumed to be particles of melted steel. A minor concentration of fuel appeared to be present on the header joining the adiabatic tube to the flow tube, and for a short distance above the header. This material was disturbed during disassembly, and its nature was not further verified. Some fission products were generated in the insulator pellets during the EBR-II irradiation.

Gamma scanning of section 147A2a (Fig. 36), which held the original fuel-column region, essentially confirmed the evidence of the neutron radiograph. Some fuel existed at the bottom of the fuel region for a height of $83 \mathrm{~mm}$. The fuel retained the semblance of stacks of pellets on the neutron radiograph.

Sectioning of piece 147A2a proceeded as indicated in Fig. 33. The fuel-pellet stacks were indeed partly intact toward the bottom of the section, but central melting of the fuel pellets had occurred. Figure 42 shows a transverse section through the fuel region about $25 \mathrm{~mm}$ from the bottom of the fuel columns, and Fig. 44 shows a similar section about $75 \mathrm{~mm}$ from the bottom. In Fig. 42, central melting had occurred in most of the peripheral elements, but the center element had no fuel at all. Central melting also occurred in the pellets of Fig. 44, and a pellet near the center lies on its side. This latter pellet could either be fuel or an insulator.

Debris from sections 147A13, 147Al7, and 147Al8 combined, and also from section 147A14, is shown in Figs. 45 and 46. More material appears to have been recovered from section 147Al 4 than from the other three sections combined. This is a verification of the evidence of the neutron radiograph, which showed that fuel had moved away from the region represented by sections 147A13, 147A17, and 147A18. The debris recovered consisted of almost whole pellets and large pieces along with some melted steel. The debris from section 147Al4 contained very little melted steel and much broken pellet material, mostly fuel, but some insulator material, in quite small pieces. Two pieces of spacer wire were also recovered from section 147Al4. Coolant flow through the bottom part of the fuel column does not appear to have been obstructed by much blocking material. 


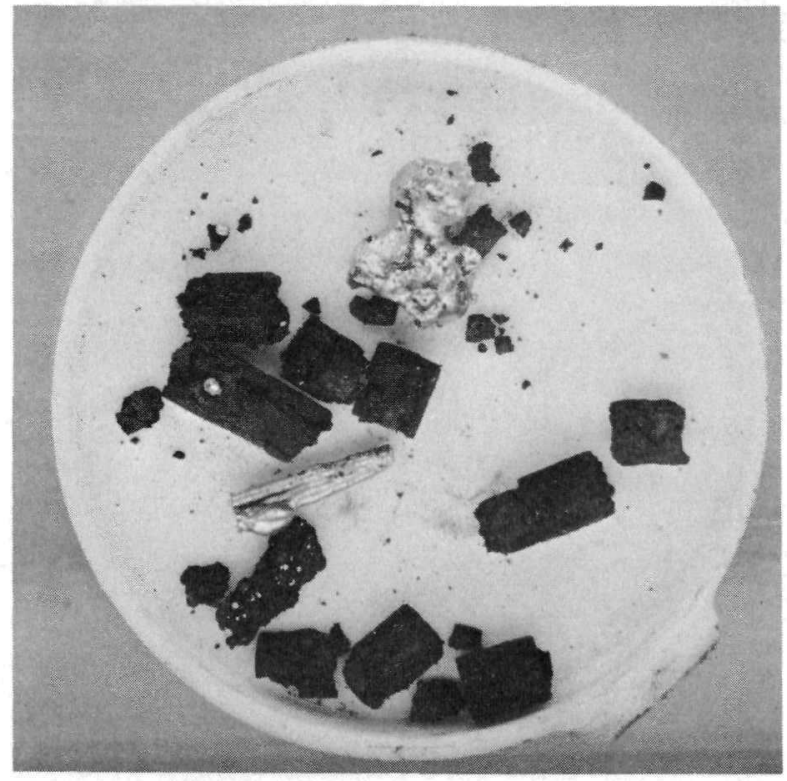

Fig. 45. Debris from Sections 147A13, 147A17, and 147A18. Mag. 1.4X. Neg. No. MSD-154257.

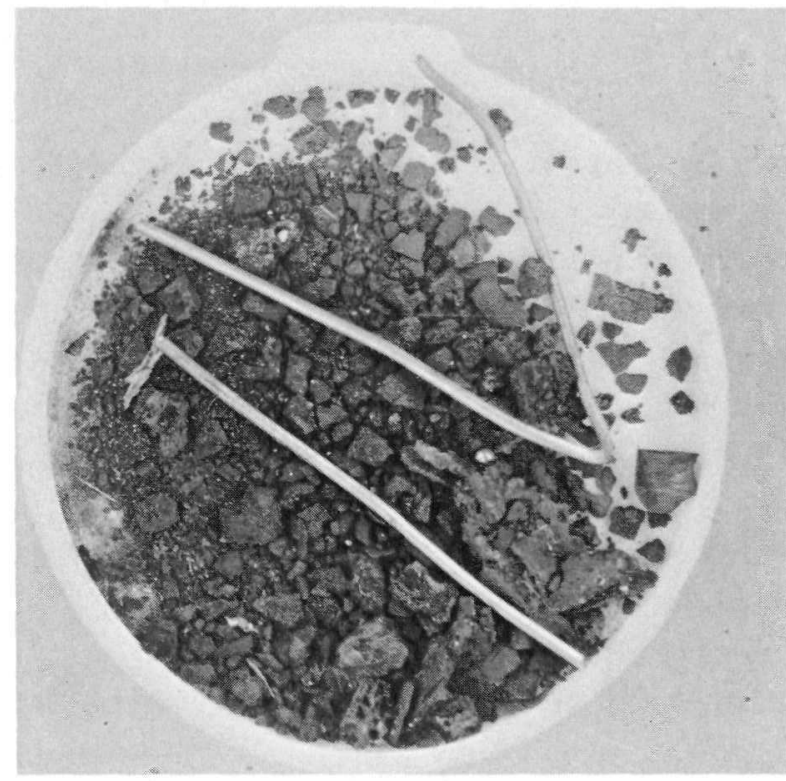

Fig. 46. Debris from Section 147A14. Mag. 1.4X. Neg. No. MSD-184471.

Section 147Al3 was located about $90 \mathrm{~mm}$ from the bottom of the fuel stack. Most of the fuel in this section fell out during cleaning with an alcohol-water mixture to remove sodium (see Fig. 45). The segment was at the bottom of the region that, according to the neutron radiograph, lost fuel. Some spongy, once-molten fuel had solidified against the inside of the flow tube. Very little melted steel was present in this section, either by itself or mixed in the fuel.

Sections through the top of the region deficient in fuel are shown in Figs. 47 (147AlOL and 147A29R) and 48 (147Al0). This region was about $150 \mathrm{~mm}$ from the bottom of the fuel column. Some fuel adhered to the wall of the flow tube, and some globules of melted steel are present.

The greater part of the fuel appears to have ended up in the region of the upper half of the original fuel column (section 147Alo of Fig. 33). All fuel in this region appeared to have melted. Section 147Alo was cut into both transverse and longitudinal sections as shown in Fig. 34. Photographs of some of these are shown in Figs. 47 and 48. A blockage to the flow of coolant existed in this region of melted fuel, insulator pellets, and some melted steel. Although the melted fuel was spongy and small voids were present, connected channels through the relatively dense, $190-\mathrm{mm}-1$ ong, fuel-bearing region did not appear to be present. 

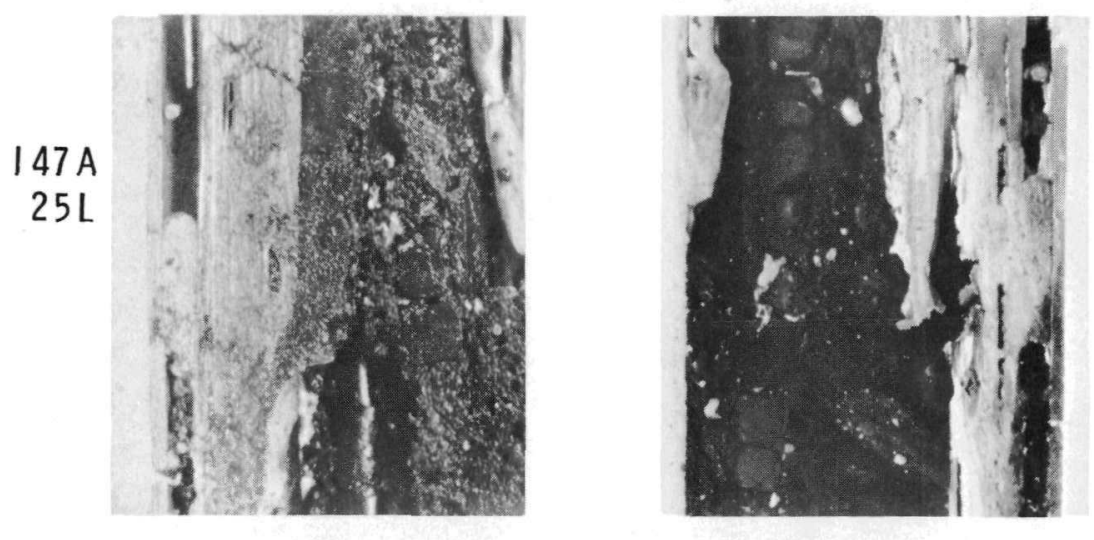

$147 \mathrm{~A}$
$26 \mathrm{R}$

Original

Top of Fuel

Columns
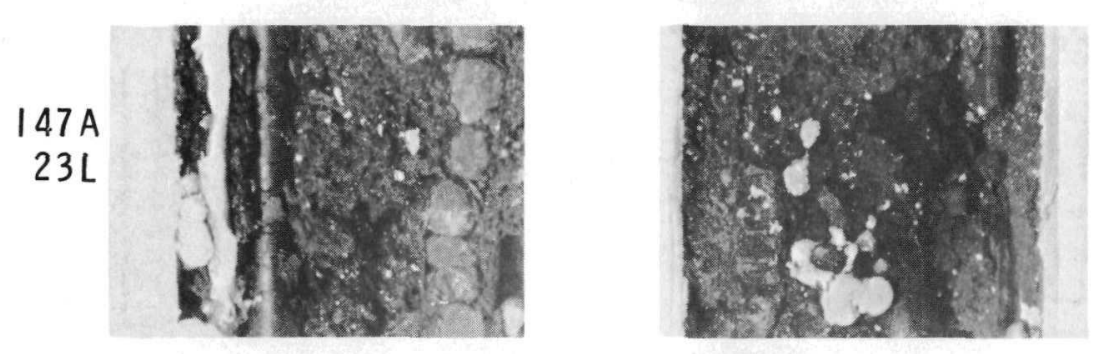

\section{$147 \mathrm{~A}$}

$27 R$
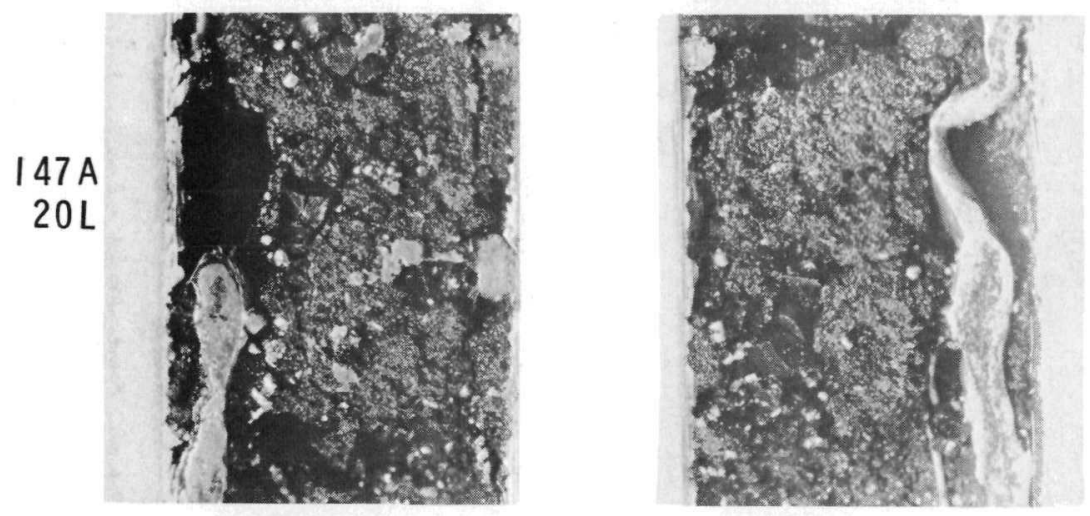

$147 \mathrm{~A}$

$28 \mathrm{R}$

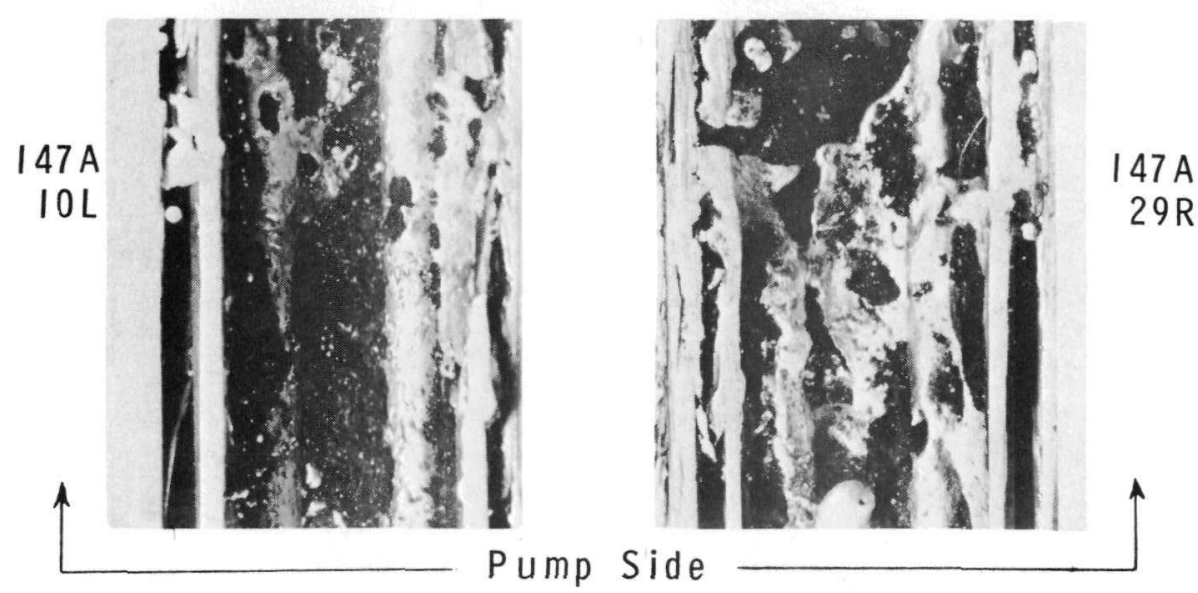

Fig. 47. Longitudinal Sections from Segment 147A10 after Cleaning. Mag. 1.3X. Neg. No. MSD-188434. 

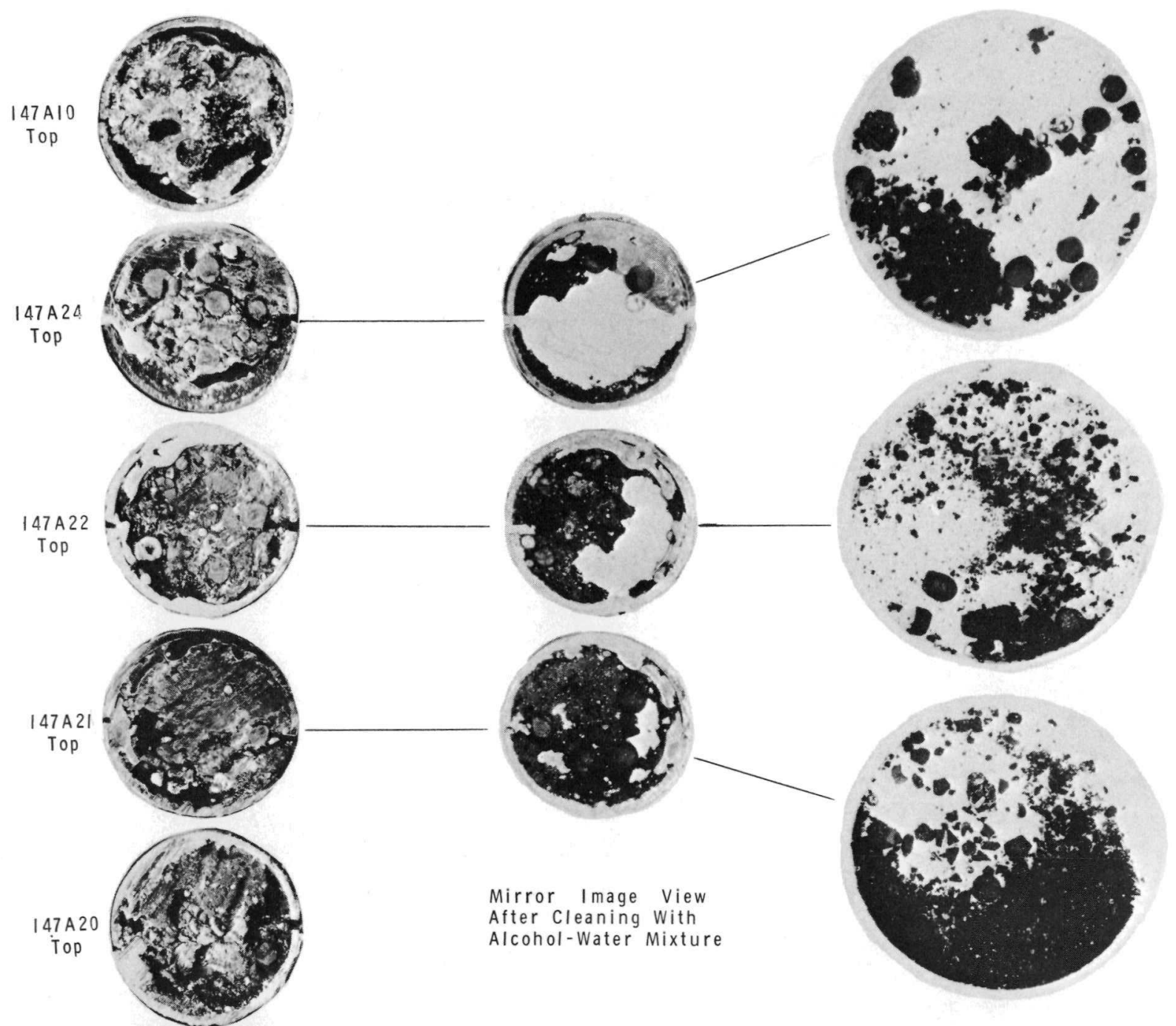

Mirror Image View

After Cleaning With Alcohol-Water Mixture
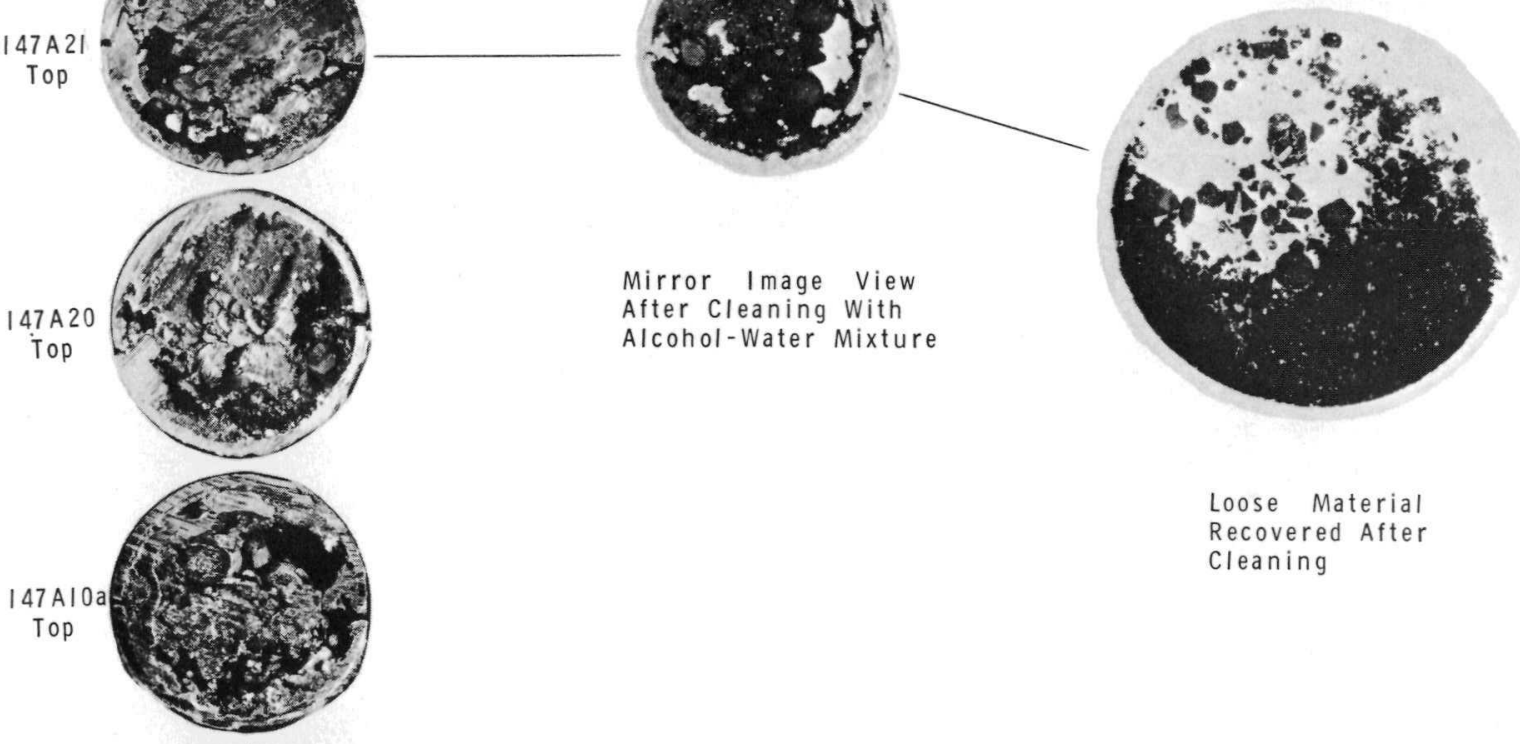
Loose Material
Recovered After
Cleaning

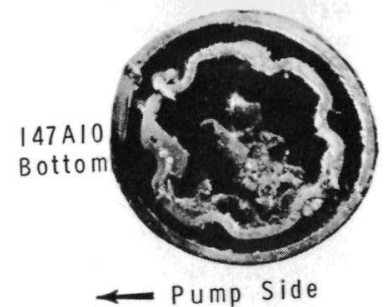

As Cut Section

Fig. 48. Transverse Sections and Some Debris from Segment 147A10. Mag. 0.9X. Neg. No. MSD-188431. 
A transverse section through the region about $16 \mathrm{~mm}$ below the original top of the fuel columns is shown in Fig. 49. Because of size limitations of the metallograph, quarter sections were examined. The missing quarter section broke up during cleaning in preparation for mounting. The three quarter sections shown are bounded by the adiabatic tube. About a quarter section of partly melted flow tube is evident. Insulator pellets and spongy melted fuel occupy most of the cross section, although some large globules of melted steel are present. Figure 50 is an enlargement of a globule of steel in the upper left quadrant of Fig. 49. With the larger globules of steel, a shrinkage gap with respect to the fuel is generally evident from the differential thermal contraction on cooling.

Quarter sections showing the character of the fuel have also been presented in Fig. 41 (sections $147 \mathrm{~A} 21$ and 147A22). The spongy nature of fuel, globules of melted steel, and some insulator pellet material are evident.

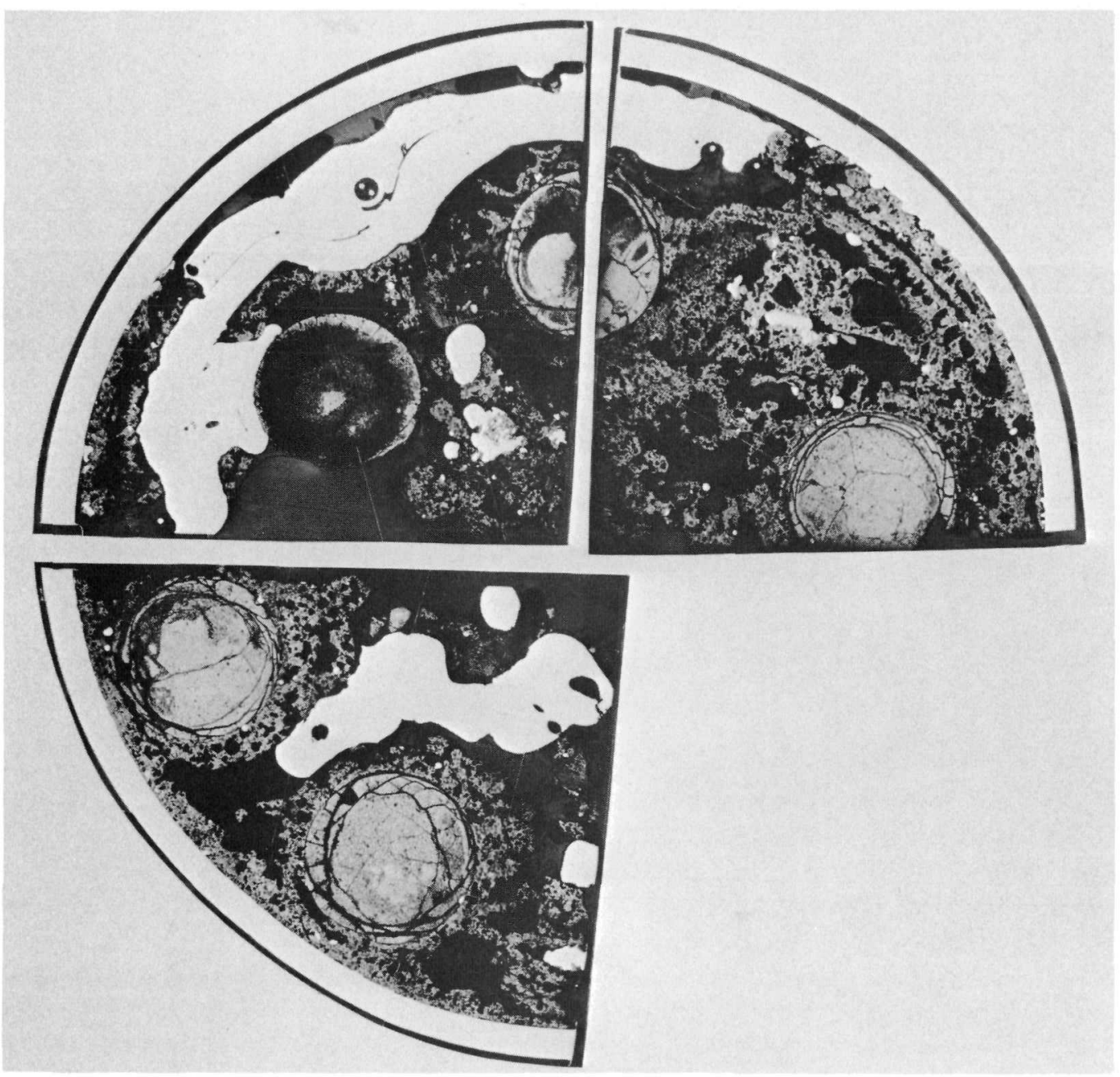

Fig. 49. Transverse Section through Fuel Region about $1.6 \mathrm{~cm}$ below Original Top of Fuel Columns. Sections 147A39L and 147A46R. Neg. No. MSD-185659. 


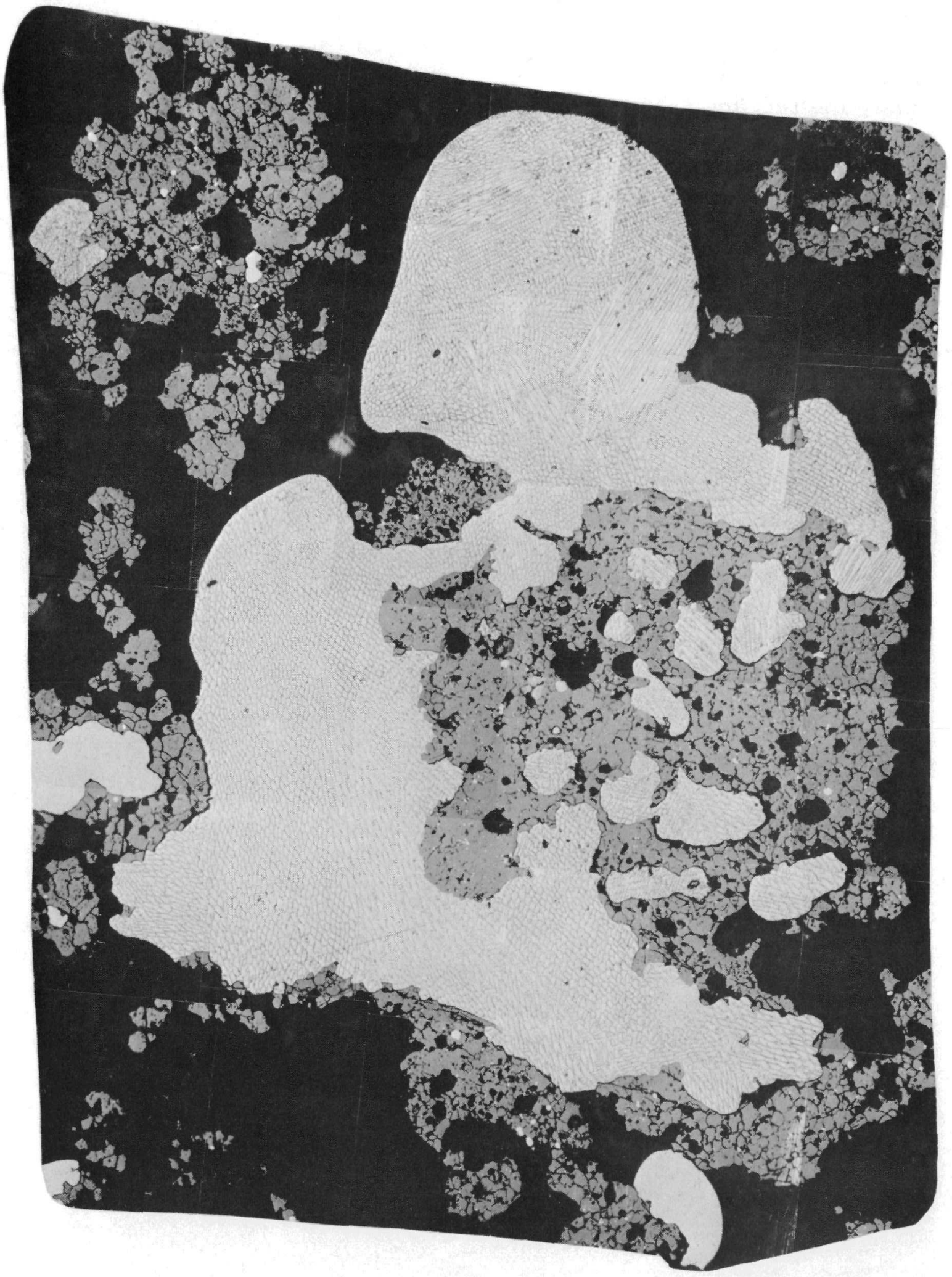

Fig. 50. Melted Steel in Melted Fuel. Section 147A39L. Mag. 85X. Neg. No. MSD-188400. 
A typical region of fuel also had a fine dispersion of steel particles as shown in Fig. 51, an 180X magnification photograph of section 147A40L.

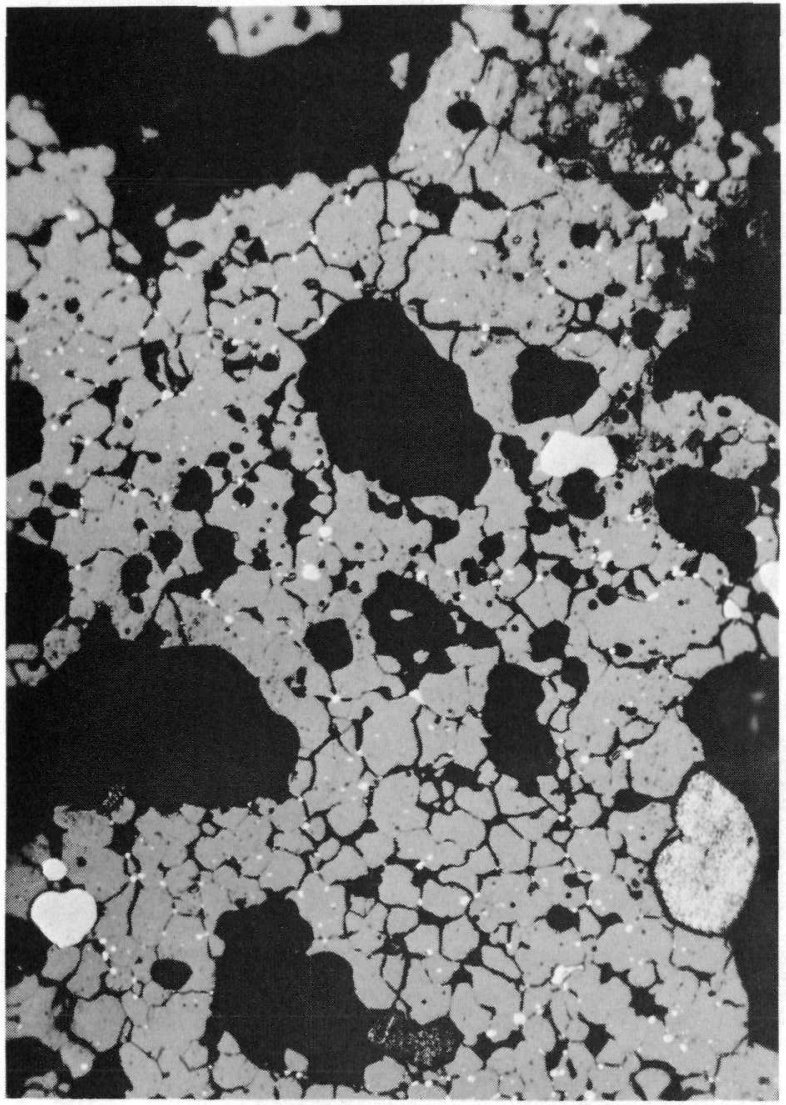

Fig. 51. Typical Melted Fuel Region with Globules of Stainless Steel. Mag. 180X. Neg. No. MSD-186139.
Above the original tops of the fuel columns, melted steel became more prominent, although considerable fuel was also present. A gamma scan of section 147A6 is shown in Fig. 37. The blockage to flow of coolant above the original tops of the fuel columns extended for about $115 \mathrm{~mm}$, and consisted of a steel blockage on the side toward the pump and a fuel blockage among the insulator pellets on the side away from the pump. Channels for coolant flow may have existed in this region. The steel blockage occupied as much as half of the cross section within the flow tube. Figure 52 is a transverse cross section (of section 147A7 in Fig. 33) from about a third of the way up the stack of insulator pellets. Only two intact insulator pellets are present. Three others may have become dislodged during disas sembly and cleaning. Two places where insulator pellets should have been are partly occupied by melted steel, indicating that these locations (of elements PNL-10-8 and -10) were vacated during the test. Melted fuel seems to have collected preferentially on the side toward the pump at this location.

\section{Fig. 52}

Transverse Section through Insulator-pellet Region. Section 147A7. Mag. 3X. Neg. No. MSD-187271.

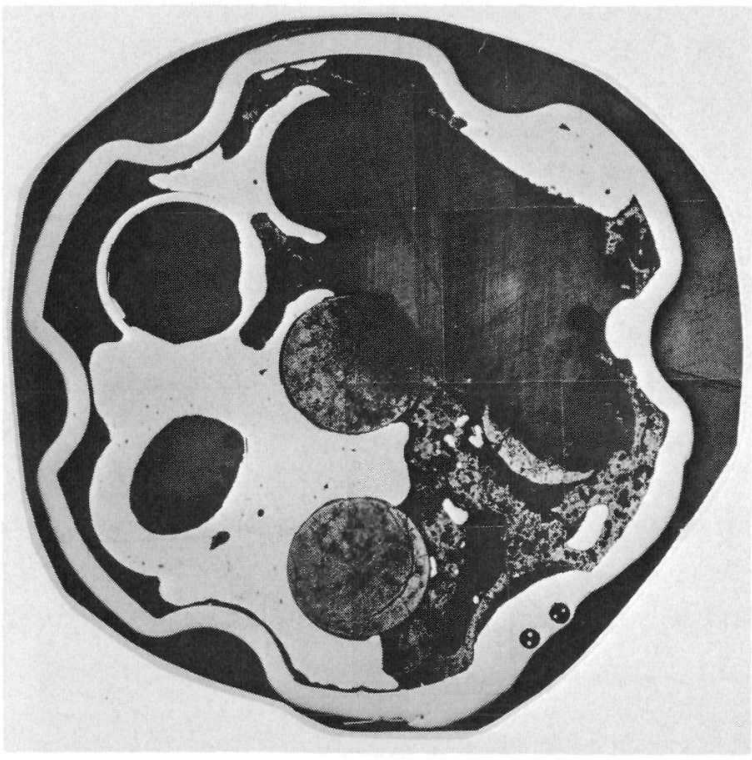


Fuel was present in considerable quantity up to the reflector-rod region, where it adhered mostly to the inside of the flow tube. This fuel, which had been molten, had resulted in local meltthrough of the cladding over the reflector rods (Fig. 39). Some small metallic globules, probably stainless steel, were evident in this fuel, as shown in Fig. 53.

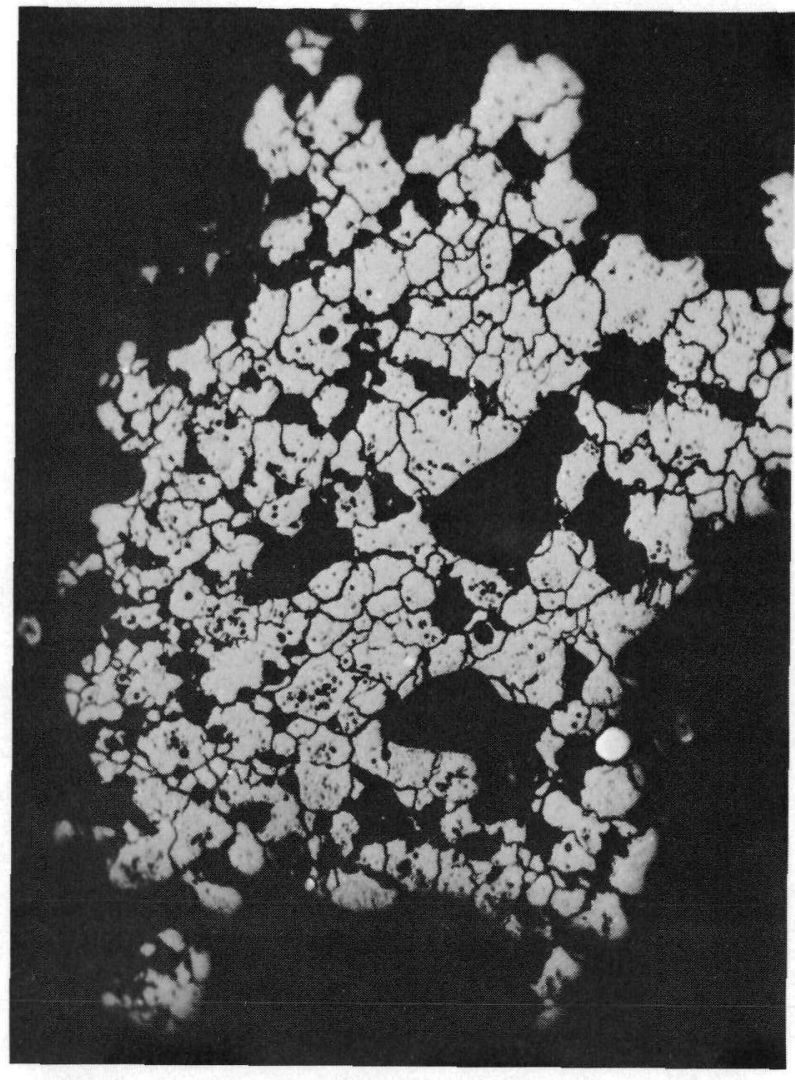

Fig. 53. Steel Globules in Melted Fuel from Upper Reflector-rod Region. Mag. 173X. Neg. No. MSD-187878.
Above the reflector-rod region, some scattered deposits of fuel were present, as indicated by the gamma scan of Fig. 38 for section 147A3. Some fuel is associated with the header. The presence of fuel on the header joining the upper end of the adiabatic tube to the flow tube was verified. The gamma spectrography of sections $147 \mathrm{~A} 6$ and $147 \mathrm{~A} 3$ indicates that some of the ${ }^{137} \mathrm{Cs}$ gammas may be associated with sodium rather than fuel deposits.

\section{By weight, $11 \mathrm{~g}$ of fuel}

was recovered from above the midsection of the insulator-pellet stacks. An additional $5 \mathrm{~g}$ was estimated as adhering to components in this part of the test train. In the first $76 \mathrm{~mm}$ above the original top of the fuel columns, 10-15 $\mathrm{g}$ of fuel was estimated to be among the insulator pellets and melted steel. These estimates attempted to make allowance for the porosity of the fuel, steel included with the fuel, and insulator-pellet material as judged from photographs of surfaces exposed in this region.

\section{Distribution of Melted Steel}

The melted steel came from the flow tube and from the cladding and wire wrap on the elements. Little of the melted steel remained below about the midlength of the original fuel section. However, a rather large globule of steel was present in the debris (see Fig. 45) of sections 147Al3, 147Al7, and $147 \mathrm{Al}$, and some melted steel is evident in the longitudinal section of $147 \mathrm{Al}$ (0 L and 147A29R of Fig. 47. Small globules of melted steel are dispersed throughout the melted fuel. Most of the melted steel appears to have been pushed up above the fuel column, where it occupied as much as half the cross section of the fluted tube on the side toward the pump for about $102 \mathrm{~mm}$. 


\section{4. $\mathrm{UO}_{2}$ Insulator Pellets}

The sections of the fuel elements containing the bottom stacks (540 mm long) of $\mathrm{UO}_{2}$ insulator pellets were checked for balance point after removal from segment $147 \mathrm{Al}$ and cleaning. All elements except PNL-10-54 had balance points $285-292 \mathrm{~mm}$ away from the bottom end. The balance point for PNL-10-54 was at $267 \mathrm{~mm}$, indicating that it was this element in which the insulator pellets had moved upward.

Eddy-current examinations of the bottom sections of the elements were used in an attempt to show the location of the gaps in the stack of insulator pellets of PNL-10-54. This technique was not successful. The eddy-current traces for these bottom sections of the elements did show various degrees of irregularity, from no wiggle to conspicuous wiggles, toward the top of the sections. The irregularities were interpreted as being due to sodium that had gained entry after the failure of the elements.

The results from gamma-scans of the individual bottom sections of the elements given in Fig. 54 show gaps in the stack of insulator pellets of PNL-10-54, the center element. Six gaps appeared to range in length from 10 to $83 \mathrm{~mm}$. These gaps did not have one-to-one correspondence with the gaps on the neutron radiograph, indicating that these pellets were probably loose. This section was cut into two pieces through one of the larger gaps, and a probe indicated that pellets could be moved.

On the basis of the overall length of the gaps, as many as 20 insulator pellets may have moved up into the fuel region. Their final resting place was not determinable, but some pellets were recovered from section 147Al3.

The gamma-ray activity in the bottom section of the six peripheral elements increases from bottom to the top. This activity appears caused by fissioning during the EBR-II irradiation. The high plateau toward the bottom of the gross scan of the PNL-10-53 (see Fig. 54) is due to ${ }^{60}$ Co activity in the Inconel 600 reflector.

The upper insulator pellets had all moved downward toward the fuel region, leaving gaps between the reflector rods and the tops of the stacks of $\mathrm{UO}_{2}$ pellets. The gap for PNL-10-8 was measured at about $25 \mathrm{~mm}$. The other gaps appeared to be smaller, but were not determined. At least five of the stacks of insulator pellets extended well into the fuel region, as shown in Figs. 47 and 48. Pellets of $\mathrm{UO}_{2}$ were observed as much as $108 \mathrm{~mm}$ below the top of the original fuel-column region. The insulator pellets are readily distinguishable because they show practically no evidence of melting and are extensively cracked on the peripheral regions from the thermal shock. 


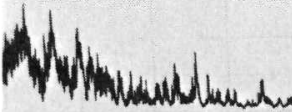

III)

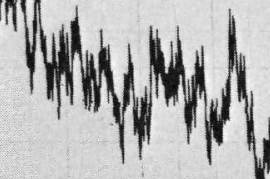

no

Whadum dula

톻ํㅎำ

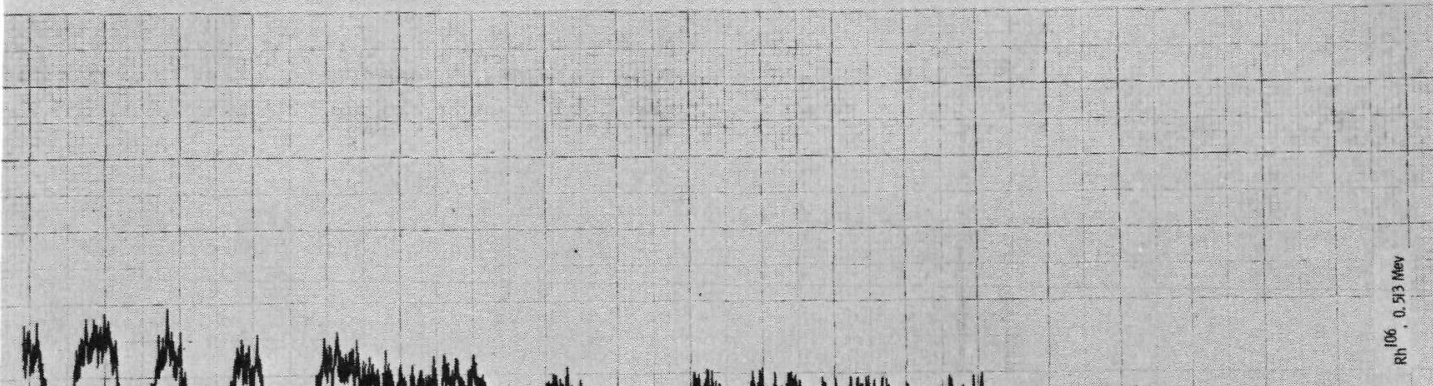

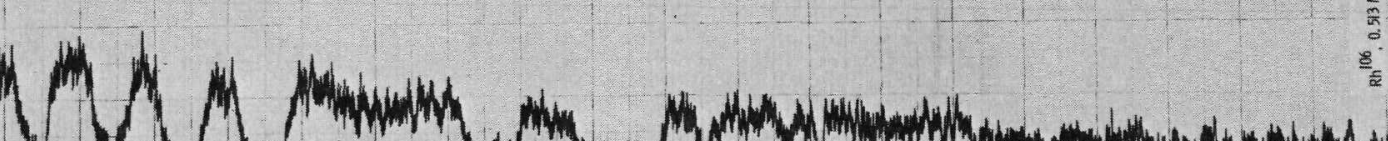

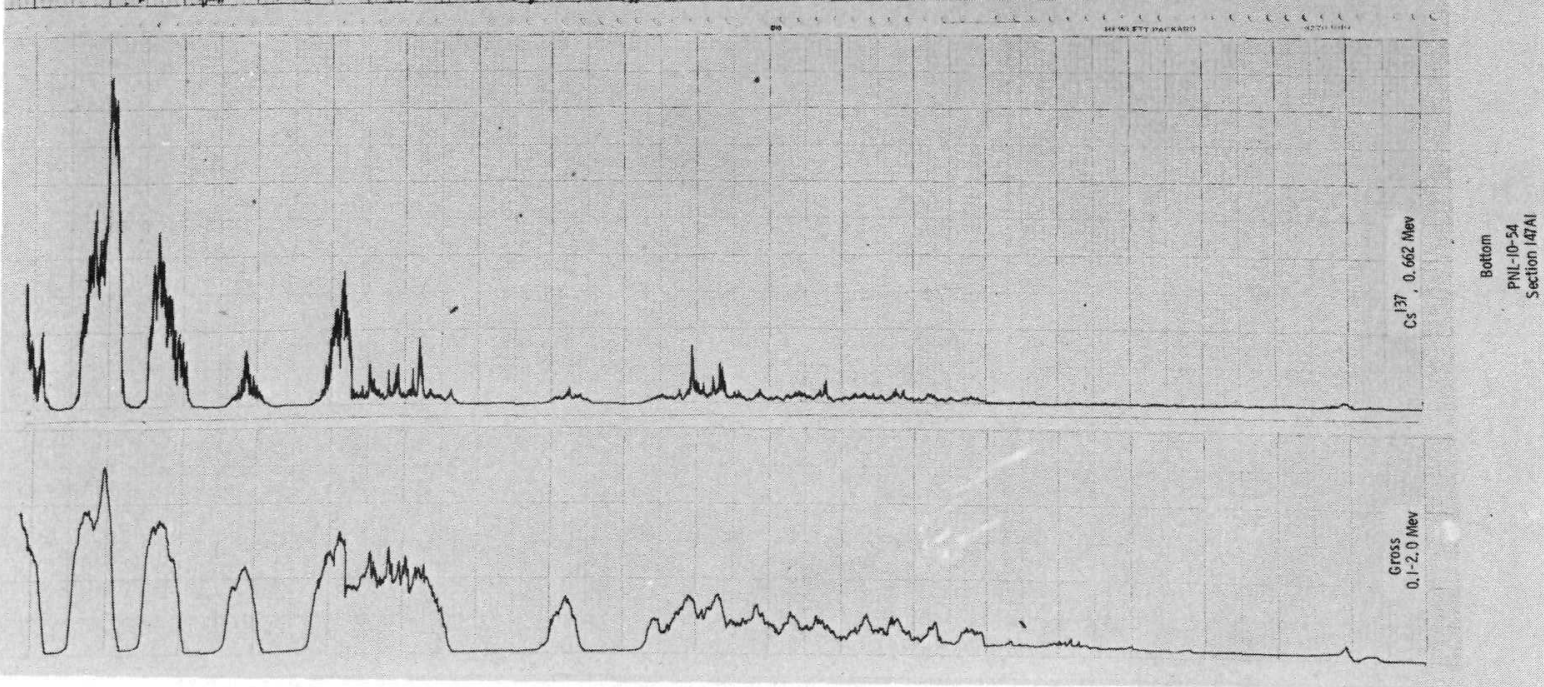

Fig. 54. Gamma Spectrometry of Bottom Sections of Elements PNL-10-53 and -44 , Showing Gaps in Stack of Insulator Pellets in Latter. Neg. No. MSD-188533. 


\section{Element Plenum Region}

As noted in Sec. VI.A above, a slight upward displacement of about $3 \mathrm{~mm}$ had occurred for the tops of the elements on the side away from the pump. Measurements of the lengths of the top sections of the elements with reference to the plane of the cut separating sections $147 \mathrm{~A} 3$ and $147 \mathrm{~A} 2$ helped to verify the relative displacement. The tops of elements PNL-10-8 and -10 did not appear to have altered their elevation. Elements PNL-10-7 and - 34 appeared to have moved upward about $1.6 \mathrm{~mm}$, and $-28,-53$, and -54 seemed to have moved upward by about $5 \mathrm{~mm}$.

The springs in the neutron radiograph of the pretest section appeared to occupy a space in the cladding about $27 \mathrm{~mm}$ long. Posttest, the space available for the springs appeared to be greater, by about $3 \mathrm{~mm}$ in the neutron radiograph. Upon removal from the elements, the measured lengths of the springs were as follows: PNL-10-7, $3.18 \mathrm{~cm}$; PNL-10-8, $3.25 \mathrm{~cm}$; PNL-10-10, $3.02 \mathrm{~cm}$; PNL-10-28, $3.33 \mathrm{~cm}$; PNL-10-34, $2.87 \mathrm{~cm}$; PNL-10-53, $3.10 \mathrm{~cm}$; and PNL-10-54, $2.87 \mathrm{~cm}$. Since the specification for the original free length of the springs was $34.54 \pm 3.18 \mathrm{~mm}$, some of the springs may have been under some compression at the end of the test. The Inconel X750 springs had 750/830 coils per meter compared to 590/670 coils per meter for the full, hard Type 302 stainless steel springs. Spring constants for two Inconel X750 springs were measured at 560 and $473 \mathrm{~N} / \mathrm{m}$. Two stainless steel springs give 1016 and $823 \mathrm{~N} / \mathrm{m}$. Specifications for the element indicated spring constants should be $701-858 \mathrm{~N} / \mathrm{m}$ for the Inconel springs. These differences in spring constants were probably caused by the EBR-II irradiation.

Cladding diameters were measured on the intact top sections of the seven fuel elements in two directions $90^{\circ}$ apart; 98 measurements gave values that ranged from 5.81 to $5.84 \mathrm{~mm}$. Similar measurements (141 in number) on the intact bottom sections of the elements gave results in the range from 5.80 to $5.84 \mathrm{~mm}$. The specified diameter was $5.84 \pm 0.025 \mathrm{~mm}$. The cladding diameters on the sections measured did not appear to have changed. No evidence for swelling or ovality was observed.

The reflector rods, as noted on the posttest neutron radiograph, showed slight relative displacements. This was verified by sections taken from this region. The reflector rods in elements PNL-10-7, -8, and -10 were at the same relative height. Element PNL-10-28 was about $5 \mathrm{~mm}$ higher, and PNL10-53 and -54 were about $6 \mathrm{~mm}$ higher than -7, -8 , and -10 . Element PNL10-34 was about $11 \mathrm{~mm}$ higher than the lowest rods. The rods appeared to have moved downward, perhaps as much as $19 \mathrm{~mm}$. This implied a possible separation between the rods and the spacer tube not directly observed either on the neutron radiograph or by examination of sections.

In all elements, there appeared to be a gap below the reflector rods where insulator pellets should have been present. This gap was determined to be about $25 \mathrm{~mm}$ long for PNL-10-8. The gaps in the other elements appeared to be smaller, but were not determined separately. 


\section{Summary of Results of Posttest Examination}

Fuel in the upper two-thirds of the original fuel columns appeared to have melted completely. On the lower third, the extent of fuel melting decreased from extensive center meltings of the pellets to practically no center melting at the extreme lower ends of the fuel columns.

The general direction of fuel motion was upward, although radial motion also occurred. The flow tube tended to set the bounds for radial fuel motion. However, for about $100 \mathrm{~mm}$ just below the tops of the fuel columns, the flow tube had completely melted, and here the adiabatic tube served as the boundary for radial motion. Within the region of the completely melted flow tube, two radial impulses had resulted in local penetrations of the wall of the adiabatic tube at different elevations and on opposite sides of the tube. Melted steel and some melted fuel impinged on the interior of the loop wall at these two locations. Most of the melted fuel was located in the region of the upper half of the fuel columns, but appreciable quantities of fuel had moved above the tops of the fuel columns as far as the reflector-rod region. Isolated fuel particles existed even farther up along the fuel elements, and some fuel collected in the vicinity of the headers.

Except for the center elements, remnants of fuel-pellet stacks survived toward the bottom of the fuel columns. Above the remains of the fuel stacks for about one-quarter of the length of the fuel columns, a decrease from the original quantity of fuel had occurred.

The melted fuel was generally spongy with globules of steel distributed throughout. The extent of the dispersion of steel in the melted fuel varied from place to place. The melted fuel up around the reflector rods contained relatively few globules of steel. Massive deposits of melted steel from the flow tube, cladding, and spacer wires were present above the top of the fuel column on the side toward the pump for about $100 \mathrm{~mm}$. Some cladding melting occurred as high as the reflector-rod region.

Pellets from the upper insulator-pellet stacks had moved down into the fuel region as much as $100 \mathrm{~mm}$. All stacks had moved downward to some extent. Insulator pellets in the bottom of the center element had moved upward, displacing fuel, and leaving gaps in the stack of $\mathrm{UO}_{2}$ pellets equivalent to $16-20$ pellets.

The remains gave no indications of the location of the first element failure. However, the first failure probably occurred along the upper third of the fuel column, where the greatest melting of the flow tube occurred. The pattern of melting of the cladding, illustrated by the remains of cladding toward the bottom of the fuel stacks, indicated that the first cladding to melt was either on the center element or on the side of a peripheral element toward the center element. Where the cladding was intact at the bottom and top of the fuel elements, neither swelling nor ovality was observed. 


\section{THERMAL-HYDRAULIC ANALYSIS OF TEST E8}

A. Introduction

Since no test instrumentation was located inside the fuel elements, the thermal and hydraulic conditions within the fuel were estimated by calculations using the modified COBRA-IIIM computer code. ${ }^{9}$

\section{B. Description of COBRA Computer Code}

The COBRA-IIIM code is an ANL modification of the COBRA-IIIC code. ${ }^{10}$ The modified version calculates the radial heat transfer through the fuel cladding, and flowing sodium as a function of radius, azimuthal sector, and height for each element in a cluster of one to seven elements. Fuel and cladding temperatures are calculated as a function of radius, azimuthal sector, and axial location. The radially averaged fuel enthalpy and the fraction of fuel above the solidus are also computed. Test conditions that must be specified are inlet coolant temperature, mass flow rate, and power histories. Axial and azimuthal heat transfers in each fuel element are not considered, except as an indirect consequence of coolant flow. Coolant temperatures are calculated for each flow channel. Heat and momentum transfer between channels due to pressure gradients, and helical element-spacer wires are considered in an approximate manner.

The accuracy of COBRA calculations depends upon the accuracy of many factors, including the mathematical formulation itself, space- and time-dependent fuel- power input, fuel thermal properties, and the conductance of the fuel-cladding gap. As previously stated, the uncertainty in the powercalibration factor of the central element is assumed to be about $\pm 10 \%$. Calculated power distributions as a function of azimuthal sector have not been verified experimentally. Fuel-density changes and central-void formation during the transient will alter these power distributions and create a variation in fuel thermal conductivity as a function of radius. These variations are not accommodated by the code.

The effect of fuel cracks on heat transfer are also not accounted for by the code. Accuracy of the simple model of fuel-cladding gap conductance used in COBRA is not known. A fundamental parameter of the model is the gap width, which depends upon the thermal-expansion coefficients of the fuel and cladding and upon fission-gas-induced fuel swelling. The latter phenomenon is poorly known and not included in the calculations.

There are considerable uncertainties in the physical-property values for fuel used as input to the computations (see Appendix F). Properties of irradiated fuel are largely unknown, as are properties of the mixed-oxide fuel above the solidus. Values of fresh mixed oxide were used for all pins, except for properties for which only data on $\mathrm{UO}_{2}$ are available. Properties of molten 
fuel are assumed to be temperature-invariant and identical to properties at the solidus. Nevertheless, the calculations among different experiments in TREAT are useful to define differences where accuracy should be improved relative to absolute values.

C. Calculated Thermal History

The channel layout and parameter input for COBRA calculations are given in Fig. F.1 (in Appendix F). Although some parameters are idealized and do not precisely represent the actual, as-fabricated dimensions, the accuracy is adequate for thermal calculations. For pressure-drop calculations, the true flow areas were used instead of the idealized parameters. Table F.1 lists only the idealized dimensions.

Figure 55 compares the calculated and measured coolant temperatures at the outlet. Figures 56 and 57 show the radial temperature distributions of the central and hottest peripheral fuel elements at $6.712 \mathrm{~s}$, the beginning of the power burst. Figures 58 and 59 show the radial temperature distributions of the central and peripheral fuel elements at the first indication of fuel-element failure at TREAT clock time of $7.212 \mathrm{~s}$ (i.e., when about $50 \%$ area of fuel reached solidus). Figures 56-59 also show the range of the axial temperatures at TREAT clock times of 6.712 and $7.212 \mathrm{~s}$. Figure 60 shows the time history of percentage of area above the solidus for the central and peripheral fuel elements, for 7.200-7.600 s of TREAT clock time. The maximum percentage of area reaching solidus was about $90 \%$ in the peripheral element and about $80 \%$ in the central element. Figure 61 shows the change of enthalpy in the central and peripheral elements during the transient. The enthalpy in fuel reached its peak at about $7.500 \mathrm{~s}$ of TREAT clock time.

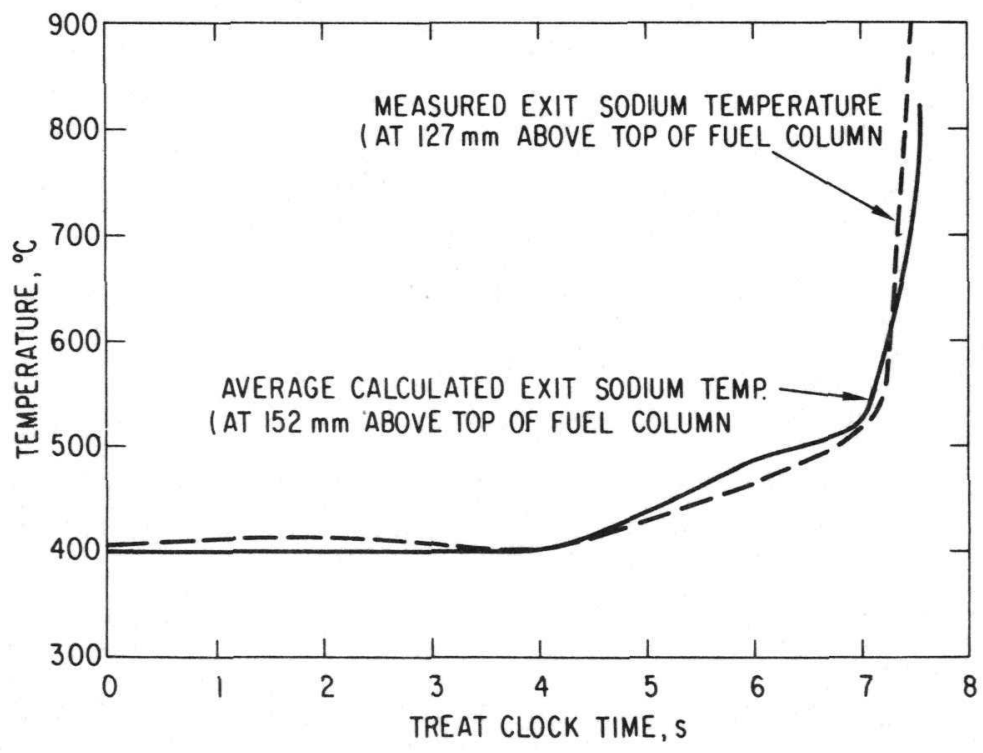

Fig. 55

Comparison of Measured and Calculated Sodium Temperatures at Exit. ANL Neg. No. 900-77-83. 

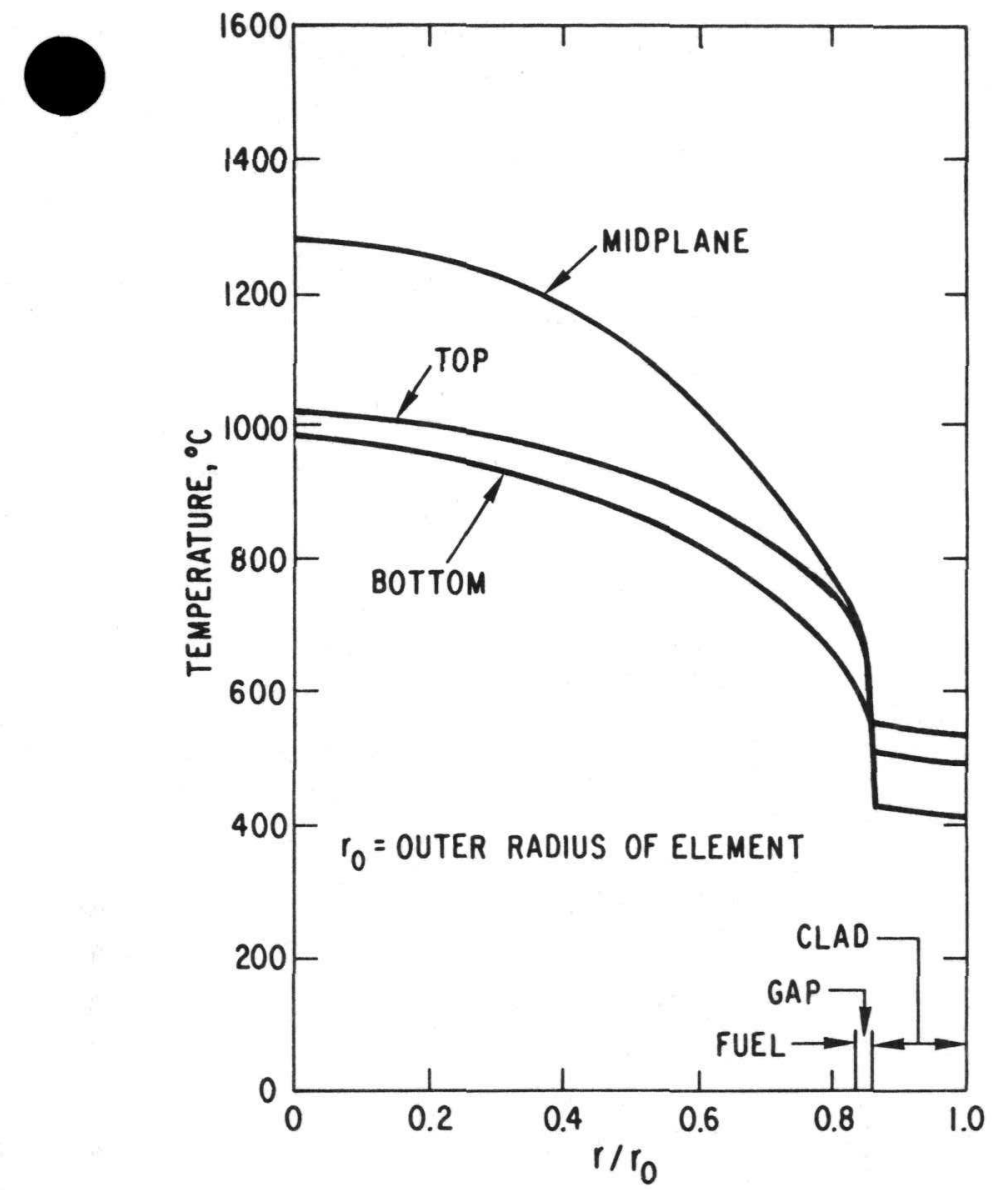

Fig. 56. Radial Temperature Distribution of Central Fuel Element at TREAT Clock Time $6.712 \mathrm{~s}$ (Beginning of power burst). ANL Neg. No. 900-77-82 Rev. 1.

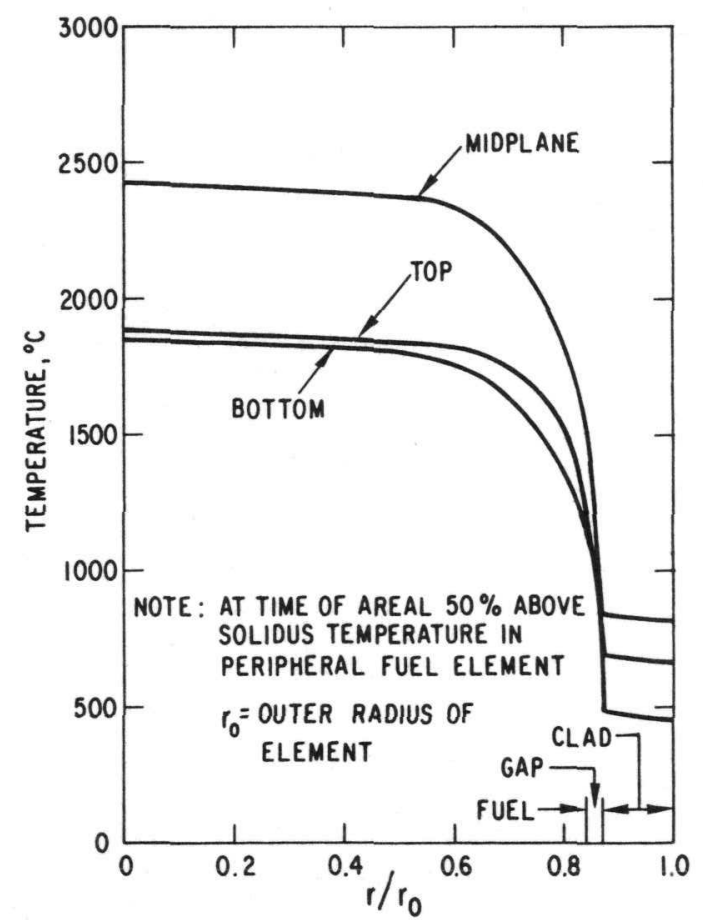

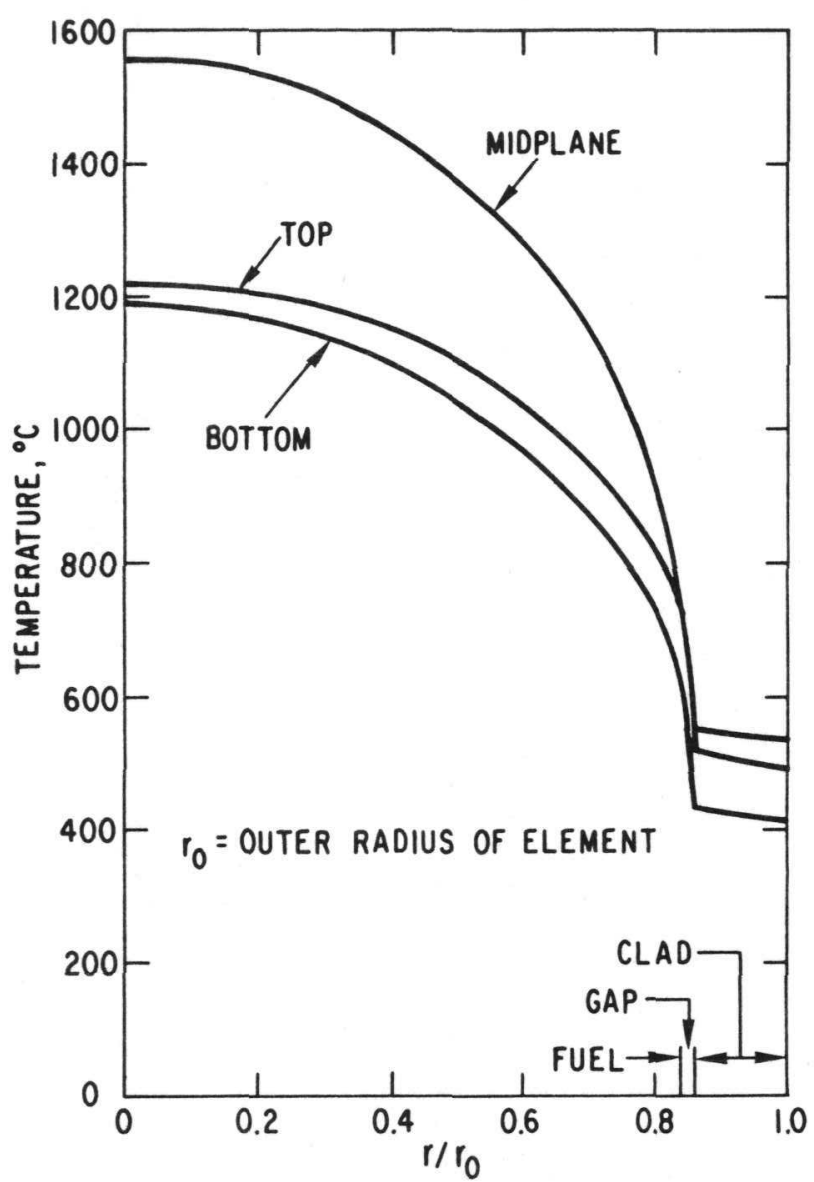

Fig. 57. Radial Temperature Distribution of Peripheral Fuel Element at TREAT Clock Time $6.712 \mathrm{~s}$ (Beginning of power burst). ANL Neg. No. 900-77-79 Rev. 2.

Fig. 58

Radial Temperature Distribution of Central Fuel Element at TREA T Clock Time 7.212 s. ANL Neg. No. 900-77-81 Rev. 1. 


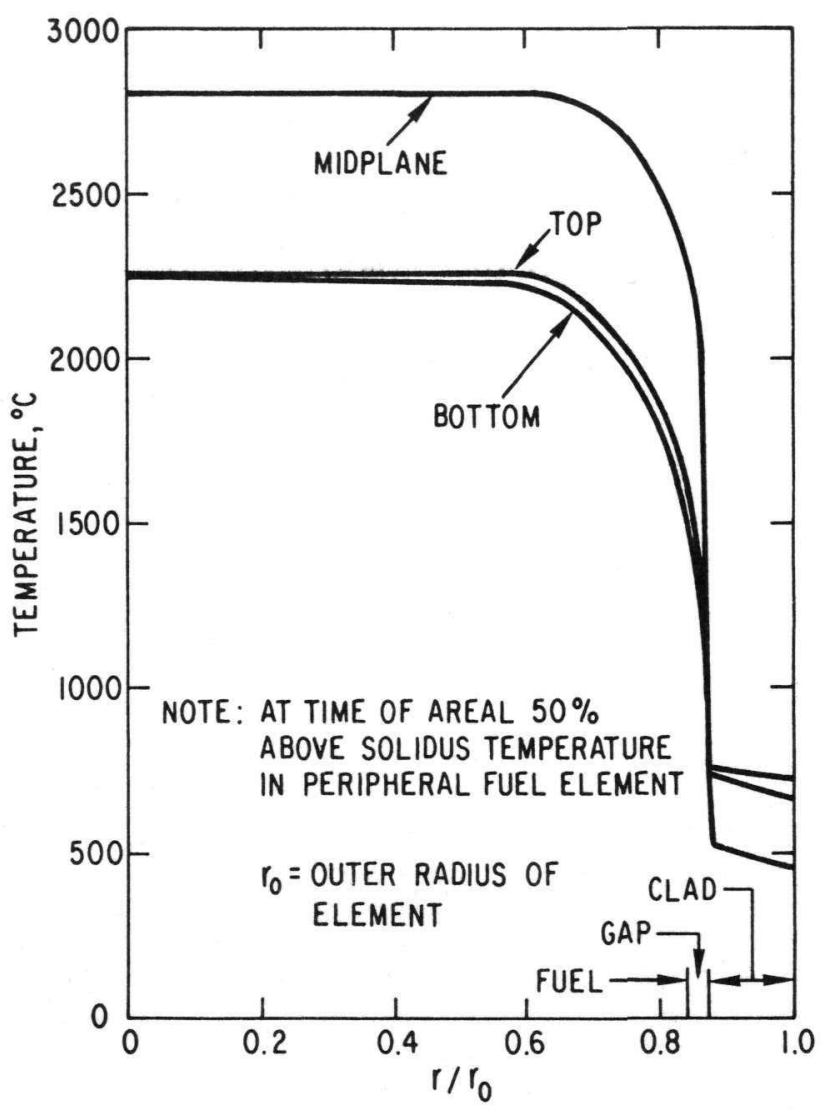

Fig. 59. Radial Temperature Distribution of Peripheral Fuel Column at TREAT Clock Time $7.212 \mathrm{~s}$. ANL Neg. No. 900-77-80 Rev. 1.

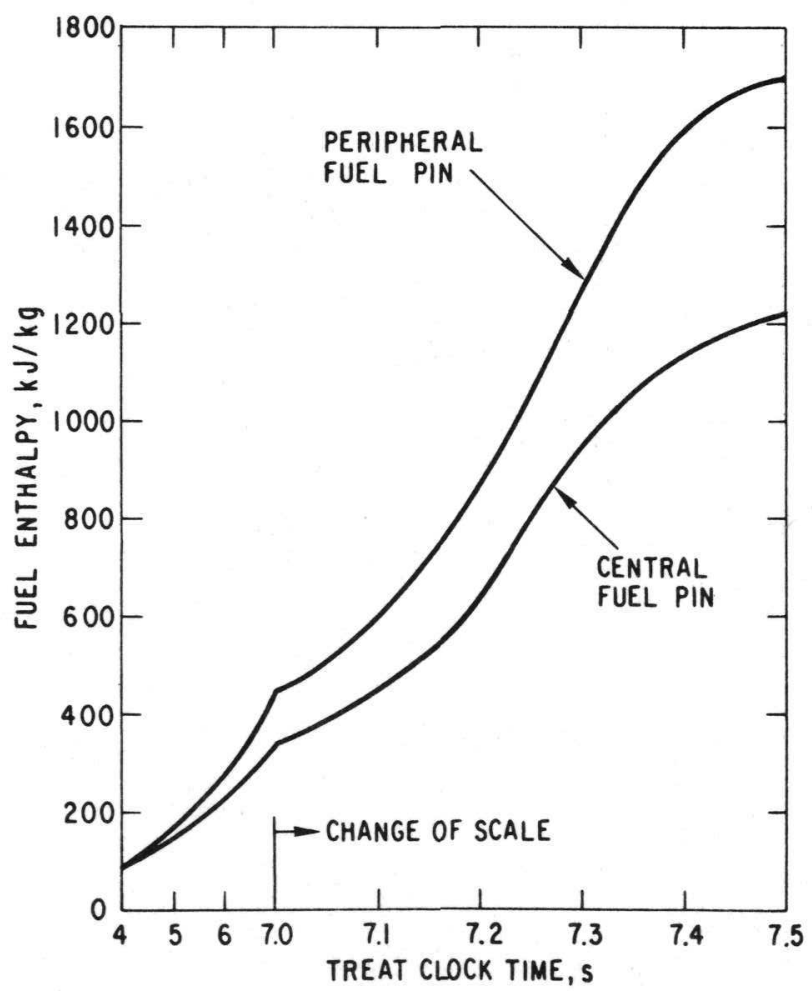

Fig. 61

Change of Fuel Enthalpy at Midplane during Transient. ANL Neg. No. 900-77-84. 
D. Summary and Conclusions

The measured and average calculated sodium temperatures at the exit are in agreement up to $7.250 \mathrm{~s}$. Between the beginning of the preheat $(4.300 \mathrm{~s})$ and the first failure of a fuel pin $(7.212 \mathrm{~s})$, the measured sodium temperatures are slightly lower than those from the calculations. Fuel failure occurred at $7.212 \mathrm{~s}$, and the measured temperatures after that time cannot be compared directly with calculations because the intact geometry was lost. The lack of agreement between the measured and calculated sodium temperatures at times after failure is therefore expected.

Figure 60 shows the areal percentage of the fuel element at, or above, the solidus, as a function of time. Note that the fuel temperature exceeded the liquidus when $80 \%$ or more of fuel area was above the solidus. As shown in Figs. 60 and 61, the percentage of fuel area above the solidus and the fuel enthalpy at the midplane of the central and peripheral elements began to decrease at about $7.50 \mathrm{~s}$. This result is caused by the reduction in the reactor power by $7.50 \mathrm{~s}$ to a power level down by about a factor of 10 from the peak power value. At this time, the total energy release was essentially complete. The temperature of the elements decreased after $7.50 \mathrm{~s}$ because the heat loss from the elements was greater than the heat generation in the elements. At no time did the calculations indicate that sodium reached boiling in these intact-geometry calculations. The results beyond $7.212 \mathrm{~s}$ are fictitious, of course. 


\section{SUMMARY AND CONCLUSIONS}

\section{A. Discussion of Test Results}

In this section, the test results are delineated, and an attempt made to distinguish between the conclusive evidence substantiating the events and the hypothesis and conclusions. A slightly different scenario could be constructed using the same information. For this summary, the events and the confirming observations are listed in Table XVIII.

TABLE XVIII. Summary of Test Results

\begin{tabular}{|c|c|c|}
\hline Observation or Event & Evidence & Comments \\
\hline \multirow[t]{2}{*}{ No energetic $\mathrm{FCl}$ occurred. } & $\begin{array}{l}\text { No pressure pulses were recorded in } \\
\text { excess of } 1.7 \mathrm{MPa}(17 \mathrm{~atm}) \text {. }\end{array}$ & $\begin{array}{l}\text { The inlet pressure sensor recorded a series of } \\
\text { pressure events, showing that it was operating. }\end{array}$ \\
\hline & $\begin{array}{l}\text { Sodium-slug ejection velocity did not exceed } \\
10 \mathrm{~m} / \mathrm{s} \text { at time of failure. }\end{array}$ & $\begin{array}{l}\text { Time difference in sudden increase of plenum } \\
\text { temperature sensors confirm low sodium-slug } \\
\text { velocity at time of ejection. }\end{array}$ \\
\hline Fuel was melted in the test. & $\begin{array}{l}\text { Postmortem examinations revealed extensive } \\
\text { melting and relocation of fuel. }\end{array}$ & $\begin{array}{l}\text { Flow tube melted through in region of original } \\
\text { active fuel. }\end{array}$ \\
\hline $\begin{array}{l}\text { Initial time of fuel-element failure } \\
\text { occurred at } 7.204 \mathrm{~s} \text {. }\end{array}$ & $\begin{array}{l}\text { Minor perturbations occurred in lower } \\
\text { (inlet) pressure sensor. }\end{array}$ & \\
\hline $\begin{array}{l}\text { Initial time of fuel-element failure } \\
\text { occurred at } 7.212 \mathrm{~s} \text {. }\end{array}$ & $\begin{array}{l}\text { Both flowmeters and the inlet pressure sensor } \\
\text { indicated a major disruption of the test region. }\end{array}$ & $\begin{array}{l}\text { This time is assumed to be more reliable than } \\
7.204 \mathrm{~s} \text {, since three detectors are responding. }\end{array}$ \\
\hline Onset of fuel dispersal was at $7.219 \mathrm{~s}$. & $\begin{array}{l}\text { Hodoscope observations in the time interval } \\
7.212-7.224 \mathrm{~s} \text {. }\end{array}$ & $\begin{array}{l}\text { Only } 6 \pm 2 \mathrm{~g} \text { moved. Estimated uncertainty } \\
\text { in this time is } \pm 10 \mathrm{~ms} \text {. }\end{array}$ \\
\hline $\begin{array}{l}\text { Axial location of fuel-element failure } \\
\text { was in top third of the fuel column. }\end{array}$ & $\begin{array}{l}\text { Detailed analysis of hodoscope data indicated } \\
30 \pm 20 \mathrm{~mm} \text { above midplane; postmortem } \\
\text { examination showed most extensive melting } \\
\text { of flow tube in top third. }\end{array}$ & Limited fuel motion. \\
\hline First element failed. & $\begin{array}{l}\text { Hodoscope observed fuel-motion inception on } \\
\text { east side of cluster (PNL-10-28, }-34 \text {, or -8). }\end{array}$ & $\begin{array}{l}\text { Most likely failure was for PNL-10-28, because } \\
\text { it had the highest calibration factor of the } \\
\text { three elements. }\end{array}$ \\
\hline Areal \% above solidus at first failure. & None other than by calculation. & $\begin{array}{l}\text { Thermal analyses calibrated by posttest results } \\
\text { where possible (such as Test } \mathrm{H} 5 \text { ). }\end{array}$ \\
\hline Inlet flow reversal occurred at $7.25 \mathrm{~s}$. & Curve of inlet-flowmeter data. & $\begin{array}{l}\text { Uncertainty in numerical values of flowmeter } \\
\text { data causes uncertainty in timing of inlet } \\
\text { flow reversal. }\end{array}$ \\
\hline Flow-tube failure occurred at $7.32 \mathrm{~s}$. & $\begin{array}{l}\text { Hodoscope indicated fuel had penetrated } \\
\text { by } 7.32 \mathrm{~s} \text {. }\end{array}$ & $\begin{array}{l}\text { The failure could have occurred in-line with } \\
\text { the hodoscope without being detected. However, } \\
\text { thermocouples mounted on flow tube began } \\
\text { to fail by } 7.356 \mathrm{~s} \text {. }\end{array}$ \\
\hline Upper blockage was formed. & $\begin{array}{l}\text { Postmortem results show a cladding blockage } \\
\text { in coolant channels above a densely packed } \\
\text { region of fuel and cladding below. }\end{array}$ & $\begin{array}{l}\text { After the test, the sodium flow could not be } \\
\text { reestablished. }\end{array}$ \\
\hline Upper blockage formed at $7.3 \mathrm{~s}$. & $\begin{array}{l}\text { Outlet flowmeter indicated flow decrease } \\
\text { below original value at about } 7.34 \mathrm{~s} \text {, reaching } \\
\text { zero at about } 7.4 \mathrm{~s} \text {. After this time, the } \\
\text { hodoscope failed to observe fuel movement } \\
\text { across this elevation. }\end{array}$ & Indirect evidence. \\
\hline
\end{tabular}

Some of the events in Table XVIII depend almost entirely on analysis of the hodoscope data. Several corrections and data-handling manipulations were applied to the original hodoscope data. The shear bulk of these data make it necessary to report results in the form used in Sec. V.C. On the other hand, the sensor data and posttest-examination results are both more visible and more easily reported. 
From the observations made with test-vehicle sensors and hodoscope, the E8 test elements were intact until about $7.212 \pm 0.01 \mathrm{~ms}$ into the transient. At this time, a disruption occurred in the test zone that resulted in the upward ejection of a small quantity of fuel concurrent with the sodium expulsion. Calculations with the COBRA code indicate that, at the time of this event $(7.212 \mathrm{~s})$, about $50 \%$ of the cross-sectional area of the element with the highest calibration was above the $(\mathrm{Pu}, \mathrm{U}) \mathrm{O}_{2}$ solidus temperature. Because of the uncertainty of $\pm 10 \%$ in the calibration factor above, the uncertainty in the fraction of the area above the solidus is about \pm 25 areal percent.* The element failures were clearly incoherent, a result predictable on the basis of the differences among the individual calibration factors. The failure site was tentatively identified at $30 \pm 20 \mathrm{~mm}$ above the fuel-column midplane. No associated violent fuel-coolant interaction or sodium-slug ejections were observed.

Based on the hodoscope data alone, a blockage to further upward sweepout of fuel occurred at about $7.3 \mathrm{~s}$, or $90 \pm 10 \mathrm{~ms}$ after the initial disruption observations. The timing is consistent with the flowmeter data. In the postmortem examinations, a quantity of once-molten cladding, nearly sufficient to cause a complete blockage just above the top of the fuel column, was observed frozen in the coolant channels. The flow tube probably survived until the postulated time of the upper-flow-channel blockage. The time of $7.3 \mathrm{~s}$ corresponds to about $20 \mathrm{~ms}$ after the attainment of peak reactor power. The reactor energy release at $7.3 \mathrm{~s}$ was $900 \mathrm{MJ}$, or about $100 \mathrm{MJ}$ below the scram setting. Because of the geometrical envelope provided by the disrupted test region, events occurring after this time probably bear no further direct relationship to the intended simulation.

\section{B. Applicability to FTR}

As with most simulations, departures from the ideal will exist. These differences must be considered when analytical models are tested against experimental data. In Test E8, physical constraints in fuel and apparatus have limited the ability of the test to provide a detailed mockup of the FTR. In this section, we will attempt to identify the various similarities and differences between Test E8 and the FTR.

For comparison, Table XIX compares some of the principal test parameters to the corresponding values for FTR. In an LMFBR overpower accident involving the failure of several subassemblies almost simultaneously, the coolant ejected downward will not pressurize the lower plenum of the reactor since adequate bypass flow channels are available to the outlet plenum through control and other as semblies. No coolant would flow back through the primary system. In the Mark-II loop, no bypass has been provided; therefore a downward-moving sodium slug moves back through the pump. A partial

\footnotetext{
* The uncertainty in the calibration factor is about $\pm 0.2 \mathrm{~W} / \mathrm{g} \cdot \mathrm{MW}$. The burst energy release was about $375 \mathrm{MJ}$ at the time of failure. The uncertainty in energy generated is therefore $75 \mathrm{~J} / \mathrm{g}$. The $75 \mathrm{~J} / \mathrm{g}$ value is about $25 \%$ of the heat of fusion for the $(\mathrm{Pu}, \mathrm{U}) \mathrm{O}_{2}$ mixed-oxide fuel.
} 
pressurization would result. The initial pressure drop across the test elements is much lower than for the FTR. At the FTR-coolant flow velocity, inlet flow reversal would probably not occur and more extensive fuel sweepout would be pos sible.

TABLE XIX. Comparison of Test E8 Cluster Parameters with FTR

\begin{tabular}{|c|c|c|}
\hline Parameters & E8 Cluster & FTR Subassembly \\
\hline \multicolumn{3}{|l|}{ Geometric } \\
\hline Number of elements & 7 & 217 \\
\hline Active fuel-column length, $\mathrm{mm}$ & $343 \pm 3$ & 914 \\
\hline Cladding outer diameter, $\mathrm{mm}$ & 5.842 & 5.842 \\
\hline Wire diameter, $\mathrm{mm}$ & 1.02 & 1.42 \\
\hline Flow area per element, $\mathrm{mm}^{2}$ & 24.6 & 20 \\
\hline \multicolumn{3}{|l|}{ Thermal-Hydraulic } \\
\hline Hydraulic diameter, $\mathrm{mm}$ & 2.91 & 3.25 \\
\hline Coolant & Sodium & Sodium \\
\hline Flow rate, $\mathrm{cm}^{3} / \mathrm{s}$ per element & 82 & 152 \\
\hline Flow velocity, $\mathrm{m} / \mathrm{s}$ & 3.33 & $\sim 7$ \\
\hline Ratio of heated perimeter to wetted perimeter & 0.638 & 0.928 \\
\hline Inlet inertial length, ${ }^{\mathrm{a}} \mathrm{m}$ & 2.2 & 2.3 \\
\hline Outlet inertial length, ${ }^{\mathrm{a}} \mathrm{m}$ & 0.82 & $1.9^{\mathrm{b}}$ \\
\hline Ratio of inlet-to-outlet inertial length & 2.7 & 1.2 \\
\hline \multicolumn{3}{|l|}{ Power Distributions } \\
\hline Radial element (Peak to average) & $\sim 1.3$ & 1 \\
\hline Axial element (Peak to average) & $\sim 1.1$ & $\sim 1.25$ \\
\hline Element to element, range & 1. $4: 1$ & $\sim 1: 1$ \\
\hline Power-Time history & Matche & nly to failure time \\
\hline \multicolumn{3}{|l|}{ Fuel } \\
\hline Fuel type & $(\mathrm{Pu}, \mathrm{U}) \mathrm{O}_{2}$ & $(\mathrm{Pu}, \mathrm{U}) \mathrm{O}_{2}$ \\
\hline Plutonium oxide content, $\%$ & 25 & 25 \\
\hline${ }^{235} \mathrm{U}$ enrichment & 65 & Normal \\
\hline Fuel fabrication & One vendor & Various vendors \\
\hline Preirradiation & In EBR-II & In FTR \\
\hline Fuel-crack healing & No & Possible \\
\hline Wear(by wire wraps) & Yes & Unknown \\
\hline Bowing stresses in transient & $\begin{array}{c}\text { Probably greater } \\
\text { than FTR }\end{array}$ & Unknown \\
\hline Retained fission-gas content & $\begin{array}{l}\text { About equal to } \\
\text { FTR }\end{array}$ & - \\
\hline Preirradiation power level, $\mathrm{kW} / \mathrm{m}$ & $\sim 30$ & Varies $(30 \mathrm{~kW} / \mathrm{m}$ included) \\
\hline Burnup, at. $\%$ & $\sim 5$ & Varies ( 5 at. $\%$ included) \\
\hline
\end{tabular}

${ }^{a}$ Refers to fuel-column midplane.

${ }^{b}$ Ignores instrument tree.

In Test E8, the requirements of representative cladding temperatures for the short elements (as well as performance of the pumps available) limited flow velocity to about half the FTR flow velocity. An FTR subassembly possesses about equal inertial length for upward and downward coolant voiding relative to the fuel-column midplane. The Mark-II loop does not have this property of equal inertial length; rather, upward-moving coolant slugs could accelerate more rapidly, leading to a greater tendency for upward voiding than for FTR. The mismatch is partly a result of having to work with short fuel elements because of the unavailability of fast-reactor-irradiated fuel with the desired fuel-column length. Future planning for other test vehicles can consider inertial-length matching, but fast-reactor-irradiated fuel elements with the desired fuel-column length might not be available before FTR operations. 
One deter rent to fuel sweepout involves the cluster size. The sevenelement cluster geometry possesses considerable unheated peripheral structure. The inside of the flow tube represents an unheated surface area convenient for fuel freezing and subsequent flow-channel blockage once fuel moves. This problem probably cannot be remedied until the cluster-size capability of the test vehicle is increased.

Other departures from prototypicality exist that are of a more fundamental nature. The TREAT reactor is a thermal reactor, and it consequently possesses the associated spectrum and kinetics characteristics. The reactor transient will not change its course from the programmed excursion because fuel in the test zone disperses. In an LMFBR, the feedback caused by fuel dispersal would be significant, leading to rapid power reduction, lower burst energy, and thus reduced melting in the failed subassembly. The amount of molten material generated in E8 may have been too great relative to an FTR accident. Nevertheless, the cladding blockage observed could also have blocked further fuel dispersal. Despite the neutron filtering with dysprosium, the radial power distribution and element-to-element power depositions caused the failures in the cluster to be incoherent, and this incoherency is probably not typical of a failing LMFBR subassembly. The incoherency should produce a somewhat more favorable environment for fuel dispersal for the first fuel to fail and a less favorable situation for the latecomers.

Another potential problem with performing experiments in a heatcapacity-burst reactor is the inability to heal fuel cracks (that is, precondition fuel). Before the excursion, a reactor accident could occur after the fuel had been operating at steady state for an extended time. Consequently, certain types of crack formations in the test fuel might not be present in actual reactor fuel just before an accident. The problem has been the subject of investigations to assess the effect. Note, however, that the applicability of TREAT-type experiments without preconditioning to analyses of LMFBR accidents occurring after extended running time at steady state has been discussed in the light of actual data. It was concluded that the tests are applicable.*

In addition to preconditioning, other factors of a highly individual nature for fuel might distinguish one element from another. Although elements for E8 were of the PNL-10 type, they nevertheless possessed individual differences. Fuel batches, burnup, wear, and residual cladding stress were not identical for the seven elements. However, there is no evidence that these differences were of such a substantial nature that the test results were somehow biased in one way or another. Also, similar differences for an LMFBR will be expected, even for subassemblies provided by the same vendor. Experimental observations of the effects of axial variation in fuel microstructure must await the testing of appropriately longer fuel columns.

*C. E. Dickerman, personal communication. 
APPENDIX A

$\underline{\text { Drawing of Test-train Assembly }}$

The drawing of the test-train assembly for Test E8 is shown in Fig. A.1. 


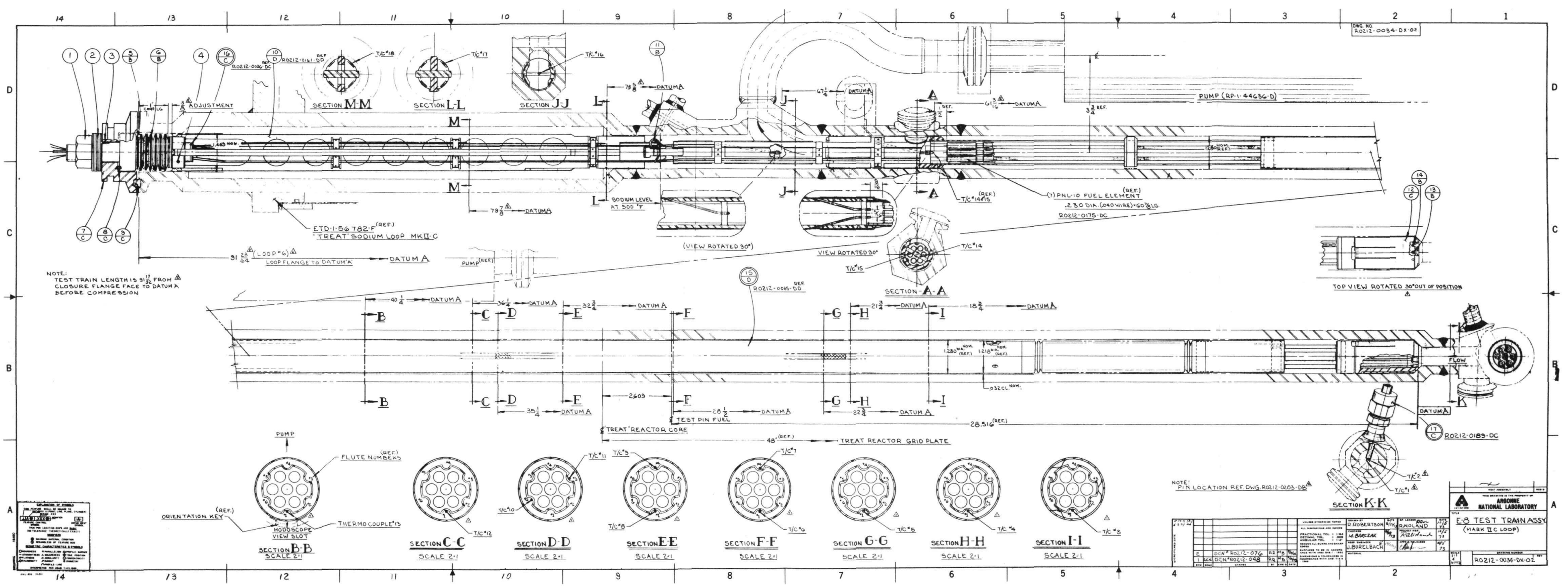

Fig. A.1. E8 Test-train Assembly 
APPENDIX B

Results of Power-calibration Tests

\section{Introduction}

The sample power-calibration constants for E8 are based primarily on the results of calibration experiments performed in TREAT using unirradiated PNL-10 fuel elements fabricated as spares for EBR-II irradiations but not used in EBR-II. Calibration elements differ from the test elements only in that the test elements have been irradiated in EBR-II to about 5 at. \%. Both the fresh fuel for the calibration and the irradiated fuel for the EBR-II irradiations were fabricated from one of two fuel batches: FE-79.0 or 92.0. These fuel batches were neutronically identical, except for minor variations in fuel density. The relevant calibration-test designations are listed in Table B.1.

TABLE B.1. Summary of E8 Calibration Tests in TREAT

\begin{tabular}{ccccccl}
\hline $\begin{array}{c}\text { Test } \\
\text { Designation }\end{array}$ & $\begin{array}{c}\text { TREAT } \\
\text { Transient } \\
\text { No. }\end{array}$ & $\begin{array}{c}\text { Date } \\
\text { Performed }\end{array}$ & $\begin{array}{c}\text { Number of } \\
\text { Fuel Elements }\end{array}$ & $\begin{array}{c}\text { Number of } \\
\text { Monitor Wires }\end{array}$ & $\begin{array}{c}\text { Energy } \\
\text { Release, MJ }\end{array}$ & \multicolumn{1}{c}{$\begin{array}{c}\text { Transient } \\
\text { Description }\end{array}$} \\
\hline E8M-1.2 & - & $3-15-74$ & 7 & 0 & $163.3^{\text {a }}$ & $\begin{array}{l}\text { Low-level, } \\
\text { steady state }\end{array}$ \\
E8M-2.1 & - & $2-12-74$ & 0 & 2 & $163.3^{\text {a }}$ & $\begin{array}{l}\text { Low-level, } \\
\text { steady state }\end{array}$ \\
E8M-2.2 & 1544 & $2-13-74$ & 0 & 2 & 1030 & $\begin{array}{l}\text { Approximate E8-type } \\
\text { transient }\end{array}$ \\
\hline
\end{tabular}

$a_{50} \mathrm{~kW}$ (nominal) for 70 min with a factor of $7 / 9$ applied to account for TREAT estimate of actual energy

\section{Theory}

No method has been devised as yet to measure directly all the required parameters for preirradiated fuel. The method employed for the E8 calibration used fresh (unirradiated) fuel, monitor-wire irradiations, and calculations (for burnup corrections) in an attempt to infer the sample-to reactor power-calibration factor for the test fuel. A consistency check (heat balance) was also conducted before the final test transient to establish that the balance) was alsoconducted before the final test transient to establish that the interpretation obtained from the calibration tests with fresh fuel was sufficient to proceed with the actual test.

The two principal parameters needed to run a TREAT test are the axial power distribution and calibration factor for each element in the cluster. The axial power distributions for the fresh fuel were obtained by counting relative pellet activity. The calibration factor for each fresh element destructively examined was determined by: 
a. Inferring the fission rate from ${ }^{140}$ La activity by counting three pellets from the element, and

b. Using monitor-wire corrections to account for differences between transient and steady-state behavior at the sample and at the detector.

The calibration factor CF for the element (peak axial value) was calculated from

$$
(\mathrm{CF})_{\mathrm{t}}=(\mathrm{CF})_{\mathrm{ss}} \mathrm{A}_{\mathrm{t}} / \mathrm{A}_{\mathrm{ss}}
$$

where

$$
\begin{aligned}
(\mathrm{CF})_{t}= & \text { Calibration factor for the fuel element in a transient, } \mathrm{W} / \mathrm{g} \cdot \mathrm{MW}, \\
(\mathrm{CF})_{\mathrm{s} s}= & \text { Calibration factor for the fueled, steady-state experiment, } \\
& \mathrm{W} / \mathrm{g} \cdot \mathrm{MW}, \\
\mathrm{A}_{\mathrm{t}}= & \text { Activity of a monitor wire in the test region for the transient, } \\
& \text { fissions } / \mathrm{g} \cdot \mathrm{MJ},
\end{aligned}
$$

and

$$
\begin{aligned}
A_{S S}= & \text { Activity of a monitor wire in the test region for steady state, } \\
& \text { fissions } / \mathrm{g} \cdot \mathrm{MJ} \text {. }
\end{aligned}
$$

Equation 1 is equivalent to the assumption that the ratio of fissions in the fuel to fissions in a monitor wire for the same transient will be the same for all similar transients and, also, when the reactor is operated at a much lower power, defined as at steady state. If the steady-state irradiations for fuel and monitor wires are conducted at the same indicated power level and for the same time duration, then the energy release of the reactor at steady state cancels in the equation, and, therefore, the exact energy release need not be known. Similarly, the energy release for the transient monitor-wire irradiation test need not be known exactly, as long as the same instrumentcalibration constant is used when the actual transient is conducted. Indeed, there may be no need to define a transient correction if the local reactor power levels can be defined using the reactor instrumentation alone.

The values obtained from these calibration tests apply to fresh fuel. The factors must therefore be corrected before the test for any differences in either the fuel or test configuration, such as for the burnup associated with the test fuel.

\section{Transient Correction Factor}

The relationship between the low-level power-calibration factor and the value that would be obtained during a transient was estimated by means of monitor-wire activations. No fuel was present during a calibration transient, 
and reliance has been placed on monitor-wire results alone. In these tests, monitor wires* were irradiated at low level. These wires were then removed and fresh wires inserted for an irradiation in a transient similar to the transient desired for actual Test E8. These irradiations were accomplished with the E8 mockup loop hardware designed and fabricated for these calibrations. The monitor-wire activity was based on the ${ }^{140} \mathrm{Ba}$ activity in the wire specimens related to fissions per gram of wire using a calibrated source. The procedure was deemed acceptable, since only the relative activations for the irradiated monitor wires were required.

The transient correction $\mathrm{At}_{\mathrm{t}} / \mathrm{A}_{\mathrm{SS}}$ for the transient relative to the lowlevel, steady-state irradiation was computed (see Table B.2) as 1.35 for the monitor wires placed in the test section at about the loc ation of the TREAT core midplane. The factor was determined by dividing the indicated wire fissions per gram-megajoule for the transient case by the value for monitor wires obtained for the irradiation in the low-level, steady-state case. Since the control-rod configurations in the low-level irradiations of monitor wires and elements were essentially identical, no further correction caused by differences in control-rod positioning was required.

TABLE B.2. Transient Correction Factor for E8, Based on Monitor-wire Results from Test Section

\begin{tabular}{|c|c|c|c|c|c|}
\hline Test & $\begin{array}{l}\text { Wire } \\
\text { Serial } \\
\text { No. }\end{array}$ & $\begin{array}{c}\text { Wire } \\
\text { Activity, } \\
10^{12} \text { fission/g }\end{array}$ & $\begin{array}{c}\text { Energy } \\
\text { Release, } \\
\text { MJ }\end{array}$ & $\begin{array}{c}\text { Relative } \\
\text { Activity of Wire, } \\
10^{9} \text { fission } / \mathrm{g} \cdot \mathrm{MJ}\end{array}$ & $\begin{array}{l}\text { Transient } \\
\text { Correction }\end{array}$ \\
\hline $\begin{array}{l}\text { Low level } \\
(\mathrm{E} 8 \mathrm{M}-2.1)\end{array}$ & ZR-02-04 & 1.25 & 163.3 & 7.65 & - \\
\hline $\begin{array}{l}\text { Transient } \\
(\mathrm{E} 8 \mathrm{M}-2.2)\end{array}$ & ZR-02-05 & 10.6 & 1030 & 10.3 & 1.35 \\
\hline
\end{tabular}

The indicated data for TREAT energy release were based on Integrator 1. The monitor wires had been examined for uniformity by counting the individual wire specimens actually used in the test. All wires were uniform within $\pm 1.5 \%$ at the $2 \sigma$ level in ${ }^{235} \mathrm{U}$ content per unit weight.

Monitor wires were also placed in a guide tube adjacent to the test section within the secondary containment can at the elevation of the TREAT core midplane. Although the monitor wires placed at this location were not under the test-section neutron filters, the results for these wires, listed in Table B.3, nevertheless gave nearly the same transient correction.

*The monitor wires used were 50-mm-long segments of $0.76-\mathrm{mm}$-dia zirconium-uranium wire (3.5 wt \% U; 93\% 235U). 
TABLE B.3. Transient Correction Factor for E8, Based on Monitor-wire Results from Secondary-containment-can Guide Tube

\begin{tabular}{cccccc}
\hline & $\begin{array}{c}\text { Wire } \\
\text { Serial } \\
\text { No. }\end{array}$ & $\begin{array}{c}\text { Wire } \\
\text { Activity, } \\
\text { 10 }\end{array}$ & $\begin{array}{c}\text { Energy } \\
\text { fission/gease, } \\
\text { MJ }\end{array}$ & $\begin{array}{c}\text { Relative } \\
\text { Activity of Wire, } \\
10^{10} \text { fission/g.MJ }\end{array}$ & $\begin{array}{c}\text { Transient } \\
\text { Correction }\end{array}$ \\
\hline $\begin{array}{l}\text { Low level } \\
(\text { E8M-2.1) }\end{array}$ & ZR-02-01 & 6.05 & 163.3 & 3.71 & - \\
$\begin{array}{l}\text { Transient } \\
(\text { E8M-2.2) }\end{array}$ & ZR-02-02 & 50.2 & 1030 & 4.88 & 1.32 \\
\hline
\end{tabular}

4. Power-calibration Results for Unirradiated Fuel at Low-level TREAT Power

In calibration Test E8M-1.2, seven unirradiated PNL-10 elements were irradiated in the calibration mockup loop at about $50 \mathrm{~kW}$. After the experiment, the seven-element cluster was removed from the loop and four elements selected for radiochemical analysis. One element had received an exposure in a similar irradiation one month before. Axial power distributions were deduced by counting about 30 individual pellets per element for gammaray activity in the energy range 0.45-0.80 MeV. The data for the axial power distribution are plotted in Fig. 12. Since the axial burnup in EBR-II of the PNL-10 fuel elements for E8 had only a slight variation with axial position, the correction applied to account for variation of axial burnup relative to the fresh-element data was negligible.

The sample calibration factor at the axial midplane of the fuel column was determined for each element by analyzing three pellets from each element by radiochemical dissolution. Pellet numbers 29, 31, and 33 (numbered from the bottom; 60 pellets per element) from PNL-10-79, -80,-81, and $-46 \mathrm{R}$ were destructively analyzed for Ba-La. The results from PNL-10-46R were corrected for its previous irradiation history. The location in the cluster for each element is shown in Fig. 9.

Absolute fission determinations for the pellets were made based on the Ba-La pair by counting ${ }^{140}$ La gamma emissions with a calibrated NaI gammaray spectrometer. The determinations were first averaged by weighting the experimental values with the pellet gamma counts (from the axial power determinations) to estimate the peak value for the element. A value of 0.0605 was used as the effective yield of barium from the mixed-oxide fuel in TREAT. The values of fissions per gram of oxide were converted to peak axial calibration factors at low-level TREAT power by (1) multiplying by $28.6 \mathrm{pJ} /$ fission and (2) dividing by the TREAT indicated energy release. The experimental result for each element is given in Table B.4. 
TABLE B.4. Experimental Radiochemical Values for Low-level

Calibration Factors for E8

\begin{tabular}{lcccc}
\hline & \multicolumn{4}{c}{ Calibration Factor, W/g.MW } \\
\cline { 2 - 5 } $\begin{array}{c}\text { Element } \\
\text { Designation }\end{array}$ & Pellet 29 & Pellet 31 & Pellet 33 & Average \\
\hline PNL-10-79 & 1.162 & 1.157 & 1.144 & 1.154 \\
PNL-10-80 & 1.232 & 1.227 & 1.213 & 1.224 \\
PNL-10-81 & 1.637 & 1.653 & 1.656 & 1.649 \\
PNL-10-46R & 1.473 & 1.445 & 1.469 & 1.462 \\
\hline
\end{tabular}

\section{Conversion to Test Elements}

This section deals with the way in which the data from the freshelement tests were used to characterize the calibration factors for the test elements. The seven test elements were characterized by assuming symmetry on the hodoscope-to-pump vertical plane. The match between elements is shown in Table B.5.

TABLE B.5. Correspondence between Test and Calibration Elements

\begin{tabular}{lll}
\hline Test Element & Calibration Element & \multicolumn{1}{c}{ Cluster Location } \\
\hline PNL-10-54 & PNL-10-79 & Central \\
PNL-10-8 & PNL-10-80 & Nearest pump \\
PNL-10-53 & PNL-10-81 & Nearest hodoscope slot \\
PNL-10-7 & PNL-10-46R & Intermediate \\
PNL-10-10 & PNL-10-80a & Nearest pump \\
PNL-10-28 & PNL-10-81a & Nearest hodoscope slot \\
PNL-10-34 & PNL-10-46R & Intermediate \\
\hline
\end{tabular}

${ }^{\mathrm{a}}$ Symmetry in cluster geometry as sumed.

Once the correspondence between the test element and calibration elements was established, the following four possible corrections were considered:
a. Transient correction.
b. Burnup correction.
c. Filter variation.
d. Fuel-batch differences.

Corrections $\mathrm{c}$ and $\mathrm{d}$ were insignificant. The transient correction of 1.35 was assumed to apply equally to all elements in the cluster. The burnup correction for each element was based on an approximate computation for the reduction in fissile content by the Vigilante code. 
The burnup corrections to the fresh-element calibration factors assumed that the calibration factors at the axial midplane are directly proportional to the effective fissile content of the element with an atom of ${ }^{239} \mathrm{Pu}$ worth $50 \%$ more than an atom of ${ }^{235} \mathrm{U}$. Fission-product poisoning and selfshielding changes were ignored. Based on these assumptions, the correction factor for burnup is

$$
C_{B}=\frac{C+1.5 D}{A+1.5 B}
$$

where

$$
\begin{aligned}
& \mathrm{A}=\text { initial concentration of }{ }^{235} \mathrm{U}, \mathrm{g} / \mathrm{m}, \\
& \mathrm{B}=\text { initial concentration of }{ }^{239} \mathrm{Pu}, \mathrm{g} / \mathrm{m}, \\
& \mathrm{C}=\text { final concentration of }{ }^{235} \mathrm{U}, \mathrm{g} / \mathrm{m},
\end{aligned}
$$

and

$\mathrm{D}=$ final concentration of ${ }^{239} \mathrm{Pu}, \mathrm{g} / \mathrm{m}$.

Burnup corrections are shown in Table B.6.

TABLE B.6. Data Used to Compute Burnup Corrections

\begin{tabular}{lcccccc}
\hline & \multicolumn{5}{c}{ Concentrations, g/m } \\
\cline { 3 - 6 } Element & $\begin{array}{c}\text { Burnup, } \\
\text { at. \% }\end{array}$ & A & B & C & D & Burnup Correction \\
\hline PNL-10-7 & 5.58 & 81.0 & 37.0 & 75.1 & 34.0 & 0.923 \\
PNL-10-8 & 5.52 & 81.2 & 37.1 & 75.1 & 34.1 & 0.923 \\
PNL-10-10 & 5.41 & 81.2 & 37.1 & 75.4 & 34.1 & 0.925 \\
PNL-10-28 & 5.36 & 81.4 & 37.1 & 75.7 & 34.3 & 0.926 \\
PNL-10-34 & 5.04 & 79.0 & 35.9 & 73.7 & 33.3 & 0.930 \\
PNL-10-53 & 4.94 & 81.3 & 37.1 & 76.0 & 34.4 & 0.932 \\
PNL-10-54 & 4.89 & 79.1 & 36.0 & 74.0 & 33.4 & 0.933 \\
\hline
\end{tabular}

6. Internal Radial Power Distributions

The radial power distribution within an element is an important parameter for the heat-transfer calculations. For E8, this distribution was obtained as a histogram by drilling concentric specimens from selected pellets in the fuel column. Unfortunately, only four points were obtained by this technique because the pellets were so fragile. Also, only the azimuthal average value was represented by the shell counted. Attempts to use foils to estimate a zimuthal as ymmetries have not always proven acceptable. These data were the first such experimental information on radial power distributions; all previous TREAT tests relied on calculations. Subsequent TREAT tests now 
use the ultrasonic trepanning technique developed originally for the E8 calibration tests to obtain the concentric sections used for estimates of the radial power distribution.

The dimensions of the core-drilled specimens, listed in Table B.7, indicate that about $30 \%$ of the original pellet was lost in the cutting process. Tables B.8-B.10 give the count rates obtained by counting the core-drilled

TABLE B.7. Dimensions of Core-drilled Specimens from

Mixed-oxide Fresh-fuel Pellets in Calibration Test

\begin{tabular}{|c|c|c|c|c|c|}
\hline $\begin{array}{r}\text { RINGS } \\
-1 \\
-1\end{array}$ & $\begin{array}{c}\text { Ring } \\
\text { Designation }\end{array}$ & $\begin{array}{c}\text { Specimen } \\
\text { Inside Diameter } \\
\text { mm }\end{array}$ & $\begin{array}{c}\text { Specimen } \\
\text { Outside Diameter, } \\
\text { mm }\end{array}$ & $\begin{array}{c}\text { Fraction of Pellet } \\
\text { Cross-sectional Area }\end{array}$ & $\begin{array}{c}\text { Fraction of } \\
\text { Total Counted }\end{array}$ \\
\hline & 0 & - & 1.7 & 0.112 & 0.158 \\
\hline & 1 & 1.90 & 2.77 & 0.166 & 0.234 \\
\hline & 2 & 3.20 & 3.89 & 0.200 & 0.282 \\
\hline & 3 & 4.32 & 4.93 & 0.232 & 0.326 \\
\hline $\begin{array}{l}\text { CORE - DRILLED PELLET } \\
\text { (ANL Neg. No. } 900-77-24 \text { ) }\end{array}$ & Sum & - & - & 0.710 & 1.000 \\
\hline
\end{tabular}

TABLE B.8. Azimuthally Averaged Radial Distribution of Fission Rate for PNL-10-79 in E8 Calibration Test (Central Element)

\begin{tabular}{|c|c|c|c|c|}
\hline \multirow{2}{*}{$\begin{array}{c}\text { Ring } \\
\text { Designation }\end{array}$} & \multicolumn{3}{|c|}{ Relative ${ }^{95} \mathrm{Zr}$ Activity } & \multirow{2}{*}{$\begin{array}{l}\text { Normalized } \\
\text { Distribution }^{a}\end{array}$} \\
\hline & Pellet 30 & Pellet 32 & Average & \\
\hline 0 & 3.086 & 3.191 & 3.138 & 1.000 \\
\hline 1 & 3.206 & 3.226 & 3.216 & 1.025 \\
\hline 2 & 3.660 & 3.577 & 3.618 & 1.153 \\
\hline 3 & 4.273 & 4.271 & 4.272 & 1.361 \\
\hline Average & & & & $1.166^{\mathrm{b}}$ \\
\hline
\end{tabular}

${ }^{\mathrm{a}}$ Uncertainty based on deviation between specimen count rates for pellets 30 and 37 of about $\pm 2.5 \%$.

${ }^{b}$ Average computed by weighting distribution values for each core-drilled specimen by its fraction of the total sample counted based on crosssectional area.

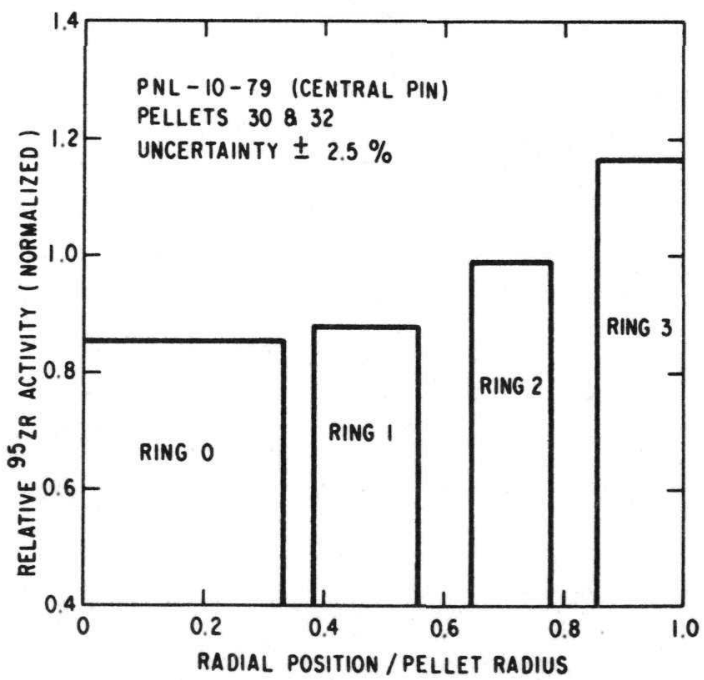

(ANL Neg. No. 900-77-26) 
TABLE B.9. Azimuthally Averaged Radial Distribution of Fission Rate for PNL-10-80 in E8 Calibration Test (Element nearest Pump Leg)

\begin{tabular}{ccccc}
\hline \multirow{2}{*}{$\begin{array}{c}\text { Ring } \\
\text { Designation }\end{array}$} & Pellet 30 & Pellet 32 & Average & $\begin{array}{c}\text { Relative } \\
\text { Distribution }\end{array}$ \\
\cline { 2 - 4 } 0 & 3.205 & 3.251 & 3.228 & 1.000 \\
1 & 3.516 & 3.325 & 3.421 & 1.060 \\
2 & 3.649 & 3.726 & 3.687 & 1.142 \\
3 & 4.566 & 4.731 & 4.648 & 1.440 \\
Average & & & & $1.198^{\mathrm{b}}$ \\
\hline
\end{tabular}

a Uncertainty based on deviation between specimen count rates for pellets 30 and 32 of about $\pm 4 \%$.

${ }^{b}$ Average computed by weighting distribution values for each core-drilled specimen by its fraction of the total sample counted based on crosssectional area.

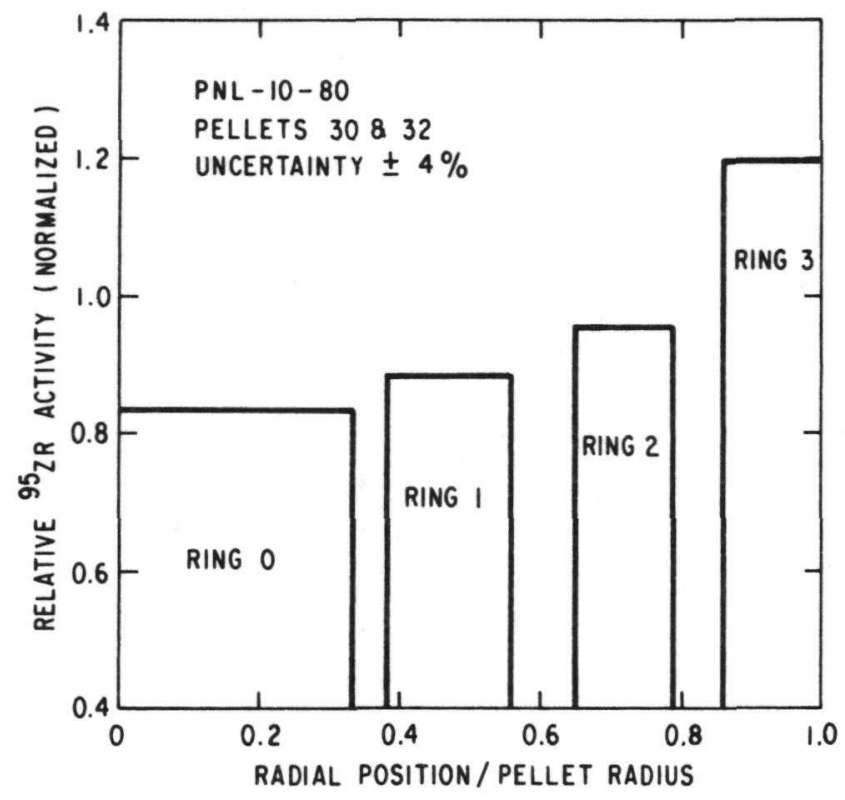

(ANL Neg. No. 900-77-27) 
TABLE B.10. Azimuthally Averaged Radial Distribution of Fission Rate for PNL-10-81 in E8 Calibration Test (Element nearest Hodoscope Slot)

\begin{tabular}{ccccc}
\hline \multirow{2}{*}{$\begin{array}{c}\text { Ring } \\
\text { Designation }\end{array}$} & Pellet 30 & Pellet 32 & Average & $\begin{array}{c}\text { Relative } \\
\text { Distribution }\end{array}$ \\
\cline { 2 - 4 } 0 & 3.975 & 3.962 & 3.969 & 1.000 \\
1 & 4.273 & 4.064 & 4.169 & 1.050 \\
2 & 4.635 & 5.367 & 5.001 & 1.260 \\
Average & 7.130 & 6.158 & 6.644 & 1.674 \\
\hline
\end{tabular}

${ }^{a}$ Uncertainty based on deviation between specimen count rates for pellets 30 and 32 of about $\pm 12 \%$.

b Average computed by weighting distribution values for each core-drilled specimen by its fraction of the total samples counted based on crosssectional area.

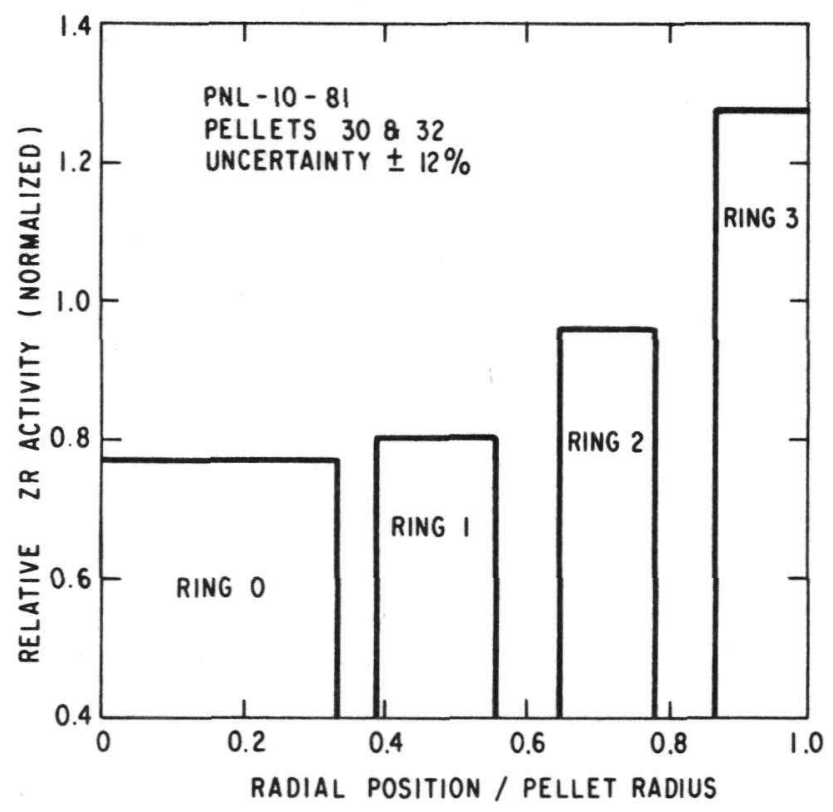

(ANL Neg. No. 900-77-25)

specimens from PNL-10-79, -80, and -81, respectively. Note that the largest value of peak-to-average was 1.3:1. The true distribution would be more peaked at the cluster edge than is represented by the core-drilled results. 


\section{APPENDIX C \\ Additional Data from E8 Heat-balance Test}

Data from the test-vehicle instrumentation were recorded on the analog tape units for $2 \mathrm{~min}$. The test duration was approximately over the first $18 \mathrm{~s}$ with constant power in the time interval of about 4-17.5 s, as shown in Fig. 13. The pressure and flow data, shown in Fig. C.1, indicate the extent of the radiation response and recovery over the 2 -min period of data acquisition. The erratic behavior of the inlet flowmeter was probably a result of the short that developed before the test and the correspondingly reduced sensitivity. Figure C.2 shows that the ALIP current and power were essentially constant during the test. The pump behavior was therefore probably not responsible for the anomalous behavior of the flowmeters.
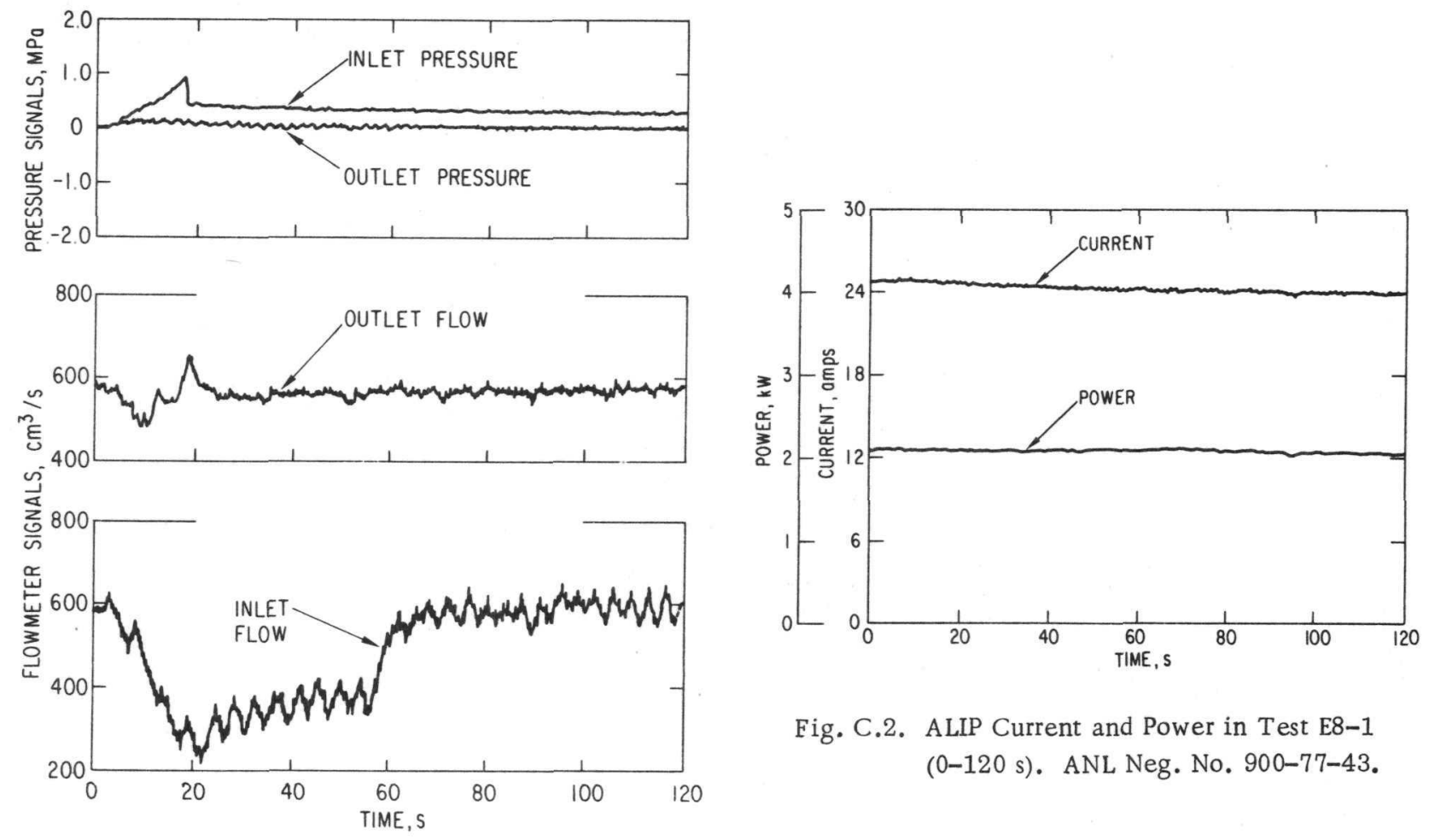

Fig. C.2. ALIP Current and Power in Test E8-1 (0-120 s). ANL Neg. No. 900-77-43.

Fig. C.1. Flow and Pressure Signals in Heatbalance Test E8-1 (0-120 s). ANL Neg. No. 900-77-23.

Thermocouple signals recorded during the test are shown in Figs. C. 3-C.6. The data in Fig. C. 3 indicate that the heat generated in the test region during the heat balance was picked up by the coolant. The rise in the bulk sodium temperature, as represented by the inlet thermocouple, did not exceed about $460^{\circ} \mathrm{C}$. At the end of the 2 -min interval of data acquisition, the loop sodium reduced slowly to $450^{\circ} \mathrm{C}$. The sodium temperatures at the test-region outlet peaked at the end of the full-power operation at about $540^{\circ} \mathrm{C}$. The loop system functioned as one might expect from a well-insulated thermal system without a heat exchanger. 


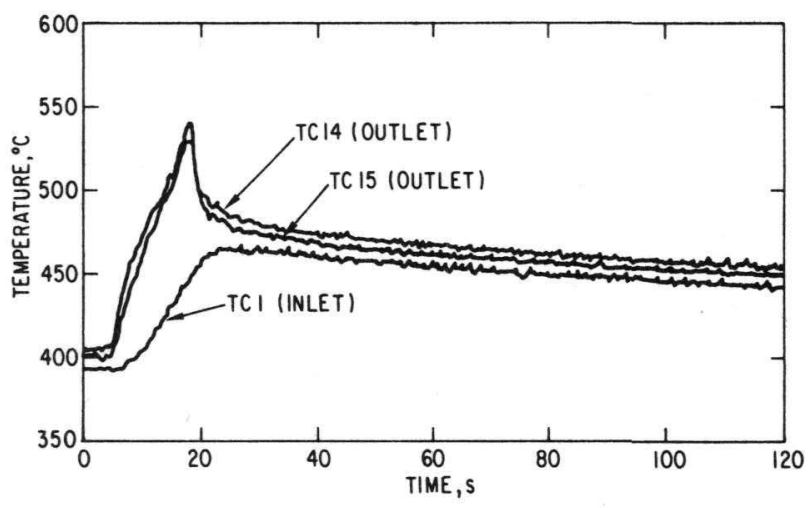

Fig. C.3. Temperatures of Coolant ThermoCouples at Inlet and Outlet of Test Region in Test E8-1 (0-120 s). ANL Neg. No. 900-77-33.
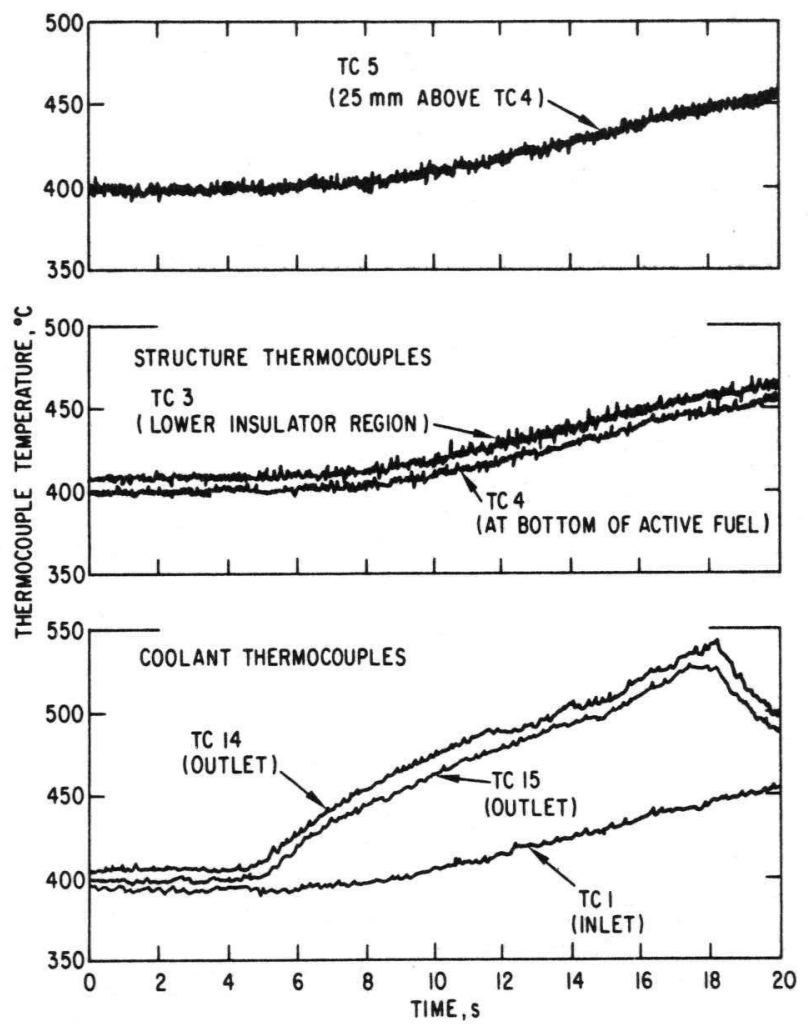

Fig. C.4. Temperatures of Coolant and Structure Thermocouples in Test E8-1 (0-20 s). ANL Neg. No. 900-77-16.

Fig. C.5

Temperatures of Structure Thermocouples in Test E8-1. ANL Neg. No. 900-77-20. 


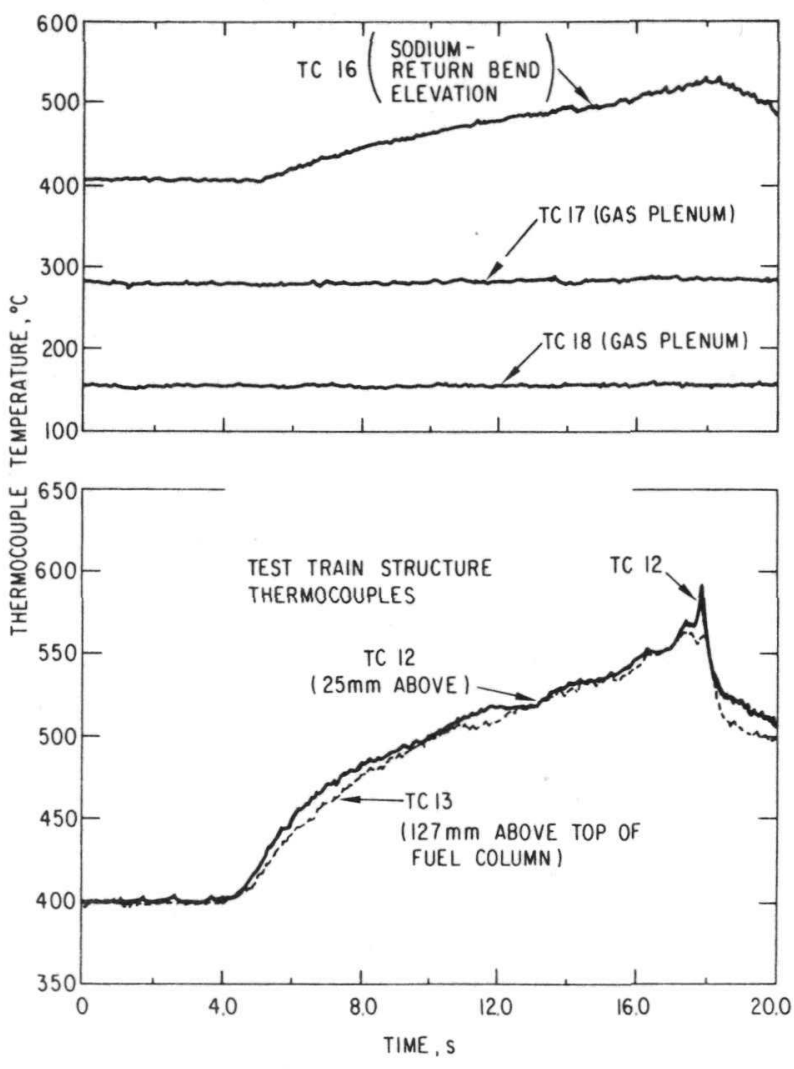

Fig. C.6. Temperatures of Test-train Thermocouples above Active Fuel Column. ANL Neg. No. 900-77-22.
Figures C.4-C.6 cover the time interval 0-20 s, which includes the period of full reactor power operation. The cause of erratic behavior of TC 10 at the top of the active fuel region cannot be identified. The thermocouple failed during the failure transient, but it is not known whether there is an association between the two results. Thermocouples 14 and 15 were located in the coolant stream at the same elevation above the top of the elements. Presumably, the $10^{\circ} \mathrm{C}$ difference between these two thermocouples, shown in Fig. C.4, indicates the probable uncertainty associated with the sensor and the analog recording system. Although the quoted accuracy of the tapes would imply a possible $\pm 15^{\circ} \mathrm{C}$ uncertainty, the system apparently functioned more accurately. Other pairs of thermocouples, such as TC 6 and TC 7 at the midplane, might be expected to read the same. However, recall that these and the others in Fig. C. 5 were located on the outside wall of the flow tube on different sides

of the cluster. Because of the variations in element-to-element powergeneration factors, the thermocouples will read differently. In some cases, the differences appear somewhat larger than would be expected on the bases of heat-transfer calculations alone. The probable explanation is that the fuel is somewhat free to move and bend in the cluster, leading to some variations with respect to the highly idealized calculational models generally used in these analyses. 


\section{APPENDIX D \\ Additional Data from E8 Failure Transient Test}

Additional data taken during Test E8-2, but not reported in Sec. V, are presented here in Figs. D.1-D.12. Thermocouple locations are identified in Table VIII or in Fig. A.1. Failure times for the thermocouples are given in Table XVI. The data recorded from the thermocouples were not plotted on the graph after the time of failure, since no apparent conversion to a meaningful temperature was possible. For the lower-pressure transducer, the radiation response during the power transient is shown in Figs. D. 3 and D. 4; the pressure pulses do not show on these graphs because of the large data-averaging intervals used in the analog-to-digital conversions. Similarly, cutoffs of peak recorded temperature at failures shown in the thermocouple plots are somewhat below the peak temperature because of the data-reduction procedure.

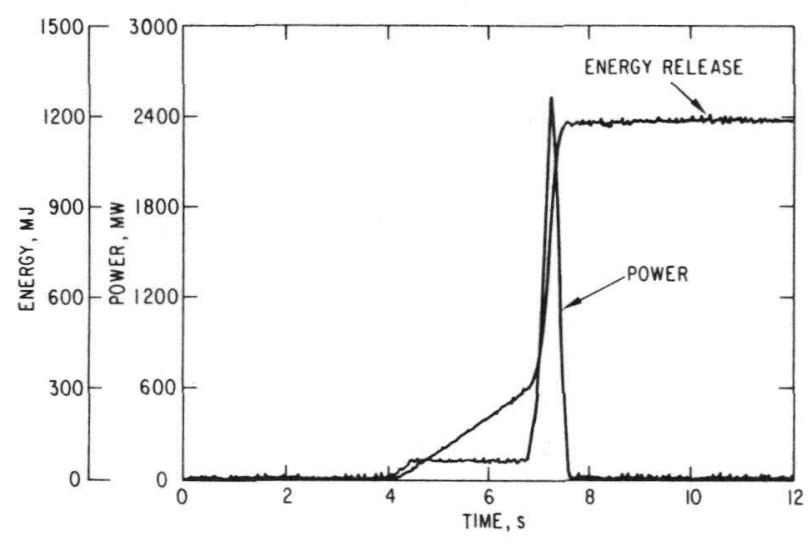

Fig. D.1. Power and Energy Release in Test E8-2 (TREAT Transient 1588). ANL Neg. No. $900-77-41$.

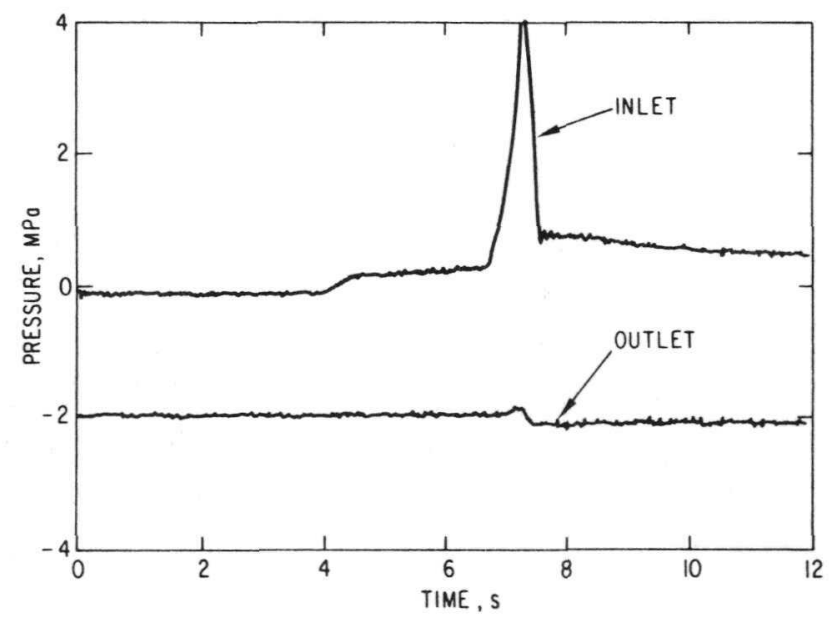

Fig. D.3. Responses of Inlet and Outlet Pressure Transducers in Test E8-2: 0-12 s. ANL Neg. No. 900-77-38.

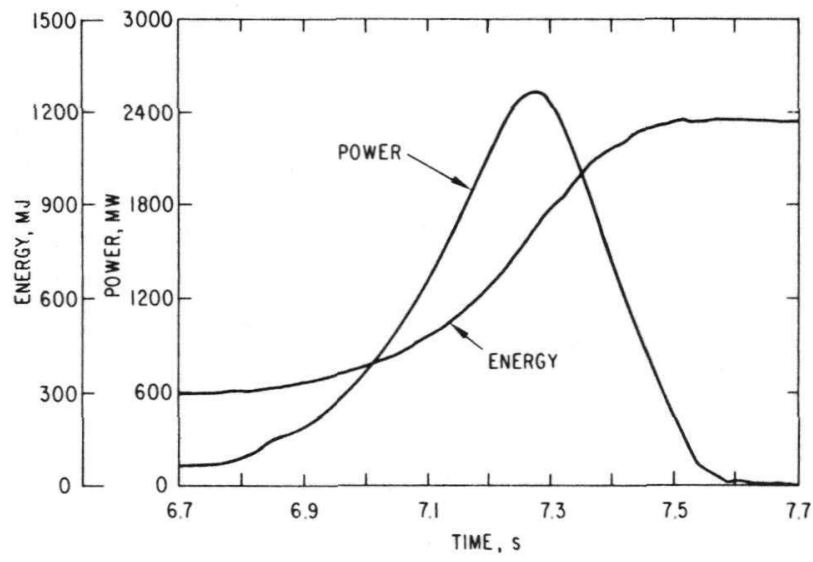

Fig. D.2. Power and Energy Release in Test E8-2 in Time Interval of Burst. ANL Neg. No. $900-77-47$.

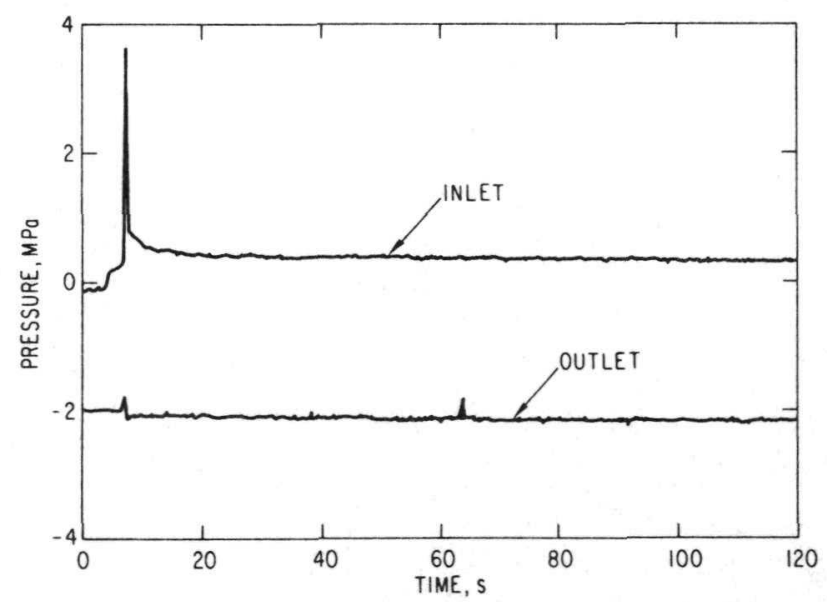

Fig. D.4. Responses of Inlet and Outlet Pressure Transducers in Test E8-2: 0-120 s. ANL Neg. No. 900-77-42. 


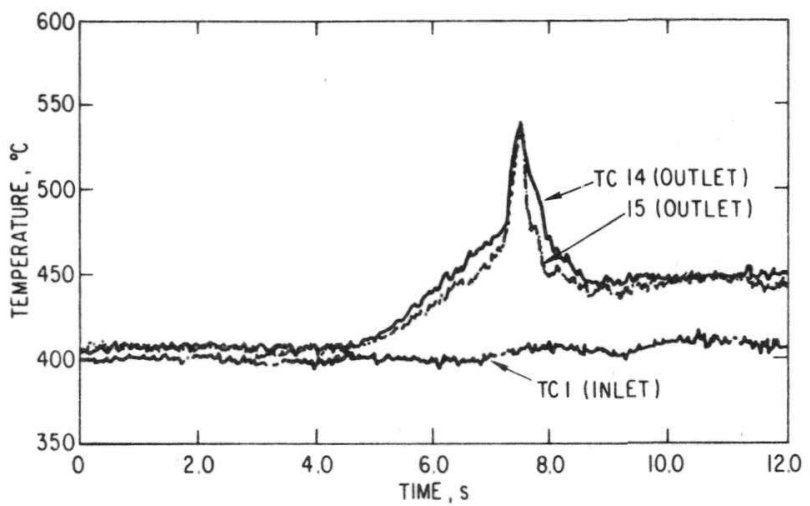

Fig. D.5. Inlet and Outlet Temperatures in Test E8-2: 0-12 s. ANL Neg. No. 900-77-29.

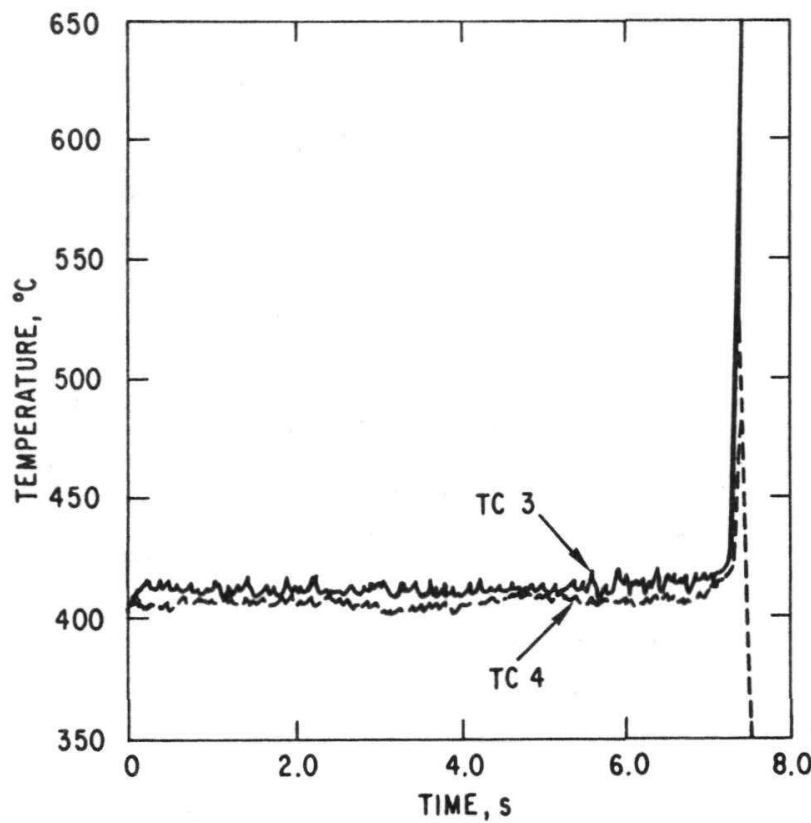

Fig. D.7. Temperatures from Structure Thermocouples at Elevations below Bottom of Active Fuel-column Region in Test E8-2 (0-8 s). ANL Neg. No. 900-77-14.

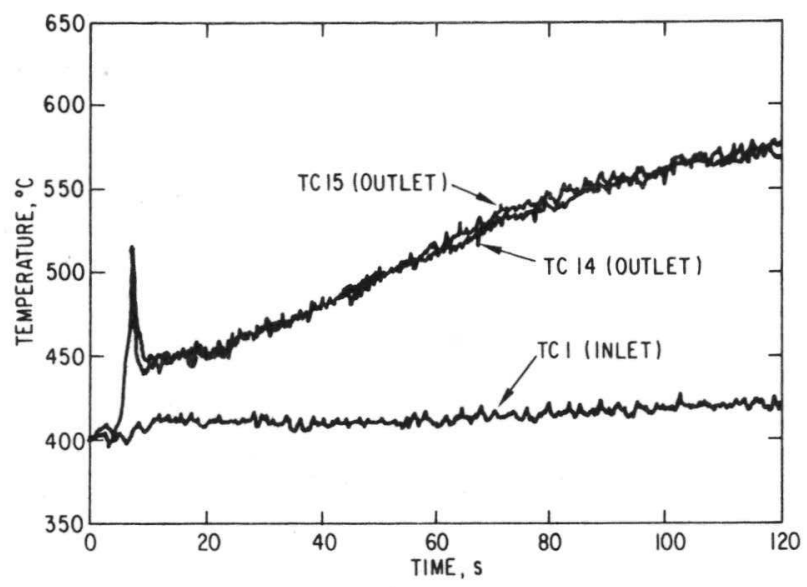

Fig. D.6. Inlet and Outlet Temperatures in Test E8-2: 0-120 s. ANL Neg. No. 900-77-15.

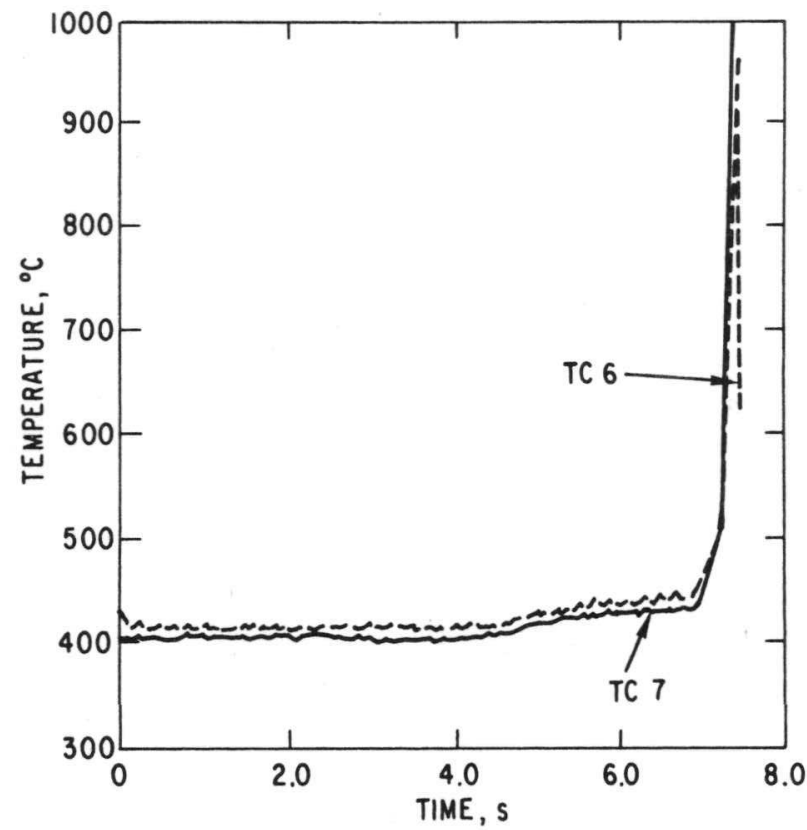

Fig. D.8. Temperatures from Structure Thermocouples at Fuel-column Midplane in Test E8-2 (0-8 s). ANL Neg. No. 900-77-45. 


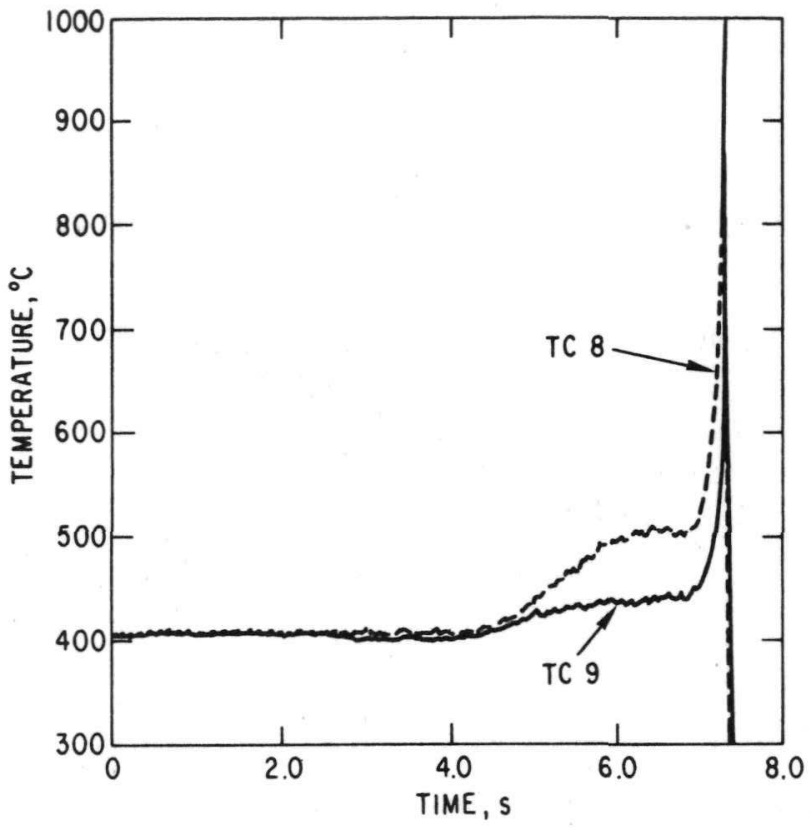

Fig. D.9. Temperatures from Structure Thermocouples $64 \mathrm{~mm}$ below Top of Active Fuel Column in Test E8-2 (0-8 s). ANL Neg. No. 900-77-44.

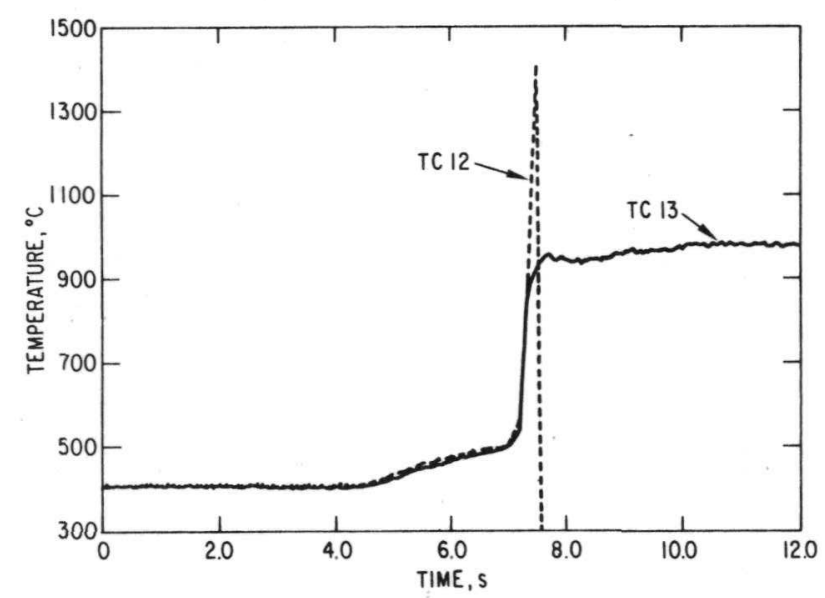

Fig. D.11. Temperatures from Structure Thermocouples above Top of Active Fuel Column in Test E8-2 (0-12 s). ANL Neg. No. $900-77-37$.

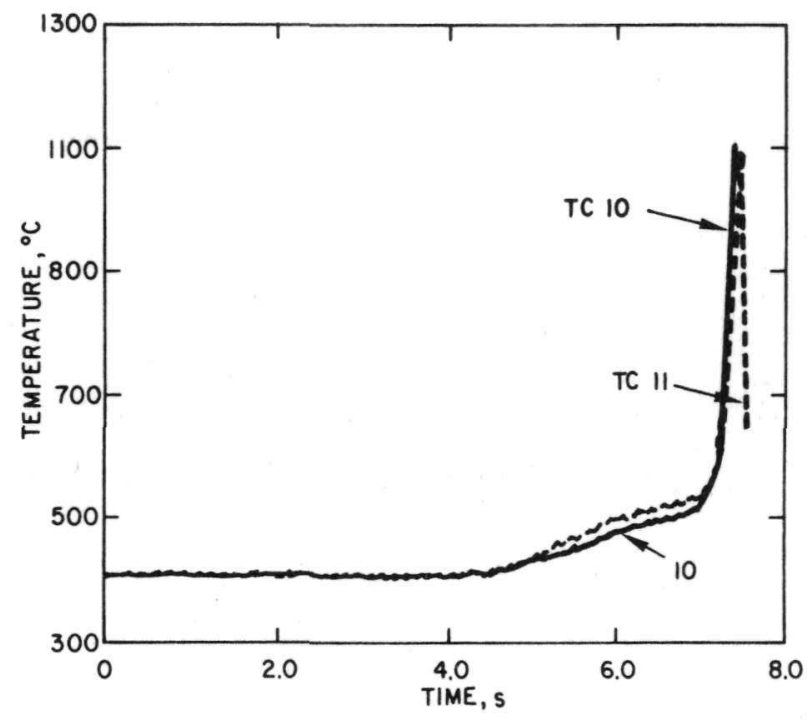

Fig. D.10. Temperatures from Structure Thermocouples at Top of Active Fuel Column in Test E8-2 (0-8 s). ANL Neg. No. 900-77-34 Rev. 1.

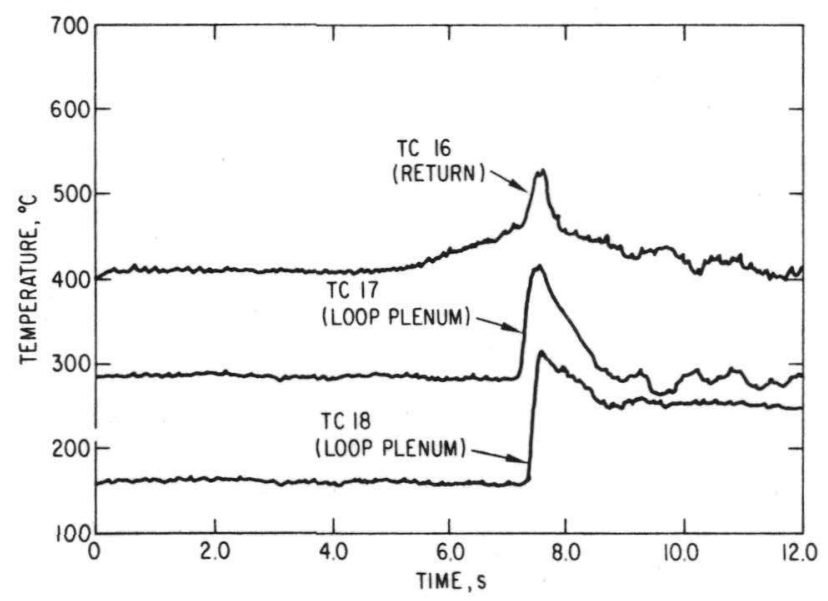

Fig. D.12. Temperatures from Thermocouples in Upper Loop Region in Test E8-2 (0-12 s). ANL Neg. No. 900-77-39.

A closer examination of the thermocouple signals at the time of fuelelement failure was made in an attempt to determine if a sharp rate of change would reveal evidence for a failure location. However, the examination failed to provide any such evidence. 


\section{APPENDIX E}

Treatment of Flowmeter Signals at Time of Failure Events in Test Region

The flowmeters in Test $\mathrm{E} 8$ had the objectives of (1) providing the basis for establishing an initial flow rate and (2) indicating the timing of testsection events influencing flow. Additional data at the time of fuel-element failure may lack a truly quantitative basis because of shifts in the output signal not apparently associated with events taking place in the test zone.

Before the test, the flow rate was set at $575 \mathrm{~cm}^{3} / \mathrm{s}$. The output of each flowmeter will not ordinarily decline to zero identically when the pump current is reduced to zero. For the lower flowmeter, the "zero shift" is usually greater than for the outlet flowmeter, and the shift exists whether or not the electromagnet is energized. The shift is attributed to a thermocouple effect where the outlet leads are connected to exit cabling. The pretest relationship for the outlet (upper) flowmeter between output signal $S$ and flow $r$ ate $R$ was

$$
R=1800(S-0.018) \text {, }
$$

whe re

$$
\mathrm{R}=\text { volumetric flow rate, } \mathrm{cm}^{3} / \mathrm{s} \text {, }
$$

and

$$
\mathrm{S}=\text { output signal, } \mathrm{mV} \text {. }
$$

For the inlet flowmeter, with its partially shorted excitation coil, the relationship was

$$
R \simeq 3000(S-0.10) .
$$

Note that the inlet magnetic flowmeter was about $40 \%$ les sensitive to flow than the outlet, that is, was below its normal sensitivity of about $600 \mathrm{~cm}^{3} /$ $\mathrm{s} \cdot \mathrm{mV}$ by a factor of 5 . The zero shift of the inlet flowmeter was nearly five times as great as for the outlet, and its magnitude was approximately the same as for an unshorted flowmeter.

The unprocessed output signals from both flowmeters are shown in Fig. E.l for the time interval that includes the failure events. The scale shown in Fig. E.l can be read approximately to the full-scale uncertainty expected for the analog tapes of about $\pm 0.05 \mathrm{mV}$ ( $1 \%$ full scale); i.e., the graph can be read approximately to the accuracy indicated for the analog tape re corders in the manufacturer's specification. Because of the low signal strength, the $60-\mathrm{Hz}$ component caused by pickup constituted an appreciable 
part of the signal, despite the common-mode rejection capability of the amplifiers. Figure E.2 shows the signal after the $60-\mathrm{Hz}$ component has been removed by averaging the $1-\mathrm{ms}$ data plotted in Fig. E.1. Electronic processing with a $60-\mathrm{Hz}$ notch filter and a $200-\mathrm{Hz}$ averaging amplifier gave essentially an identical result.

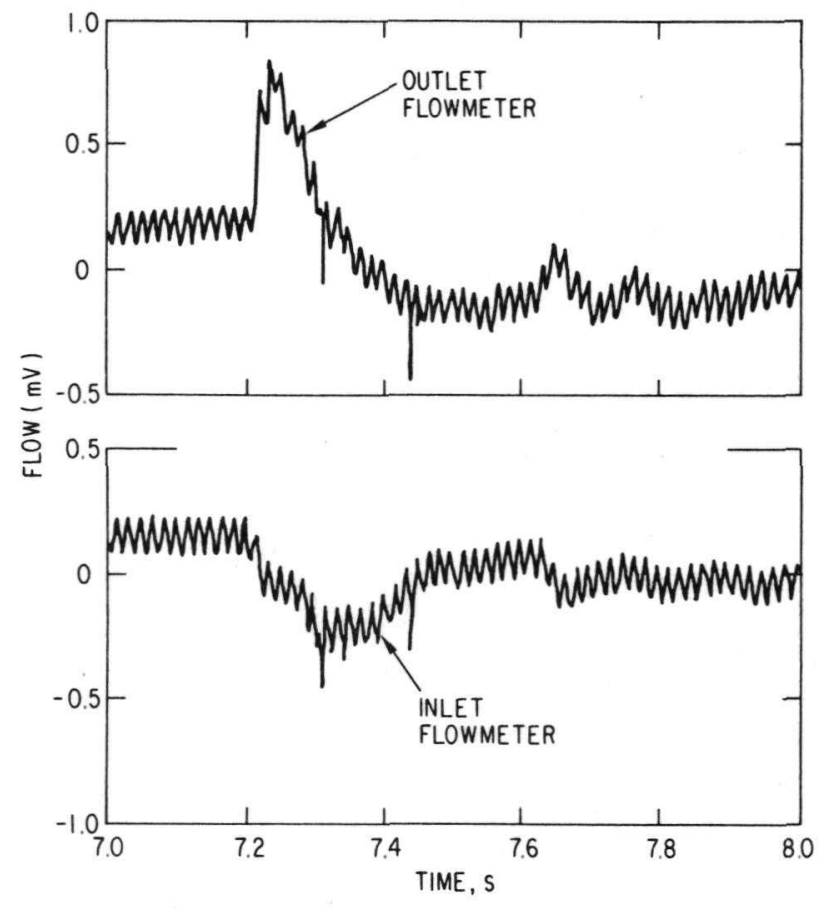

Fig. E.1. Signal Output from Inlet and Outlet Flowmeters from Test E8-2. ANL Neg. No. 900-77-40.

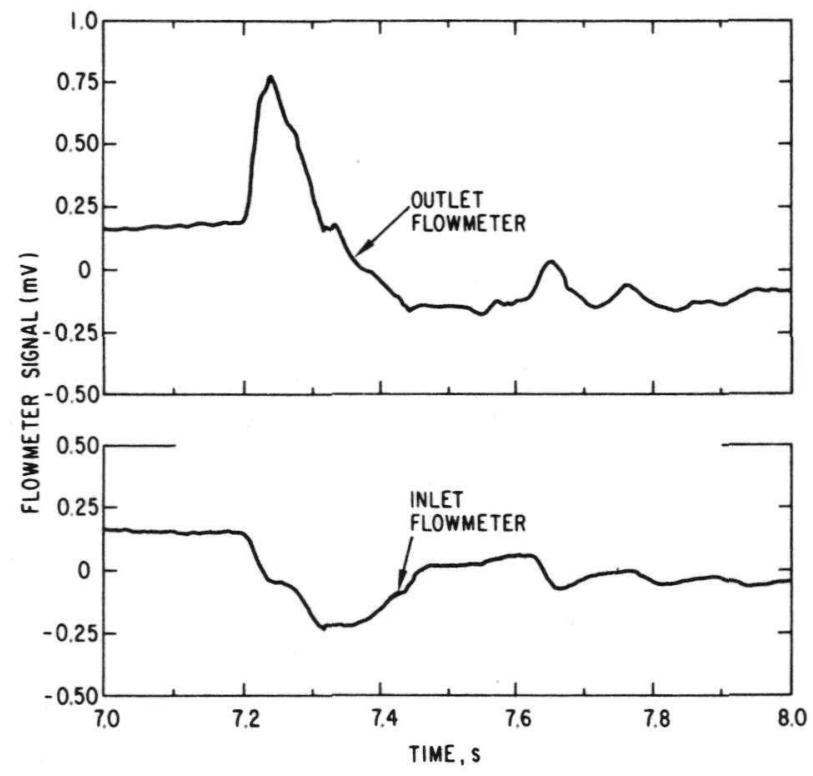

Fig. E.2. Signal Output from Flowmeter after Removal of $60-\mathrm{Hz}$ Component for Test E8-2. ANL Neg. No. 900-77-31.

At the time of the failure event at $7.212 \mathrm{~s}$, both flowmeters indicated a reduced flow rate from the initial value of $575 \mathrm{~cm}^{3} / \mathrm{s}$, although no flow changes were programmed, expected, or inferred from the pump-power data. The interpretation used here was that the zero point had shifted, either on the tape unit or from the flowmeters themselves, but that the sensitivity remained constant. In that case, the relationships for the flowmeters become (approximately)

$$
R=1800(S+0.13) \text { for the outlet }
$$

and

$$
R=3000(S+0.04) \text { for the inlet. }
$$

The shift for both corresponds to about $-0.14 \mathrm{mV}$ in the ze ro shift from the pretest settings. Because of the generally large uncertainty this caused in the data-reduction procedure and the small millivolt outputs from 
both flowmeters, the use of the data for detailed quantitative evaluations should be done with caution. The flow data, shown in Fig. 16, were derived from Fig. E.2 in this way. Although not necessarily precise, the above equations were also applied to the flowmeter signals over the 10 -s interval between 4 and $14 \mathrm{~s}$, as shown in Fig. E.3. Apparently the correction procedure provides an acceptable conversion over this time range also, since the initial flow rate was approximately equal to the flow rate set before the test, using the Control Console DVM.

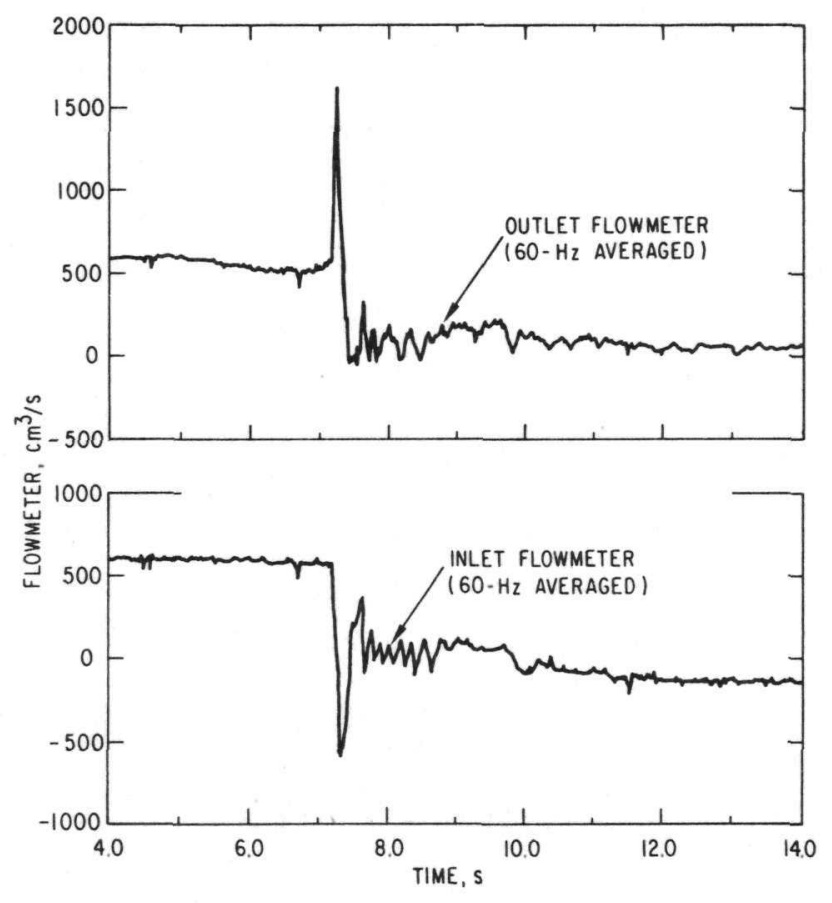

Fig. E.3

Inlet and Outlet Flow Rates for Test E8-2 (4-14 s). ANL Neg. No. 900-77-32. 
This appendix presents the channel layout and input parameters for the COBRA calculations in Sec. VII. Figure F.l shows the channel layout of $1 / 12$ th of the idealized seven-element test section. Correspondingly Table F.l lists the idealized dimensions of the geometry shown in Fig. F.1. Table F.2 lists the element-power distribution into adjacent coolant channel. Table F.3 lists the miscellaneous input values. Table F.4 lists the fuel properties. Table F.5 lists input values for gap-conductance model. Table F.6 lists the coolant enthalpy and the reactor power function. The physical properties of the three materials used (sodium, cladding and fuel) are obtained from Refs. 11-13.

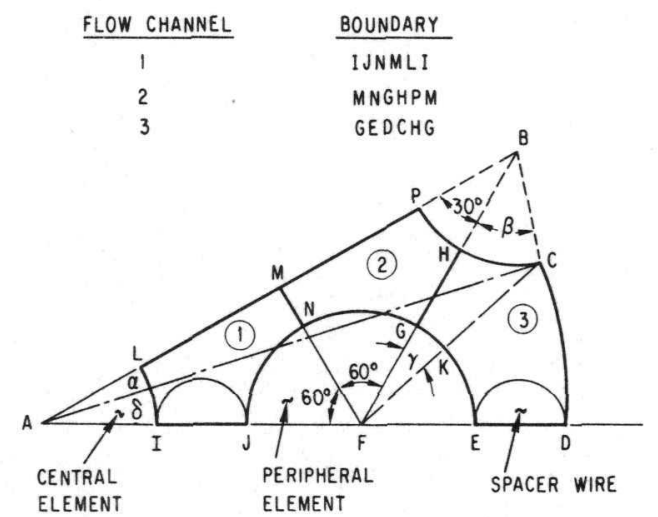

Fig. F.1

One-twelfth of Idealized Seven-element Test Section for COBRA Calculation. ANL Neg. No. 900-5158.

TABLE F.1. Dimensions of Idealized Cluster Geometry in Test E8

Channel Values

Area, $\mathrm{cm}^{2}$

Channel 1

0.03279

Channel 2

0.03349

Channel 3

Wetted perimeter, $\mathrm{cm}$

Channel 1

0.5386

Channel 2

0.5120

Channel 3

0.8257

Heated perimeter, cm

Channel 1

0.4587

Channel 2

Interchannel contact length (gap spacing), cm

Channel 1-Channel 2

Channel 2-Channel 3

Duct-wall wetted length, cm 
TABLE F.2. Element-power Distributions into Adjacent Coolant Channels at Steady State

Central element to Channel 1 0.0833

Peripheral element to Channel 1 0.1667

Peripheral element to Channel 2 0.1668

Peripheral element to Channel 3 0.1646

TABLE F.3. Miscellaneous COBRA Input Values

Friction factor for flow

$\mathrm{Wall}^{\mathrm{a}}$ thickness

Wall density

Heat-transfer coefficient to bypass

Bypass temperature

Film-coefficient correlation constants

Crossflow resistance factor

Momentum turbulent factor

Channel length

Number of axial nodes (equal $\Delta l$ )

Number of axial nodes in fuel

Number of radial nodes in fuel

Number of radial nodes in cladding (equal $\Delta \mathbf{r}$ )

Time step

Crossflow error

Sodium-temperature error

Fuel-temperature relative error

Subcooled mixing, beta

Conduction mixing factor

System pressure ${ }^{b}$

Initial inlet enthalpy

Initial average mass velocity

Average heat flux

Radial power factor, central element

Radial power factor, peripheral element
$0.316 / \mathrm{Re}^{0.25}$

$0.0889 \mathrm{~cm}$

$7.98 \mathrm{~g} / \mathrm{cm}^{3}$

$1.14 \mathrm{~J} / \mathrm{s} \cdot \mathrm{cm}^{2} \cdot{ }^{\circ} \mathrm{C}$

$398.9^{\circ} \mathrm{C}$

$\mathrm{Nu}=5.87+0.2206 \mathrm{Pe}^{0.8}$

0.5

0.0

$51.4 \mathrm{~cm}$

15

15

7

3

$0.1 \mathrm{~s}$

$4.54 \mathrm{~g} / \mathrm{s}$

$0.05^{\circ} \mathrm{C}$

$0.0028^{\circ} \mathrm{C}$

0.0125

2.0

$2.068 \mathrm{MPa}$

$887.2 \mathrm{~J} / \mathrm{g}\left(\right.$ at $\left.398.8^{\circ} \mathrm{C}\right)$

$285 \mathrm{~g} / \mathrm{cm}^{2} \cdot \mathrm{s}$

$1.0362 \mathrm{~W} / \mathrm{cm}^{2}$

$1.45 \mathrm{~W} / \mathrm{g} \cdot \mathrm{MW}$

$2.07 \mathrm{~W} / \mathrm{g} \cdot \mathrm{MW}$

${ }^{a}$ Fluted holder or duct.

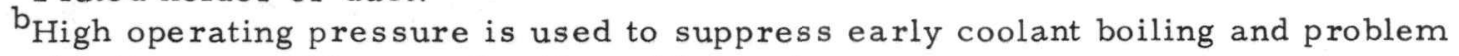
abortion caused by negative Reynolds numbers. 
TABLE F.4. Input Values for Fuel Properties

\begin{tabular}{ccc}
\hline Density ${ }^{\mathrm{a}}$ & $9.4 \mathrm{~g} / \mathrm{cm}^{3}$ & \\
Heat of fusion & $275 \mathrm{~J} / \mathrm{g}$ & \\
Specific heat of liquid & $0.35 \mathrm{~J} / \mathrm{g}-{ }^{\circ} \mathrm{C}$ & \\
Thermal -expansion coefficient & {$\left[3.76 \mathrm{x} 10^{-10}+(1.8 \mathrm{~T}+32)\right](1.8 \mathrm{~T}-38)$} \\
& for T in ${ }^{\circ} \mathrm{C}$ & \\
\hline Temperature, & Thermal Conductivity, & Spe cific Heat, \\
${ }^{\circ} \mathrm{C}$ & $\mathrm{J} / \mathrm{g} \cdot{ }^{\circ} \mathrm{C} \cdot \mathrm{cm}$ & $\mathrm{J} / \mathrm{g} \cdot \mathrm{C}$ \\
\hline 25.0 & 0.0418 & 0.176 \\
436.7 & 0.041 & 0.240 \\
826.7 & 0.028 & 0.296 \\
1126.7 & 0.022 & 0.334 \\
1526.7 & 0.020 & 0.377 \\
1926.7 & 0.019 & 0.415 \\
2226.7 & 0.020 & 0.438 \\
2426.7 & 0.021 & 0.451 \\
2626.7 & 0.023 & 0.463 \\
2760.0 & 0.026 & 0.469 \\
\hline & $0.024{ }^{\mathrm{b}}$ & 0.469 \\
\hline
\end{tabular}

${ }^{\mathrm{a}}$ Constant across fuel radius.

${ }^{\mathrm{b}}$ Assumed also for liquid at all temperatures above $2815.6^{\circ} \mathrm{C}$.

TABLE F.5. Input Values for Gap-conductance Model

\begin{tabular}{lcc}
\hline & $\begin{array}{c}\text { Central } \\
\text { Element }\end{array}$ & $\begin{array}{c}\text { Peripheral } \\
\text { Element }\end{array}$ \\
\hline Initial gap size, cm & 0.0060 & 0.0060 \\
$\begin{array}{l}\text { Initial gap conductance, } \\
\mathrm{J} / \mathrm{s} \cdot \mathrm{cm} \cdot{ }^{\circ} \mathrm{C}\end{array}$ & 25.10 & 25.10 \\
$\mathrm{Maximum}$ gap conductance, & & \\
$\mathrm{J} / \mathrm{s} \cdot \mathrm{cm} \cdot{ }^{\circ} \mathrm{C}$ & 31.09 & 31.09 \\
\hline
\end{tabular}

TABLE F.6. Input Function for Exit Coolant Enthalpy

\begin{tabular}{ll}
\hline Time, s & Coolant Enthalpy, ${ }^{\mathrm{a}} \mathrm{J} / \mathrm{kg}$ \\
\hline 0.00 & 0.8872 \\
4.04 & 0.8872 \\
4.94 & 0.9395 \\
5.94 & 1.007 \\
6.94 & 1.043 \\
7.50 & 1.405 \\
\hline
\end{tabular}

Exit coolant enthalpy at Channel 1. 


\section{ACKNOW LEDGMENTS}

The successful implementation of a test such as $E 8$ required the participation of many individuals and groups at ANL. The program was conducted under the management of Charles Dickerman and Bob Noland. For Test E8, the following personnel made notable contributions to the success of the experiment.

The test train was designed by Jim Burelbach, Russ Robertson, and Mike Barczak. Ken Schmidt was the test engineer. The RAS technicians who converted the hardware into a workable experimental device were Gene Maslowicz, Joe Burghardt, Gerry Dewey, Charley August, and Jim Emerson. Ed Johanson provided the Mark-IIC loop control console and assisted in its operation at test time. The test elements were provided as a result of the HEDL Components Testing program under the supervision of John Hanson.

In Idaho, Jay Cook, Ken Teraguchi, and Jim Kerr at HFEF provided the capability to handle pretest and posttest hot-cell operations associated with the loop. At TREAT, the experiment coordination was the responsibility of Leo McVean. In addition, the TREAT Operations staff contributed to the experiment program at its various stages. Larry Harrison provided overall management of the TREAT Facility.

Bob Land, Gerry Klotzkin, Frank Yaggee, and Joe Tylka assisted by supporting in the pre - and posttest planning and analysis efforts. Paul Froehle reduced the analog data to graphical form. Frank Yaggee also worked out the ultrasonic trepanning technique for sampling pellet cores in the calibration experiments. Bob Villarreal, John Krsul, and Roland Armani performed radiochemistry associated with the calibrations.

The posttest examinations were conducted by the AGHCF personnel under the supervision of Larry Neimark. 


\section{REFERENCES}

1. E. O. Ballard and L. A. Pember, Proposal to Irradiate Unencopsulated Fuel Pins in the EBR-II Subassemblies PNL-9, PNL-10 and PNL-11, HEDLTME-72--16 (1972).

2. W. W. Marr, COBRA-3M: A Digital Computer Code for Analyzing ThermalHydraulic Behavior in Pin Bundles, ANL-8131 (Mar 1975).

3. A. B. Rothman, L. W. Deitrich, R. C. Doerner, A. E. Wright, and C. E. Dickerman, "Review of TREAT Experiments in Support of Transient Overpower (TOP) Analysis for Fast Reactors," Proc. Am. Nucl. Soc. Conf. Fast Reactor Safety, Beverly Hills, CA, USAEC-CONF 740401 (1974).

4. H. J. Wellenberg, W. L. Partain, and A. E. Waltars, "Dynamics of Molten Fuel Motion During a Fast Reactor Overpower Transient," Proc. Am. Nucl. Soc. Conf. Fast Reactor Safety, Beverly Hills, CA, USAEC-CONF 740401 (1974).

5. W. L. Partain, A. E. Waltars, G. E. Culley, J. H. Scott, and J. E. Hanson, Effects of Molten Fuel Movement During a Fast Reactor Overpower Transient, HEDL-TME-72-109 (Aug 1972).

6. J. H. Scott et al., Post-Irradiation Excomination of Fuel Pins PNL-10-23 and PNL-10-63, HEDL-TME 74-23 (May 1974).

7. F. L. Yaggee and G. M. Dragel, An ULtrasonic Trepanning Technique for Radial Sampling of Ceramic Fuel Pellets, Nuc1. Tech. 27, 292 (1975).

8. A De Volpi et al., Fast Neutron Hodoscope at TREAT; Development and Operation, Nuc1. Tech. 27, 449 (1975).

9. W. W. Marr, COBRA-3M: A Digital Code for Analyzing Thermal Hydraulic Behavior in Pin Bundles, ANL-8131 (Aug 1973).

10. D. S. Rowe, COBRA-IIIC: A Digital Computer Progrom for Steady-State and Transient Thermal-Hydraulic Analysis of Rod Bundle Nuclear Fuel Elements, BNWL-1695 (Mar 1973).

11. G. H. Golden and J. V. Tokar, Thermophysical Properties of Sodium, ANL-7323 (Aug 1967).

12. Nuclear Systems Materials Handbook, Vols. 1 and 2, Hanford Engineering Development Laboratory, TID-26666 (with latest revision).

13. Liquid Metal Fast Breeder Reactor Materials Handbook, Hanford Engineering Development Laboratory Report HEDL-TME 71-32. 
Distribution of ANL-77-93

Internal:

J.A. Kyger

R. Avery

L. Burris

D. W. Cissel

S. A. Davis

B. R. T. Frost

D. C. Rardin

R. J. Teunis

C. E. Till

R. S. Zeno

H. K. Fauske

S. Fistedis

B. D. LaMar

J. F. Marchaterre

H. O. Monson

R. Sevy

A. J. Goldman

D. Rose

I. Bornstein

D. R. Ferguson

L. Baker

H. V. Rhude

K. J. Schmidt
P. A. Lottes

T. C. Chawla

W. C. Lipinski

R. A. Noland

C. E. Dickerman (2)

R. K. Lo (2)

G. S. Stanford (2)

A. B. Rothman (2)

B. A. Korelc (4)

R. Simms (10)

J. P. Burelbach

N. J. Carson

A. DeVolpi

R. C. Doerner

C. L. Fink

P. H. Froehle

N. R. Koopman

O. R. McNary

R. G. Page

R. G. Palm

L. W. Person
L. A. Semenza

A. E. Klickman

J. P. Tylka

A. E. Wright

H. U. Wider

L. W. Deitrich

D. H. Cho

M. Kurtz

R. E. Henry

J. H. Tessier

D. R. Pedersen

D. H. Lennox

L. A. Neimark

W. F. Murphy

F. L. Yaggee

E. W. Johanson

L. J. Harrison

R. L. McVean

R. Villarreal

A. B. Krisciunas

ANL Contract File

ANL Libraries (5)

TIS Files (3)

\section{External:}

DOE-TIC, for distribution per UC-79p (282)

Manager, Chicago Operations Office

Chief, Chicago Patent Group

Director, Reactor Programs Div., CH

Director, CH-INEL

Director, DOE-RRT (2)

President, Argonne Universities Association

Reactor Analysis and Safety Division Review Committee:

S. Baron, Burns and Roe, Inc.

W. Kerr, U. Michigan

M. Levenson, Electric Power Research Inst.

S. Levy, S. Levy, Inc.

R. B. Nicholson, Exxon Nuclear Co., Inc.

D. Okrent, U. California, Los Angeles

N. C. Rasmussen, Massachusetts Inst. Technology 